\title{
Cellular mechanisms of altered neuronal sensitivity in the genetically epilepsy-prone rat
}

\author{
Lance Russell Molnar \\ West Virginia University
}

Follow this and additional works at: https://researchrepository.wvu.edu/etd

\section{Recommended Citation}

Molnar, Lance Russell, "Cellular mechanisms of altered neuronal sensitivity in the genetically epilepsyprone rat" (1998). Graduate Theses, Dissertations, and Problem Reports. 3150.

https://researchrepository.wvu.edu/etd/3150

This Dissertation is protected by copyright and/or related rights. It has been brought to you by the The Research Repository @ WVU with permission from the rights-holder(s). You are free to use this Dissertation in any way that is permitted by the copyright and related rights legislation that applies to your use. For other uses you must obtain permission from the rights-holder(s) directly, unless additional rights are indicated by a Creative Commons license in the record and/ or on the work itself. This Dissertation has been accepted for inclusion in WVU Graduate Theses, Dissertations, and Problem Reports collection by an authorized administrator of The Research Repository @ WVU.

For more information, please contact researchrepository@mail.wvu.edu. 
Cellular Mechanisms of Altered Neuronal Sensitivity in the Genetically Epilepsy-Prone Rat

\author{
Dissertation \\ Submitted to the School of Medicine \\ West Virginia University \\ Morgantown, WV
}

In Partial Fulfillment of the Requirements

for the degree of

Doctor of Philosophy

in Pharmacology and Toxicology

by

Lance R. Molnar

September, 1998 


\section{Contents}

TOPIC PAGE

TABLE OF CONTENTS............................................................................................... i

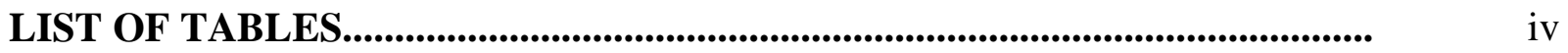

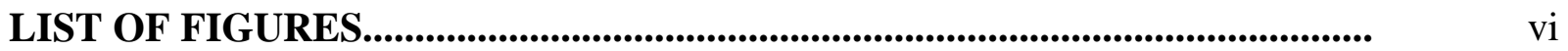

ABSTRACT ..........................................................................................................................

I. CELLULAR RESPONSIVENESS...........................................................................

A. Adaptive Changes in Sensitivity 2

B. Plastic Changes in Sensitivity

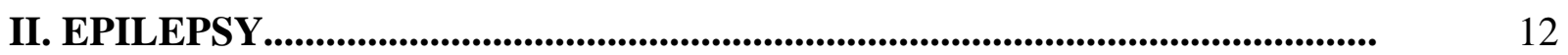

A. Animal Models of Epilepsy 14

B. The Genetically Epilepsy-Prone Rat (GEPR) 16

III. THE CEREBELLUM................................................................................................. 22

A. Basic Features $\quad 24$

B. Neuronal Elements 26

C. Functional Divisions 29

D. Circuitry 36

E. Development

IV. THE GABA $A_{A}-$ RECEPTOR................................................................................. 50

A. $G A B A_{A}-$ Receptor Structure and Composition 50

B. Activation and Modulation of the $G_{A B A_{A}-\text { Receptor }}$

C. The Benzodiazepine Binding Sites

D. Subunit-Specific Interactions of Various Modulators 58

E. In Vivo Regulation of the GABA $_{A}$-Receptor $\quad 60$

F. Cerebellar Purkinje Neurons and the GABA $A_{A}$-Receptor 63 
V. EXPERIMENTAL DESIGN...................................................................................

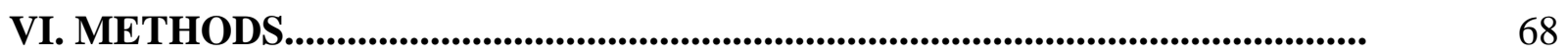

$\begin{array}{ll}\text { A. Brain Slices } & 70\end{array}$

B. Electrophysiological Recording I: Intracellular Recording 71

C. Statistical Analysis of Intracellular Data 78

D. Electrophysiological Recording II: Whole-Cell and Single-Channel Patch 79 Clamp

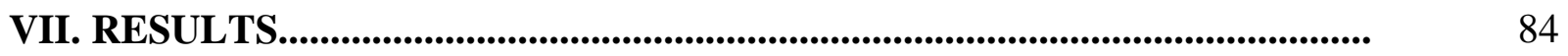

A. Basic Electrical Membrane Properties $\quad 85$

B. The Effects of Ouabain in Sprague-Dawley Rats 92

C. Intracellular Comparison of Sprague-Dawley and GEPR-NE Purkinje 96 Neurons

D. Intracellular Comparison of Sprague-Dawley and GEPR-9 Purkinje 106 Neurons

E. Intracellular Comparison of Sprague-Dawley and GEPR-3 Purkinje 118 Neurons

F. Comparison of GABA Responses using the Whole-Cell Patch-Clamp 128 Technique

G. Comparison of GABA Responses in Single-Channel Outside-Out Patches

A. Purkinje Neurons in Cerebellar Slices Obtained from Sprague-Dawley, GEPR-NE, GEPR-3, and GEPR-9 Animals have Equivalent Basic Electrical Membrane Properties

B. Developmental Changes in Cellular Responsiveness of Purkinje Neurons

C. Cellular Responsiveness of Sprague-Dawley Purkinje Neurons to Various Agonists

D. Comparison of the Responsiveness of Purkinje Neurons from GEPR-NE, GEPR-3, and GEPR-9 Animals with that of Sprague-Dawley Purkinje Neurons 
E. Comparison of GEPR-9, GEPR-3, and Sprague-Dawley Purkinje Neuron Whole-Cell and Single-Channel Conductance Responses

F. Conclusions

IX. REFERENCES.............................................................................................. 


\section{LIST OF TABLES}

TABLE 1. ARS scoring system for seizure severity in GEPRs exposed to audiogenic stimulation

TABLE 2. Timeline of major developmental events for the rat cerebellum focusing..... $.48-49$ upon the Purkinje neurons and those events which directly impact upon the.

TABLE 3. Various compounds which interact with the $\mathrm{GABA}_{\mathrm{A}}$-receptor complex and.........56 their effects.

TABLE 4. Resting membrane potential $(\mathrm{mV})$ of Purkinje neurons in cerebellar. .88 slices from Sprague-Dawley, GEPR-NE, GEPR-3, and GEPR-9 rats at various postnatal ages.

TABLE 5. Input resistance $(M \Omega)$ of Purkinje neurons in cerebellar slices from .90 Sprague-Dawley, GEPR-NE, GEPR-3, and GEPR-9 rats at various postnatal ages.

TABLE 6. Effects of superfusing ouabain $(1 \mathrm{mM})$ on the resting membrane potential........95 (RMP) of Purkinje neurons in cerebellar slices from Sprague-Dawley rats of various postnatal ages determined using intracellular recording techniques.

TABLE 7. Changes in membrane potential of Purkinje neurons in vermal cerebellar...........98 slices from Sprague-Dawley and GEPR-NE rats induced by various GABA-receptor agonists and antagonists as determined using intracellular recording techniques.

TABLE 8. Changes in membrane potential of Purkinje neurons in vermal cerebellar. slices from Sprague-Dawley and GEPR-NE rats induced by excitatory agonists as determined using intracellular recording techniques.

TABLE 9. Changes in membrane potential of Purkinje neurons in vermal cerebellar. slices from Sprague-Dawley and GEPR-9 rats induced by various GABA-receptor agonists and antagonists as determined using intracellular recording techniques.

TABLE 10. Changes in membrane potential of Purkinje neurons in vermal cerebellar. 109 slices from Sprague-Dawley and GEPR-9 rats induced by excitatory agonists as determined using intracellular recording techniques.

(continued) 
TABLE 11. Changes in membrane potential of Purkinje neurons in vermal cerebellar. slices from Sprague-Dawley and GEPR-9 rats induced by GABA and/or modulators of the $\mathrm{GABA}_{\mathrm{A}}$-receptor as determined using intracellular recording techniques.

TABLE 12. Changes in membrane potential of Purkinje neurons in vermal cerebellar. 119 slices from Sprague-Dawley and GEPR-3 rats induced by various GABA-receptor agonists and antagonists as determined using intracellular recording techniques.

TABLE 13. Changes in membrane potential of Purkinje neurons in vermal cerebellar. 121 slices from Sprague-Dawley and GEPR-3 rats induced by excitatory agonists as determined using intracellular recording techniques.

TABLE 14. Geometric mean $\mathrm{EC}_{50}$ values \pm S.E.M. (in $\mu \mathrm{M}$ ) determined from............127 concentration-response curves for membrane polarization effects of various agonist using intracellular recording techniques in Purkinje neurons.

TABLE 15. Resting membrane potential $(\mathrm{mV})$ and input resistance $(\mathrm{M} \Omega)$ of Purkinje.........129 neurons in cerebellar slices immediately following attainment of whole cell configuration of the patch-clamp technique.

TABLE 16. Mean open durations (msec) and closed durations (msec) obtained from..........136 single-channel recordings of Purkinje neurons from Sprague-Dawley, GEPR-3, and GEPR-9 animals. 


\section{LIST OF FIGURES}

FIGURE 1. Drawing of the external rat cerebellum, a sagittal section, and a folium.

FIGURE 2. Depictions of the vestibulocerebellar (A), cerebrocerebellar (B), and $.32-35$ spinocerebellar (C) pathways.

FIGURE 3. Diagramatic illustration of cerebellar neuronal connections and the major.......39-40 transmitters involved in these connections.

FIGURE 4. Schematic illustrating the postnatal development of the rat cerebellum .47

FIGURE 5. Intracellular recording of a Purkinje neuron in a cerebellar slice showing.........73 antidromic action potential invasion of the soma following white matter stimulation.

FIGURE 6. Representative voltage responses (A) and current injection (B) traces as..............74 used for the formation of current-voltage $(\mathrm{I} / \mathrm{V})$ curves.

FIGURE 7. Current-voltage (I/V) plots for Purkinje neurons in cerebellar slices from. .75 a 10 day (P10) and a 27 day (P27) old Sprague-Dawley rat as determined using intracellular recording techniques.

FIGURE 8. Response of a Purkinje neuron in a cerebellar slice from a Sprague-Dawley .77 rat to $1 \mu \mathrm{M}$ muscimol application via superfusion.

FIGURE 9. Representative whole-cell (A) and single-channel current (B) traces from.........82 Purkinje neurons of Sprague-Dawley rats.

FIGURE 10. Bar graph comparing the resting membrane potential of Purkinje neurons in cerebellar slices from Sprague-Dawley, GEPR-NE, GEPR-3, and GEPR-9 rats measured using intracellular recording techniques.

FIGURE 11. Bar graph comparing the input resistance of Purkinje neurons in cerebellar. slices from Sprague-Dawley, GEPR-NE, GEPR-3, and GEPR-9 rats measured using intracellular recording techniques.

FIGURE 12. Plots of the resting membrane potential $(\square)$ and input resistance $(\triangle)$ for .91 Purkinje neurons in cerebellar slices from Sprague-Dawley rats at various postnatal ages as determined using intracellular recording techniques.

(continued) 
FIGURE 13. A trace of the membrane response of a Purkinje neuron in a cerebellar slice. from a P22 Sprague-Dawley rat to ouabain superfusion illustrates the depolarizing effects of ouabain on the membrane potential.

FIGURE 14. Plot of the depolarizing effects of superfusing ouabain $(1 \mathrm{mM})$ on the .94 resting membrane potential of Purkinje neurons in cerebellar slices from SpragueDawley rats as determined using intracellular recording techniques.

FIGURE 15. Concentration-response curves of Purkinje neurons to superfusion of GABA........102 for Sprague-Dawley and GEPR-NE animals.

FIGURE 16. Concentration-response curves of Purkinje neurons to superfusion of. 103 muscimol for Sprague-Dawley and GEPR-NE animals.

FIGURE 17. Concentration-response curves of Purkinje neurons to superfusion of 104 glutamate for Sprague-Dawley and GEPR-NE animals.

FIGURE 18. Concentration-response curves of Purkinje neurons to superfusion of aspartate.....105 for Sprague-Dawley and GEPR-NE animals.

FIGURE 19. Concentration-response curves of Purkinje neurons to superfusion of GABA........111 for Sprague-Dawley and GEPR-9 animals.

FIGURE 20. Concentration-response curves of Purkinje neurons to superfusion of muscimol for Sprague-Dawley and GEPR-9 animals.

FIGURE 21. Concentration-response curves of Purkinje neurons to superfusion of. 114 glutamate for Sprague-Dawley and GEPR-9 animals.

FIGURE 22. Concentration-response curves of Purkinje neurons to superfusion of aspartate.....115 for Sprague-Dawley and GEPR-9 animals.

FIGURE 23. Concentration-response curves of Purkinje neurons to superfusion of GABA........122 for Sprague-Dawley and GEPR-3 animals.

FIGURE 24. Concentration-response curves of Purkinje neurons to superfusion of .123 muscimol for Sprague-Dawley and GEPR-3 animals.

FIGURE 25. Concentration-response curves of Purkinje neurons to superfusion of. 125 glutamate for Sprague-Dawley and GEPR-3 animals.

(continued) 
FIGURE 26. Concentration-response curves of Purkinje neurons to superfusion of aspartate.....126 for Sprague-Dawley and GEPR-3 animals.

FIGURE 27. Concentration-response curves of the mean neuron peak current amplitudes of Purkinje neurons to superfusion of GABA.

FIGURE 28. Mean concentration-response curves of Purkinje neurons to superfusion of........132 higher concentrations of GABA depicting the steady-state current.

FIGURE 29. Mean I/V curves of Purkinje neurons exposed to $1 \mathrm{mM} \mathrm{GABA}$ held at.............134 various membrane potentials.

FIGURE 30. Histogram plot of the amplitude of detected open events for GEPR-9...............138 Purkinje neurons.

FIGURE 31. Histogram plots of open durations for Sprague-Dawley, GEPR-3, and GEPR-9 Purkinje neurons upon application of $100 \mu \mathrm{M}$ GABA. 


\begin{abstract}
The genetically epilepsy-prone rat (GEPR) is an animal model of epilepsy which exhibits deficits in GABAergic neurotransmission in a variety of brain regions. However, the underlying cause for this deficit has yet to be described. The present studies were therefore performed in order to elucidate the mechanism(s) underlying this GABAergic deficit. To accomplish this task, electrophysiological recordings of Purkinje neurons in sagittal slices of the cerebellar vermis were performed. The initial aim was to compare the basic electrical membrane characteristics of Purkinje neurons from GEPR and control animals using standard intracellular recording techniques. These studies indicated that there is no significant difference in resting membrane potential or input resistance between GEPRs and control. To compare GEPR and control neurons pharmacologically, full concentration response curves were constructed for membrane polarization responses to GABA, muscimol, glutamate, and aspartate. While there was an approximate 4-fold increase in the GABA and muscimol $\mathrm{EC}_{50} \mathrm{~s}$ for GEPR Purkinje neurons compared to control animals without a change in maximal response, $\mathrm{EC}_{50} \mathrm{~s}$ generated for glutamate and aspartate were not significantly different between animal strains, indicating a specific subsensitivity to $\mathrm{GABA}_{\mathrm{A}}$-receptor activation for GEPR Purkinje neurons. In order to further investigate the underlying cause of this specific subsensitivity, whole and single-channel patch recording techniques were used to compare conductance properties of $\mathrm{GABA}_{\mathrm{A}}$-receptors from Purkinje neurons from GEPR and control animals. These studies indicated that GEPR Purkinje neuron $\mathrm{GABA}_{\mathrm{A}}$-receptors display a decreased level of maximal chloride conductance upon activation by ligand as well an increased rate of desensitization. This provides further evidence that GEPR Purkinje neurons display a specific subsensitivity to $\mathrm{GABA}_{\mathrm{A}^{-}}$ receptor activation which is due to the chloride gating characteristics of this receptor complex.
\end{abstract}




\section{CELLULAR RESPONSIVENESS}

The basic functional units of the nervous system are neurons, which, along with muscle cells and pancreatic $\beta$-cells, are unique in that they respond to stimuli by generating electrical impulses, that is, they are excitable. The function of an individual neuron is dependent upon both its innate electrical properties in conjunction with its interaction with afferent input and efferent target(s), such that, for any neuronal circuit to operate properly, each neuron along the pathway must correctly respond to the input it is receiving and then appropriately convey this information to its postsynaptic effector(s). In this way, the maintenance and regulation of cellular responsiveness is fundamentally important to the proper functioning of neuronal circuits. Abnormal responsiveness can, consequently, lead to the misinterpretation of ongoing activity and thus yield undesirable communication between neurons.

Historically, most of our understanding of how cells regulate their responsiveness has been obtained by investigating experimentally induced changes in responsiveness. Through a variety of procedures (see review by Fleming and Westfall, 1988), it is possible to produce alterations in responsiveness by which cells attempt to adapt to changes in their microenvironment to maintain a proper flow of information. In general, such induced changes have fallen into one of two categories, deviation or adaptive changes in sensitivity. More recently, the closely related but somewhat different concept of neuronal, or synaptic, plasticity has garnered significant attention as an adaptive phenomenon. This plasticity can be defined as modifications in synaptic strength that follow specific patterns of neuronal activity (Abraham and Tate, 1997). The most common uses 
of this term are for describing changes in neuronal communication that occur during processes such as long-term potentiation and long-term depression, and to describe the capacity of the nervous system to undergo major and relatively rapid reorganization after input manipulation. Thus, some forms of synaptic plasticity and certain types of altered sensitivity, as described below, may have a similar fundamental basis. In either case, neurons regulate their activity by altering their cellular responsiveness to better accommodate to the microenvironment with which they are presented.

\section{A. Adaptive Changes in Sensitivity}

Adaptive changes in sensitivity, by definition, involve alterations in the cellular responsiveness to an agonist or agonists that occur in response to a chronic modification in the level of cellular activity. This is in contrast to deviation supersensitivity which is the result of acute inhibition or loss of either metabolism or uptake of neurotransmitters resulting in an elevated level of transmitter in the biophase (Fleming and Westfall, 1988). Since the research presented here is relevant specifically to adaptive changes in sensitivity, further discussion will be limited to that subject.

Adaptive supersensitivity is characterized by a leftward shift of the agonist dose-response curve. Coincident with this shift, there may also be an increase in the maximal response and/or a change in the slope of the dose-response curve (Fleming et al., 1973). Similarly, adaptive subsensitivity is evidenced by a rightward shift of the dose-response curve with or without decreases in the slope and maximal response. Thus, for either subsensitivity or supersensitivity, there is an alteration in the quantitative relationship between the stimulus and the cellular response evoked by that stimulus. There is, however, no single mechanism that accounts for all adaptive changes in 
responsiveness. Mechanisms that have been firmly supported by experimental evidence include alterations in receptor number (or density), alterations in signal transduction mechanisms, and alterations in electrophysiological membrane properties, such as the resting membrane potential (Fleming and Taylor, 1995). The mechanism(s) involved depend(s) on the type of cell or species of animal. Furthermore, a given adaptive response may employ more than one of these mechanisms to produce an overall change in responsiveness (see below).

The fact that altering the number of functional receptors in turn alters the responsiveness of a cell to an agonist can be demonstrated by the law of mass action. This law dictates that, at equilibrium, the following relationship exists for the reaction $R+A \rightleftharpoons R A$ :

$$
\mathrm{K}_{\mathrm{D}}=[\mathrm{R}][\mathrm{A}] /[\mathrm{RA}]
$$

where $[\mathrm{R}],[\mathrm{A}]$, and $[\mathrm{RA}]$ represent the concentrations of free receptors, free agonist, and agonistreceptor complexes, respectively, and $\mathrm{K}_{\mathrm{D}}$ is the dissociation constant for the agonist-receptor complex. If $\left[R_{t}\right]$ is then used to represent the total concentration of receptors (i.e., $\left[R_{t}\right]=[R]+$ [RA]), the following relationship can be derived:

$$
\left(\mathrm{K}_{\mathrm{D}} /[\mathrm{A}]\right)+1=\left[\mathrm{R}_{\mathrm{t}}\right] /[\mathrm{RA}]
$$

Thus, when $[\mathrm{A}]$ is unchanged, and since $\mathrm{K}_{\mathrm{D}}$ is a constant, as the concentration of total receptors changes $\left(\left[\mathrm{R}_{\mathrm{t}}\right]\right)$, the concentration of agonist-receptor complexes ([RA]) must also change proportionally. Therefore, if the ability of the agonist to activate the receptor has not changed (i.e., affinity and efficacy remain the same), the effect of a given concentration of agonist ([A]) will change according to the magnitude and direction of the alteration in receptor population. An increase in receptor population would produce a leftward shift in the agonist dose-response curve (supersensitivity), whereas a decrease in receptor population would yield a rightward shift 
(subsensitivity). Importantly, this shift in responsiveness is specific for A, the agonist(s) which activate the receptor, $\mathrm{R}$.

The first documented evidence of changes in responsiveness due to alterations in receptor levels was in denervated skeletal muscle (Thesleff, 1960). With chronic denervation, skeletal muscle becomes supersensitive to nicotinic agonists (Thesleff, 1960). Furthermore, evidence suggests that a large part of this increased sensitivity is due to the spread of cholinoceptors beyond the neuromuscular endplate which renders the entire muscle responsive to nicotinic agonists (Axelson and Thesleff, 1959; Miledi, 1960). Evidence for such receptor regulation in the nervous system also exists. One such example is in a classical rodent model of Parkinson's disease in which the dopaminergic nigrostriatal pathway is lesioned with 6-hydroxydopamine (6-OHDA). Chronic depression of dopaminergic transmission to the striatum in this manner leads to an up-regulation of dopamine receptors in the striatum (Seeman, 1980). In each of these examples, denervated skeletal muscle and experimental parkinsonism, it should be noted that changes in the total number of receptors do not fully account for the adaptive changes which are expressed (Fleming and Westfall, 1988). However, in both cases there is firm evidence that receptor levels are altered and that these alterations contribute significantly to shifts in the sensitivity of these receptors to agonists. Furthermore, the fact that a single neuron or muscle cell may employ multiple methods for adjusting its responsiveness emphasizes the flexibility which neurons have when accomplishing this task.

As mentioned above, another mechanism by which cells can alter their responsiveness is through changes in electrophysiological characteristics. The membrane potential $\left(\mathrm{E}_{\mathrm{m}}\right)$ of excitable cells is determined for the most part by the permeability to, and electrochemical gradients of, ions across the cellular membrane. A fundamental component of creating and maintaining much of these 
gradients is the $\mathrm{Na}^{+}-\mathrm{K}^{+}$pump (or $\mathrm{Na}^{+}, \mathrm{K}^{+}$-ATPase). The pump, which exchanges sodium and potassium ions across the cellular membrane, may be either electroneutral (one for one ionic exchange) or electrogenic (unequal exchange of charge). It is important to note that the pump may, in fact, be electroneutral in some instances and electrogenic in others within a given tissue depending on the experimental conditions (Thomas, 1972; Fleming, 1980).

When the pump is electrogenic, it creates a positive outward current that contributes to the membrane potential. Thomas (1972) estimated this contribution of the pump (Ep) to the membrane potential to be:

$$
\mathrm{E}_{\mathrm{p}}=\frac{\mathrm{RT}}{\mathrm{F}} \ln \frac{1}{\mathrm{r}} \cdot \frac{\mathrm{r \textrm {K } _ { 0 }}+b \mathrm{Na}_{0}}{\mathrm{~K}_{0}+b \mathrm{Na}_{0}}
$$

where $\mathrm{r}$ is the coupling ratio of the pump (i.e., $\mathrm{r}=1.5$ when $3 \mathrm{Na}^{+}$are exchanged for $2 \mathrm{~K}^{+}$), $b$ is the ratio of the sodium and potassium ionic permeabilities, $\mathrm{K}_{\mathrm{O}}$ is the external potassium ion concentration, $\mathrm{Na}_{\mathrm{O}}$ is the external sodium ion concentration, and $\mathrm{R}, \mathrm{T}$, and $\mathrm{F}$ are the gas constant, temperature, and Faraday's constant, respectively. Though the contribution of this ATPase to the membrane potential will vary from tissue to tissue and from cell to cell, estimations of its contribution in a variety of cells have tended to be in the 10 to 30 millivolt (mV) range (Fleming, 1980). One such estimation of this contribution was put forth by Urquilla et al. (1978) for cells of the guinea pig vas deferens. Using procedures to inhibit the electrogenic pump potential (application of $10^{-5} \mathrm{M}$ ouabain or decreased extracellular $\mathrm{K}^{+}$), they were able to depolarize the cells by approximately $10 \mathrm{mV}$. Since the pump may be responsible for quite a significant portion of the membrane potential in some cases, the regulation of its activity represents a potential target by which neurons may nonspecifically shift their responsiveness to neurotransmitters, essentially by changing their state of excitability. The nonspecificity of this shift, which arises since changes in 
RMP will alter responsiveness to any agonist that acts via altering the membrane potential (see below), serves as an important diagnostic tool when investigating changes in sensitivity.

A classic example of the relationship between the membrane potential and the responsiveness of cells is the adaptive supersensitivity of the guinea pig vas deferens which can be induced by chronic reserpine treatment, decentralization (preganglionic denervation of autonomically innervated cells), or denervation of the smooth muscle (Westfall, 1970a; Westfall et al., 1972). Such procedures induce an approximate $10 \mathrm{mV}$ depolarization of the smooth muscle cells (Fleming and Westfall, 1975), similar to the level of depolarization attainable by inhibiting the pump (above; Urquilla et al., 1978). Furthermore, there is evidence that a reduction in the amount of $\left[{ }^{3} \mathrm{H}\right]$ ouabain binding to the pump (Wong et al., 1981) as well as a reduction in enzyme activity (Gerthoffer et al., 1979) exist and that these reductions are due specifically to a decrease in the amount of the $\alpha_{2}$-subunit of the pump (Hershman et al., 1993). Furthermore, the $\alpha$-subunit is the subunit responsible for both the enzymatic activity and cardiac glycoside (ouabain) binding (Sweadner, 1989). Concomitant with these changes are increased sensitivities to $\alpha$-adrenoceptor agonists, muscarinic agonists, histamine, and potassium ions that follow similar time courses to the depolarization (Westfall, 1970a; Fleming and Westfall, 1975) and the reduction in pump protein (Hershman et al., 1995). Since the threshold potential at which action potentials are elicited remains unchanged in the supersensitive muscle (Goto et al., 1978) and a given amount of transmitter produces relatively equal amounts of depolarization in both control and supersensitive cells, less transmitter is needed to reach the threshold for firing. Thus, for a variety of unrelated agonists which function by depolarizing the cells to the threshold of action potential firing, supersensitive cells require less of these agonists to produce firing. 
A third mechanism which has been shown to account for adaptive changes in sensitivity is a change in cellular signaling transduction process(es). Altering sensitivity by changes in the amount, availability, or effectiveness of mediators of activity presents, in some cases, quite a different picture than those mechanisms described above. Whereas changes in receptor number or density clearly yield highly specific changes in cellular responsiveness and alterations of the membrane potential changes responsiveness nonspecifically via either decreased or increased excitability, the impact of changes in signal transduction processes on the specificity of changes is not as clear cut. Such changes may lead to specific alterations in responsiveness. An example of this would be a change in the gating of a ligand-operated ion channel. By altering the conductance characteristics of such a receptor-gated channel, a neuron could potentially alter its responsiveness specifically to transmitters that mediate the activity of that channel. Such receptor modification has been observed for the $\mathrm{GABA}_{\mathrm{A}}$-receptor via protein kinase A (Porter et al., 1990), protein kinase C (Lin et al., 1994), or tyrosine kinase (Moss et al., 1995) mediated receptor phosphorylation.

On the other hand, with certain changes in signal transduction mechanisms, most notably with intracellular signaling pathways and second messengers, neuronal responsiveness can potentially be altered to a wide array of transmitters which interact with such messengers via their signal transduction cascade. One such example of this sort of adaptational process occurs in cultured dorsal root ganglia neurons which are chronically exposed to etorphine, a non-selective opioid agonist. Attali and Vogel (1989) have shown that such chronic exposure to etorphine leads to a specific reduction in the amount of the $\alpha$-subunit of the G-protein, $G_{i}$, but no changes in adenylyl cyclase activity. As would be predicted, they were also able to show that these cultured neurons displayed marked subsensitivity to the activation of receptor systems which rely upon $G_{i}$ 
to mediate their signaling, including $\kappa$-opioid receptor activation (U50488H), $\alpha_{2}$-adrenergic receptor activation (clonidine), and muscarinic cholinoceptor activation (carbachol).

As has been described, adaptive sensitivity changes represent mechanisms by which cells alter their responsiveness. Such adaptive changes are, however, merely a subset of the mechanisms by which cellular responsiveness can be regulated, namely, those changes induced either experimentally, pharmacologically, or pathologically via deprivation or elevation of input. Thus, they represent ways in which cells attempt to return to a "normal" level of activity subsequent to physiologically abnormal input. Such homeostatic responses allow individual cells to compensate for perturbations of their microenvironment. Plasticity, on the other hand, is somewhat different in that the trigger for changes in responsiveness is not necessarily abnormal input. In these instances, rather than acting to regain homeostasis after receiving abnormal input, cells essentially become able to recognize patterns of input, alter their responsiveness according to this pattern, and then convey a predictable output to their efferent targets based on such particular patterns of input.

\section{B. Plastic Changes in Sensitivity}

Since the original description of long-term potentiation in the dentate gyrus (Bliss and Lømo, 1973) twenty five years ago, the study of plasticity and the description of phenomena which it encompasses has dramatically evolved. Plasticity is now being used to describe a number of different events which involve altered cellular communication, and thus an important distinction should be made. There are forms of plasticity, as alluded to earlier, that involve structural reorganization within the nervous system leading to changes in cellular communication rather than changes in responsiveness. Examples of such processes include reorganization of sensory systems 
after peripheral nerve injury (Kaas and Florence, 1997) and neural overgrowth after limb restriction (Schallert et al., 1997). Though the discovery of such processes is both important and exciting, it is, in fact, changes in cellular responsiveness which are the emphasis of the present studies. For this reason, further discussion will focus on those instances where neural plasticity involves changes in cellular responsiveness. Thus, the term plasticity in this discussion can appropriately be defined as changes in synaptic efficacy or function which are induced by prior activity or modifications in activity and which persist across time.

Many such forms of use-dependent enhancement of synaptic transmission have been identified in the mammalian nervous system (Artola and Singer, 1993; Malenka and Nicoll, 1993; Abraham and Tate, 1997). The underlying theme to these alterations is that relatively brief patterns of synaptic activity can lead to longer term changes in synaptic strength. The terms used for these persisting changes are long-term potentiation (LTP) and long-term depression (LTD). LTP, in general, is considered to be homosynaptic and associative (Artola and Singer, 1993). The term homosynaptic is used to illustrate that alterations in synaptic efficacy are specific to the afferent fibers stimulated (i.e., they are input-specific). Thus, high-frequency $(>100 \mathrm{~Hz})$ tetanic stimulation of an afferent pathway leads to a prolonged increase in the synaptic efficacy at that synapse alone (Madison et al., 1991; Tsien and Malinow, 1991). LTP is associative since it is induced in synapses only during those times when they are active while at the same time other, distinct inputs are also active. This accounts for the fact that periodic, low-frequency $(<5 \mathrm{~Hz})$ stimulation of one pathway which is in phase with periodic, high-frequency $(>100 \mathrm{~Hz})$ stimulation of another conditioning pathway, will result in LTP of both pathways (Linden, 1994).

In contrast to LTP, LTD has been found to occur at inactive synapses as well as active ones 
(Artola and Singer, 1993). Thus, LTD may be homosynaptic or heterosynaptic. Briefly, homosynaptic LTD occurs at inputs whose activation directly contributes to inducing the modification, whereas heterosynaptic LTD describes modifications which occur to inputs which were inactive during induction (Artola and Singer, 1993). For example, homosynaptic LTD describes the process by which low-frequency $(<1 \mathrm{~Hz})$ stimulation results in a persistent decrease in the efficacy of that synapse (Sejnowski, 1991; Artola and Singer, 1993; Linden, 1994). On the other hand, heterosynaptic LTD describes a situation which occurs concurrent with homosynaptic LTP. That is, tetanic stimulation of one afferent pathway results in both homosynaptic LTP of that pathway and LTD in an unstimulated pathway(s) to the same neuron. Like LTP, LTD may also be associative. Periodic, low-frequency stimulation of an afferent pathway out of phase with a periodic, high-frequency stimulation of another pathway results in an associative LTD of the lowfrequency pathway (Artola and Singer, 1993; Linden, 1994).

Having described these processes, one important issue becomes the manner by which they occur. Though many factors are important in the overall induction of plasticity, there are a few critical events which appear to be a common theme among such plastic changes. These include a change in membrane potential which is typically a postsynaptic depolarization, elevations in intracellular $\mathrm{Ca}^{++}$concentration $\left(\left[\mathrm{Ca}^{++}\right]_{\mathrm{I}}\right)$, and modifications of intracellular protein content (Abraham and Tate, 1997). Changes in protein content fall into one of two classes. Shorter term forms of plasticity are typically dependent on post-translational modification of existing proteins whereas longer term forms of plasticity are usually dependent upon gene expression and de novo protein synthesis. As well as having factors of induction in common, it has also become apparent that these plastic changes also share similar features for the maintenance of these changes. Such 
maintenance is typically via the activation of protein kinase A and various isoforms of the adenylyl cyclases (Abraham and Tate, 1997). Among these modifications, the step which appears to determine whether LTD or LTP will be witnessed is the rise in $\left[\mathrm{Ca}^{++}\right]_{\mathrm{I}}$. LTD requires an initial surge of $\left[\mathrm{Ca}^{++}\right]_{I}$ above resting levels (Linden et al., 1991) as buffering of intracellular $\mathrm{Ca}^{++}$blocks the induction of LTD (Sakurai, 1990; Bröcher et al., 1992; Hirsch and Crépel, 1992; Mulkey and Malenka, 1992). Though this mechanism is also evident in LTP, the induction of LTP requires a stronger depolarization of the postsynaptic membrane and a greater subsequent rise of $\left[\mathrm{Ca}^{++}\right]_{I}$ (Artola et al., 1990; Bliss and Collinridge, 1993; Abraham and Tate, 1997).

As described above, adaptive sensitivity changes are typically studied to help better understand how normal cells adjust certain aspects of their responsiveness in order to compensate for abnormal changes in their microenvironment. Similarly, plastic changes are typically investigated to determine how cells "learn" to interpret certain patterns of signals and then reinforce those signals during subsequent presentations of them. However, often overlooked aspects of these phenomena are the consequences of deficiencies in these processes or instances where such phenomena occur without proper provocation, in other words, those situations in which cells do not alter their responsiveness in an appropriate manner or inherently maintain an inappropriate level of responsiveness. Thus, it is important to recognize that such abnormal regulation of responsiveness can, in and of itself, represent a pathological condition. One group of pathological conditions which appear to be likely candidates for such a problem are the epilepsies. Inherent to many of these disorders, as will be described in section II, is abnormal excitability of neurons in the central nervous system. 


\section{Epilepsy}

The epilepsies are a group of neurological disorders which manifest themselves as seizures characterized by paroxysmal neuronal discharge. This abnormal neuronal discharge results from the recruitment of neurons throughout the brain into synchronous activity. The result of this discharge in large ensembles of neurons is an epileptic seizure which produces involuntary, stereotyped alterations in behavior. Epileptic seizure disorders afflict approximately two million individuals in the United States (Shin and McNamara, 1994; French, 1994) and as many as forty million people throughout the world (Delgado-Escueta et al., 1986), making epilepsies the second most common neurological disease in man (Martin, 1991). Though there are numerous types and manifestations of such seizure disorders (for comprehensive review see Delgado-Escueta et al., 1986), they can be characterized as types of a few basic forms of seizures. Based upon the mechanism of onset and propagation, seizures can be categorized as being partial, partial with secondary generalization, or generalized (Hopkins and Appleton, 1996).

If the abnormal discharge arises and then remains localized within a specific region of the brain, it is termed a partial (or focal) seizure. The perception of the seizure by the individual and/or the external manifestations depend primarily upon the site of origin. For example, if such a seizure were to originate in the large toe region of the motor cortex, initial manifestation would be the contraction of muscles in the contralateral big toe. The extent of the motor cortex over which the discharge spread would subsequently determine which other muscles would contract, with muscles represented in directly neighboring regions of the motor cortex being the next to be afflicted (e.g., 
the rest of the toes, the foot, the ankle and so forth). When such a seizure occurs without a disturbance in consciousness, it is called a simple partial seizure.

If such a discharge continues to spread throughout the entire brain, it is said to be a partial seizure with secondary generalization (to a convulsive seizure). These are known as tonic-clonic or grand-mal seizures due to their symptomology. The first phase of such a seizure is characterized by widespread contraction (tonic) of muscles throughout the body making it very rigid. The rate at which different muscles are incorporated into these contractions depends upon the rate at which the discharge spreads in the central nervous system. After a few minutes in the tonic phase, the seizure will progress to the clonic (convulsive) phase characterized by rhythmic movements of limb and trunk muscles. Furthermore, these seizures, like any seizure which spreads throughout the entire brain, are accompanied by the loss of consciousness.

The third possibility is that a seizure is generalized at the onset such that neuronal discharge is generated and subsequently spreads to all areas of the brain almost simultaneously. Typical absence (or petit-mal) seizures are of this type. The onset and termination of such seizures are very abrupt, as might be expected from the rapid rate of transmission which is required. They are often just brief interruptions in the normal stream of consciousness and may occur as frequently as 50 times a day (Hopkins and Appleton, 1996). Absence seizures are also frequently associated with myoclonic jerks of the musculature which are of similarly short duration.

The causes of the many different forms of epilepsy (see review by Delgado-Escueta et al., 1986) include genetic inheritance, trauma, infectious diseases, degenerative disorders and a host of others. Even with the various precipitating causes, each type results in a seizure disorder that is due to the same underlying cause, namely, neuronal hyperexcitability. Proposed mechanisms for this 
hyperexcitability are based on the premise that there is a shift in the excitatory/inhibitory balance of neurotransmission in the brain (Meldrum, 1990; Tasker and Dudek, 1991) which could be attributed to:

1) Altered sensitivity to excitatory neurotransmitter(s),

2) Altered sensitivity to inhibitory neurotransmitter(s),

3) Alterations in the release and/or metabolism of neurotransmitter(s), or

4) Some combination of the above

\section{A. Animal Models of Epilepsy}

In most cases of human epilepsy, it has proven very difficult to pinpoint a cellular basis for this hyperexcitability. Most studies of human epilepsy rely upon techniques such as brain imaging analysis, electroencephalogram (EEG) recordings, or postmortem analysis of brain chemicals. Because of the variety of forms of epilepsy, it is difficult to correlate alterations of these parameters with the disease, and often the findings appear to be contradictory (Glass and Dragunow, 1995). Furthermore, one must use caution in interpreting the results of such analyses since one rarely knows whether the observed changes actually contribute to the cause of the disease state or perhaps represent a consequence of the disease state. It should be remembered that the epilepsies are a variety of diseases which happen to share a common basis (neuronal hyperexcitability) and a common symptom (seizure), rather than a single disease with a single cause. Consequently, animal models of seizures and epilepsy serve as invaluable tools in deciphering the mechanisms of the epilepsies and developing therapeutic strategies for managing them.

Animal models of epilepsy are relatively abundant. Many of the original animal models of 
epilepsy relied upon inducing seizures, by some means, in otherwise normal animals. Most prominent among these approaches were the use of chemical convulsants (De Dyn et al., 1992) and the use of both chemical and electrical kindling (McNamara, 1986). Chemical convulsants, those substances which induce seizures in vivo, come in a variety of forms. Typically they are substances which either produce lesions of the brain (e.g., metal compounds), enhance excitatory transmission (e.g., excitatory amino acids), or decrease inhibitory transmission (e.g., bicuculline or mercaptoproprionic acid). Kindling refers to the phenomenon by which repeated exposure of the brain to subconvulsive levels of an electrical or chemical stimulus results in the intensification of seizure activity which typically culminates in a generalized seizure (McNamara, 1986). Both of these models have served valuable functions in identifying the ways by which seizures are initiated and spread. Furthermore, they have proven to be valuable resources in the development of anticonvulsant compounds (Shin and McNamara, 1994). In some cases, they may closely approximate a subset of epilepsies which affect certain individuals (e.g., lesion studies compared to trauma). However, such methods do not adequately represent the types of epilepsy which are not the result of some form of an external insult to the brain.

The genetic models of epilepsy, of which there are now many, possess an inherent advantage for investigating the mechanisms of epilepsy. Namely, these animal models result from inadequacies of the brain itself rather than relying upon external manipulation of the central nervous system. Such models have been bred in a variety of different species and include examples such as the DBA/2 mouse, the tottering mouse (C57BL/6j tg/tg), the genetically epilepsy-prone rat (GEPR), the genetic absence epilepsy rat (GAER), the Mongolian gerbil, and the Senegalese (photoepileptic) baboon (Jobe et al., 1991). Models such as these have all been well characterized 
relative to their seizure development, predisposition, and characteristics. Therefore, these animals serve as valuable tools in which to investigate the mechanisms by which neuronal hyperexcitability develops in animals predisposed to seizures. It should be emphasized that no single model is likely to provide all the answers in understanding the epilepsies, whether it be a genetic, kindling, or chemical model. Instead, it is the information accumulated from a variety of these models which will provide the insights to better understand the origin of the pathology as well as to develop better strategies for treatment of the epilepsies.

\section{B. The Genetically Epilepsy-Prone Rat (GEPR)}

The GEPR model of epilepsy consists of two separately derived strains of seizure-prone rats, GEPR-3s and GEPR-9s, and a genetic non-epileptic control strain, GEPR-NEs (originally called GEPR-0s). These animals were selectively bred from Sprague-Dawley stock based upon their seizure predisposition (Jobe et al., 1991). The seizure-prone strains have characteristic and reproducible convulsive patterns in response to audiogenic stimulation which are phenotypic markers by which these animals are bred and categorized. The numeric identifiers of these animals are based upon a system of audiogenic response scores (ARS) developed by Jobe et al. (1973) for the evaluation of convulsive intensity such that GEPR-3s display an ARS of 3 and GEPR-9s an ARS of 9. These ARS scores correlate to convulsive properties as indicated in Table 1.

The GEPR is an animal model that inherits the propensity for seizures as a polygenetic and autosomal trait (Ribak et al., 1988a) and shares a number of important features with some human forms of epilepsy. Other than a convulsive predisposition, the GEPRs exhibit no gross evidence of neurological dysfunction such that eating, sleeping, ambulation, and breeding habits are not 
Table 1. ARS scoring system for seizure severity in GEPRs exposed to audiogenic stimulation (Dailey and Jobe, 1985).

\begin{tabular}{|c|c|c|}
\hline ARS Score & Early Response & Convulsive Posture \\
\hline $\mathbf{0}$ & No response & \multirow{2}{*}{ No convulsion } \\
\hline 1 & Running Fit & \\
\hline 2 & Two running fits & \multirow{2}{*}{ Clonic convulsion (generalized clonus) } \\
\hline 3 & One running fit & \\
\hline 4 & Two running fits & \multirow{2}{*}{$\begin{array}{l}\text { Tonus of the neck, trunk, and forelimbs; } \\
\text { hindlimb clonus }\end{array}$} \\
\hline 5 & One running fit & \\
\hline 6 & Two running fits & \multirow{2}{*}{$\begin{array}{l}\text { Nearly complete tonic extension, except } \\
\text { hindfeet }\end{array}$} \\
\hline 7 & One running fit & \\
\hline 8 & Two running fits & \multirow{2}{*}{$\begin{array}{l}\text { Complete tonic extension (full tonic-clonic } \\
\text { convulsion) }\end{array}$} \\
\hline 9 & One running fit & \\
\hline
\end{tabular}

characteristically different from those of normal animals (Jobe et al., 1993a,b). Perhaps the most important trait shared with many human epilepsies is the genetic component. Both humans with epilepsy and GEPRs exhibit seizures which are precipitated by events which do not give rise to seizures in normal counterparts. In addition to being susceptible to audiogenic seizures, GEPRs are susceptible to seizures induced by hyperthermia (a characteristic retained into adulthood) and a significant incidence of spontaneous seizures (Jobe et al., 1986; Dailey et al., 1989). The GEPRs also exhibit an increased sensitivity to a variety of seizure-evoking stimuli including electroshock (Browning et al., 1990), pentylenetetrazol (Browning et al., 1990), kindling (Savage et al., 1986a,b), convulsant drugs (Dailey et al., 1989), and hyperbaric oxygen (Laird and Jobe, 1987; Millan et al., 1991). Moreover, clinically useful antiepileptic drugs for the management of 
generalized tonic-clonic seizures in humans also inhibit audiogenic seizures in GEPRs, though the most effective agents are not the same for both the GEPR-3s and GEPR-9s (Dailey and Jobe, 1985; Dailey et al., 1989, 1992).

Numerous deficits in the GEPR central nervous system have been described which could contribute to the seizure predisposition of these animals. However, whether any or all of these represent the exact cause has yet to be determined. Two problems complicate the determination of the true precipitating factor for the seizure-prone state, similar to the problems with investigating human epilepsy. One of these is in determining which deficits are inherent and which are the result of compensatory responses by the animal to other deficits. This is, of course, very difficult to determine. However, as more data have accumulated from various brain regions concerning many neurotransmitter systems, greater confidence in discriminating between precipitating and compensatory factors has been gained.

The other complication concerns the impact of prior seizure history on the deficits seen. In order to minimize the possibility that prior seizures are the precipitating factor for a given deficit, more recent studies have begun to take advantage of an, as of yet unmentioned, aspect of seizure predisposition in these animals. Though the precise reason is not yet known, these animals do not exhibit the predisposition to seizures prior to postnatal day 15 (Jobe et al., 1980). Thus, by using animals which are very young, it is possible to ensure that the animals have never displayed seizure activity (e.g., $<15$ days old) or that such activity has been minimal.

A vast majority of the available literature on GEPRs discusses evidence of altered noradrenergic and serotonergic transmission. Presynaptic norepinephrine and serotonin content in most areas of the CNS appears to be reduced equally in seizure naive GEPR-9s and GEPR-3s 
compared to controls (Dailey et al., 1991). In addition to reduced presynaptic norepinephrine and serotonin content, the GEPRs also exhibit a reduced norepinephrine and serotonin turnover (Jobe et al., 1984), reduced norepinephrine synthetic enzymatic activity, i.e., tyrosine hydroxylase (Dailey and Jobe, 1986) and dopamine- $\beta$-hydroxylase (Browning et al., 1989a; Lauterborn and Ribak, 1989), reduced serotonin synthetic enzymatic activity, i.e., tryptophan hydroxylase (Statnick et al., 1996), and a reduced capacity for norepinephrine (Browning et al., 1989b) and serotonin uptake (Statnick et al., 1996) in many areas of the CNS.

Though not as thoroughly investigated at this point, there are a number of regions in the brain which also exhibit deficits in GABAergic neurotransmission. Electrophysiological studies in the inferior colliculus (Faingold et al., 1986a,b), cerebral cortex (Waterhouse., 1986), cerebellum (Gould et al., 1991, 1995), striatum (Lasley et al., 1989), and the hippocampus (Browning et al., 1986) have consistently reported reductions in sensitivity to GABA. In each case, a two- to fivefold reduction in sensitivity has been reported. Importantly, this is a feature which the GEPRs share with a number of other epilepsy models (Gale, 1989, 1992; DeDyn et al., 1990; Houser, 1991; Jobe et al., 1991; Snodgrass, 1992). Furthermore, there is evidence for reduced effectiveness of GABAergic transmission in a large variety of human epilepsies (Delgado-Escueda et al., 1986; Houser, 1991; Richens, 1992) and many of the therapeutic agents currently being employed to treat the epilepsies function to facilitate GABAergic transmission (Richens, 1992).

Due to a number of factors, the cerebellum is a very attractive area of the brain in which to further investigate the possible presence and mechanism of deficits in GABAergic transmission in the GEPR. First, the fundamentals of physiological GABAergic transmission in the cerebellum have been well characterized. The characteristics of the postjunctional receptors for this transmitter 
in normal rats have been intensely investigated and have provided a sound basis from which hypotheses can be formed and conclusions can be made regarding the role of GABA in neuronal function. The reason that the GABAergic system has been so well characterized in the cerebellum is due, primarily, to the other factors which make the cerebellum a desirable region of the brain to study. The cerebellum is an evolutionarily conserved structure in which the anatomy, physiology, and pharmacology have been extensively characterized (see section III). In addition, it is an attractive region of the brain in which to study development since most of the development of the rat cerebellum occurs postnatally.

To this point, the study of the GEPR cerebellum has been mostly via extracellular recordings obtained in situ. In these studies (Gould et al., 1991, 1995), Purkinje neurons were shown to be subsensitive to the effects of GABA and muscimol (a GABA $A_{A}$-receptor selective agonist) but not to baclofen (a $\mathrm{GABA}_{\mathrm{B}}$-selective agonist), norepinephrine, or glutamate, indicating that the subsensitivity is at least relatively specific for $\mathrm{GABA}_{\mathrm{A}}$-receptor activation. Radioligand binding studies in cerebellar homogenates, however, provided no evidence of a change in the cerebellar binding characteristics of $\left[{ }^{3} \mathrm{H}\right]$-muscimol or $\left[{ }^{3} \mathrm{H}\right]$-flunitrazepam (Gould et al., 1995), each of which targets different sites on the $\mathrm{GABA}_{\mathrm{A}}$-receptor complex (see section IV).

One inherent disadvantage of using the cerebellum as a brain region of investigation in the study of epilepsy is its highly inhibitory nature. The vastly inhibitory architecture of the cerebellum, which will be more thoroughly described in the following section (section III), prohibits its direct participation in seizure activity. That is, though the cerebellum may have altered discharge patterns, it does not display the characteristic synchronous, paroxysmal discharge typical of cerebral cortical neurons during seizure activity. Thus, evidence of factors which might contribute to seizure 
predisposition obtained via investigation of the cerebellum is somewhat indirect evidence. However, it should be remembered that in order for an animal to be inherently prone to a generalized seizure, many populations of neurons are presumably deficient in their ability to inhibit seizure activity. Therefore, the wide spread change(s) which affect cortical neurons are likely to be present in neurons of the cerebellum as well. Furthermore, in an animal which has no other apparent abnormalities, cellular changes evident in the cerebellum could quite likely be representative of alterations that exist in various other brain regions. 


\section{THE CEREBELLUM}

In an attempt to paint a precise and accurate picture of the cerebellum which can be readily followed by those of various backgrounds, general features of the cerebellum will first be described, followed by more specific discussion of the pertinent features of the cellular anatomy, physiology, and pharmacology. Many of the general features of the cerebellum, except where referenced, come from textbook type sources including Adelman (1987), Carpenter (1991), Cooper et al. (1991), Ito (1984), and Kandel et al. (1991). Once this general overview of the cerebellum has been presented, a relatively detailed description of the postnatal development of this structure will be developed. This discussion will be broken down into subtopics to facilitate easier reference to specific points of interest. Though, as will be discussed later, this study deals primarily with the development and responsiveness of only the Purkinje neurons of the cerebellum, it will prove useful to have a solid understanding of all the major constituents of the cerebellum as they have important interactions and play integral roles in regulation of both the development and responsiveness of Purkinje neurons. Lastly, it should be reiterated that references to the size and number of structures, timing of developmental events, and other such features will be descriptive of the rat cerebellum unless otherwise noted as this is the animal model which has been employed for these studies. 


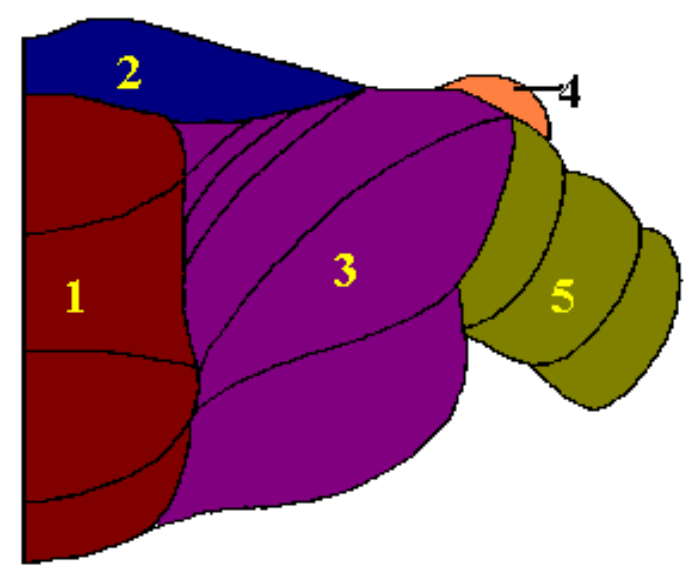

A. Drawing of one half of a rat cerebellum depicted from a caudal to rostral perspective. The numbers indicate: (1) vermis; (2) colliculus caudalis; (3) lateral cerebellar hemisphere; (4) flocculus; (5) paraflocculus.

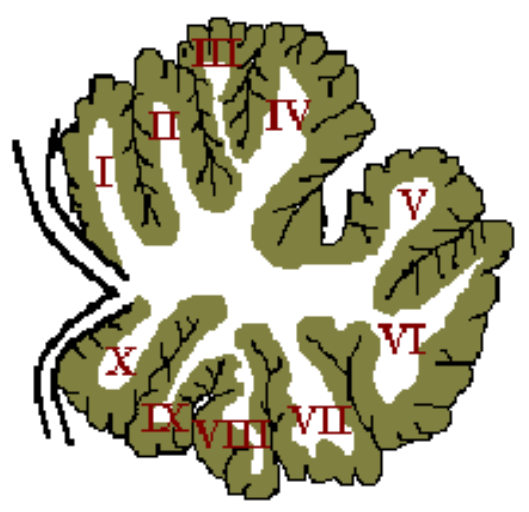

B. Drawing of a mid-saggital section of the cerebellum. The white area approximates the white matter and the Roman numerals indicate lobules with each small fold representing numerous folia.

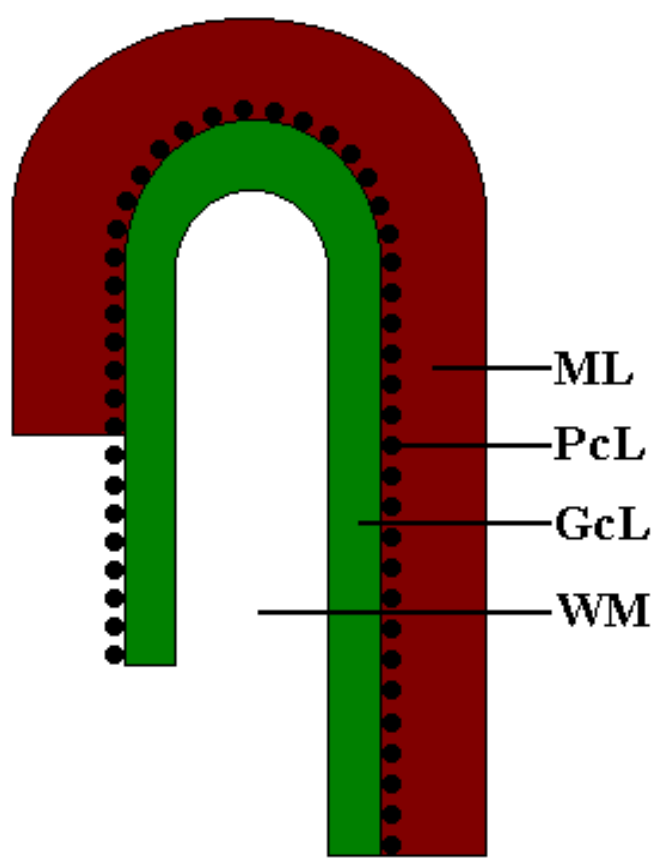

C. Drawing of a single folium of the cerebellum, illustrating the three layers of the cerebellar cortex as well as the white matter. Abbreviations indicate: (ML) molecular layer; (PcL) Purkinje cell layer; (GcL) granule cell layer; (WM) white matter.

FIGURE 1. Series of three drawings depicting the external structure of the rat cerebellum (A), a mid-saggital section of the cerebellum (B), and a folium from within the cerebellum (C). 


\section{A. Basic Features}

The cerebellum occupies the majority of the posterior cranial fossa, overlying the posterior aspects of the pons and medulla, and extending laterally beneath the tentorium cerebelli. It constitutes only about $14 \%$ of the total volume of the human brain (Inukai, 1928) yet contains more than half of its total number of neurons. Its main function is to indirectly regulate movement and posture by acting as a type of comparator which compensates for errors in movement by comparing intention with performance and then adjusting the output of the major descending motor systems of the brain. Though the relative size of the cerebellum has increased dramatically through evolution, the basic structure and wiring have been remarkably preserved (Eccles et al., 1967a,b; Larsell, 1967; Palay and Chan-Palay, 1974; Ito, 1984). Structurally, the cerebellum consists of a superficial gray mantle (the cerebellar cortex), an internal white mass (the medullary substance), and four pairs of intrinsic nuclei (fastigial, globose, emboliform, dentate) which are embedded in the white matter.

As seen in Figure 1A, the cerebellum is divided into three main portions, a medial part (the vermis) and two lateral lobes (the hemispheres) as well as the flocculonodular lobe and the colliculus caudalis. These are connected to the lower segments of the brainstem by three pairs of cerebellar peduncles, the inferior, superior, and middle cerebellar peduncles, which contain all efferent and afferent fibers passing to and from the cerebellum. The inferior cerebellar peduncles connect the cerebellum to the medulla and contain two divisions, the restiform body and the juxtarestiform body. The restiform body is primarily composed of dorsal- and rostralspinocerebellar tracts, the cuneocerebellar tract, as well as the olivocerebellar tract. The juxtarestiform body contains primarily vestibulocerebellar and cerebellovestibular fibers. The 
middle cerebellar peduncles, which connect the cerebellum to the pons, are also known as the brachium pontis and contain the pontocerebellar fibers. The superior cerebellar peduncles contain the majority of the cerebellar output pathways and are also called brachium conjunctivum. The tracts which they contain include the dentatorubral, dentatothalamic, ventral spinocerebellar, interpositorubrothalamic, fastigiothalamic, and fastigiovestibular tracts as well as the trigeminocerebellar and ceruleocerebellar fibers.

The entire cerebellar cortex is a uniform, laminated structure throughout and is composed of three transversely oriented layers which are folded into a large number of narrow leaf-like laminae known as folia (see Figures $1 \mathrm{~B}$ and 1C). The outermost layer, known as the molecular layer, contains two major cell types: basket cells and stellate cells. Other major components of the molecular layer include the beautiful, fan-like dendritic arborizations of the Purkinje neurons, the axons of granule cells (termed parallel fibers), and the dendrites of Golgi type II cells. The middle, Purkinje cell layer of the cortex is named after its primary constituents, the somata of Purkinje neurons. The innermost layer, or granular layer, contains an abundance of small, tightly packed granule cells along with Golgi type II cells, cerebellar glomeruli, and sparse numbers of other cells such as unipolar brush cells and Lugaro cells (Mugnaini et al., 1997; Slater et al., 1997).

The essential functional design of the cerebellum comes in the form of an interaction between the neurons of the cerebellar cortex and the cerebellar nuclei. Major afferent fibers to the cortex come in two varieties, climbing fibers and mossy fibers, and the sole efferent output of the cerebellar cortex is the axons of the Purkinje neurons which primarily target the cerebellar nuclei. These cerebellar nuclei, which also receive collateral inputs from the incoming climbing and mossy fibers, then project to other brain regions. In general, the deep cerebellar nuclei maintain a tonic, 
high-frequency, excitatory discharge which is inhibited by the GABAergic projections of the Purkinje neurons.

\section{B. Neuronal Elements}

As mentioned, cerebellar afferents are of two types, climbing fibers and mossy fibers. In mammals, all climbing fibers originate from a single nucleus of the brainstem, the inferior olivary nucleus (Desclin, 1974, 1976; Courville and Farco-Cantin, 1978; Campbell, 1980; Montarolo et al., 1980; Campbell and Armstrong, 1983a,b). Projections to the inferior olive originate in the spinal cord, motor cortex, brainstem, and cerebellar nuclei. The climbing fibers are only thinly myelinated with a diameter of $1-3 \mu \mathrm{m}$. As they enter the innermost granular layer of the cerebellar cortex, these fibers lose their myelin and then arborize into long branches which ascend through the cerebellar cortex giving off numerous collaterals (Scheibel and Scheibel, 1954). Though some of these collaterals terminate in the granular layer, the vast majority eventually terminate on the trunk and smooth dendrites of Purkinje neurons in the molecular layer (O'Leary et al., 1971; Palay and ChanPalay, 1974). While the branching of these fibers is very expansive across a folium, or convolution, it is quite minimal along an individual folium, thus restricting these branches to a single plane. Mossy fibers, on the other hand, are both larger and more numerous than the climbing fibers and constitute the major afferent input to the cerebellum. Unlike climbing fibers, mossy fibers originate from neurons located in a variety of regions within the central nervous system, including, the pontine nuclei, the spinal cord, the reticular formation, the cerebellar nuclei, and the vestibular nuclei. Mossy fibers also branch repeatedly along both planes of the cerebellum so that an individual fiber may terminate extensively within an individual folium as well as across many folia. 
As these fibers enter the granular layer, they too lose their myelination, branch, and subsequently terminate in as many as 44 large, mossy-like arborizations, or rosettes, from which their name was derived.

Purkinje neurons, the sole output neurons of the cerebellar cortex, are arranged with their cell bodies lying in a single folded sheet. Each of these cell bodies, with a diameter of 20-40 $\mu \mathrm{m}$ (Inukai, 1928; Mugnaini, 1972), gives rise to a single, large $(\approx 10 \mu \mathrm{m})$ dendritic trunk directed toward the pial surface. This dendrite subsequently gives rise to numerous primary, secondary, and tertiary branches. Though the primary and secondary branches are typically smooth, the small tertiary branches are richly invested with spines, with a single Purkinje cell having approximately 100,000 such spines in the molecular layer. The axons of Purkinje cells proceed centrally through the granular layer, give off numerous recurrent collaterals which are typically restricted to the folium of origin, become myelinated, course through the cerebellar white matter, and terminate in the cerebellar nuclei (McCrea et al., 1976).

There are four such cerebellar nuclei on each side of the midline. From medial to lateral these are termed the fastigial, globose, emboliform, and dentate nuclei. The fastigial nuclei, which lie near the midline in the roof of the fourth ventricle, receive input from Purkinje cells in the vermis of the cerebellar cortex. The fastigial nuclei send projections to the pons, the spinal cord, the vestibular nuclei, and the ventral thalamic nuclei. Appearing continuous in lower mammals, the globose and emboliform nuclei are collectively termed the interposed nuclei and receive their afferents from Purkinje cells in the paravermis of the cerebellar cortex, which is that portion of the cortex immediately adjacent and just lateral to the vermis. The largest of the cerebellar nuclei, the dentate nuclei, receive the axons of Purkinje neurons in the lateral portion of the cerebellar 
hemispheres. These hemispheres are the large, lateral regions of the cerebellar cortex (see Figure 1A). The dentate and interposed nuclei project primarily to the ventral thalamic nuclei and the red nucleus.

Intrinsic neuronal elements of the cerebellum other than the deep cerebellar nuclei and Purkinje neurons include granule cells, Golgi cells, basket cells, and stellate cells. Granule cells, located in the granular layer, have relatively small cell bodies $(5-8 \mu \mathrm{m})$ and give rise to approximately 3-5 dendrites which are no more than $30 \mu \mathrm{m}$ in length before terminating in a clawlike expansion (Palkovits et al., 1971). It has been estimated that there are as many as $10^{11}$ granule cells in the human cerebellum, more cells than are found in the entire cerebral cortex (Jacobsen, 1991). The thin $(\leq 1 \mu \mathrm{m})$ axon of each of these granule cells ascends several hundred micrometers, past the Purkinje cell layer, into the molecular layer where it bifurcates in a T-shaped fashion. This bifurcation yields two branches that run horizontally in opposite directions through the length of the molecular layer. Running parallel to the long axis of the folium, these axonal branches are termed parallel fibers. This particular orientation in the folium situates these fibers perpendicular to the large dendritic arborizations of the Purkinje cells, allowing each granule cell to interact with the spiny processes of numerous such dendritic trees along their course as well as allowing each Purkinje cell to receive synapses from hundreds of thousands of granule cells (Larramendi and Victor, 1967; Chan-Palay and Palay, 1970).

The Golgi cells of the rat cerebellum come in two varieties, large and small, with somal diameters of 9-16 $\mu \mathrm{m}$ and 6-11 $\mu \mathrm{m}$, respectively (Jakob, 1928; Palay and Chan-Palay, 1974). The larger cells are located primarily in the upper portion of the granular layer, directly adjacent to the Purkinje cell layer, whereas the smaller cells tend to occupy the lower half of the granular layer. 
Regardless of the type of Golgi cell, the large dendrites of these cells are scattered throughout the cerebellar cortex, accepting input from parallel fibers, mossy fibers, and climbing fibers. For the most part, the axons of Golgi cells extend only slightly into the granular layer, branch repeatedly, and subsequently terminate upon granule cell dendrites in clusters called cerebellar glomeruli. These glomeruli are a complex synaptic structure with three primary participants, the dendritic terminals of as many as twenty granule cells, one mossy fiber terminal rosette, and the terminals of Golgi cell axons. Thus, two types of presynaptic fibers (from Golgi cells and mossy fibers) enter into a complex with one postsynaptic element (granule cell dendrites). This configuration of synapses allows the Golgi cell to function as a negative feedback control of mossy fiber to granule cell signaling.

The basket and stellate cells are the primary interneurons of the cerebellum. Both are located in the molecular layer, with basket cells residing in the deeper third of this layer (closest to the Purkinje cell layer) and stellate cells tending to occupy the outermost two-thirds of the molecular layer. In the molecular layer both receive input from the parallel fibers of granule cells. Basket cells have branching dendrites which are oriented parallel to the Purkinje dendritic trees, thus perpendicular to the parallel fibers, and give rise to an axon which, during its course, gives off numerous branches. Each of these axonal branches, as many as ten per basket cell, entwines around the soma of neighboring Purkinje neurons in a basket-like form which gives them their name. Stellate cells, on the other hand, tend to be larger as one moves from the outermost granular layer toward the Purkinje cell layer, typically have a few radial dendrites, and possess a short axon parallel to the dendritic fields of the Purkinje neurons. 


\section{Functional Divisions}

Functionally, the cerebellum is broken down into three divisions, including the vestibulocerebellum, spinocerebellum, and the cerebrocerebellum (see Figure 2). The vestibulocerebellum, so named by Angaut and Brodal (1967), is made up of the flocculonodular lobes of the cerebellum. The flocculonodular lobe (or flocculus) is a small part of the cerebellum which is separated from the larger main body (see Figure 1A), containing the vermis and hemispheres, by the posterolateral fissure. The vestibulocerebellum receives its name from the main source of its direct input, the vestibular nuclei. The vestibular nuclei relay information concerning head position from the semicircular canals and the orientation of the head from the otolith organs. Through its reciprocal connections back to the vestibular nuclei, the flocculonodular lobe participates in the control of equilibrium, the control of axial and proximal limb muscles which are used to maintain balance, and the coordination of movements of the head and eyes. To further aid in the regulation of these functions, visual information from the lateral geniculate nucleus, superior colliculus, and striate cortex is relayed via the pontine nuclei to the vestibulocerebellum.

The spinocerebellum is composed of the vermis and the intermediate, most medial portions

of the hemispheres. As can be deduced from its name, the primary input to this region is from the spinal cord via the spinocerebellar tracts, though afferents from the auditory, visual, and vestibular systems also converge upon Purkinje neurons in these portions of the cerebellar cortex. The spinocerebellar tracts are mossy fiber pathways which convey somatic sensory information to the cerebellar cortex directly from the spinal cord, resulting in two complete somatosensory maps of the body in the cerebellum. Whereas the dorsal- and ventral-spinocerebellar tracts project information for the trunk and lower extremities, the cuneo- and rostral-spinocerebellar tracts present the 
cerebellum with information regarding the upper extremities and neck. This information is then relayed, processed and affects Purkinje neurons, that project to the fastigial and interposed nuclei. The fastigial nucleus then projects bilaterally to the brainstem reticular formation and the lateral vestibular nuclei which subsequently send efferents back to the spinal cord. There are also projections from the fastigial nucleus to the primary motor cortex via the contralateral ventrolateral nucleus of the thalamus. Through these projections, the fastigial nucleus is able to regulate the ongoing movements of axial and proximal musculature. The interposed (i.e., globose and emboliform) nuclei, on the other hand, aid in the coordination of distal limb movement via projections to the magnocellular portion of the contralateral red nucleus. The red nucleus relays this information to the ventrolateral nucleus of the thalamus and then on to the limb areas of the motor cortex.

The remaining lateral portions of the cerebellar hemispheres collectively make up the cerebrocerebellum. The cerebrocerebellum indirectly receives information from sensory, motor, premotor, and posterior parietal cortices via contralateral projections from the pontine nuclei. Purkinje neurons of the lateral hemispheres then project to the dentate nucleus which sends its efferent fibers to the contralateral ventrolateral nucleus of the thalamus. Projections from the ventrolateral nucleus of the thalamus to the motor and premotor regions of the cerebral cortex enable the dentate nuclei to be involved with the planning and initiation of limb movements. The dentate nuclei also project to the parvocellular portion of the red nucleus which relays this information back to the cerebellum, primarily via the ipsilateral inferior olivary nucleus. 
FIGURE 2. Depictions of the vestibulocerebellar (A), cerebrocerebellar (B), and spinocerebellar (C) pathways. Abbreviations: (CL) Contralateral; (BL) Bilateral; (ICP) Inferior cerebellar peduncle; (MCP) Middle cerebellar peduncle; (SCP) Superior cerebellar peduncle; (CBT) Corticobulbar tract; (RST) Rubrospinal tract; (LCST) Lateral corticospinal tract; (VCST) Ventral corticospinal tract; (VSTs) Vestibulospinal tracts; (SCTs) Spinocerebellar tracts. An X indicates that the pathway decussates during its course from one structure to the other. 

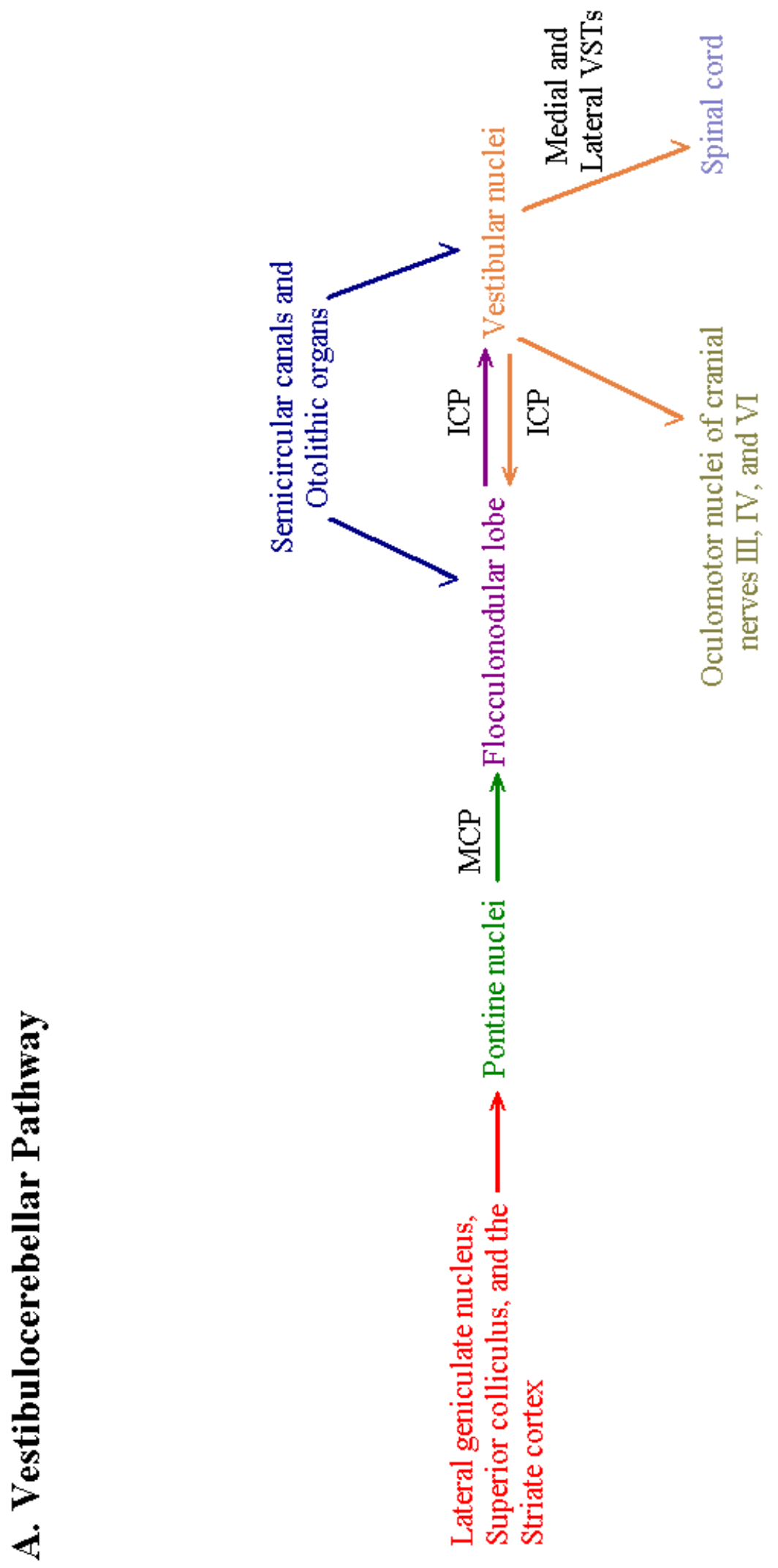


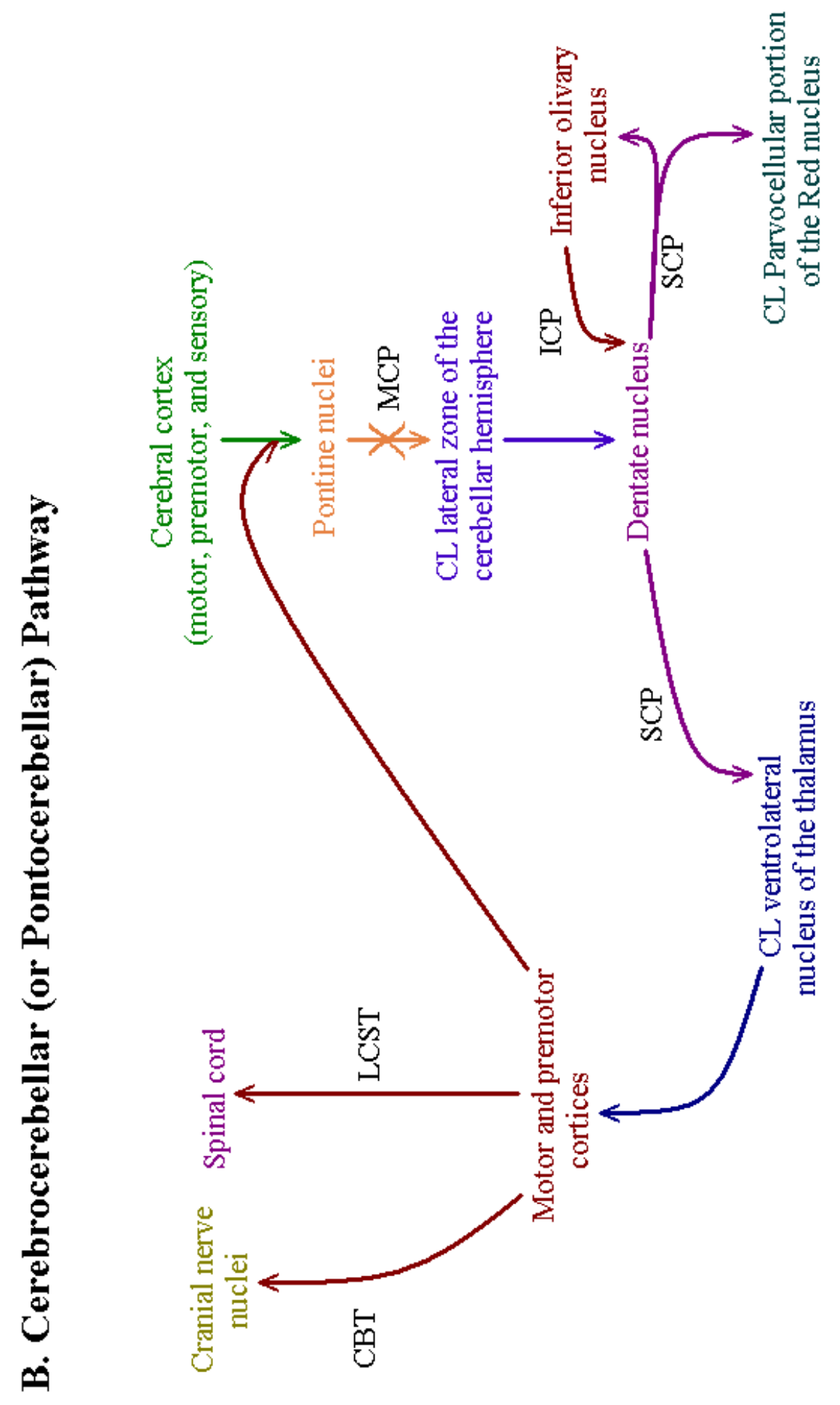



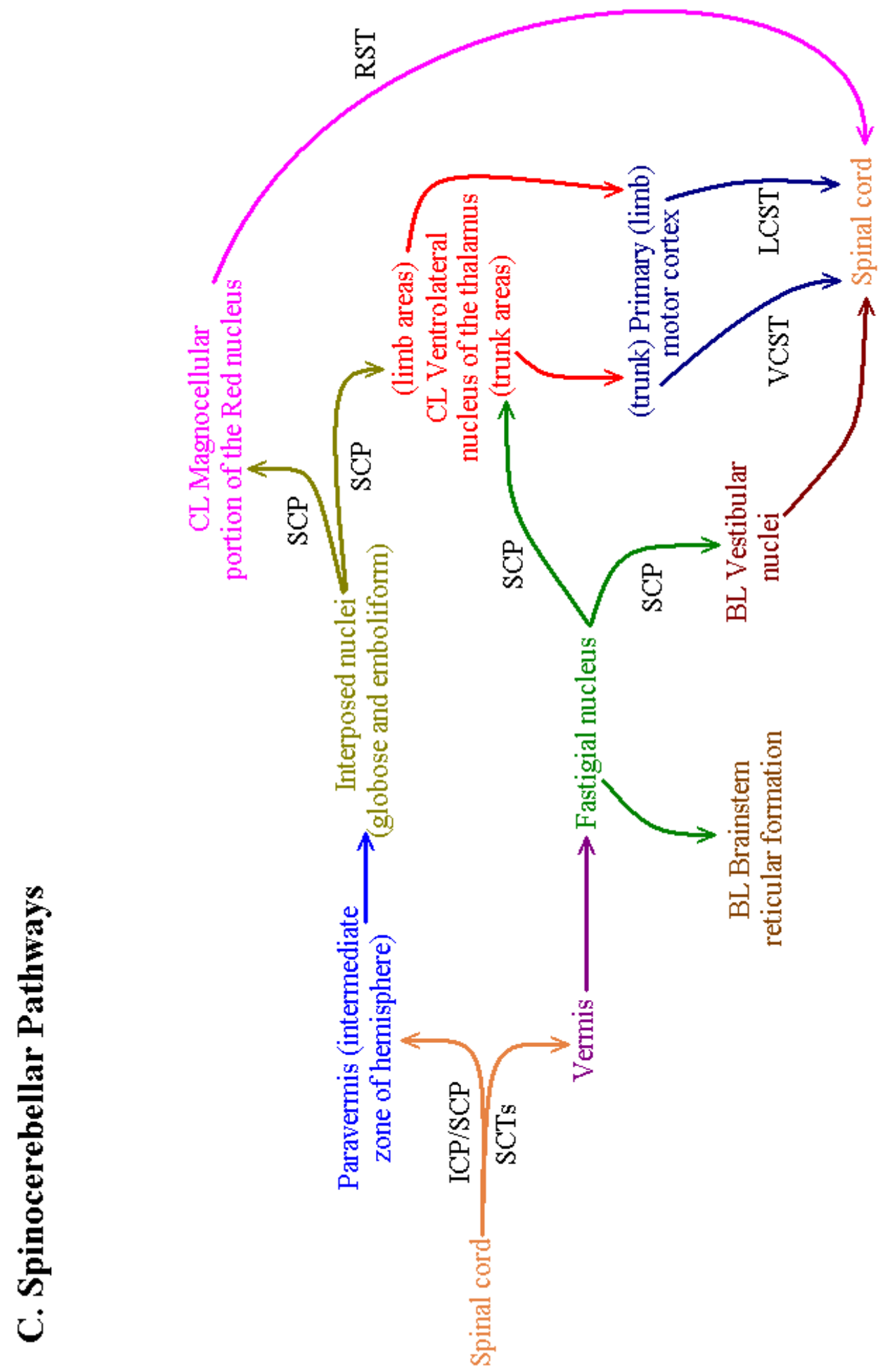


\section{Circuitry}

Although a more thorough description and discussion of the pharmacology will be considered later in this manuscript, it is prudent at this point to describe some of the basic neuropharmacology of the cerebellum in order to aid the understanding of cerebellar circuitry and the transmitters which are involved in information processing. One easy way to think about the transmitter function of the cerebellum is that it is intrinsically composed of inhibitory cells, except for the granule cells. Purkinje neurons, Golgi cells, basket cells, and stellate cells all possess inhibitory actions mediated by GABAergic projections. Granule cells, on the other hand, are excitatory and employ glutamate as their transmitter. Similarly, both main afferent pathways to the cerebellum are excitatory. The majority of mossy fibers use glutamate, whereas aspartate is the primary neurotransmitter of climbing fibers, though there are relatively minor numbers of both mossy fibers and climbing fibers which utilize serotonin or monoamines. Finally, the cerebellar nuclei are also excitatory, using either glutamate or aspartate as their transmitter.

The basic circuitries of the cerebellar cortex may be described as two input circuits, via mossy fibers and climbing fibers, and a sole output circuit, via Purkinje neurons (see Figure 3). The mossy fiber circuit is best understood by breaking it down into smaller units. Upon stimulation of a small group of excitatory mossy fibers, granule cells are activated. The granule cells subsequently excite all other neuronal types in the cerebellum. Via their parallel fibers, granule cell axons activate Purkinje

neurons, stellate cells, and basket cells. Additionally, in the cerebellar glomeruli, Golgi cells are activated via the dendrites of granule cells. It is the location and temporal relationships of these interactions which produce the interesting array of effects that follow mossy fiber stimulation. The 
activation of Purkinje neurons via the parallel fibers is quickly inhibited to some extent by neighboring basket and stellate cells which are simultaneously activated by the same fibers. However, because of the axonal orientation of these inhibitory interneurons, adjacent Purkinje neurons which are not activated by the parallel fibers are strongly inhibited by the newly active interneurons. Such "off-beam" inhibition functions to strengthen the signal by sharpening the distinction between those Purkinje neurons which have been activated and those which have not. At the same time, there is a negative feedback loop, via the activation of Golgi cells, which limits the effect of granule cell activation. Thus, the overall outcome of mossy fiber stimulation tends to be a brief, but relatively large and sharply defined, activation of firing from a discrete population of Purkinje neurons.

Compared to the mossy fiber circuitry, the climbing fiber circuit is much simpler. In mature mammals, a single Purkinje neuron is contacted by only one climbing fiber, though a single climbing fiber may contact up to ten Purkinje neurons. Furthermore, this connection is one of the most powerful excitatory contacts in the mammalian nervous system (Eccles et al., 1966) and acts as an all-or-none excitatory connection. Climbing fibers also activate Golgi cells which function to inhibit input from mossy fibers, as described above. Thus, upon stimulation of a group of climbing fibers, Purkinje cells are dominated by the climbing fiber input and produce prolonged bursts of high-frequency activity known as complex spikes (Thach, 1968, 1970). Thus, in either case, stimulation of climbing fibers or of mossy fibers, an increase in Purkinje neuron activity is observed.

This brings us to the third circuit of the cerebellum, the output circuit. Afferents which activate Purkinje neurons also activate cells of the deep nuclei since collaterals of both climbing 
fibers and mossy fibers extend to these areas. This excitation of the deep cerebellar nuclei is then followed, after a brief delay, by a rather powerful inhibition via the Purkinje neurons activated by the same signal. Though there are also some interneuronal connections which come into play, the basic depiction of a brief excitation, followed by a powerful inhibition still holds true for the output of Purkinje neurons to the deep cerebellar nuclei. 
FIGURE 3. Diagramatic illustration of cerebellar neuronal connections and the major transmitters involved in these connections. (+) and (-) signs indicate excitatory and inhibitory transmission, respectively. The deep cerebellar nuclei represent the primary efferent target of Purkinje neurons and the sole output pathway from the cerebellum. Abbreviation: (pf) Parallel fibers. 


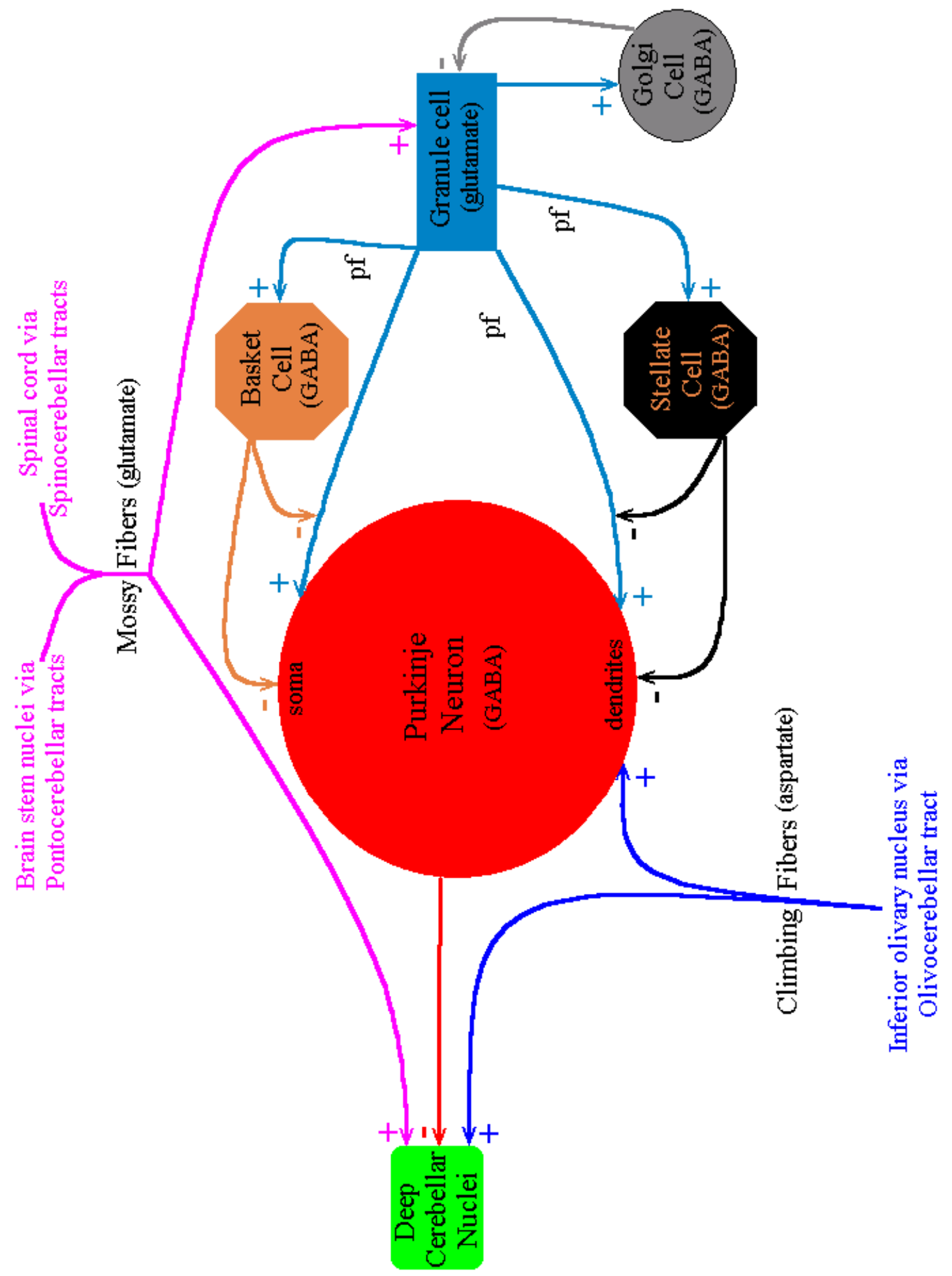




\section{E. Development}

This section on cerebellar development will be concerned mainly with highlighting those events in the development process which may impact upon the responsiveness of Purkinje neurons. However, some additional details which are, in general, important steps in cerebellar development, will be included if they provide a benefit in developing an overall understanding of the processes which are occurring at different stages during cerebellar development. Many of the manuscripts referenced in this section provide far more detail than will be presented here and are recommended reading if a more in depth understanding of this process is desired. In addition, the book by Masao Ito (1984) entitled The Cerebellum and Neural Control is a particularly useful source for a general understanding of all the development processes in the cerebellum. Finally, as a reminder, the time frames depicted for developmental events to occur in the following discussion are described for the rat unless otherwise indicated. However, it should be noted that the development of the cerebellar cortex proceeds in a similar manner, though at somewhat different rates, among various vertebrates, including man. Postnatal ages will be indicated with a 'P' and embryonic ages with an ' $E$ ' such that P0 will represent the day of birth, P7 will represent the seventh postnatal day of life, and E7 will represent the seventh embryonic day. A basic summary of the following descriptions are pictured in Figure 4 and listed as a timeline in Table 2 at the end of this section.

In general, the stage of development of the cerebellum at birth can be correlated with the animal's powers of locomotion and motor coordination such that precocial animals tend to have a more developed cerebellum at birth than do altricial animals (Jacobsen, 1991). Furthermore, the birth process itself plays no part in triggering the postnatal events of cerebellar neurogenesis and morphogenesis such that artificially shortening or prolonging the gestational period does not appear 
to affect the time at which these events occur (Zagon, 1975). The histogenesis of the cerebellar cortex occurs from well defined germinal zones which give rise to the different types of neurons in a predictable manner.

For Purkinje neurons, development occurs in essentially three phases. The initial, embryonic stage of this development occurs as the rhombic lip of the fourth ventricle gives rise to the deep cerebellar nuclei, Purkinje neurons, and Golgi cells during the second and third weeks of gestation, with Purkinje neurons originating between E12 and E17 (Das and Nornes, 1972; Altman and Bayer, 1978). This is followed by the formation of granule cells, stellate cells, basket cells, and some glial cells from another germinal zone, the external granular layer, which is found immediately beneath the pia covering the cerebellar plate. By E24 the Purkinje neurons complete their migration to what then becomes the Purkinje cell layer (Addison, 1911; Daduone, 1966). Initially, however, the cell bodies stack in an immature pattern of up to twelve cells deep. Even before the Purkinje neurons attain their adult alignment of a single row pattern, the earliest synaptic contacts to these newly formed Purkinje neurons occur in the form of climbing fiber axons. This synaptic contact first becomes anatomically apparent on E27 (O’Leary et al., 1971) though functional climbing fiber activation of Purkinje neurons has been found no earlier than P3 (Woodward et al., 1971; Crepel, 1972; Shimono et al., 1997). Just prior to P0, the Purkinje neurons enter the second stage of their development.

The second stage of Purkinje neuron ontogenesis is the process by which the cell bodies become aligned into a monolayer and subsequently sprout the axons which ultimately form synaptic connections with the deep cerebellar nuclei. This process is completed by P4 (Addison, 1911; Altman 1972a,b; Altman and Winfree, 1977) though few functional synapses with the Purkinje 
neurons have yet formed (Altman, 1972a,b). At birth (P0), the cytological organization of the inferior olivary nucleus, which gives rise to the climbing fibers, is well established (Altman and Bayer, 1978), but the level of spontaneous activity of these cells is very low (Mariani and Changeux, 1981b). However, just hours after birth, extracellular recording of Purkinje neurons reveals that spontaneous action potentials can already be observed (Woodward et al., 1969), and by P1 antidromic activation of Purkinje cells is observed upon white matter stimulation (Shimono et al., 1997). During P1-P2, Purkinje neurons also develop regular, sustained activity (Woodward et al., 1969) and become sensitive to iontophoretically applied GABA, norepinephrine (Woodward et al., 1969, 1971), glutamate, aspartate, and quisqualate (Dupont et al., 1987).

Also during this period (P0 to P5), a small portion of granule cells begin their migration from their original position in the external granular layer (Hager et al., 1995), though most will not begin this process for another week. The external granular layer is a germinal zone lying beyond the molecular layer (see above) which disappears as the granule cells migrate toward their mature position in the (internal) granular layer. Such a migration requires that the granule cells traverse both the molecular and Purkinje cell layers. They do so in radial pathways as their newly forming axons, which will later become parallel fibers, trail behind them, occupying the full length of distance through which these cells migrate. Finally, during the first five postnatal days, climbing fiber afferents begin to wrap profusely around Purkinje neuron somata. Unlike the mature pattern where each Purkinje neuron receives afferents from only one climbing fiber, neonatal Purkinje neurons may receive afferents from three to four climbing fibers beginning on P3 (Crepel et al., 1976; Mariani and Changeux, 1981a).

The third period of ontogenesis, when a single apical dendrite first emerges from the $-43-$ 
Purkinje neuron soma, extends toward the pial surface, and branches repeatedly, occurs from P5 to P30. During this period, there are numerous developmental events which occur as the Purkinje cells mature, many over similarly protracted periods of time. For this reason, these events will be organized and discussed based upon the day which they occur, or start to occur. On P5 mossy fibers start to enter the cerebellum (Altman, 1972b), redundant innervation of Purkinje neurons by climbing fibers reaches a maximum of approximately 3.57 climbing fibers per Purkinje neuron (Mariani and Changeux, 1981a,b), and Purkinje neurons extend abundant, temporary perisomatic processes (Altman, 1972a). From P5-P8, these perisomatic processes are contacted by climbing fibers (Altman, 1972a), and a substantial number of granule cell axons begin to extend horizontally along the long axis of the folium from their outermost tip to form the parallel fibers (Hager et al., 1995).

The next few days of postnatal development likewise bring numerous changes. On days P6 and P7 the vast majority of inhibitory basket cells form, though synaptic contacts between them and neighboring cells have yet to develop (Altman, 1972a). On P7, spontaneous climbing fiber bursts appear, as well as coincident high-frequency discharges of Purkinje cells (Woodward et al., 1969). Furthermore, from P7 to P10, the cellular mechanisms necessary for the rhythmical and synchronized discharge of inferior olivary neurons, which give rise to the climbing fibers, is established (Mariani and Changeux, 1981b). Also on P7, glial processes begin to ensheath parts of the Purkinje cell soma (Altman, 1972a), increasing numbers of climbing fiber synapses onto Purkinje perisomatic processes are seen (Altman, 1972a), and action potentials in the parallel fibers of granule cells appear (Shimono et al., 1997). From P8 to P11, stellate cells will originate, though synapses will not begin to occur for a few more days (Altman, 1972a). At the same time, parallel 
fiber synapses begin to form with the previously formed basket cells (Altman, 1972a). From P8 to P14, the majority of granule cells will have begun their radial descent through the molecular and Purkinje cell layers (as described above) with the peak in this movement occurring on P10 to P11 (Altman, 1972b). During this same period (P8-14), the temporary perisomatic processes of Purkinje somata start to disappear (Altman, 1972a; Berry and Bradley, 1976) and the number of redundant innervations of Purkinje neurons by climbing fibers begins to decline (Mariani and Changeux, 1981b).

The next six days, P10 to P15, are days during which many of the neuronal and synaptic elements of the cerebellum begin to rapidly mature. During this period, the Purkinje neurons begin showing an increase in spontaneous firing rates (Crepel, 1972), a decrease in spike duration, and a shift from regular to irregular discharge patterns (Woodward et al., 1969). The development of this mature pattern of spontaneous activity (Crepel, 1972) results from both endogenous properties of autorhythmicity (Llinas and Sugimori, 1980a,b) and synaptic activation of the Purkinje cells through their main afferents (Puro and Woodward, 1977). Concomitantly, the Purkinje neuron dendrites grow almost exclusively in the lateral domain, reaching their mature width on P15 (Berry and Bradley, 1976). On P10 immature basket cell axon terminals are first seen to establish synapses on Purkinje cell soma (Altman, 1972a), the mossy fiber-granule cell synapses become functional (Larramendi, 1969; Mugnaini, 1969; Altman, 1972b; Shimono et al., 1997), and Golgi cell inhibition of granule cells is observed (Shimono et al., 1997). By P12, nearly all of the Purkinje soma is ensheathed by glial processes (except at synaptic boutons) and the perisomatic processes are greatly reduced (Altman, 1972a). One point of discrepancy in the literature during this period of development concerns the formation of parallel fiber synapses with Purkinje dendritic spines. 
Although it appears in anatomical studies that these synapses do not occur until P15 (Altman, 1972a), electrophysiological evidence indicates that such synapses are functional as early as P10 (Woodward et al., 1969; Shimono et al., 1997).

On P15 more of the mature, adult characteristics of Purkinje neurons become evident. The somata has both an adult appearance (Altman, 1972a) and size (Jacobsen, 1991), the redundant innervation by climbing fibers is absent (Mariani and Changeux, 1981a,b; Jacobsen, 1991), and the glial sheathing has extended to secondary and tertiary dendrites in the lower molecular layer (Altman, 1972a). Also on P15, lower stellate cells begin forming their inhibitory contacts with outgrowing Purkinje cell dendrites (Altman, 1972a), Golgi cells have matured (Altman, 1972b), Purkinje cell dendrites begin growing primarily in the vertical domain toward the pial surface (Berry and Bradley, 1976), and the development of cerebellar glomeruli begins to increase (Altman, 1972b,c) as the bulk of the granule cells are formed (Altman, 1969). On P21 the inferior olivary nucleus reaches an adult level of activity (Mariani and Changeux, 1981b), which represents a tenfold increase over that observed at birth, as the formation of Purkinje dendritic spines has spread upward to about the middle of the molecular layer. Finally, the Purkinje cell dendritic tree reaches its maximum vertical height on P30 (Berry and Bradley, 1976) though the dendrites will continue to increase in size through P110 (Jacobsen, 1991). 


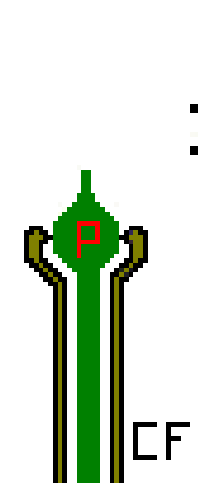

P3

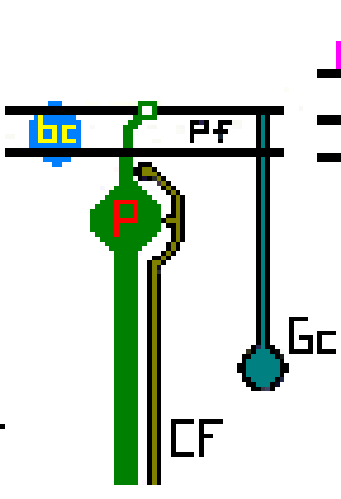

P7

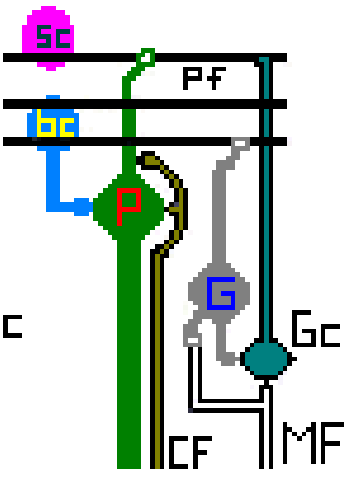

P10

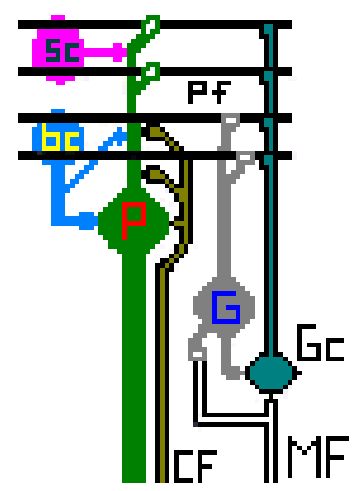

P15

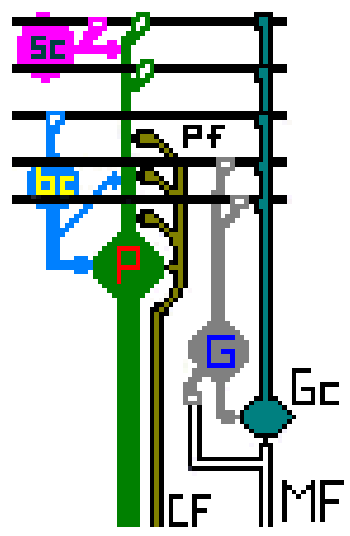

P21

FIGURE 4. Schematic illustrating the postnatal development of the rat cerebellum. The stage of development is indicated below each section (in postnatal days). Letters represent: Purkinje neuron $(\mathrm{P})$; climbing fiber $(\mathrm{CF})$; basket cell (bc); granule cell (Gc); parallel fiber (Pf); stellate cell (Sc); Golgi cell (G); mossy fiber (MF). 
TABLE 2. Timeline of major developmental events for the rat cerebellum focusing upon the Purkinje neurons and those events which directly impact upon them. References for specific events are indicated in the text (IIIE).

\begin{tabular}{|c|c|}
\hline DAY(S) & Developmental Event \\
\hline E12-17 & -Purkinje neurons are formed \\
\hline $\mathrm{P} 0$ & $\begin{array}{l}\text {-Cytological organization of the inferior olivary nucleus is well established but the } \\
\text { level of spontaneous activity is low } \\
\text {-Purkinje neuron extracellular action potentials are observed as early as several hours } \\
\text { after birth }\end{array}$ \\
\hline $\mathrm{P} 1$ & $\begin{array}{l}\text {-Antidromic action potentials in Purkinje neurons following white matter stimulation } \\
\text { is observed } \\
\text {-Regular, sustained activity of Purkinje neurons first seen } \\
\text {-Purkinje neurons are sensitive to iontophoretically applied GABA and } \\
\text { norepinephrine }\end{array}$ \\
\hline P3 & -Climbing fiber excitation of Purkinje neurons observed \\
\hline P4 & -Purkinje neurons have formed a monolayer with few or no synapses \\
\hline P5 & $\begin{array}{l}\text {-Mossy fibers are seen } \\
\text {-Multiple innervation of Purkinje neurons by climbing fibers first observed at P3 is } \\
\text { maximal, approximately } 3.5 \text { climbing fibers per Purkinje neuron } \\
\text {-Purkinje neurons have abundant transient perisomatic processes with occasional } \\
\text { climbing fiber synapses }\end{array}$ \\
\hline P6-7 & -Origination of basket cells \\
\hline P7 & $\begin{array}{l}\text {-Glial processes begin to ensheath Purkinje neuron soma } \\
\text {-Increase in the number of climbing fiber synapses on Purkinje neuron perisomatic } \\
\text { processes } \\
\text {-Action potentials in parallel fibers appear } \\
\text {-High frequency climbing fiber burst discharges of Purkinje neurons arise } \\
\text {-The rhythmical and synchronized discharge of inferior olive neurons begins to be } \\
\text { established }\end{array}$ \\
\hline P8 & $\begin{array}{l}-65 \% \text { of Purkinje neurons are multiply innervated by climbing fibers } \\
\text {-Commencement of synaptogenesis and stellate cell formation in the lower molecular } \\
\text { layer }\end{array}$ \\
\hline P9 & $\begin{array}{l}-46 \% \text { of Purkinje neurons are multiply innervated by climbing fibers with a mean } \\
\text { number of } 1.46 \text { climbing fiber collaterals per Purkinje neuron }\end{array}$ \\
\hline
\end{tabular}




\begin{tabular}{|c|c|}
\hline P10 & $\begin{array}{l}\text {-29\% of Purkinje neurons are multiply innervated by climbing fibers } \\
\text {-Activation of Purkinje neurons by parallel fiber stimulation observed } \\
\text {-Functional mossy fiber-granule cell synapses } \\
\text {-Golgi cell inhibition of granule cells appears } \\
\text {-Disappearance of Purkinje neuron perisomatic processes } \\
\text {-Basket cell synapses with Purkinje neuron soma begin to form and continues for a } \\
\text { few days }\end{array}$ \\
\hline P10-15 & $\begin{array}{l}\text {-Increase in spontaneous firing rates, a decrease in spike duration (P12-14), and a } \\
\text { shift from regular to irregular discharge patterns in Purkinje neurons }\end{array}$ \\
\hline $\mathrm{P} 12$ & $\begin{array}{l}\text {-Essentially the entire Purkinje neuron soma not covered with boutons is ensheathed } \\
\text { with glia } \\
\text {-Mossy fiber terminals are seen in small numbers but are immature with few } \\
\text { synapses formed } \\
\text {-Cerebellar glomeruli first seen and formation continues for more than } 30 \text { days }\end{array}$ \\
\hline P15 & $\begin{array}{l}\text {-Purkinje neuron soma have an adult-like appearance } \\
\text {-Parallel fibers form synapses with the outgrowing dendritic spines of Purkinje } \\
\text { neurons and lower stellate cells } \\
\text {-Redundant innervation of Purkinje neurons by climbing fibers disappears } \\
\text {-Glial sheathing has extended to the secondary and tertiary dendrites in the lower } \\
\text { molecular layer } \\
\text {-Golgi cells are mature in appearance } \\
\text {-Granule cells extend dendrites } \\
\text {-Cerebellar glomeruli are small and few in number } \\
\text {-Purkinje neuron dendritic tree growth shifts from the lateral to the vertical plane }\end{array}$ \\
\hline P15-21 & $\begin{array}{l}\text {-Purkinje neuron dendrites arborize with outgrowth of secondary and tertiary } \\
\text { branches coupled to the formation of parallel fiber synapses with them }\end{array}$ \\
\hline P21 & $\begin{array}{l}\text {-Inferior olive neurons reach adult level of activity (ten-fold increase since birth) } \\
\text {-Purkinje neuron dendritic spines spread upward to the middle of the molecular layer }\end{array}$ \\
\hline $\mathrm{P} 30$ & -Height of the Purkinje neuron dendritic tree has reached adult level \\
\hline P110 & -Entire growth of Purkinje neurons is complete \\
\hline
\end{tabular}




\section{THE GABA $A_{A}$-RECEPTOR}

$\gamma$-Amino butyric acid (GABA), the most abundant neurotransmitter in the mammalian brain, exerts its actions via three subsets of $\mathrm{GABA}$ receptors termed $\mathrm{GABA}_{\mathrm{A}^{-}}, \mathrm{GABA}_{\mathrm{B}^{-}}$, and $\mathrm{GABA}_{\mathrm{C}^{-}}$ receptors. Whereas $\mathrm{GABA}_{\mathrm{A}^{-}}$and $\mathrm{GABA}_{\mathrm{C}}$-receptors are ligand-gated ion channel receptors, the $\mathrm{GABA}_{\mathrm{B}}$-receptor is of the seven transmembrane, G-protein coupled receptor family. Of these three receptor subtypes, it is the $\mathrm{GABA}_{\mathrm{A}}$-receptor which mediates the principal fast synaptic inhibitory transmission and is of particular interest here. For this reason, the following discussion will focus primarily upon this group of receptors.

\section{A. $G A B A_{A}-$ Receptor Structure and Composition}

As stated above, the $\mathrm{GABA}_{\mathrm{A}}$-receptor is a member of the superfamily of ligand-gated ion channel receptors and consequently shares many structural and functional similarities with the other members of this superfamily which also includes the nicotinic acetylcholine receptors, the strychnine-sensitive glycine receptors, and the serotonergic 5-HT 3 receptor (Boulter et al., 1987; Grenningloh et al., 1987; Schofield et al., 1987). The basic structure of these receptors is that of a pentameric pseudosymmetrical transmembrane structure surrounding a central pore (Seeburg et al., 1990; Nayeem et al., 1994). Each of the five subunits is composed of a large N-terminal extracellular domain thought to mediate ligand interactions, four transmembrane spanning domains (M1-M4) with a large intracellular loop containing consensus sites for phosphorylation (in some subunits) between transmembrane segments M3 and M4, and an extracellular C-terminal domain (Betz, 1990; Galzi and Changeux, 1994; Macdonald and Olsen, 1994; Barnard, 1995; Möhler et 
al., 1995). The M2 transmembrane regions (second from the $\mathrm{N}$-terminus) of each subunit form the lining of a central chloride channel pore, providing the environment needed for the passage of select ions, namely $\mathrm{Cl}^{-}$and $\mathrm{HCO}_{3}^{-}$(Unwin, 1993).

To date, at least fifteen different $\mathrm{GABA}_{\mathrm{A}}$-receptor subunit isoforms from five distinct families have been cloned from the mammalian central nervous system, including $\alpha_{1-6}, \beta_{1-3}, \gamma_{1-3}, \delta$, and $\rho_{1-2}$ (Seeburg et al., 1990; Lüddens and Wisden, 1991). In addition, there have been two other isoforms identified in chick brain, $\beta_{4}$ and $\gamma_{4}$ (Bateson et al., 1991; Harvey et al., 1993), and five subunit isoforms exist as splice variants, including variants for the $\alpha_{6}, \beta_{2}, \beta_{3}, \beta_{4}$, and $\gamma_{2}$ isoforms (Whiting et al., 1990; Bateson et al., 1991; Kofuji et al., 1991; Harvey et al., 1994; Korpi et al., 1994). Of these subunit isoforms, only the two $\rho$ subunits are found predominantly outside of the brain. These subunits, primarily located in the retina (Cutting et al., 1991), combine only with other $\rho$ subunits in vivo and thus form a subset of $\mathrm{GABA}_{\mathrm{A}}$-receptors with unique enough characteristics to be classified as separate receptors termed $\mathrm{GABA}_{C}$-receptors. These $\mathrm{GABA}_{\mathrm{C}}$-receptors, however, share only two basic traits with $\mathrm{GABA}_{\mathrm{A}}$-receptors, binding GABA and conducting chloride ions (Sieghart, 1995).

With such a large number of subunit isoforms, it quickly becomes obvious that there are a vast multitude of possible receptor subunit compositions. However, with all the possible compositions, it appears that relatively few of these possible combinations are employed in vivo. Although the true number of physiologically relevant $\mathrm{GABA}_{\mathrm{A}}$-receptors and their subunit stoichiometries are still far from being determined, in vivo, the majority of $\mathrm{GABA}_{\mathrm{A}}$-receptors are formed by subunit combinations consisting of, 1) $2 \alpha, 2 \beta$, and $1 \gamma, 2) 2 \alpha, 1 \beta$, and $2 \gamma$, or 3) $2 \alpha, 1 \beta, 1 \delta$, and $1 \gamma$ with the $\gamma$-subunit typically being of the $\gamma_{2}$-subtype in each case (Benke et al., 1991, 1994; 
Duggan et al., 1991; Pollard et al., 1991; Backus et al., 1993; Mertens et al., 1993; Barnard, 1995;

Fritschy and Möhler, 1995; Stephenson, 1995; Bohlhalter et al., 1996; Wisden et al., 1996). Although this is by no means true for all of the $\mathrm{GABA}_{\mathrm{A}}$-receptors, it does provide some guidelines by which to predict which receptors might most prominently be formed when the subunit constituents are known. This is, in turn, important based upon the fact that many aspects of $\mathrm{GABA}_{\mathrm{A}}$-receptor function are critically dependent on subunit composition, as will become evident in the subsequent discussion.

\section{B. Activation and Modulation of the $G_{A B A_{A}-\text { Receptor }}$}

$\mathrm{GABA}_{\mathrm{A}}$-receptors, which require the binding of at least two GABA molecules for full activation (Sakmann et al., 1993), have multiple conductance levels which vary slightly depending on the subunit composition. The main conductance level of between 27 and 30 picoSiemens (pS; Hamill et al., 1983; Sakmann et al., 1983; Macdonald and Olsen, 1994) is responsible for 95\% of the total current which flows through the chloride channel (Macdonald, 1994). Other conductance levels of 11-12 pS, 17-19 pS, and 44 pS have also been observed with low frequency (Sakmann et al., 1983; Macdonald and Olsen, 1994). Upon activation, the $\mathrm{GABA}_{\mathrm{A}}$-receptor opens in a burst-like fashion which is evidenced by openings or groups of openings separated by relatively long closed periods (Colquhuon and Sigworth, 1983). With each of these bursts, chloride ions flow down their electrochemical gradient through the pore of the channel. The rate of ion transport is, however, limited by the binding of anions at one of two sites inside the channel (Sakmann et al., 1983).

Studies in mammalian brain tissue utilizing $\left[{ }^{3} \mathrm{H}\right] \mathrm{GABA}$ initially revealed the existence of high and low affinity states for GABA binding with $\mathrm{K}_{\mathrm{D}}$ values in the low and high nanomolar range, 
respectively (Olsen et al., 1981). However, more recent studies have revealed an additional very low affinity binding site which requires micromolar concentrations of GABA to open the chloride channel and modulate other binding sites on the $\mathrm{GABA}_{\mathrm{A}}$-receptor complex (see below), and it is this site at which GABA is now generally considered to exert its physiological effects (Olsen et al., 1982; Squires et al., 1983; Segal and Barker, 1984; Kardos and Cash, 1990). The actual location of binding sites for GABA have yet to be fully determined. Some studies have indicated that the GABA binding sites may reside at the interface between $\alpha$ and $\beta$ subunits, since this was the minimal composition required for completely effective GABA-dependent chloride gating (Smith and Olsen, 1995). However, recombinant studies employing homoligomeric channels consisting of $\alpha, \beta, \gamma$, or $\delta$ subunits revealed that these receptors display multiple conductance states in response to activation by GABA (Sieghart, 1995). The results of these latter studies have been interpreted to indicate that each subunit contains a GABA binding site, allowing for up to five such binding sites on any given receptor (Sieghart, 1995).

In addition to being activated by $\mathrm{GABA}$ and $\mathrm{GABA}_{\mathrm{A}}$-receptor selective agonists such as muscimol, the $\mathrm{GABA}_{\mathrm{A}}$-receptor is modulated and antagonized at numerous sites on the receptor complex. In order to fully describe the activity of such modulators and antagonists, it is important to understand what their "typical" action on ion conductance is, and this information will be followed by a summary of how these "typical" actions are affected by the presence or absence of individual subunit isoforms.

Benzodiazepines, barbiturates, and neurosteroids (and neuroactive steroids) form the major modulatory classes of agents that interact with the $\mathrm{GABA}_{\mathrm{A}}$-receptor. Although all of these compounds enhance $\mathrm{GABA}_{\mathrm{A}}$-receptor-activated chloride currents (Choi et al., 1977; Macdonald 
and Barker, 1978a,b; Callachan et al., 1987a,b), they do so via distinct mechanisms and by acting at separate allosteric regulatory sites on the receptor complex (Study and Barker, 1981; Olsen, 1981, 1987; Twyman et al., 1989). Benzodiazepines increase $\mathrm{GABA}_{\mathrm{A}}$-mediated current by increasing opening frequency via an increase in receptor-ion channel coupling without altering single channel conductance or open duration (Study and Barker, 1981; Vicini et al., 1987; Edgar and Schwarz, 1992). These ligands, which act at the appropriately named benzodiazepine site (or receptor) on the $\mathrm{GABA}_{\mathrm{A}}$-receptor complex, do not gate the chloride channel in the absence of GABA or $\mathrm{GABA}_{\mathrm{A}^{-}}$ receptor agonists (Macdonald, 1994).

Barbiturates have a different modulatory effect on the channel. These compounds increase the average open duration without altering single channel conductance amplitude (Barker and McBurney, 1979; Study and Barker, 1981), and at higher concentrations ( $>50 \mu \mathrm{M})$ can directly gate the $\mathrm{GABA}_{\mathrm{A}}$-receptor chloride channel even in the absence of GABA (Bormann, 1988; Inomata et al., 1988), indicating the existence of at least two sites of interactions for barbiturates with the receptor complex (Sieghart, 1995). Neurosteroids and neuroactive steroids (the distinction being that neurosteroids are endogenously synthesized de novo, primarily by glia), acting at still other sites distinct from those mentioned above (Callachan et al., 1987b; Gee et al., 1988; Turner et al., 1989; Morrow et al., 1990), increase both the opening frequency (Peters et al., 1988) and the average open channel duration (Twyman and Macdonald, 1992). Like barbiturates, neurosteroids may also produce direct opening of the channel, an effect which can be inhibited by the plant alkaloid and $\mathrm{GABA}_{\mathrm{A}}$-receptor antagonist, bicuculline (Callachan et al., 1987a,b). However, compared to barbiturates, neurosteroids are much more potent as allosteric regulators of $\mathrm{GABA}_{\mathrm{A}}$-receptor activation (Woodward et al., 1992; Belelli et al., 1996). 
For each of these previously described sites, the $\mathrm{GABA}_{\mathrm{A}}$-receptor, benzodiazepine, barbiturate, and neurosteroid sites, there are also numerous synthetic ligands which act as antagonists, partial agonists, and inverse agonists (modulatory sites only). The inverse agonists of modulatory sites are, in simplest terms, ligands which bind to these sites but act in an opposite manner to that of the "native" agonist. For example, a benzodiazepine inverse agonist such as Ro 15-4513 has the effect of decreasing $\mathrm{GABA}_{\mathrm{A}}$-receptor mediated current by decreasing opening frequency without altering single channel conductance. An identification and characterization of many of the numerous compounds which act as agonists, antagonists, or as modulators of the $\mathrm{GABA}_{\mathrm{A}}$-receptor via an action at various sites on the receptor complex is summarized in Table 3. For many of these compounds their interaction with the $\mathrm{GABA}_{\mathrm{A}}$-receptor complex is critically dependent upon the subunit composition of the receptor. The most well defined and characterized of these isoform-dependent interactions for will be briefly described below. 
TABLE 3. Various compounds which interact with the $\mathrm{GABA}_{\mathrm{A}}$-receptor complex and their effects.

\begin{tabular}{|c|c|c|}
\hline Effect & Compounds & References \\
\hline Antagonism & $\begin{array}{l}\text { Picrotoxin, Pentylenetetrazol, } \\
\text { Bicuculline, Bicyclic cage } \\
\text { compounds, Insecticides, } \\
\mathbf{Z n}^{++} \text {, Antidepressants } \\
\text { (amoxapine, mianserin), } \\
\text { Penicillin G }\end{array}$ & $\begin{array}{l}\text { Yoon et al., 1993; Olsen, 1982; Bormann, } \\
\text { 1988; Caseda, 1993; Nagata and } \\
\text { Narahashi, 1994; Celentano et al., 1991; } \\
\text { Smart, 1992; Smart and Constanti, 1990; } \\
\text { Squires and Saederup, 1988; Raichle et al., } \\
\text { 1971 }\end{array}$ \\
\hline $\begin{array}{l}\text { Negative } \\
\text { modulators }\end{array}$ & $\begin{array}{l}\text { Avermectin } B_{1} a, \gamma- \\
\text { butyrolactones, Ro 5-4864 } \\
\text { Antidepressants (amoxapine, } \\
\text { mianserin), Quinolones, } \\
\text { Arachadonic acid, } \\
\text { Unsaturated fatty acids }\end{array}$ & $\begin{array}{l}\text { Payne and Soderlund, 1993; Holland etal., } \\
\text { 1993; Sieghart, 1995; Squires and } \\
\text { Saederup, 1988; Akaike et al., 1991; } \\
\text { Woodward et al., 1994; Schwartz et al., } \\
\text { 1988; Schwartz and Yu, } 1992\end{array}$ \\
\hline $\begin{array}{l}\text { Positive } \\
\text { modulators }\end{array}$ & $\begin{array}{l}\text { Avermectin } \mathrm{B}_{\mathbf{1}} \mathbf{a}, \mathbf{L a}^{3+} \text {, } \\
\text { Lanthanides, } \mathrm{Cl}^{-} \text {, } \\
\text { Chlormethiazole, Propofol, } \\
\text { Inhalation anesthetics, } \\
\text { Ethanol, Loreclezole, } \\
\text { Melatonin, } \gamma \text {-butyrolactones, } \\
\text { Dihydrogenated ergot } \\
\text { compounds, Substituted } \\
\text { pyrazinones, } \\
\text { Dihydroimidazoquinoxalines, } \\
\text { Quinolones }\end{array}$ & $\begin{array}{l}\text { Payne and Soderlund, 1993; Ma and } \\
\text { Narahashi, 1993a,b; Olsen, 1982; Squires } \\
\text { et al., 1983; Drexler and Sieghart, } \\
\text { 1984a,b; Sieghart, 1995; Schumacher and } \\
\text { McEwen, 1989; Moody and Skolnick, } \\
\text { 1989; Hales and Lambert, 1991, 1992; } \\
\text { Concas et al., 1991; Wingrove et al., 1994; } \\
\text { Coloma and Niles, 1988; Holland et al., } \\
\text { 1993; Tvrdeic and Pericic, 1991, 1992; Im } \\
\text { et al., 1993; Dillon } \text { et al., 1993; Akaike } \text { et } \\
\text { al., } 1991\end{array}$ \\
\hline $\begin{array}{l}\text { Unknown } \\
\text { interaction }\end{array}$ & $\begin{array}{l}\text { Polyamines, 1-aryl-3- } \\
\text { (aminoalkylidene)oxindoles }\end{array}$ & Sarges et al., 1989; Gilad et al., 1992 \\
\hline
\end{tabular}




\section{The Benzodiazepine Binding Sites}

Ligands acting as agonists at the benzodiazepine binding (or receptor) site allosterically enhance $\mathrm{GABA}_{\mathrm{A}}$-receptor function, clinically producing anxiolytic, sedative-hypnotic, and anticonvulsant effects. In general, there are three "subtypes" of benzodiazepine sites that may be formed within the $\mathrm{GABA}_{\mathrm{A}}$-receptor complex. These subtypes have been termed BzI, BzII, and BzIII sites. The BzI (or $\omega 1$ ) pharmacological profile is considered the classical benzodiazepine receptor and constitutes the major population of benzodiazepine binding sites in most rodent brain structures with a particular predominance in the cerebellum (Upton and Blackburn, 1998). The BzII (or 02 ) sites are prominent in only a few areas of the brain, including the hippocampus and striatum (Benavides et al., 1993), whereas the even rarer BZIII (or diazepam-insensitive) receptor is primarily located in cerebellar granule neurons.

For the most part, the heterogeneity of the benzodiazepine binding sites is due to the existence of the various $\alpha$-subunit isoforms, although the presence of the $\gamma_{2}$-subunit is also required for the formation of a fully functional benzodiazepine receptor site (below; Pritchett et al., 1989a, b; Angelotti and Macdonald, 1993). In accordance with this, photoaffinity labeling experiments indicate that the benzodiazepine binding site is located on the $\alpha$-subunit or at the interface between $\alpha$ - and $\gamma$-subunits (Fuchs et al., 1988; Stephenson et al., 1990). In recombinant pharmacological and electrophysiological experiments, the $\alpha_{1}$-subunit (in combination with $\beta_{\mathrm{x}}$ - and $\gamma_{2}$-subunits) confers the BZI receptor profile whereas the BZII receptor profile is conferred by these same $\beta$ - and $\gamma$-subunits in combination with the $\alpha_{2^{-}}, \alpha_{3^{-}}$, or $\alpha_{5^{-}}$-subunit isoform (Pritchett et al., 1989; Pritchett and Seeburg, 1990, 1991; Wieland et al., 1992). The BZII receptors may also be further classified according to their differential affinity for zolpidem, with $\alpha_{2}$ - and $\alpha_{3}$-containing receptors displaying 
an intermediate affinity (compared to the high affinity of $\alpha_{1}$-containing BZI receptors) and $\alpha_{5^{-}}$ containing receptors possessing a very low affinity for zolpidem (Upton and Blackburn, 1998). Furthermore, the BzI and BzII receptors may be differentiated by their affinity for the compounds $\mathrm{Cl}$ 218,872, a triazolpyridine, and the 1,4-benzodiazepine 2-oxo-quazepam as well as zolpidem, each of which has a greater affinity for the BzI subtype than the BzII subtype (Lüddens et al., 1995).

Finally, the diazepam insensitive BZIII receptors are those consisting of either the $\alpha_{4}$ subunit, which is present only in very low quantities throughout the mammalian brain, or the $\alpha_{6}$ isoform (Sieghart, 1995), which also confers ethanol insensitivity (Korpi et al., 1993) and is localized to cerebellar and cochlear granule cells (Lüddens et al., 1990; Laurie et al., 1992a; Wisden et al., 1992; Drescher et al., 1993; Varecka et al., 1994). Both the $\alpha_{4}$ - and $\alpha_{6}$-subunits confer this insensitivity to benzodiazepine due to a common single amino acid substitution (arginine for histidine) in their large extracellular domain (Lüddens et al., 1990; Wisden et al., 1991; Wieland et al., 1992; Gammill and Carter, 1993). In addition to these BZIII, benzodiazepine insensitive receptors, there are benzodiazepine receptors which have only a weak sensitivity to agonist binding. This weak sensitivity is imparted by the presence of the relatively rare $\gamma_{1}$ - or $\gamma_{3}$-subunits in place of the almost ubiquitous $\gamma_{2}$-subunit (Togel et al., 1994).

\section{Subunit-Specific Interactions of Various Modulators}

As noted in the preceding section, the $\alpha$-subunit plays a very prominent role in determining the sensitivity to benzodiazepine receptor agonists. However, this prominent role does not appear to extend to most other modulators of $\mathrm{GABA}_{\mathrm{A}}$-receptor function. Although the $\alpha$ subunit composition also plays a minor role in the modulatory effects of neurosteroids, it appears to have 
no impact upon the effects of barbiturates, picrotoxin, or bicuculline (Macdonald and Olsen, 1994). The $\beta$ subunits, which are required for full activation of channel conductance by $\mathrm{GABA}_{\mathrm{A}}$-agonists, appear to play an even less vital role in the interactions of modulatory agents with the receptor complex. However, the presence of different $\beta$-subunit isoforms do influence the affinity and efficacies of benzodiazepines, barbiturates, and neurosteroids (Bureau and Olsen, 1990, 1993; von Blankenfeld et al., 1990; Sigel et al., 1990).

The nature of the $\gamma$ subunit(s) present in the receptor/channel complex affects the affinity and efficacy of benzodiazepine receptor agonists and is also an important determinant in the sensitivity of receptors to $\mathrm{Zn}^{++}$, ethanol, and zolpidem (Draguhn et al., 1990; von Blankenfeld et al., 1990; Knoflach et al., 1991; Puia et al., 1991; Smart et al., 1991; Pritchett et al. 1992; Lüddens et al., 1994; Wafford et al., 1994). However, the $\gamma_{2}$ isoform is present in far greater abundance in all areas of the brain compared to any of the other isoforms such that most receptors tend to have predominantly a $\gamma_{2}$ isoform profile which confers sensitivity of the receptor to ethanol, benzodiazepines, and zolpidem-mediated modulation but low sensitivity to $\mathrm{Zn}^{++}$(Macdonald and Olsen, 1994; Lüddens et al., 1995; Sieghart, 1995).

The $\delta$ subunit is the least well characterized of the subunit isoforms and, consequently, little relevant pharmacological importance of this subunit has been identified (Sieghart, 1995; Wisden et al., 1996). However, electrophysiological analysis has implied that receptors containing this subunit display an enhanced response to $\mathrm{GABA}_{\mathrm{A}}$-agonists (Saxena and Macdonald, 1994) as well as a particularly high affinity for diazepam. Interestingly though, the primary location of $\delta$-subunit expression is in cerebellar granule cells (Fritschy and Möhler, 1995). This is, as noted above, also the primary location of the $\alpha_{6}$-subunit, which imparts benzodiazepine insensitivity to the receptor. 


\section{E. In Vivo Regulation of the $\mathrm{GABA}_{A}$-Receptor}

As emphasized in the initial section of this document (section I), the ability of neurons to adapt or alter their responsiveness to neurotransmission is a vital component in the proper functioning of neuronal circuitry. Specific alterations in GABAergic responsiveness via $\mathrm{GABA}_{\mathrm{A}^{-}}$ receptors have, to this point, been found to occur by four different mechanisms, including changes in receptor number, subunit composition, receptor phosphorylation, and receptor conformation. It should be noted that there are also non-receptor mediated ways to alter GABAergic function, such as alterations in membrane potential or chloride concentration gradients, which will not be included in this discussion. It should, however, be noted that such changes are known to occur, especially during development where changes in intracellular chloride concentration allow $\mathrm{GABA}_{\mathrm{A}}$-receptors to function in an excitatory role in a number of CNS structures (Conner et al., 1987; Janigro and Schwartzkroin, 1988; Ben-Ari et al., 1989; Cherubini et al., 1990; Yuste and Katz, 1991; Wu et al., 1992).

The regulation of $\mathrm{GABA}_{\mathrm{A}}$-receptor number has been observed in a number of experimental systems including stress paradigms, chronic alcohol treatment, and sensory deprivation of the visual system, which is perhaps the best studied system for such regulation (Kang et al., 1991; Montpied et al., 1991; Primus and Gallager, 1992; Tietz et al., 1993; Hendry et al., 1994; Huntsman et al., 1994; Mhatre and Ticku, 1994; We et al., 1994). Transcriptional control of $\mathrm{GABA}_{\mathrm{A}}$-receptor subunit expression has been shown to occur at both the mRNA and protein levels in experiments studying visual deprivation (Hendry et al., 1994; Huntsman et al., 1994). In these studies, intraocular injection of TTX (tetrodotoxin) led to an adaptational down-regulation of $\alpha_{1}, \beta_{2}$, and $\gamma_{2^{-}}$ subunits in the primary visual cortex of adult monkeys. 
The regulation of receptor subunit composition has been most notable in the study of embryonic and early postnatal development. One clear example of such regulation is in the rat forebrain. The embryonic rat forebrain $\mathrm{GABA}_{\mathrm{A}}-$ receptors are characterized by the presence of the $\alpha_{2}$-subunit isoform and absence of the $\alpha_{1}$ isoform. However, late in embryonic development the adult population of $\mathrm{GABA}_{\mathrm{A}}$-receptor subunits begins to emerge with the $\alpha_{1}$-subunit existing in most receptors and only a minor population of $\alpha_{2}$ isoforms (Fritschy et al., 1994). Furthermore, these authors were able to show that this subunit switch occurred in individual neurons rather than the shift in expression simply being up-regulation by one group of cells concomitant with downregulation in another group of cells.

Regulation of $\mathrm{GABA}_{\mathrm{A}}$-receptors by subunit phosphorylation is still a topic of debate. Although the fact that these receptors are regulated by intracellular phosphorylation is well accepted, reports on the consequences of such phosphorylations are still contradictory. Several subunit isoforms contain consensus kinase substrate sequences in the cytoplasmic loop between the third and fourth transmembrane regions (M3 and M4) for PKA (protein kinase A), $\mathrm{PKC}\left(\mathrm{Ca}^{++}\right.$-dependent protein kinase C), and tyrosine protein kinase (Macdonald and Olsen, 1994). In a number of experiments, phosphorylation of these sites appears to enhance $\mathrm{GABA}_{\mathrm{A}}$-receptor currents by either decreasing desensitization of the receptor, enhancing assembly of subunits, and/or decreasing the degradation of receptors (Cheun and Yeh, 1993; Macdonald and Olsen, 1994). Thus, for example, endogenously released norepinephrine via locus coeruleus stimulation or exogenously applied norepinephrine (acting via $\beta$-adrenoceptors), cAMP analogs, or PKA, can potentiate GABAmediated currents in cerebellar Purkinje cells (Siggins et al. 1971; Moises and Woodward, 1980; Waterhouse et al., 1982; Yeh and Woodward, 1983; Sessler et al, 1989; Cheun and Yeh, 1993, 
1996).

However, in some instances, phosphorylation of the $\mathrm{GABA}_{\mathrm{A}}$-receptor has apparently produced the opposite effect of reducing GABAergic current. For example, injection of the PKA catalytic subunit into mouse spinal cord neurons reduced GABA-evoked currents (Porter et al., 1990). Similarly, studies in HEK 293 cells revealed that PKA and PKC phosphorylation of a specific serine residue of the $\beta_{1}$-subunit decreased $\mathrm{GABA}_{\mathrm{A}}$-receptor function (Moss et al., 1992). Thus, it appears that there are a number of factors which govern the ultimate effects of receptor phosphorylation. Though these factors have yet to be precisely determined, it can be clearly stated that such phosphorylation does regulate GABAergic function.

In addition, the significance and value of the different subunits in mediating such effects is that only certain subunit isoforms contain the putative phosphorylation sites with $\beta$ and $\gamma$ subunits serving as the primary targets of these phosphorylations (Macdonald and Olsen, 1994). For example, the $\gamma_{2 \mathrm{~L}}$ splice variant contains an 8 amino acid insert (compared to the $\gamma_{2 \mathrm{~S}}$ splice variant) with a consensus substrate sequence for an additional PKC phosphorylation site (Whiting et al., 1990) which may be necessary for the modulation of certain $\mathrm{GABA}_{\mathrm{A}}$-receptors by ethanol (Wafford et al., 1991).

Similar to other allosteric proteins, $\mathrm{GABA}_{\mathrm{A}}$-receptors have multiple conformational states which may influence the effectiveness of receptor activation (Galzi and Changeux, 1994). This has been demonstrated via the analysis of single channel kinetics, allosteric interactions between ligand binding sites, and the just noted functional alterations induced by receptor phosphorylation (Sieghart, 1992; Macdonald and Olsen, 1994; Möhler et al., 1995). To this point, changes in receptor conformation have been observed to primarily influence desensitization properties of the 
receptor. For example, following chronic benzodiazepine exposure, recombinant receptors displayed changes in protein conformation which led to a decrease in allosteric coupling that was unaccompanied by changes in receptor number or affinity but did lead to a reversible decrease in agonist efficacy (Klein et al., 1994).

\section{F. Cerebellar Purkinje Neurons and the $G A B A_{A}$-Receptor}

There are a number of different pharmacological profiles created by the assembly of receptors containing different subunit isoforms. However, it appears that the impact of some of these complicating factors which different subunit combinations introduce is reduced by the fact that certain discrete brain regions, and in some cases discrete cell populations, tend to express only a few isoforms abundantly (Laurie et al., 1992a,b; Fritschy and Möhler, 1995; Sieghart, 1995). The cerebellum is an ideal example of such localization and is one of the reasons that it is considered such an opportune area of the brain in which to study $\mathrm{GABA}_{\mathrm{A}}$-receptor pharmacology (Wisden $e t$ al., 1996). Although the subunit isoform profile of nearly all of the cells of the rat cerebellum is relatively well characterized (Fritschy and Möhler, 1995; Sieghart, 1995; Wisden et al., 1996) only the neurons of interest to this study, the Purkinje neurons, will be described in detail here. The reader is directed to Sieghart (1995) or Wisden et al. (1996) for a more in depth discussion of the composition of other cerebellar cell types.

For all of the GABAergic input the Purkinje neurons receive, their subunit isoform profile in normal rats is surprisingly simple. In situ hybridization studies to localize subunit mRNAs show strong expression of the $\alpha_{1}, \beta_{2}, \beta_{3}$, and $\gamma_{2}$ genes with $\beta_{2}$ levels being greater than those of $\beta_{3}$ (Laurie et al., 1992a; Persohn et al., 1992). A rat $\beta_{2}$-specific antibody, however, is only weakly reactive 
with Purkinje cells (Benke et al., 1994), suggesting that very low levels of this subunit isoform are expressed. For the splice variants of the $\gamma_{2}$ isoform, in situ hybridization studies indicate that adult rat Purkinje neurons contain more of the long version $\left(\gamma_{2 \mathrm{~L}}\right)$ than the short $\left(\gamma_{2 s}\right.$; Miralles et al., 1994). Immunocytochemical studies reveal that the $\alpha_{1}$ and $\beta_{2 / 3}$ (the $\beta_{2}$ and $\beta_{3}$ isoforms could not at that time be distinguished immunocytochemically) combination is present on both Purkinje neuron spines and dendritic shafts (Somogyi et al., 1989), and it appears that the $\gamma_{2}$ isoform is colocalized with these subunits (Benke et al., 1991a,b; Gutiérrez et al., 1994).

Developmentally, each of these subunit isoform mRNAs is present in Purkinje neurons at birth and their levels accumulate over the first few weeks of postnatal life, reaching their adult levels by P21 (Zdilar et al., 1991, 1992; Laurie et al., 1992b; Luntz-Leybman et al., 1993). In addition, Purkinje cells of immature animals transiently stain with antibodies to the $\delta$ subunit (Müller et al., 1994). This staining, which occurs through P14 (Müller et al., 1994), has not been confirmed by in situ hybridization analysis (Laurie et al., 1992b). Thus, throughout the postnatal development of the Purkinje neurons, there is little if any change in the isoform profile. However, it should be noted that the studies just described had no means of determining the exact composition of the assembled receptors that were present in the Purkinje neurons or, for that matter, the relative levels of the different combinations that were present. However, based upon the general guidelines described above, the most likely subunit compositions of $\mathrm{GABA}_{\mathrm{A}}$-receptors for adult Purkinje neurons are $\left(\alpha_{1}, \alpha_{1}, \beta_{2 / 3}, \beta_{2 / 3}, \gamma_{2}\right)$ and $\left(\alpha_{1}, \alpha_{1}, \beta_{2 / 3}, \gamma_{2}, \gamma_{2}\right)$ with the $\gamma_{2 \mathrm{~L}}$ representing most of the $\gamma_{2}$ isoforms. 


\section{EXPERIMENTAL DESIGN}

The present studies employed in vitro cerebellar slices and the electrophysiological techniques of intracellular recording, whole-cell patch-clamp recording, and single channel recording in excised outside-out patches to examine the cellular mechanism(s) of a previously identified specific subsensitivity of GEPR-9 Purkinje neurons to GABA ${ }_{A}$-receptor activation (Gould et al., 1991, 1995). In addition, these studies also investigated the cellular responsiveness of Purkinje neurons from both GEPR-NE and GEPR-3 rats. The initial aims of these studies were to employ intracellular recording techniques, investigating animals of various postnatal ages, to:

1.) Determine if the Purkinje neuron membrane properties, namely resting membrane potential (RMP) and input resistance (IR), were the same for Sprague-Dawley, GEPR-NE, GEPR3, and GEPR-9 animals,

2.) Determine whether the cellular responsiveness of Purkinje neurons from GEPR-NE animals, the genetic control strain for GEPR-3 and GEPR-9 rats, were equivalent to that of normal Sprague-Dawley rats, and

3.) Determine if the specific subsensitivity to $G A B A_{A}$-receptor activation observed in situ (Gould et al., 1991, 1995) was also demonstrable in the in vitro slice model for the GEPR-9.

As expected based upon the specific nature of the subsensitivity previously observed in the GEPR-9 (Gould et al., 1991, 1995), the neuronal membrane properties of GEPR-9 rats were statistically equivalent to those of Sprague-Dawley, GEPR-NE, and GEPR-3 animals (see Results, section VII). Furthermore, the data revealed that around postnatal day 15, which coincided with the onset of seizure development in the GEPR, Purkinje neurons from all four animal strains exhibited a significant hyperpolarization which was associated with a significant decrease in their input resistance. In addition, during this early age at which the cerebellum is still maturing, 
differing responses to glutamate, aspartate, NMDA, GABA, and muscimol were revealed in each animal strain. Although these universal (i.e., occurring in each animal strain) changes in responsiveness were not investigated further, studies were conducted to determine the mechanism for the change in RMP and to see if it played a role in the development of seizure predisposition in the GEPR.

If the subsensitivity of GEPR-9 Purkinje neurons to $\mathrm{GABA}_{\mathrm{A}}$-receptor activation is involved in the seizure-susceptibility of these animals, it would also be presumed that the GEPR-NE would fail to display such a subsensitivity, as they are not seizure-prone. In accordance with this, the GEPR-NE Purkinje neurons displayed equivalent membrane polarization responses to SpragueDawley Purkinje neurons when various inhibitory (including GABA) and excitatory ligands were applied via superfusion (see Results, section VII).

The third of these tasks was performed in order to assure that the model system chosen would still be applicable for studying the characteristics of these neurons. These studies employed superfusion of a variety of ligands onto cerebellar slices while recording intracellularly from individual neurons. The results (see section VII) indicated that a GEPR-9 Purkinje neuron subsensitivity to GABA and muscimol, the effects of which could be blocked by both bicuculline and picrotoxin, did exist without a change in sensitivity of these neurons to glutamate, aspartate, or norepinephrine. Thus, the specific subsensitivity to $\mathrm{GABA}_{\mathrm{A}}$-receptor activation was demonstrable in this preparation, and was of approximately of the same magnitude as observed in the in situ model (Gould et al., 1991, 1995).

The next objective of the present studies was to investigate the cellular responsiveness of GEPR-3 Purkinje neurons using techniques similar to those employed with Sprague-Dawley, GEPR- 
NE, and GEPR-9 animals. Since these animals display both a different level and different severity of seizure-susceptibility, it was expected that they would be identical neither to GEPR-9 nor to Sprague-Dawley and GEPR-NE animals with respect to their cellular responsiveness. Due to the lack of much prior information, however, the nature of their responsiveness could not be confidently predicted. Via the intracellular recordings and the superfusion of various drugs and neurotransmitters (as described above), it was found that GEPR-3 Purkinje neurons displayed an altered cellular responsiveness to $\mathrm{GABA}_{\mathrm{A}}$-receptor activation compared to Sprague-Dawley animals which was of a different nature than that of the GEPR-9s. Whereas the GEPR-9 Purkinje neurons displayed a parallel rightward shift of the GABA and muscimol concentration-response curves without a significant change in maximal response, GEPR-3 Purkinje neurons displayed a decrease in maximal response to these agonists without a significant shift of the concentration-response curve.

As a final step to investigate the cellular mechanism(s) of these altered responses in GEPR-3 and GEPR-9 Purkinje neurons, whole-cell and single-channel patch-clamp techniques were employed. The primary aims of these experiments were to determine:

1.) If Purkinje neurons of the GEPR-9 and/or GEPR-3 also displayed decreased levels of whole cell chloride conductance upon GABA receptor activation and

2.) If GEPR-9 and/or GEPR-3 Purkinje neurons (compared to Sprague-Dawley Purkinje neurons) displayed decreased single-channel conductance amplitudes in response to GABA.

The findings of the whole-cell experiments were that, similar to the membrane polarization responses, whole cell conductances were altered for both GEPR-3 and GEPR-9 Purkinje neurons, though in a different manner (see Results, section VII). However, single-channel analysis of GABA responses did not reveal differences in conductance amplitude among the three animal strains. 


\section{METHODS}

The methods used for these studies involve intracellular microelectrode, whole-cell patch clamp, and excised outside-out patch clamp recording from slices of the rat cerebellar vermis maintained in vitro. The brain slice preparation, in its original form, was first developed in the 1930's by Quastel and Elliot (see Elliot and Wolfe, 1962). Prior to the 1970's, most of this work focused on cellular metabolism (Mcllwain and Bachelard, 1971). The subsequent development of olfactory bulb and hippocampal slice preparations (Yamamoto and Kurokawa, 1970; Skrede and Westgaard, 1971) led to more sophisticated studies of neuronal activity permitting more refined electrophysiological and pharmacological analysis. As with most techniques, performing such recordings in slices has both advantages and disadvantages. Compared to recording in situ, in acutely dissociated cells, or from cells maintained in culture, the in vitro slice preparation was the best choice for the purposes of these experiments, for the reasons detailed below.

Foremost among these advantages over whole animal recordings is the precision with which drug applications can be made. Neuron(s) of interest are identifiable visually and/or by electrical stimulation of fiber tracts which give rise to characteristic responses in such neurons. Compared to acutely dissociated cells, and in many cases, cells in culture, the slice preparation allows the investigator to maintain more of the in vivo characteristics of the neuron(s) of interest by invoking less trauma in these cells. The ability to simulate the in vivo environment in slices is greater since the loss of synaptic connections and intrinsic neuronal structure can be minimized though it does limit one to studying only local circuits contained within a given slice. Along with dissociated cells, slices have the advantage of allowing one to investigate the properties of neurons in an environment 
in which variables such as temperature, $\mathrm{pH}$, cellular energy source, oxygen tension, ionic composition, and osmolarity can be maintained precisely and at levels similar to those found in vivo.

In order for the in vitro slice technique to retain such advantages, however, the long term maintenance of the slices must be conducted in such a way that it preserves viability and function for a period long enough to obtain successful recordings. Thus, there are certain precautions which must be taken to avoid problems experienced with many brain slice preparations which may interfere with the integrity of neurons to be studied. Such problems include tissue damage due to the slicing process, postdecapitation ischemia/hypoxia, and slice anoxia. To reduce the possible effects of postdecapitation ischemia/hypoxia, the speed of slice preparation is critical. The shorter the amount of time from decapitation to removal of the desired brain region, the better. Ideally, removal of the brain tissue in less than 1 minute after decapitation should be obtained (Kano and Konnerth, 1992). However, even in slice preparations taking as long as 2-6 minutes to prepare, no such lasting postdecapitation effects appear to be present following 90 minutes of postpreparation incubation (Lust et al., 1982). Furthermore, Nicholson and Hounsgard (1983) have shown that for $300-400 \mu \mathrm{m}$ slices, the cellular microenvironment is similar to that reported in the intact brain.

The mechanical damage of the slicing process itself cannot be entirely avoided. During the procedure a region on either edge of the slice will be disrupted as the cutting blade passes through the tissue block. If care is taken during this procedure, however, this damage can be reduced to an area 40-50 $\mu \mathrm{m}$ deep at each cut site (Garthwaite et al., 1979; Misgeld and Frotscher, 1982). Thus, in a $300 \mu \mathrm{m}$ slice, there is essentially a $200-220 \mu \mathrm{m}$ zone of viable, "normal" tissue with which to work. Avoiding the possible development of an "anoxic core" in the slice preparation is dependent upon slice thickness. Studies utilizing relatively slow superfusion rates $(0.6 \mathrm{ml} / \mathrm{min})$ revealed that 
such an area of anoxia did not occur in slices up to $430 \mu \mathrm{m}$ in thickness (Fujii et al., 1982). Thus thinner slices and higher superfusion rates are the most valuable tools in counteracting the possibility of producing an anoxic core.

\section{A. Brain Slices}

Cerebellar slices were prepared according to the methods described by Llinas and Sugimori (1980a,b), Crepel et al. (1981), Dupont et al. (1987), and Kano and Konnerth (1992) with some modifications. Animals were anesthetized with either $25 \mathrm{mg} / \mathrm{kg}$ sodium pentobarbital or $\mathrm{CO}_{2}$ and subsequently decapitated with a guillotine. The choice of anesthetic did not alter the viability of the slices obtained. Following decapitation, the skull and dura mater overlying the cerebellum were removed, the cerebellar peduncles were severed using a sterile scalpel, and the cerebellum was removed. Immediately after removal, the cerebellum was placed into aerated $\left(95 \% \mathrm{O}_{2} / 5 \% \mathrm{CO}_{2}\right)$ artificial cerebrospinal fluid (aCSF; composition below) kept on ice at approximately $4{ }^{\circ} \mathrm{C}$. This process never required longer than 45 seconds to complete. The cerebellum, still in iced aCSF, was then blocked by sagittal cuts at each vermian vein and one of the cut ends was glued to a teflon chuck using cyanoacrylate adhesive. The cerebellum was supported on the chuck by a notched agar block previously prepared and glued to the chuck. Agar cutting blocks were prepared by pouring molten agar $(5 \%$ by weight in $150 \mathrm{mM} \mathrm{NaCl})$ into $10 \mathrm{cc}$ plastic syringes cut off at one end, cooled, then cut to an appropriate size as needed.

Using a Vibroslice oscillating tissue slicer (World Precision Instruments), $300 \mu \mathrm{m}$ thick sagittal sections of the cerebellar vermis were cut while maintained in aerated, $4^{\circ} \mathrm{C}$ aCSF. Upon obtaining each slice, it was immediately transferred, using a wide mouthed, fire-polished glass 
pipette, to a plastic-mesh basket submerged in a plastic beaker containing continuously aerated aCSF and kept on ice. All slices used were cut and transferred to the incubation beaker within 10 minutes after decapitation. The incubation beaker was kept on ice until 15 minutes postdecapitation, then removed from ice and allowed to slowly (over a two hour period) warm to room temperature $\left(20-22^{\circ} \mathrm{C}\right)$ prior to initial recordings.

\section{B. Electrophysiological Recording I: Intracellular Recording}

Following the recovery period, slices were individually transferred to a holding apparatus made of nylon mesh glued to a glass micropipette which had been heated and formed into a Ushape. The holding apparatus with the brain slice was then placed in a $1.5 \mathrm{ml}$ laminar flow recording chamber continuously superfused with aerated aCSF maintained at $22-25^{\circ} \mathrm{C}$. Originally, slices were superfused and recordings obtained at $37^{\circ} \mathrm{C}$. However, the lower temperature allowed for greater slice viability during recording and preliminary studies indicated that the electrophysiological parameters were not significantly altered by recording at the lower temperature. Temperature was monitored using a Yellow Springs Instruments thermoprobe placed in the recording chamber. Perfusion of aCSF was maintained at $3 \mathrm{ml} / \mathrm{min}$ via a pressure assisted gravity feed system. The slice was then viewed under a dissecting microscope (Nikon SMZ-2T) utilizing a Dolan-Jenner Fiber-Lite fiber optic light source and a bipolar stimulating electrode (teflon coated platinum wire) for antidromic identification of neurons was placed on the white matter (see Figure 5). Artificial cerebrospinal fluid contained (in mM): $\mathrm{NaCl}$ (126); $\mathrm{KCl}$ (5); $\mathrm{MgSO}_{4}$ (1.3); $\mathrm{NaH}_{2} \mathrm{PO}_{4}$ (1.2); $\mathrm{NaHCO}_{3}(26) ; \mathrm{CaCl}_{2}(2.4) ;$ glucose (10).

Standard intracellular recording was performed using single-barreled borosilicate glass 
microelectrodes filled with $3 \mathrm{M}$ potassium acetate (KAc) with resistances of $80-110 \mathrm{M} \Omega$. The electrical activity and cellular currents generated were then amplified and monitored under the bridge recording configuration using an AXOCLAMP-2A amplifier (Axon Instruments). Electrophysiological signals were monitored on an oscilloscope (Tektronix 5110, 5111A) and led to a computer following A/D conversion through a TL-1 DMA interface (Axon Instruments) for data acquisition, real time analysis, and/or storage for subsequent off-line analysis using Axotape 2.0 (Axon Instruments).

Cells at least $50 \mu \mathrm{m}$, but no greater than $250 \mu \mathrm{m}$, from the surface of the slice were impaled with the assistance of a Narishige hydraulic micromanipulator and were identified as Purkinje neurons based upon the antidromic invasion of the soma following electrical stimulation of the axon (white matter). An example of such an antidromic action potential is illustrated in Figure 5. Criteria for inclusion of a given neuron in the population for statistical analysis included the establishment of a stable resting membrane potential (RMP) between -35 and $-75 \mathrm{mV}$ and the production of an antidromic action potential following white matter stimulation. Cellular input resistance was determined by regularly (2-5 second intervals) passing several steps of depolarizing and hyperpolarizing currents through the recording electrode. The voltage change induced by each electrotonic potential was later quantified, used to assess input resistance based upon Ohm's law ( $\mathrm{V}=\mathrm{IR}$ ), and used to construct I/V curves. The duration of the electrotonic potential used was individualized for each neuron so that the membrane capacitance was fully charged for that neuron (typically 150-250 msec). An example of I/V curve construction is illustrated in Figures 6 and 7 , with Figure 6 showing the actual voltage responses used to construct the I/V curve shown in Figure 


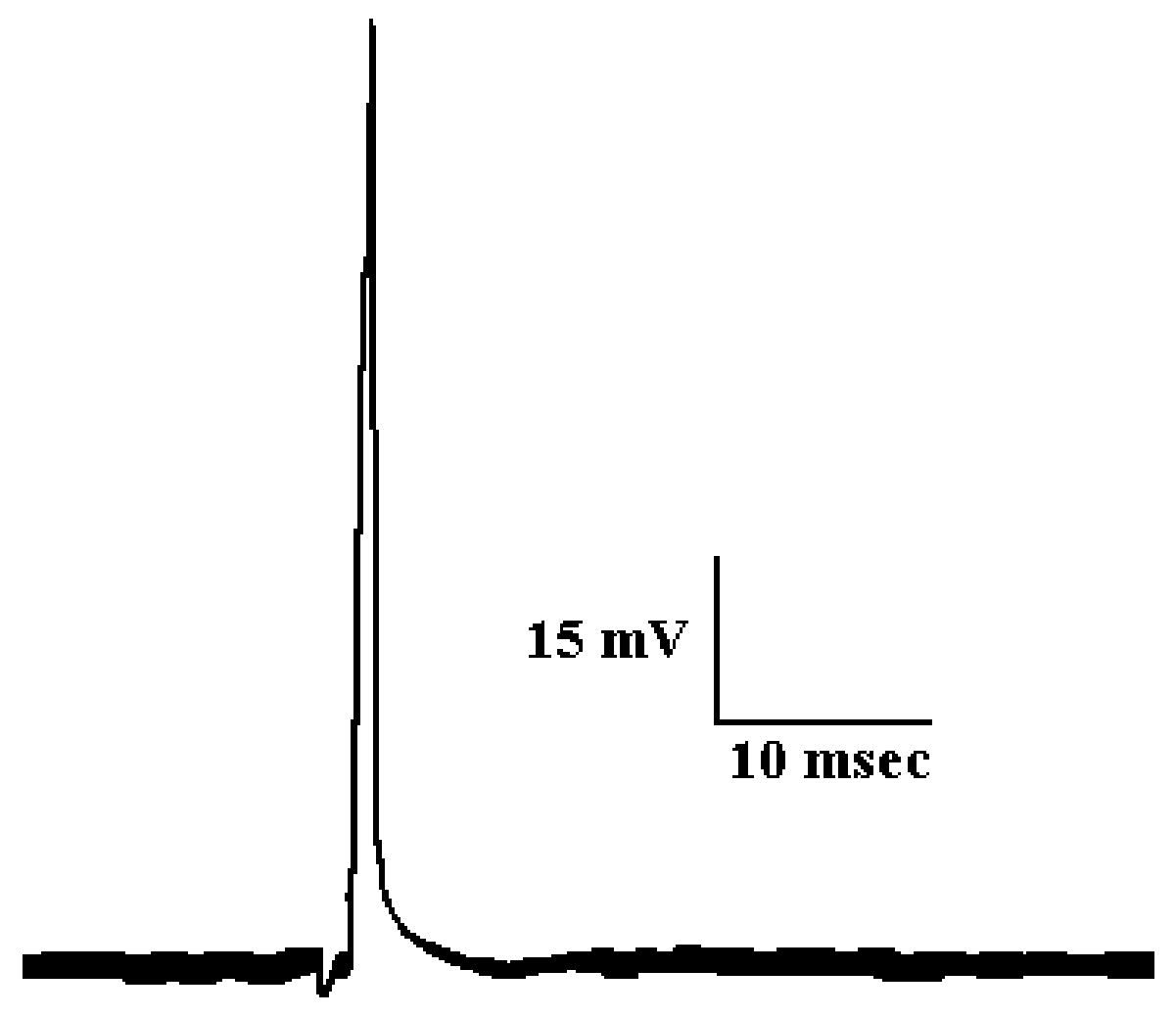

FIGURE 5. Intracellular recording of a Purkinje neuron in a cerebellar slice showing antidromic action potential invasion of the soma following white matter stimulation. Potential amplitudes were typically in the 65 to $85 \mathrm{mV}$ range with durations near $1 \mathrm{msec}$. The pictured potential had an amplitude of $72 \mathrm{mV}$ and a duration of $1.2 \mathrm{msec}$. 


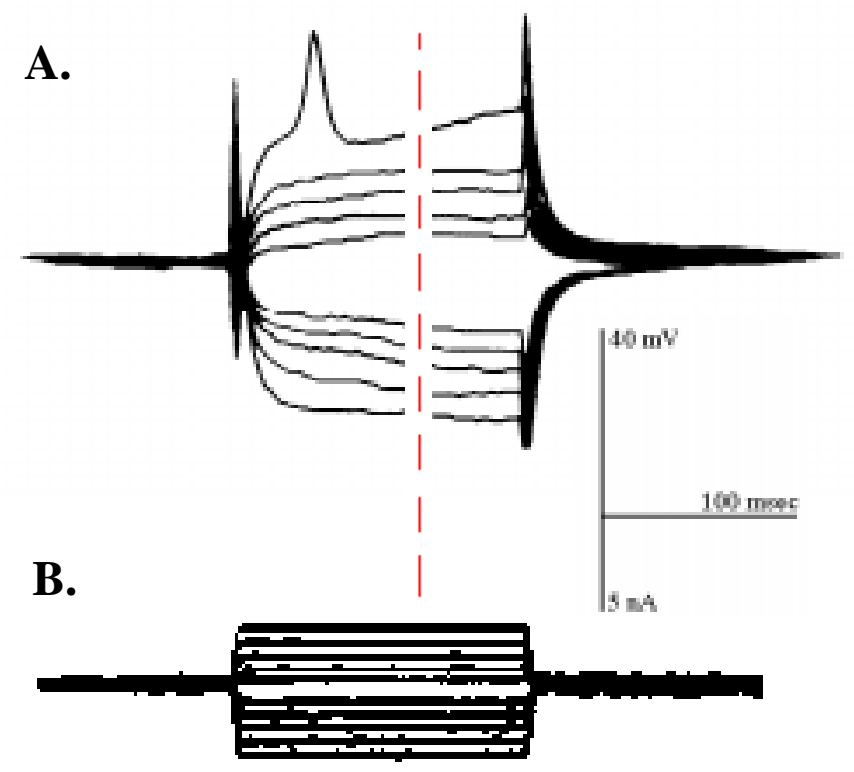

FIGURE 6. Representative voltage responses (A) and current injection (B) traces as used for the formation of current-voltage (I/V) curves (see Figure 7) are depicted. The upper and lower portions of the inset axis correspond to the upper (A) and lower (B) traces, respectively. Although a time period long enough for most voltage responses to plateau was used, some voltage responses failed to plateau as can be seen in (A). Thus, in order to standardize measurements, voltage responses were measured at $100 \mathrm{msec}$ from the start of current injection as noted by the dashed vertical line in (A). The large deflections at the beginning and end of the voltage sweeps represent the combined stimulus artifacts associated with each individual current pulse. 


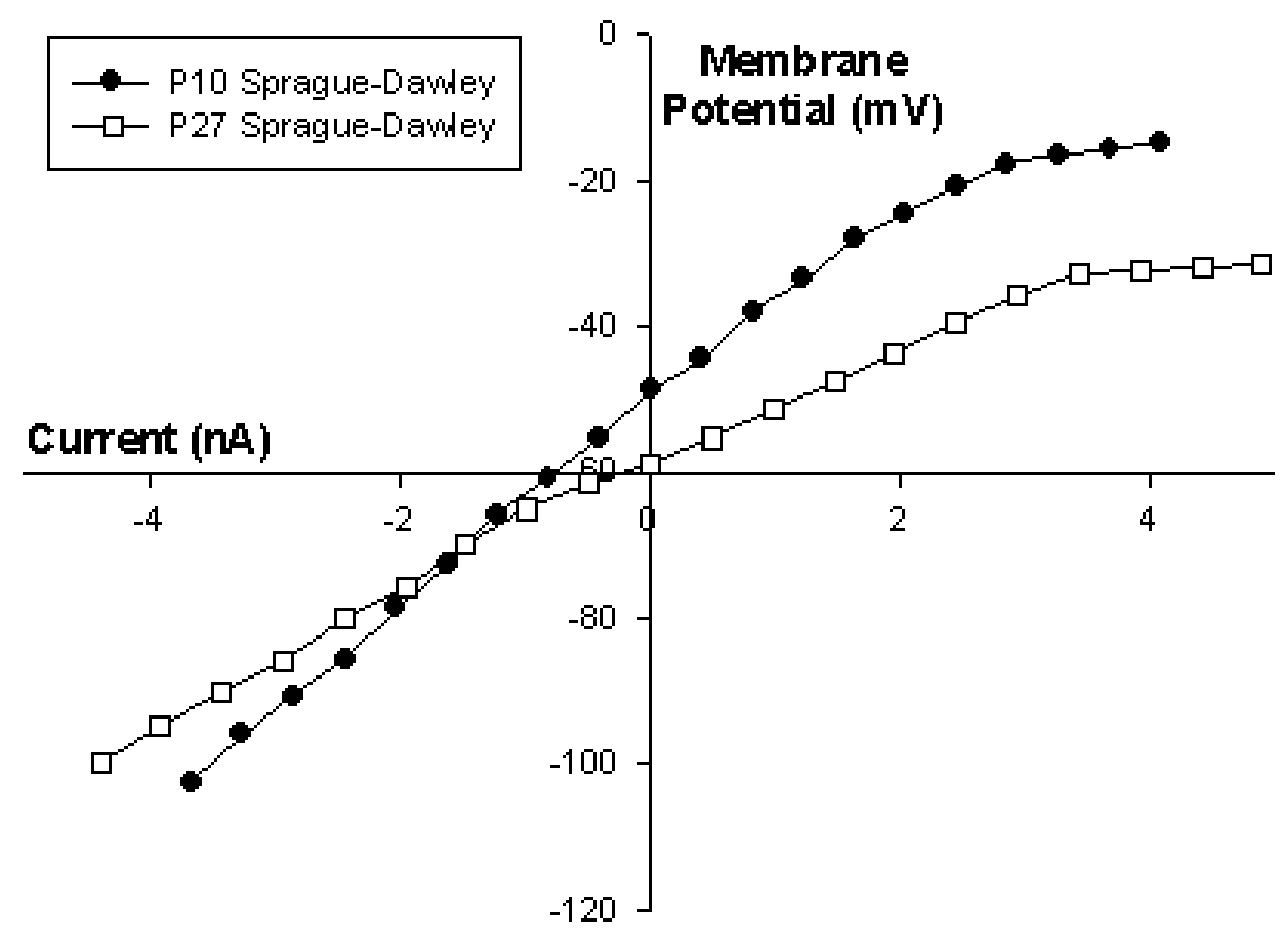

FIGURE 7. Current-voltage (I/V) plots for Purkinje neurons in cerebellar slices from a 10 day (P10) and a 27 day (P27) old Sprague-Dawley rat as determined using intracellular recording techniques. Values were determined from voltage response to injected current as seen in Figure 6. 
7. It should also be noted that even though a large range of values are depicted in Figure 7, nine smaller current steps between -1.5 and $1.5 \mathrm{nA}$ were used to calculate input resistance (e.g. -1.5, -1.1, $-0.7,-0.3,0,0.3,0.7,1.1$, and $1.5 \mathrm{nA})$.

Exposure of neurons to drugs was accomplished through the addition of known concentrations of drug to the superfusing solution. Dead time for drug application was less than 5 seconds. Muscimol, $\gamma$-aminobutyric acid (GABA), glutamate, aspartate, N-methyl-D-aspartate (NMDA), ouabain, diazepam, bicuculline, picrotoxin, baclofen, and norepinephrine were prepared as stock solutions in advance in aCSF and stored at $-20^{\circ} \mathrm{C}$. Aliquots were thawed and diluted to final concentrations in fresh, aerated aCSF just prior to use. When multiple drugs were applied to a single neuron, the effects of prior drug applications were allowed to completely wash out before subsequent exposure to another agent. This was noted by a complete return of the membrane potential back to RMP (an example for muscimol is depicted in Figure 8). For determining changes in IR during drug applications, IR was compared before and during drug application by injecting current at a regular interval during the recording of RMP (see Figure 8). The IR was calculated from a series of randomly selected electrotonic potential injections (ten before drug application while at RMP, ten at steady-state maximal effect of drug) and then averaged before comparison. When ouabain $\left(\mathrm{Na}^{+}-\mathrm{K}^{+}\right.$, ATPase inhibitor), bicuculline, or picrotoxin $\left(\mathrm{GABA}_{\mathrm{A}}\right.$-selective antagonists) were applied to a slice, no subsequent recordings from that slice were made in order to avoid residual effects upon other neurons in the same slice. Furthermore, concentration-response curves were made by applying single increasing concentrations of drug (about 1 minute per concentration) while allowing time for complete washout of effect between concentrations (noted by a return to RMP) which varied with the drug used. 


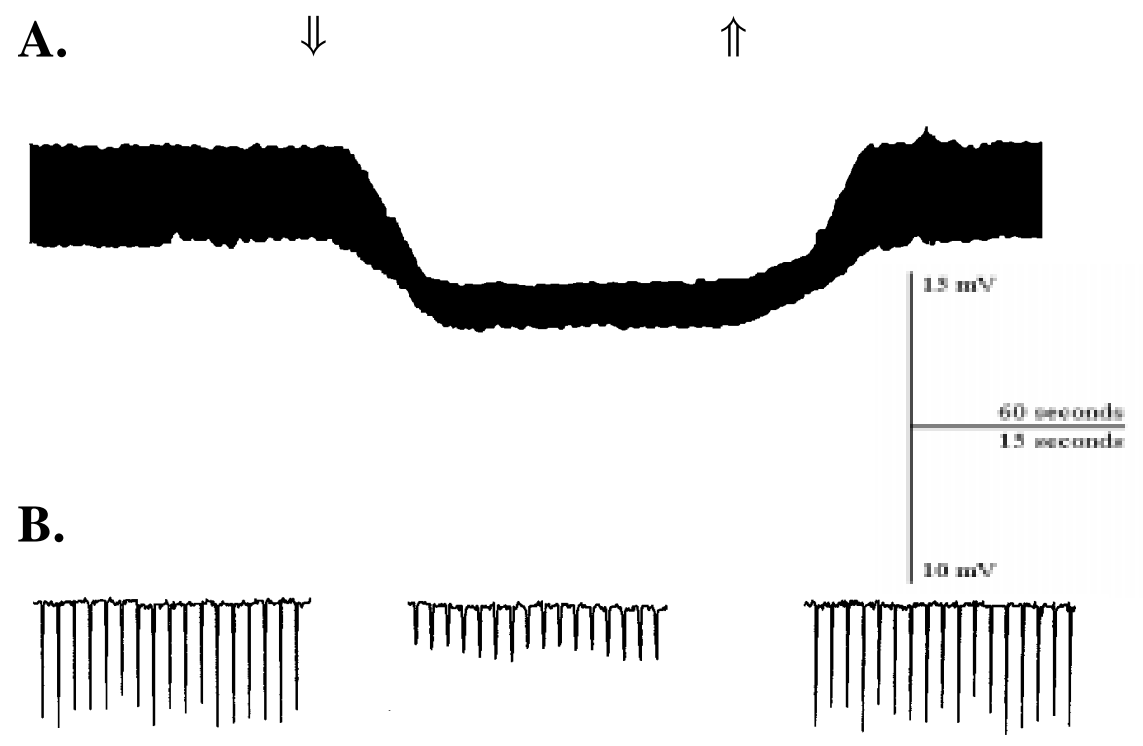

FIGURE 8. Response of a Purkinje neuron in a cerebellar slice from a Sprague-Dawley rat to $1 \mu \mathrm{M}$ muscimol application via superfusion. The arrows, $\uparrow$ and $\downarrow$, indicate time of drug addition and removal from the superfusion fluid, respectively. (A) Depicts the hyperpolarization of the membrane potential noted by the downward movement of the trace and the return to resting membrane potential (RMP) noted by the upward movement of the trace back to its original level. (B) Shows portions of this trace on an extended time scale thus illustrating the effects of muscimol on input resistance (IR) before, during, and after drug application. The downward deflections depict the voltage responses to injected current ( $3 \mathrm{nA})$. The upper half of the inset axis is for trace (A) and the lower half is for trace $(B)$. 


\section{Statistical Analysis of Intracellular Data}

Two similar methods were used for statistical analysis of collected data. For parameters which were assessed across time (e.g., versus age), an analysis of variance (ANOVA) using a nested design was performed to test for the effect of age. Multiple comparisons were then made using orthogonal contrast and the $\alpha$-values were adjusted via the method of Bonferroni. Since ten multiple comparisons were made in each instance where this method was used, a significant $p$ value was 0.005 for these comparisons. For comparing the effects of drugs between animals, for example Sprague-Dawley vs. GEPR-9, an analysis of variance with nested design was also used. However, in these instances no multiple comparisons were performed, thus a significant $\mathrm{p}$ value was 0.05 for these comparisons.

An important point which should be made concerning the intracellular concentrationresponse curves for membrane hyperpolarizing responses to both GABA and muscimol presented in the present manuscript is the saturation of the membrane hyperpolarizing response as the membrane potential $\left(\mathrm{V}_{\mathrm{m}}\right)$ approaches the chloride equilibrium potential $\left(\mathrm{E}_{\mathrm{Cl}}\right)$. The change in membrane potential induced solely by the movement of chloride ions is limited by the $\mathrm{E}_{\mathrm{Cl}}$ such that as $\mathrm{V}_{\mathrm{m}}$ increases towards $\mathrm{E}_{\mathrm{Cl}}$, the driving force for chloride movement into the cell decreases, and the change in $\mathrm{V}_{\mathrm{m}}$ asymtotically approaches $\mathrm{E}_{\mathrm{Cl}}$ in a hyperbolic manner. The non-linearity of this hyperbolic response makes interpretation of the concentration-response curves more difficult due to the influence of two hyperbolic functions on the shapes of the curves, namely, the saturable binding of ligand and receptor and the saturable hyperpolarizing response. For this reason, similar maximal responses obtained for the hyperpolarization concentration-response curves may be a function of the saturation of this hyperpolarization and, thus, similar maximal conductances 
between neurons from different animals should not be inferred.

\section{Electrophysiological Recording II: Whole-Cell and Single-Channel Patch Clamp}

Following the recovery period, slices were individually transferred to a superfusion and recording chamber (Warner Instrument Corp.), mounted on the stage of an Olympus BX50WIF microscope equipped for infrared videomicroscopy, and continuously superfused with aerated aCSF (same composition as for intracellular recording) at room temperature. Superfusion of aCSF was via a gravity feed system at a rate of $3 \mathrm{ml} / \mathrm{min}$. The slice was then viewed under 50 -fold $(5 \mathrm{X}$ objective, 10X eyepiece) magnification in order to locate the Purkinje cell layer. Once the Purkinje cell layer was identified based upon its location at the interface between the granule cell and molecular layers (see section III), an infrared (IR) filter was installed and a 40X water immersion objective (total magnification $=400 \mathrm{X}$ ) was used to identify an individual Purkinje cell from which to record.

Conventional whole-cell patch clamp recording techniques (Hamill et. al., 1981) were used to record currents from Purkinje neurons in the cerebellar vermis. Patch electrodes were fabricated from thin-walled borosilicate glass capillaries using a Flaming/Brown micropipette puller (model P-87, Sutter Instrument Co.) and the shank subsequently coated near the tip with a thin layer of Sylgard (Dow) to reduce tip capacitance and thus improve background noise (Hamill et al., 1981). After briefly curing the Sylgard with a hot air gun, electrode tips were fire-polished under magnification using a microforge (Narishige). The electrode was then filled with an intracellular

solution containing (in $\mathrm{mM}$ ): $\mathrm{CsCl}$ (145); $\mathrm{MgCl}_{2}$ (1); $\mathrm{Mg}^{++}$-ATP (5); EGTA (5); HEPES (10); balanced to a $\mathrm{pH}$ of 7.2 using $\mathrm{CsOH}$. $\mathrm{Mg}^{++}$-ATP was included in the pipette solution in order to 
prevent run-down of GABA-induced currents (Cheun and Yeh, 1991). Cesium $\left(\mathrm{Cs}^{+}\right)$was used as a replacement for potassium $\left(\mathrm{K}^{+}\right)$in order to reduce or eliminate potassium currents. The extracellular solution (aCSF) was identical to that used for intracellular recordings (see above) with the exception that tetrodotoxin (TTX; $1 \mu \mathrm{M})$ was added to reduce or eliminate sodium currents. EGTA was present in the electrode solution to buffer calcium which helps prevent spontaneous increases in the access resistance as the result of partial resealing of the patch membrane (Penner, 1995).

Once a candidate Purkinje neuron was identified with the assistance of a CCD camera (Dage) and a Sony high-resolution monitor, the patch electrode was brought into the proximity of the cell with the aid of a Narishige 3D micromanipulator attached to the stage of the microscope. During the approach, positive pressure was kept on the patch pipette in order to prevent occlusion of the electrode tip while clearing away tissue debris. Contact with the cell was then noted as an increase in the electrode resistance (to a $200 \mu \mathrm{V}$ test pulse) at which point mild negative pressure was applied to potentiate seal formation while monitoring on a Tektronix oscilloscope. As the current signal decreased, the test pulse was increased to $20 \mathrm{mV}$ to determine if a giga-ohm seal was obtained. Further suction was applied until such a seal was obtained and any seal which did not reach a minimum resistance of $1 \mathrm{G} \Omega$ was not used for analysis. Capacitive transients were then nulled using capacity compensation controls on the amplifier (Dagan, model 8900). The filtering was then increased from $1 \mathrm{kHz}$ to $10 \mathrm{kHz}$ and residual transients were compensated for.

Further negative pressure was then applied to rupture the membrane which was noted by the appearance of a large capacity transient and a marked increase in current noise. The resting membrane potential was noted and the cell was promptly voltage clamped to a membrane potential 
of $-60 \mathrm{mV}$. This membrane potential was chosen based upon intracellular studies which indicated that this was the approximate resting membrane potential of Purkinje neurons in vermal cerebellar slices from rats (postnatal age 15 days or older) of each strain used (see Results, Figure 11). At this point the series resistance was compensated using series resistance controls on the amplifier. For single-channel recordings, the patch electrode was slowly withdrawn from the cell surface (following formation of giga-seal and subsequent rupture of the membrane to obtain the whole-cell configuration) to create an excised outside-out patch with the outer surface of the cellular membrane in contact with the superfusing fluid.

For determination of the effects of drugs applied via superfusion (e.g., added to the extracellular perfusate as above), whole cell currents before, during, and after drug application were recorded at a holding potential $\left(\mathrm{V}_{\mathrm{H}}\right)$ of $-60 \mathrm{mV}$ (see Figure 9). Additionally, I/V curves during drug administration were constructed using a series of voltage ramps from -80 to $+20 \mathrm{mV}$ and measuring the subsequent current. These values were then used to construct I/V plots based upon Ohm's law (V=IR; see Results, Figure 29). Agonist-activated membrane currents were amplified using a model 8900 Dagan patch clamp amplifier and led to a computer following digitization (TL1-DMA, Axon Instruments) for storage and later analysis using pClamp software. 

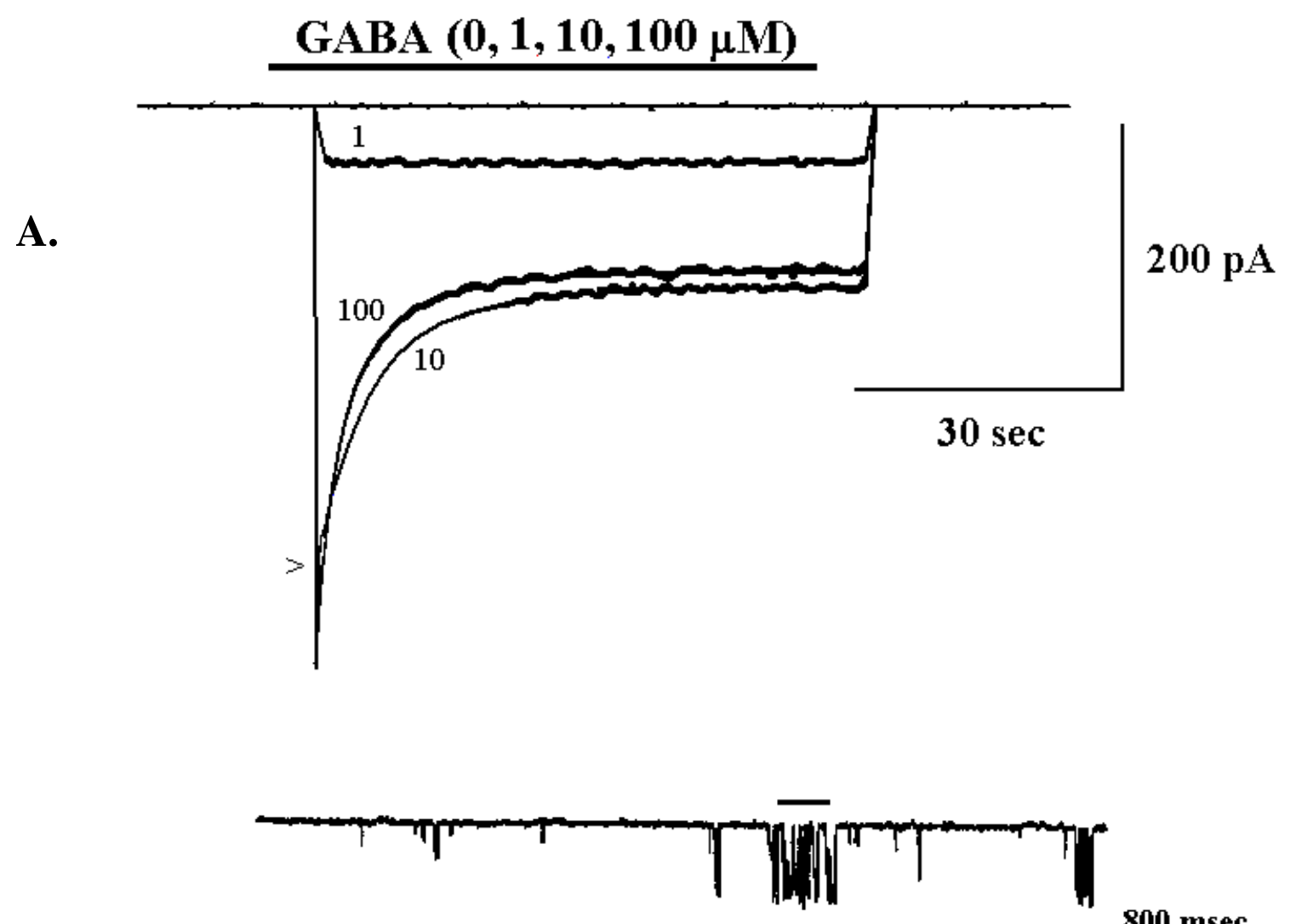

B.

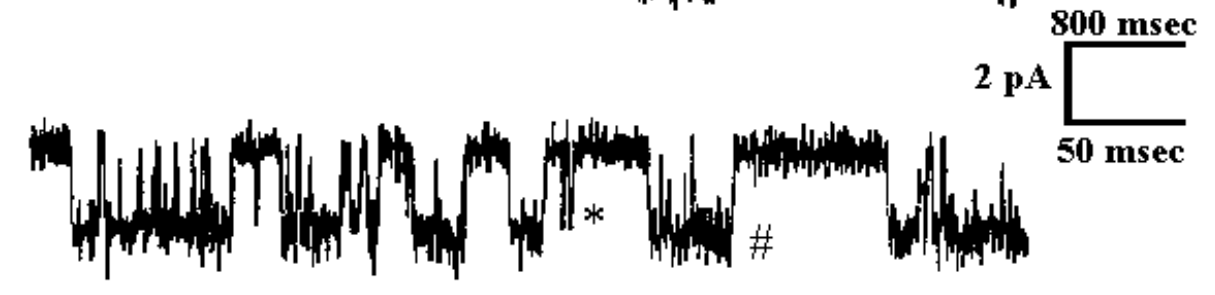

FIGURE 9. Representative whole-cell (A) and single-channel current (B) traces from Purkinje neurons of Sprague-Dawley rats. In (A) whole cell currents from before and during step applications of GABA are superimposed. The numbers next to the individual traces represent the concentration of GABA $(\mu \mathrm{M})$ in the superfusing fluid. The > indicates the peak amplitude of the current for the $10 \mu \mathrm{M}$ GABA current trace. GABA was applied for approximately 1 minute at 5 minute intervals to allow time for recovery from desensitization (Sigel et al., 1990). For a means of standardizing measurements, steady-state $\left(\mathrm{I}_{\mathrm{SS}}\right)$ or desensitized currents were measured at 45 seconds after drug application (see text for details). In (B) single-channel currents from a SpragueDawley Purkinje neuron in response to $10 \mu \mathrm{M}$ GABA are shown for two different time scales as indicated on the right. The bar above the top trace indicates the portion of the trace seen in the bottom portion of the figure. The * and \# indicate the opening of the channel to two different conductance levels. 
The analysis of dwell times (open and closed durations) of single-channel currents was performed using pSTAT (pClamp, Axon Instruments). Open durations were placed into frequency histograms using linear binning using $0.5 \mathrm{msec}$ bins. Closed durations were placed into frequency histograms using logarithmic binning and a square-root ordinate transmformation was used (Sigworth and Sine, 1987). Closed durations were binned using a 10 bins/decade resolution with a $200 \mu \mathrm{sec}$ minimum duration. For curve fitting of the binned data, the Simplex method for maximum likelihood fitting was used. It should also be pointed out that observed open and closed dwell times were reported. Due to the presence of unresolved openings and closures, the observed durations will be longer than the true durations (Colquhuon and Sigworth, 1983). No steps were taken to account for these missed events. 


\section{RESULTS}

The initial aim of the present study was to extend the investigations of Gould et al. $(1991,1995)$ in an experimental preparation which would permit more precise definition of the deficits in GABAergic transmission in the genetically epilepsy-prone rat (GEPR). As noted, these previous electrophysiological studies relied primarily upon extracellular single unit recordings obtained in situ. The results of these experiments indicated that Purkinje neurons of the GEPR-9 cerebellum displayed a specific subsensitivity to $\mathrm{GABA}_{\mathrm{A}}$-receptor activation. This conclusion was based upon the observation that the firing rates of Purkinje neurons from GEPR-9 were equally responsive to norepinephrine, glutamate, and baclofen but less responsive to GABA and muscimol compared to control animals. Such specific subsensitivity would not be expected if membrane properties had been altered (see section IA), but instead, would likely be due to either a decrease in the number of $\mathrm{GABA}_{\mathrm{A}}$-receptors or an alteration in the signal transduction process $\left(\mathrm{Cl}^{-}\right.$ conductance) for these receptors.

To further elucidate the mechanism(s) responsible for this subsensitivity, these investigations

(Gould et al., 1995) next evaluated $\mathrm{GABA}_{\mathrm{A}}$-receptor binding in the cerebellum. This was accomplished by comparing the binding of $\left[{ }^{3} \mathrm{H}\right]$-muscimol and $\left[{ }^{3} \mathrm{H}\right]$-flunitrazepam, both of which bind to the $\mathrm{GABA}_{\mathrm{A}}$-receptor complex, in cerebellar homogenates from GEPR-9 and control animals. These studies indicated that there was no difference in the $\mathrm{GABA}_{\mathrm{A}}$-receptor population in the cerebellum between these two animal strains. This finding suggested that the mechanism underlying the subsensitivity to GABA in the Purkinje neurons of the GEPR-9 was likely to be due 
to a decreased ability of the $\mathrm{GABA}_{\mathrm{A}}$-receptors in the Purkinje neurons of this animal to conduct $\mathrm{Cl}^{-}$ upon activation by a ligand. In order to determine if this is the primary cause of the subsensitivity, a different, more precise electrophysiological technique needed to be employed. The method we chose to accomplish this task was to record from Purkinje neurons in slices of the cerebellar vermis maintained in vitro in order to characterize the electrophysiological properties of these neurons and to permit more quantitative analysis of the effects of agonist exposure to these neurons.

\section{A. Basic Electrical Membrane Properties}

The resting membrane potential (RMP) and input resistance (IR) of Purkinje neurons were examined using intracellular recording in vermal cerebellar slices from control (Sprague-Dawley and GEPR-NE) and epileptic (GEPR-3and GEPR-9) animals. Based upon the observations that indicated a specific subsensitivity to $\mathrm{GABA}_{\mathrm{A}}$-receptor activation (Gould et al., 1991, 1995), RMP and IR were not expected to vary between animal strains. In addition to comparing these electrical membrane properties between animal strains, they were also compared with respect to animal age. Since later portions of the present study relied on the ability to perform experiments in relatively young animals with a minimal seizure history (for GEPR-3 and GEPR-9 rats), and at an age during which the cerebellum has yet to complete its development (see section III), this analysis with respect to age was important to ensure that possible developmental events common to each animal strain were accounted for. Furthermore, possible differences between animal strains with regard to cerebellar maturation could provide further insight into the development of seizure predisposition in the epileptic GEPR animals.

Figures 10 and 11 are plots of the RMP and IR, respectively, for control Sprague-Dawley 
and GEPR-NE as well as epileptic GEPR-3 and GEPR-9 rats of various postnatal ages. Tables 4 and 5 provide the means and standard errors plotted in Figures 10 and 11, respectively, as well as the sample sizes for each group. In order to provide reasonable sample sizes for valid comparisons between animal strains, the data were grouped according to age groups consisting of five day periods beginning with postnatal day 10 (P10) and an adult group (P30+) which consisted of animals 30 days postnatal or older. In addition, this grouping method provided an age group consisting purely of animals with no prior seizure history (P10-14).

While there were no statistically significant differences between any of the animal strains for RMP or IR during a given age period ( $\mathrm{p}>0.005)$, there were differences in both RMP and IR for each animal strain with respect to age $(\mathrm{p}<0.005)$. The RMP became more hyperpolarized and the IR decreased with increased animal age with the majority of the change occuring between the P1014 and P15-19 aged animals. As such, the RMP and IR from P10-14 animals of each strain were significantly different from all other age groups $(\mathrm{p}<0.005)$. Also included in Figures 10 and 11 as well as Tables 4 and 5 is a P15+ group, which was also significantly different from the P10-14 group. This is included as a reference for later experiments which employ the use of only animals 15 days postnatal and older which grouped these animals as a single experimental population. These mean values include values recorded from Purkinje neurons from all animals 15 days or older. As an example of how these characteristics are altered during cerebellar development, Figure 12 presents a plot of both the RMP and IR of Sprague-Dawley Purkinje neurons for the different 5-day age groups. As can be seen, there is a large hyperpolarization of the membrane potential between P10-14 and P15-19. The IR declines more gradually, but a large portion of this decrease also occurs 


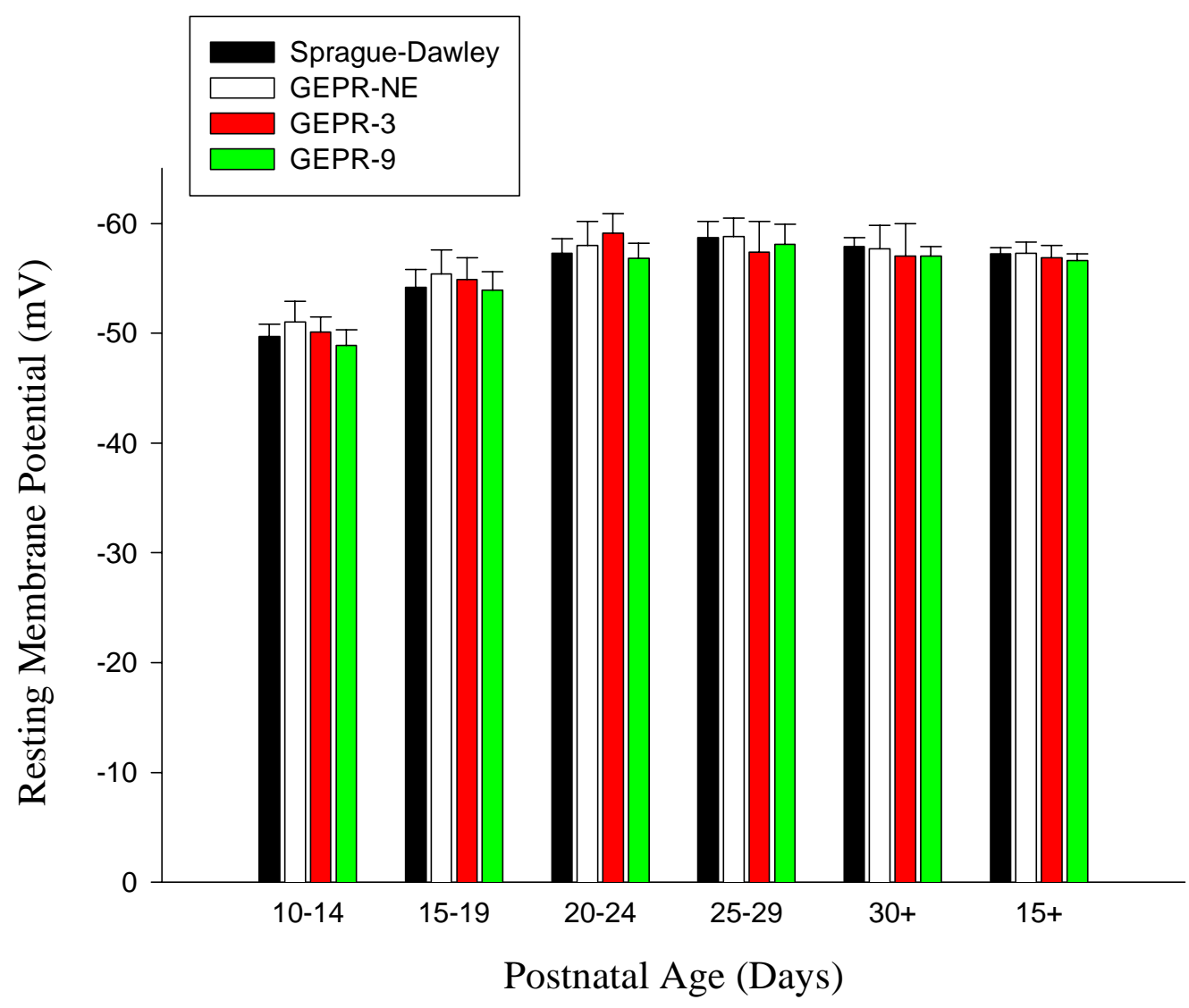

FIGURE 10. Bar graph comparing the resting membrane potential of Purkinje neurons in cerebellar slices from Sprague-Dawley, GEPR-NE, GEPR-3, and GEPR-9 rats measured using intracellular recording techniques. Values are plotted as mean \pm S.E.M. There were no significant differences among the animal strains for any age group $(p<0.05)$. Sample sizes can be found in the accompanying table (Table 4). 


\begin{tabular}{|c|c|c|c|c|c|c|}
\hline $\begin{array}{c}\text { Postnatal } \\
\text { Age (Days) }\end{array}$ & $10-14$ & $15-19$ & 20-24 & $25-29$ & $30+$ & $15+$ \\
\hline $\begin{array}{l}\text { Sprague- } \\
\text { Dawley }\end{array}$ & $\begin{array}{c}-49.7 \pm 1.1 \\
\quad(46)\end{array}$ & $\begin{array}{c}-54.2 \pm 1.6 \\
(32)\end{array}$ & $\begin{array}{c}-57.3 \pm \\
1.3 \\
(30)\end{array}$ & $\begin{array}{c}-58.7 \pm \\
1.5 \\
(28)\end{array}$ & $\begin{array}{c}-57.9 \pm 0.8 \\
(86)\end{array}$ & $\begin{array}{c}-57.2 \pm 0.6 \\
(176)\end{array}$ \\
\hline GEPR-NE & $\begin{array}{c}-51.0 \pm 1.9 \\
(15)\end{array}$ & $\begin{array}{c}-55.4 \pm 2.2 \\
\quad(13)\end{array}$ & $\begin{array}{c}-58.0 \pm \\
2.2 \\
(10)\end{array}$ & $\begin{array}{c}-58.8 \pm \\
1.7 \\
(11)\end{array}$ & $\begin{array}{c}-57.7 \pm 2.1 \\
(8)\end{array}$ & $\begin{array}{c}-57.3 \pm 1.0 \\
(42)\end{array}$ \\
\hline GEPR-3 & $\begin{array}{c}-50.1 \pm 1.4 \\
\quad(12)\end{array}$ & $\begin{array}{c}-54.9 \pm 1.6 \\
(13)\end{array}$ & $\begin{array}{c}-59.1 \pm \\
1.8 \\
(10)\end{array}$ & $\begin{array}{c}-57.4 \pm \\
2.8 \\
(6)\end{array}$ & $\begin{array}{c}-57.0 \pm 3.0 \\
\text { (3) }\end{array}$ & $\begin{array}{c}-56.9 \pm 1.1 \\
(32)\end{array}$ \\
\hline GEPR-9 & $\begin{array}{c}-48.9 \pm 1.4 \\
\quad(22)\end{array}$ & $\begin{array}{c}-53.9 \pm 1.7 \\
(20)\end{array}$ & $\begin{array}{c}-56.8 \pm \\
1.4 \\
(24)\end{array}$ & $\begin{array}{c}-58.1 \pm \\
1.8 \\
(18)\end{array}$ & $\begin{array}{c}-57.0 \pm 0.9 \\
(64)\end{array}$ & $\begin{array}{c}-56.6 \pm 0.6 \\
(126)\end{array}$ \\
\hline
\end{tabular}

TABLE 4. Resting membrane potential $(\mathrm{mV})$ of Purkinje neurons in cerebellar slices from Sprague-Dawley, GEPR-NE, GEPR-3, and GEPR-9 rats at various postnatal ages. Data are presented as mean \pm S.E.M. Number in parentheses indicates the number of cells averaged. See text for comparison of mean values. 


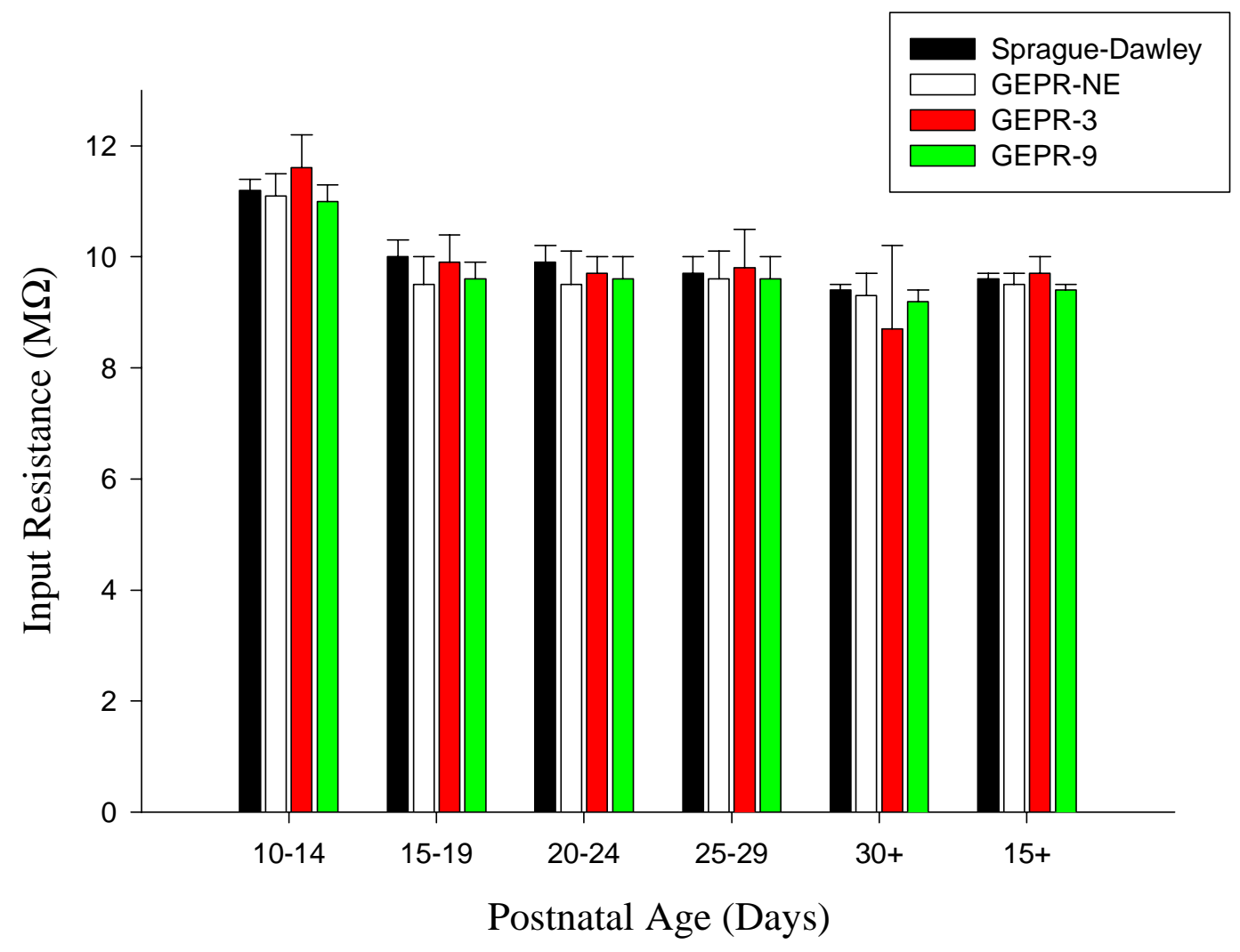

FIGURE 11. Bar graph comparing the input resistance of Purkinje neurons in cerebellar slices from Sprague-Dawley, GEPR-NE, GEPR-3, and GEPR-9 rats measured using intracellular recording techniques. Values are plotted as mean \pm S.E.M. There were no significant differences among the animal strains for any age group $(\mathrm{p}<0.05)$. Sample sizes can be found in the accompanying table (Table 5). 


\begin{tabular}{|l|c|c|c|c|c|c|}
\hline $\begin{array}{c}\text { Postnatal Age } \\
\text { (Days) }\end{array}$ & $\mathbf{1 0 - 1 4}$ & $\mathbf{1 5 - 1 9}$ & $\mathbf{2 0 - 2 4}$ & $\mathbf{2 5 - 2 9}$ & $\mathbf{3 0 +}$ & $\mathbf{1 5 +}$ \\
\hline $\begin{array}{l}\text { Sprague- } \\
\text { Dawley }\end{array}$ & $\begin{array}{c}11.2 \pm 0.2 \\
(46)\end{array}$ & $\begin{array}{c}10.0 \pm 0.3 \\
(32)\end{array}$ & $\begin{array}{c}9.9 \pm 0.3 \\
(30)\end{array}$ & $\begin{array}{c}9.7 \pm 0.3 \\
(28)\end{array}$ & $\begin{array}{c}9.4 \pm 0.1 \\
(86)\end{array}$ & $\begin{array}{c}9.6 \pm 0.1 \\
(176)\end{array}$ \\
\hline GEPR-NE & $\begin{array}{c}11.1 \pm 0.4 \\
(15)\end{array}$ & $\begin{array}{c}9.5 \pm 0.5 \\
(13)\end{array}$ & $\begin{array}{c}9.5 \pm 0.6 \\
(10)\end{array}$ & $\begin{array}{c}9.6 \pm 0.5 \\
(11)\end{array}$ & $\begin{array}{c}9.3 \pm 0.4 \\
(8)\end{array}$ & $\begin{array}{c}9.5 \pm 0.2 \\
(42)\end{array}$ \\
\hline GEPR-3 & $\begin{array}{c}11.6 \pm 0.6 \\
(12)\end{array}$ & $\begin{array}{c}9.9 \pm 0.5 \\
(13)\end{array}$ & $\begin{array}{c}9.7 \pm 0.3 \\
(10)\end{array}$ & $\begin{array}{c}9.8 \pm 0.7 \\
(6)\end{array}$ & $\begin{array}{c}8.7 \pm 1.5 \\
(3)\end{array}$ & $\begin{array}{c}9.7 \pm 0.3 \\
(32)\end{array}$ \\
\hline GEPR-9 & $\begin{array}{c}11.0 \pm 0.3 \\
(22)\end{array}$ & $\begin{array}{c}9.6 \pm 0.3 \\
(20)\end{array}$ & $\begin{array}{c}9.6 \pm 0.4 \\
(24)\end{array}$ & $\begin{array}{c}9.6 \pm 0.4 \\
(18)\end{array}$ & $\begin{array}{c}9.2 \pm 0.2 \\
(64)\end{array}$ & $\begin{array}{c}9.4 \pm 0.1 \\
(126)\end{array}$ \\
\hline
\end{tabular}

TABLE 5. Input resistance ( $\mathrm{M} \Omega$ ) of Purkinje neurons in cerebellar slices from Sprague-Dawley, GEPR-NE, GEPR-3, and GEPR-9 rats at various postnatal ages. Data are presented as mean \pm S.E.M. Number in parentheses indicates the number of cells averaged. See text for comparison of mean values. 


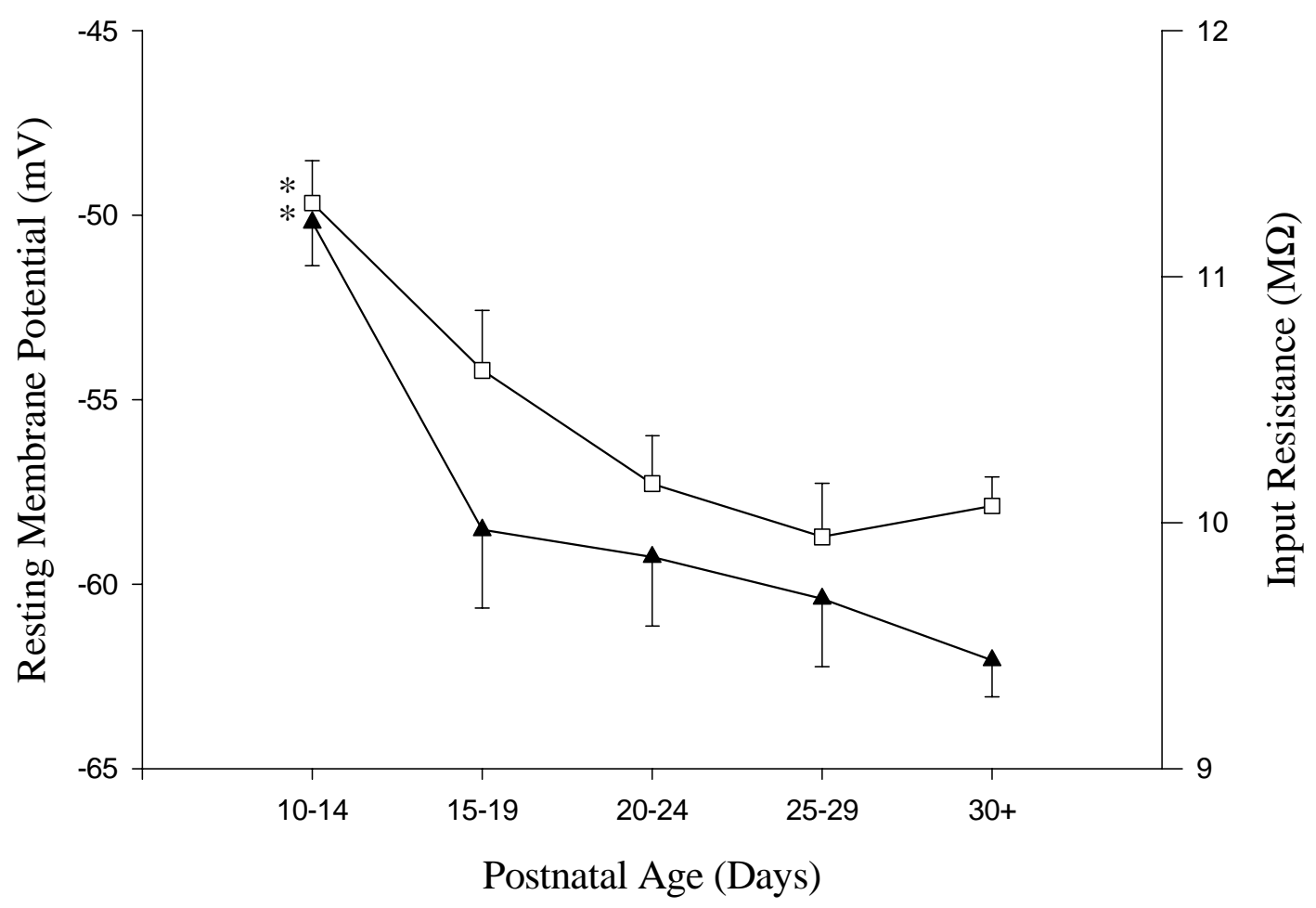

FIGURE 12. Plots of the resting membrane potential $(\square)$ and input resistance ( $\Delta$ ) for Purkinje neurons in cerebellar slices from Sprague-Dawley rats at various postnatal ages as determined using intracellular recording techniques. Means are plotted \pm S.E.M. Both the mean resting membrane potential and input resistance of Purkinje neurons from animals 10-14 days postnatal are significantly different from all other age groups as indicated by the asteriks $(*)$. Sample size for both plots are (number of cells): P10-14 (46); P15-19 (32); P20-24 (30); P25-29 (28); P30+ (86). 
between P10-14 and P15-19. Curves constructed for the other animal strains (not shown) display similar characteristics.

\section{B. The Effects of Ouabain in Sprague-Dawley Rats}

Although, as expected, there were no differences in the basic electrical membrane properties between animal strains (see above), the developmental hyperpolarization of the Purkinje neuron membrane was of interest, especially since it coincided with the period of time when the GEPRs become seizure prone (see section IIB). In an attempt to better understand the nature of this hyperpolarization, the effects of ouabain on the membrane characteristics of Purkinje neurons in slices of the Sprague-Dawley cerebellum were examined for various age groups. Ouabain inhibits the $\mathrm{Na}^{+}, \mathrm{K}^{+}$-pump, leading to a depolarization of the membrane potential, and, thus, by applying saturating concentrations of ouabain it is possible to estimate the contribution of the pump to RMP (Thomas, 1972; Urquilla et al., 1978). The role of the $\mathrm{Na}^{+}, \mathrm{K}^{+}$-pump was the focus of these investigations due to the critical role which it plays in determining resting membrane potential (see section I).

In these experiments, ouabain $(1 \mathrm{mM})$ was applied to Sprague-Dawley Purkinje neurons in cerebellar slices via superfusion and the effects on RMP and IR were measured. An example of the effects of a typical ouabain application is illustrated in Figure 13. Figure 13 presents the membrane response of a Purkinje neuron from a 22 day old Sprague-Dawley rat to $1 \mathrm{mM}$ ouabain showing a depolarization of the membrane potential $(24 \mathrm{mV})$ and a slight decrease in input resistance $(2.1$ $\mathrm{M} \Omega$ ) as determined from the periodic injection of $3 \mathrm{nA}$ current pulses via the recording electrode. As typical of the membrane responses to this concentration of ouabain, this cell did not return to RMP during the course of the experimental observation. 


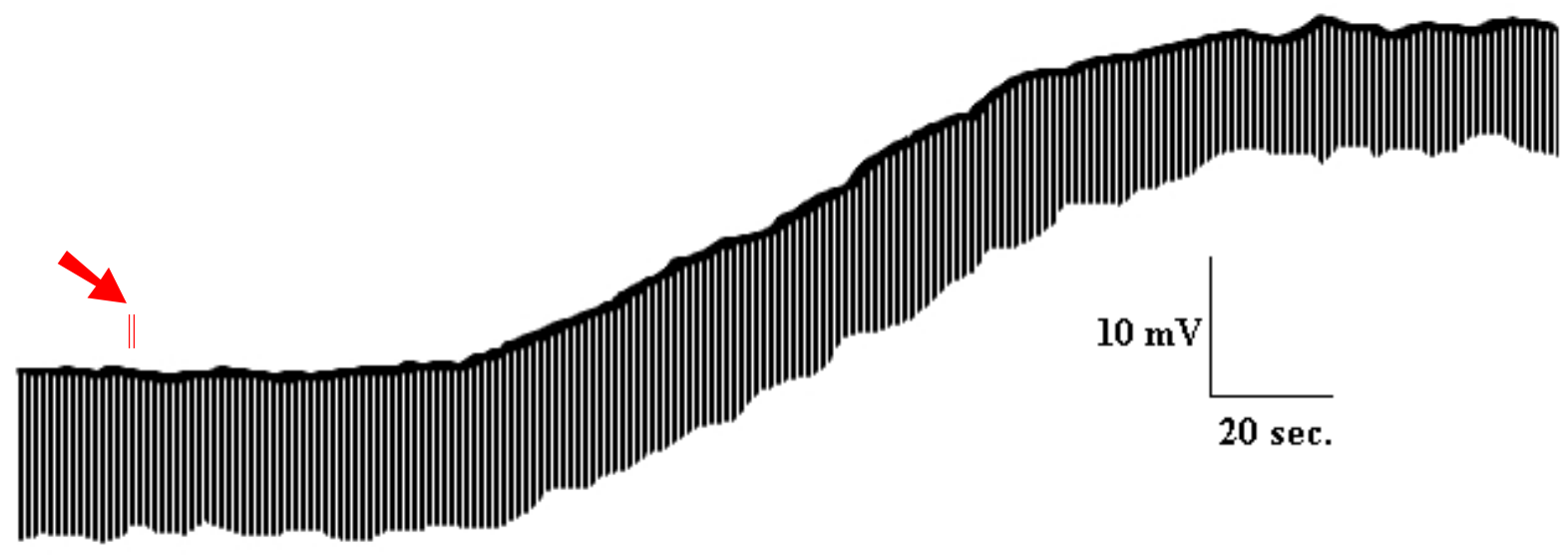

FIGURE 13. A trace of the membrane response of a Purkinje neuron in a cerebellar slice from a P22 Sprague-Dawley rat to ouabain superfusion illustrates the depolarizing effects of ouabain on the membrane potential. Downward traces reflect the membrane response to injected current (3 nA). Arrow indicates the time of addition of ouabain to the superfusion fluid. Due to the long lasting effects of ouabain this cell did not return to resting membrane potential upon removal of ouabain during the course of the experimental observation. 


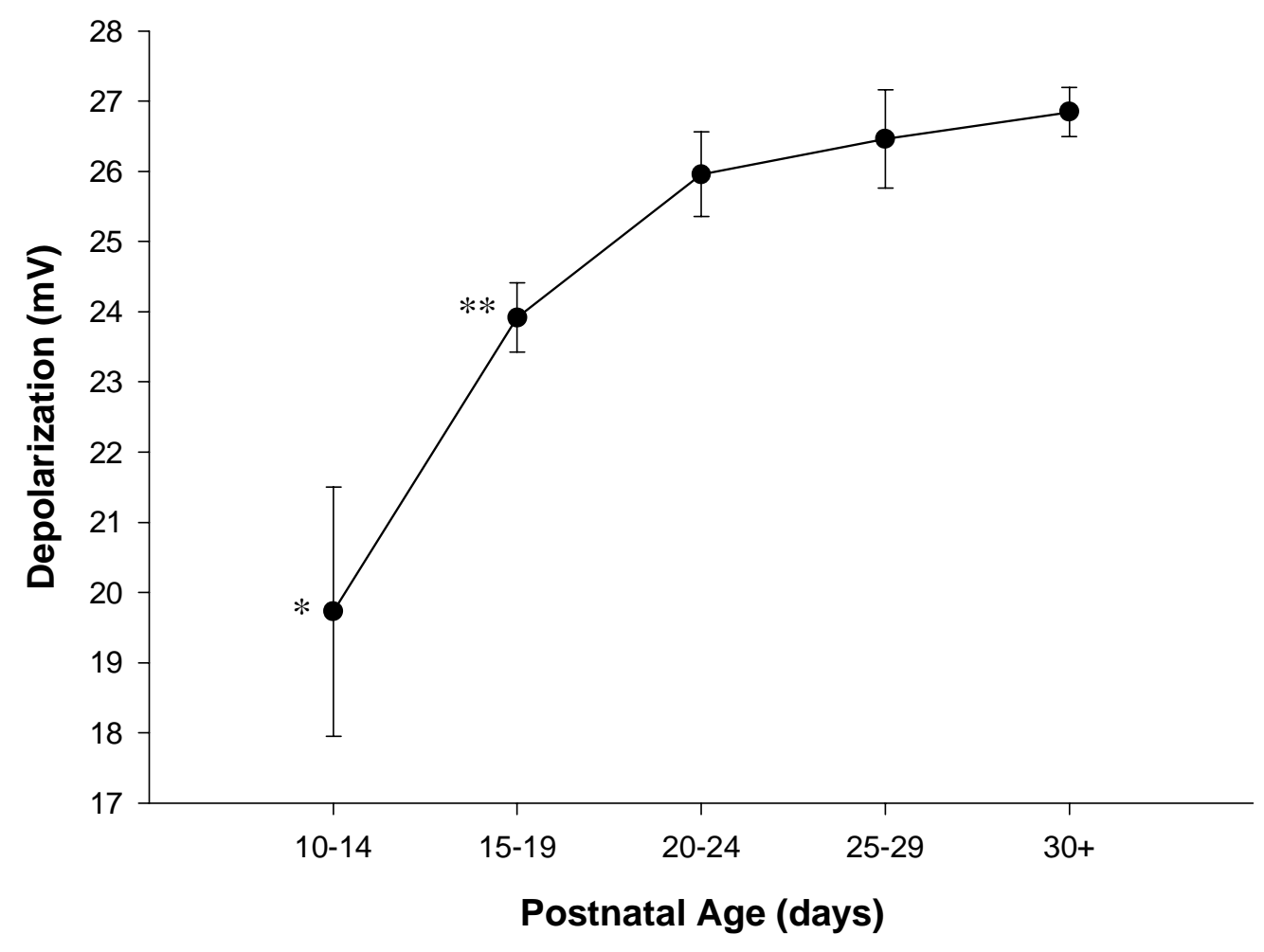

FIGURE 14. Plot of the depolarizing effects of superfusing ouabain $(1 \mathrm{mM})$ on the resting membrane potential of Purkinje neurons in cerebellar slices from Sprague-Dawley rats as determined using intracellular recording techniques. Results are plotted as mean \pm S.E.M. The asterik (*) denotes a significantly reduced depolarizing effect of ouabain compared to all other age groups $(\mathrm{p}<0.005)$. The double-asterik $(* *)$ denotes a significant difference from all other age groups except the 20-24 age group ( $\mathrm{p}<0.005)$. The sample size for each age group are (number of cells): P10-14 (7); P15-19 (9); P20-24 (9); P25-29 (8); P30+ (15). 


\begin{tabular}{|l|c|c|c|c|c|}
\hline \multicolumn{1}{|c|}{ Age (days) } & $\mathbf{1 0 - 1 4}$ & $\mathbf{1 5 - 1 9}$ & $\mathbf{2 0 - 2 4}$ & $\mathbf{2 5 - 2 9}$ & $\mathbf{3 0 +}$ \\
\hline Depolarization $(\mathbf{m V})$ & $19.7 \pm 1.8^{*}$ & $23.9 \pm 0.5^{* *}$ & $26.0 \pm 0.6$ & $26.5 \pm 0.7$ & $26.8 \pm 0.3$ \\
\hline $\begin{array}{l}\text { Final Membrane } \\
\text { Potential }(\mathbf{m V})\end{array}$ & $-29.1 \pm 2.2$ & $-30.5 \pm 3.5$ & $-31.8 \pm 2.7$ & $-31.9 \pm 0.9$ & $-31.4 \pm 1.7$ \\
\hline Sample Size $^{\dagger}$ & $\mathrm{n}=7(4)$ & $\mathrm{n}=9(6)$ & $\mathrm{n}=9(5)$ & $\mathrm{n}=8(5)$ & $\mathrm{n}=15(7)$ \\
\hline
\end{tabular}

TABLE 6. Effects of superfusing ouabain $(1 \mathrm{mM})$ on the resting membrane potential (RMP) of Purkinje neurons in cerebellar slices from Sprague-Dawley rats of various postnatal ages determined using intracellular recording techniques. Means are reported \pm S.E.M. *Denotes significant difference from all other age groups ( $\mathrm{p}<0.005)$. **Denotes significant difference from 10-14, 25-29, and $30+$ age groups $(\mathrm{p}<0.005)$. Indicates number of cells from (number of animals). There were no significant differences between the final membrane potentials after ouabain $(1 \mathrm{mM})$ application $(\mathrm{p}<0.005)$. 
The results of superfusion of $1 \mathrm{mM}$ ouabain onto Purkinje neurons of Sprague-Dawley rats of various ages are presented in Figure 14 and Table 6. Figure 14 presents a plot of the magnitude of the depolarization induced by ouabain superfusion with respect to age. As can be seen, there is a statistically significant increase $(\mathrm{p}<0.005)$ in the magnitude of depolarization with increasing animal age indicating an increase in the contribution of the $\mathrm{Na}^{+}, \mathrm{K}^{+}$-pump to $\mathrm{RMP}$ with development. As noted for Figure 13, the application of ouabain typically led to a slight decrease of the IR of Purkinje neurons (mean $=3.9 \pm 0.9$ ) but there was no statistically significant agedependent effect of ouabain on IR ( $>>0.005)$. Illustrated in Table 6 are the values used to construct Figure 14 (magnitude of ouabain-induced depolarization) as well as the mean final membrane potential of neurons after obtaining maximal depolarization. Interestingly, these final membrane potentials were quite similar irrespective of age and were not significantly different from each other $(\mathrm{p}<0.005)$.

The remaining experiments described below were concerned primarily with the agonist sensitivity of Sprague-Dawley, GEPR-NE, GEPR-3, and GEPR-9 rats. As these studies represent the primary focus of this manuscript, no further experiments were conducted concerning the developmental hyperpolarization of Purkinje neurons. However, due to the possible impact of this hyperpolarization on membrane responses to other agonists, the results described in succeeding sections are divided into those obtained from animals less than 15 days of age (P10-14) and those 15 days of age or older (P15+).

\section{Intracellular Comparison of Sprague-Dawley and GEPR-NE Purkinje Neurons}

For a control group of animals, the studies presented in this manuscript employed normal 
Sprague-Dawley rats. However, there is a genetic control strain of GEPR animals (GEPR-NEs) which were derived from Sprague-Dawley stock. Thus, it was pertinent to compare membrane responses from Sprague-Dawley and GEPR-NE rats to ensure that no differences exist. If, in fact, no differences existed between Sprague-Dawley and GEPR-NE Purkinje neurons, the data obtained from Sprague-Dawley animals could be considered a valid source of control data with which to compare similar data obtained from GEPR-9 and GEPR-3 animals. In addition, similarities between the GEPR-NE and Sprague-Dawley animals would provide further evidence that any changes subsequently observed for seizure-prone animals was a possible contributor to the epileptic nature of these animals. On the other hand, common differences of epileptic (GEPR-3 and GEPR-9) and non-epileptic (GEPR-NE) compared to Sprague-Dawley animals would not likely be involved in seizure predisposition due to the absence of seizure susceptibility in the GEPR-NEs.

In order to compare the GEPR-NE and Sprague-Dawley rats, the membrane responses to various drugs and neurotransmitters were measured using intracellular recording techniques. The first step of these studies was to compare the effects of single concentrations of drug on the membrane potential of Purkinje neurons. The effects of GABA receptor agonists (muscimol, GABA, and baclofen) as well as the $\mathrm{GABA}_{\mathrm{A}}$-receptor antagonist, bicuculline, on the membrane potential are presented in Table 7 for P10-14 and P15+ animals. Both GABA $(10 \mu \mathrm{M})$ and the $\mathrm{GABA}_{\mathrm{A}}$-selective agonist, muscimol $(1 \mu \mathrm{M})$, induced prominent hyperpolarizations of the Purkinje neuron membrane which were not statistically different between animals for either age group $(\mathrm{p}<0.05)$. Furthermore, these hyperpolarizations were antagonized by bicuculline $(30 \mu \mathrm{M})$, which had no effect on the membrane potential when given alone. Baclofen, a $\mathrm{GABA}_{\mathrm{B}}$-receptor agonist, also had very little effect on the membrane potential at a concentration of $10 \mu \mathrm{M}$. 


\begin{tabular}{|c|c|c|c|c|}
\hline & $\begin{array}{l}\text { Sprague-Dawley } \\
(\mathrm{P} 10-14)^{\infty}\end{array}$ & $\begin{array}{l}\text { GEPR-NE } \\
\text { (P10-14) }\end{array}$ & $\begin{array}{l}\text { Sprague-Dawley } \\
(\mathrm{P} 15+)^{\nabla}\end{array}$ & $\begin{array}{c}\text { GEPR-NE } \\
(\mathrm{P} 15+)\end{array}$ \\
\hline Muscimol $(1 \mu \mathrm{M})^{\S}$ & $\begin{array}{l}-11.3 \pm 0.4 \\
(17)^{+}\end{array}$ & $\begin{array}{c}-10.8 \pm 0.6 \\
(6)\end{array}$ & $\begin{array}{c}-11.6 \pm 0.2 \\
\quad(78)\end{array}$ & $\begin{array}{c}-11.3 \pm 0.3 \\
(8)\end{array}$ \\
\hline $\begin{array}{l}\text { Muscimol }(1 \mu \mathrm{M})+ \\
\text { Bicuculline }(10 \mu \mathrm{M})\end{array}$ & $\begin{array}{l}-0.3 \pm .2 \\
\quad(3)\end{array}$ & $\begin{array}{l}0.5 \pm 0.6 \\
\quad(6)\end{array}$ & $\begin{array}{c}-0.1 \pm 0.3 \\
(9)\end{array}$ & $\begin{array}{c}-0.1 \pm 0.5 \\
(6)\end{array}$ \\
\hline GABA $(10 \mu \mathrm{M})^{\S}$ & $\begin{array}{c}-11.7 \pm 0.7 \\
(5)\end{array}$ & $\begin{array}{c}-10.3 \pm 0.7 \\
(6)\end{array}$ & $\begin{array}{l}-11.1 \pm 0.2 \\
\quad(14)\end{array}$ & $\begin{array}{c}-11.6 \pm 0.3 \\
\quad(12)\end{array}$ \\
\hline $\begin{array}{c}\text { GABA }(10 \mu \mathrm{M})+ \\
\text { Bicuculline }(10 \mu \mathrm{M})\end{array}$ & $\begin{array}{c}-0.1 \pm 1.1 \\
\text { (3) }\end{array}$ & $\begin{array}{l}0.7 \pm 0.5 \\
\quad(5)\end{array}$ & $\begin{array}{l}-1.2 \pm 0.3 \\
\text { (4) }\end{array}$ & $\begin{array}{l}0.8 \pm 0.4 \\
\quad(8)\end{array}$ \\
\hline Bicuculline $(30 \mu \mathrm{M})$ & $\begin{array}{l}0.6 \pm 0.4 \\
\quad(3)\end{array}$ & $\begin{array}{c}0.1 \pm 0.5 \\
\quad(4)\end{array}$ & $\begin{array}{c}1.0 \pm 0.5 \\
(6)\end{array}$ & $\begin{array}{c}-0.1 \pm 0.5 \\
(6)\end{array}$ \\
\hline Baclofen $(10 \mu \mathrm{M})$ & $\begin{array}{c}-1.6 \pm 0.2 \\
\text { (3) }\end{array}$ & $\begin{array}{c}-0.3 \pm 0.6 \\
(6)\end{array}$ & $\begin{array}{c}-0.9 \pm 0.2 \\
(6)\end{array}$ & $\begin{array}{c}1.0 \pm 0.4 \\
(6)\end{array}$ \\
\hline
\end{tabular}

TABLE 7. Changes in membrane potential of Purkinje neurons in vermal cerebellar slices from Sprague-Dawley and GEPR-NE rats induced by various GABA-receptor agonists and antagonists as determined using intracellular recording techniques. ${ }^{\S}$ Indicates that only hyperpolarizing responses to these $\mathrm{GABA}_{\mathrm{A}}$-receptor agonists were included in the mean values. Means are reported \pm S.E.M. There were no significant differences between the responses for a given drug (or combination of drugs) for identical age groups between the two animal strains ( $\mathrm{p}<0.05)$. ${ }^{+}$Indicates sample size (number of cells). ${ }^{\infty}$ Indicates that the group includes only Purkinje neurons from animals between the ages of 10 and 14 days postnatal. ${ }^{\nabla}$ Indicates that the group includes only Purkinje neurons from animals 15 days postnatal or older. 
As noted in the legend to Table 7, the mean effects for GABA and muscimol on the membrane potential presented reflect only hyperpolarizing responses which were obtained. An unexpected outcome of these experiments was occasional depolarizing effects of these agonists when applied to Purkinje neurons from animals less than 15 days of age. These depolarizations, which were quite variable in amplitude, occurred for six Sprague-Dawley and three GEPR-NE Purkinje neurons and led to mean depolarizations of $6.0 \pm 1.1 \mathrm{mV}$ and $4.6 \pm 1.6 \mathrm{mV}$, respectively, when both GABA and muscimol responses are pooled. Since both the mean ampltitude and relative occurrence (21\% of Sprague-Dawley and $23 \%$ of GEPR-NE Purkinje neurons) of these depolarizations were similar between animals, they were not investigated further.

Table 8 presents the mean membrane depolarizing effects of the excitatory neurotransmitters, glutamate and aspartate, at a concentration of $10 \mu \mathrm{M}$ in young (P10-14) and old (P15+) animals determined using intracellular recording techniques. As for the GABA receptor ligands, there were no significant differences between the two animal strains for either age group in response to these depolarizing agonists $(\mathrm{p}<0.05)$. The Purkinje neurons from younger animals responded differently from those obtained from older animals in both rat strains. In the case of aspartate and glutamate this was in the form of a slight but significant increase in the depolarizing effect of these agonists in the older animals $(\mathrm{p}<0.05)$.

The next step in comparing the Sprague-Dawley and GEPR-NE animals was to determine concentration-response curves to agonists of the major neurotransmitter receptors for Purkinje neurons from animals 15 days and older (P15+). Concentration-response curves were constructed by superfusing single, increasing concentrations of drug while allowing recovery to RMP between applications as described in the methods (section VI). The responses to each of these agonists are 


\begin{tabular}{|c|c|c|c|c|}
\hline & $\begin{array}{c}\text { Sprague-Dawley } \\
(\mathrm{P} 10-14)^{\infty}\end{array}$ & $\begin{array}{c}\text { GEPR-NE } \\
(\mathrm{P} 10-14)\end{array}$ & $\begin{array}{c}\text { Sprague-Dawley } \\
(\mathrm{P} 15+)^{\nabla}\end{array}$ & $\begin{array}{c}\text { GEPR-NE } \\
(\mathrm{P} 15+)\end{array}$ \\
\hline Glutamate $(10 \mu \mathrm{M})$ & $\begin{array}{c}12.8 \pm 0.3 \\
(7)^{+}\end{array}$ & $\begin{array}{c}12.9 \pm 0.6 \\
(5)\end{array}$ & $\begin{array}{c}16.7 \pm 0.2 \\
(9)\end{array}$ & $\begin{array}{c}16.3 \pm 0.3 \\
(8)\end{array}$ \\
\hline Aspartate $(10 \mu \mathrm{M})$ & $\begin{array}{c}10.8 \pm 0.4 \\
(4)\end{array}$ & $\begin{array}{c}11.6 \pm 0.6 \\
(5)\end{array}$ & $\begin{array}{c}13.6 \pm 0.2 \\
(9)\end{array}$ & $\begin{array}{c}13.2 \pm 0.4 \\
(7)\end{array}$ \\
\hline
\end{tabular}

TABLE 8. Changes in membrane potential of Purkinje neurons in vermal cerebellar slices from Sprague-Dawley and GEPR-NE rats induced by excitatory agonists as determined using intracellular recording techniques. Means are reported \pm S.E.M. There were no significant differences between the responses for either agonist for identical age groups between the two animal strains $(p<0.05)$. ${ }^{+}$Indicates the sample size (number of cells). ${ }^{\infty}$ Indicates that the group includes only Purkinje neurons from animals between the ages of 10 and 14 days postnatal. ${ }^{7}$ Indicates that the group includes only Purkinje neurons from animals 15 days postnatal or older. 
relatively rapid and, thus, drug application time was typically one minute or less. Full concentration-response curves to GABA, muscimol, glutamate, and aspartate are depicted in Figures 15 through 18 . In each case, the membrane response (hyperpolarization for GABA and muscimol; depolarization for glutamate and aspartate) was normalized to the maximum response obtained with Sprague-Dawley Purkinje neurons, such that differences in maximal responses would still be evident by examining the concentration-response curve. Curves were fit by non-linear regression analysis using SigmaPlot software (Jandel Scientific), and the subsequent best fit estimations of $\mathrm{EC}_{50}$ values are reported.

Figure 15 is the concentration-response curve generated from the superfusion of GABA at various concentrations $(0.1-300 \mu \mathrm{M})$. Maximal hyperpolarizing responses, of approximately $15 \mathrm{mV}$ in magnitude, were similar for both Sprague-Dawley and GEPR-NE rats. The geometric mean $\mathrm{EC}_{50}$ values for Sprague-Dawley and GEPR-NE Purkinje neurons were $6.6 \pm 0.7 \mu \mathrm{M}$ and $6.1 \pm 0.6 \mu \mathrm{M}$, respectively. Likewise, the concentration-response curves to muscimol superfusion (Figure 16) yielded similar curves for both Sprague-Dawley and GEPR-NE animals, with $\mathrm{EC}_{50}$ values of 0.61 $\pm 0.05 \mu \mathrm{M}$ and $0.70 \pm 0.05 \mu \mathrm{M}$, respectively, and maximal hyperpolarizations of approximately 15 $\mathrm{mV}$ in magnitude.

Concentration-response curves for the excitatory neurotransmitters, glutamate and aspartate, are depicted in Figures 17 and 18, respectively. Again, a high degree of similarity between the curves for Purkinje neurons from both animal strains is evident. For both GEPR-NE and SpragueDawley rats, glutamate and aspartate induced maximal depolarizations of approximately $17-18 \mathrm{mV}$, with glutamate doing so at a slightly lower concentration. Glutamate $\mathrm{EC}_{50}$ values were $3.3 \pm 0.3$ $\mu \mathrm{M}$ and $3.0 \pm 0.2 \mu \mathrm{M}$, whereas aspartate $\mathrm{EC}_{50}$ values were $6.3 \pm 0.6 \mu \mathrm{M}$ and $7.2 \pm 0.6 \mu \mathrm{M}$ for 


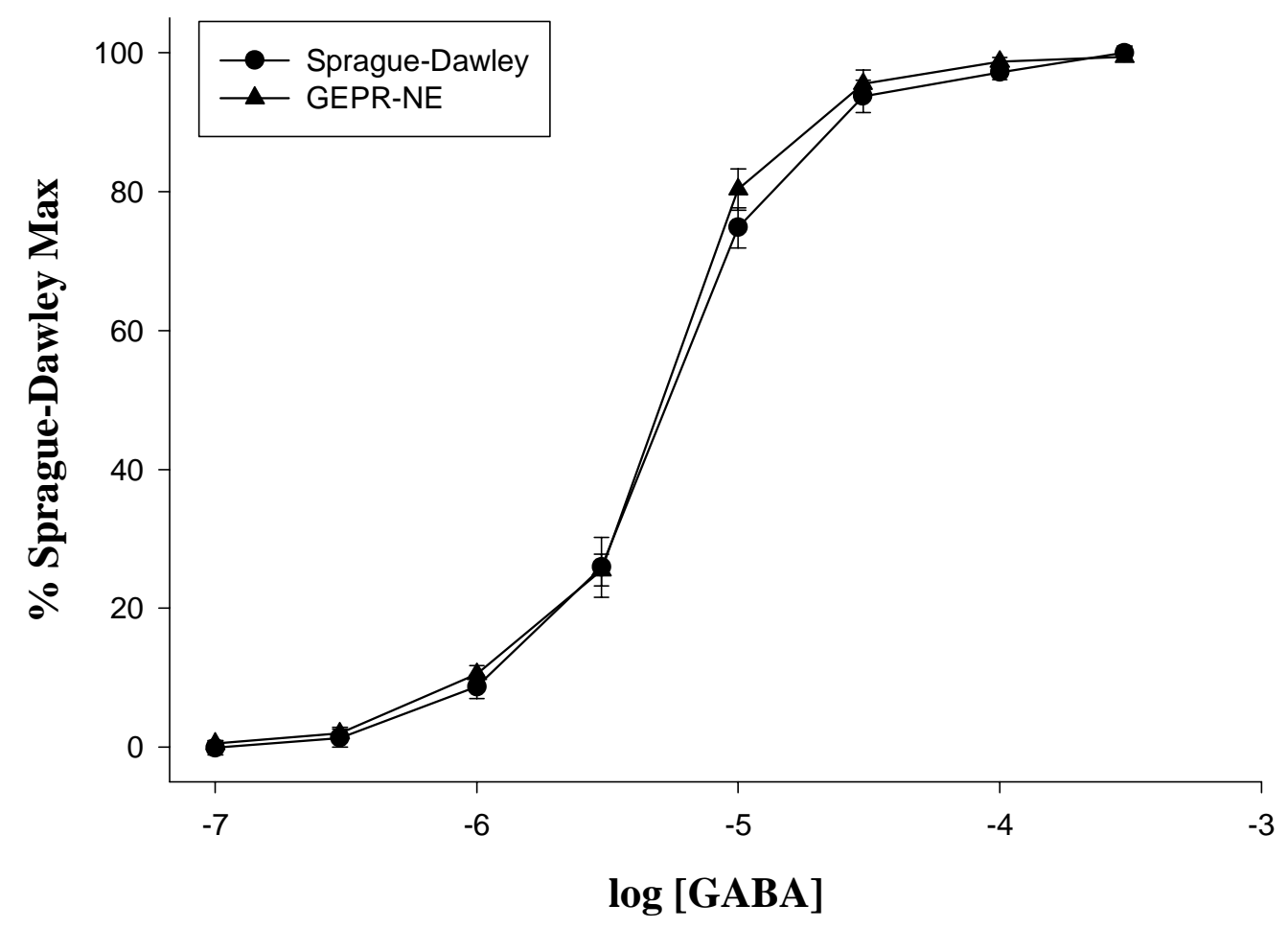

FIGURE 15. Concentration-response curves of Purkinje neurons to superfusion of GABA. Hyperpolarizing responses are normalized to the percent of the maximal Sprague-Dawley Purkinje neuron response. There were no statistically significant differences in the estimated geometric mean $\mathrm{EC}_{50}$ (see text) or maximal hyperpolarization for Purkinje neurons from Sprague-Dawley and GEPRNE rats $(\mathrm{p}>0.05)$. Data are presented as mean \pm S.E.M. 


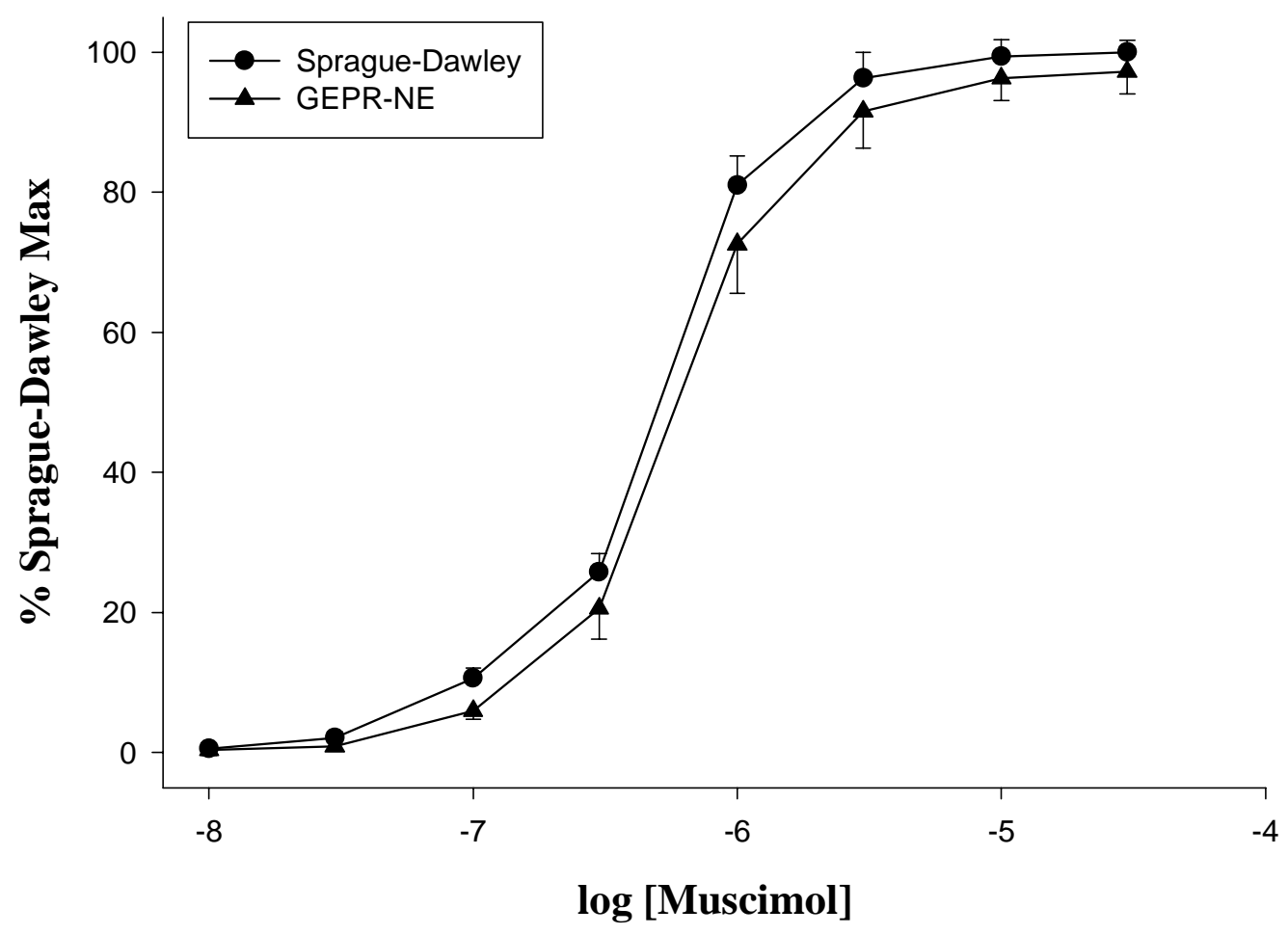

FIGURE 16. Concentration-response curves of Purkinje neurons to superfusion of muscimol. Hyperpolarizing responses are normalized to the percent of the maximal Sprague-Dawley Purkinje neuron response. There were no statistically significant differences in the estimated geometric mean $\mathrm{EC}_{50}$ (see text) or maximal hyperpolarization for Purkinje neurons from Sprague-Dawley and GEPRNE rats $(\mathrm{p}>0.05)$. Data are presented as mean \pm S.E.M. 


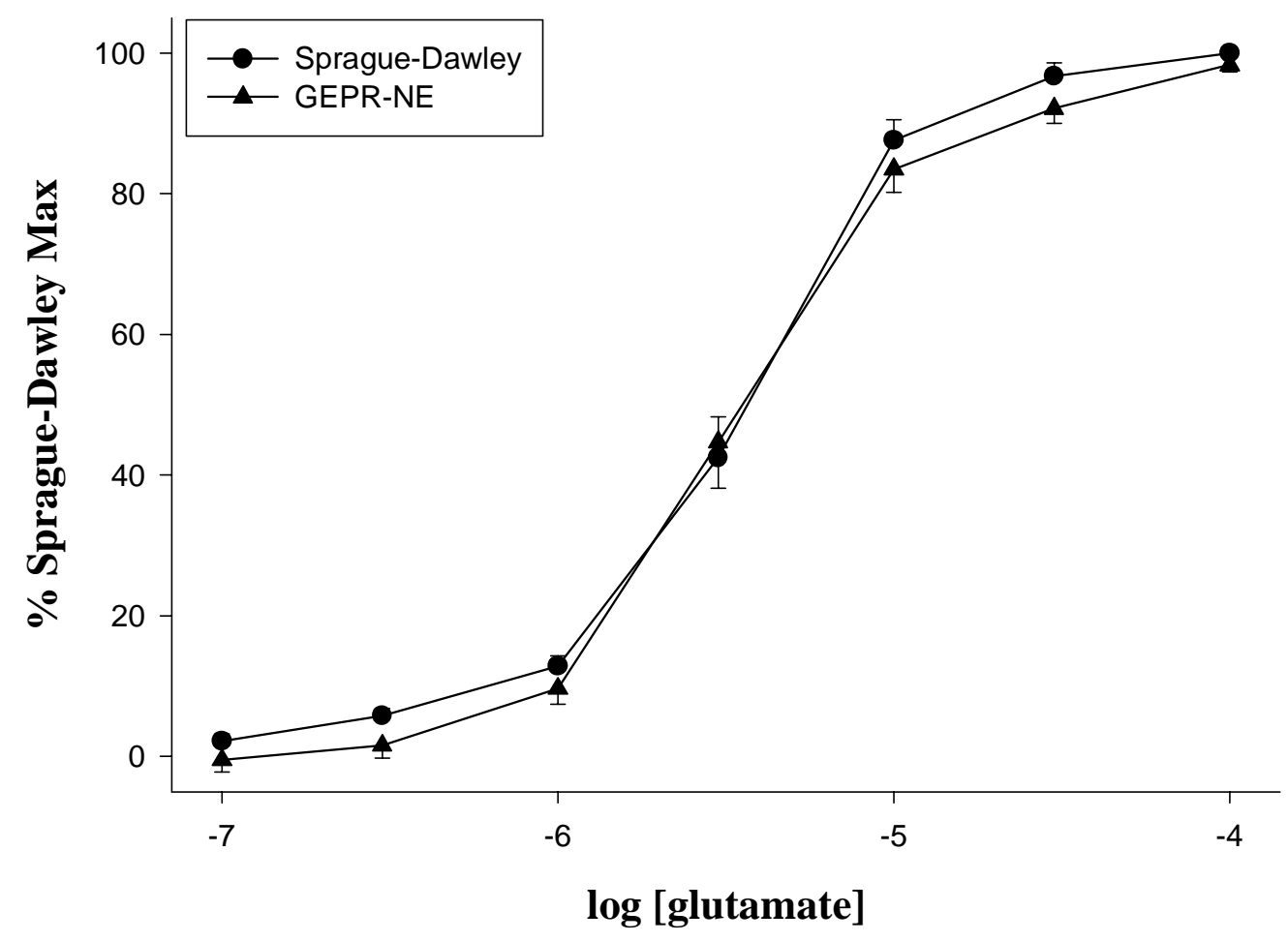

FIGURE 17. Concentration-response curves of Purkinje neurons to superfusion of glutamate. Depolarizing responses are normalized to the percent of the maximal Sprague-Dawley Purkinje neuron response. There were no statistically significant differences in the estimated geometric mean $\mathrm{EC}_{50}($ see text) or maximal depolarization for Purkinje neurons from Sprague-Dawley and GEPR-NE rats $(\mathrm{p}>0.05)$. Data are presented as mean \pm S.E.M. 


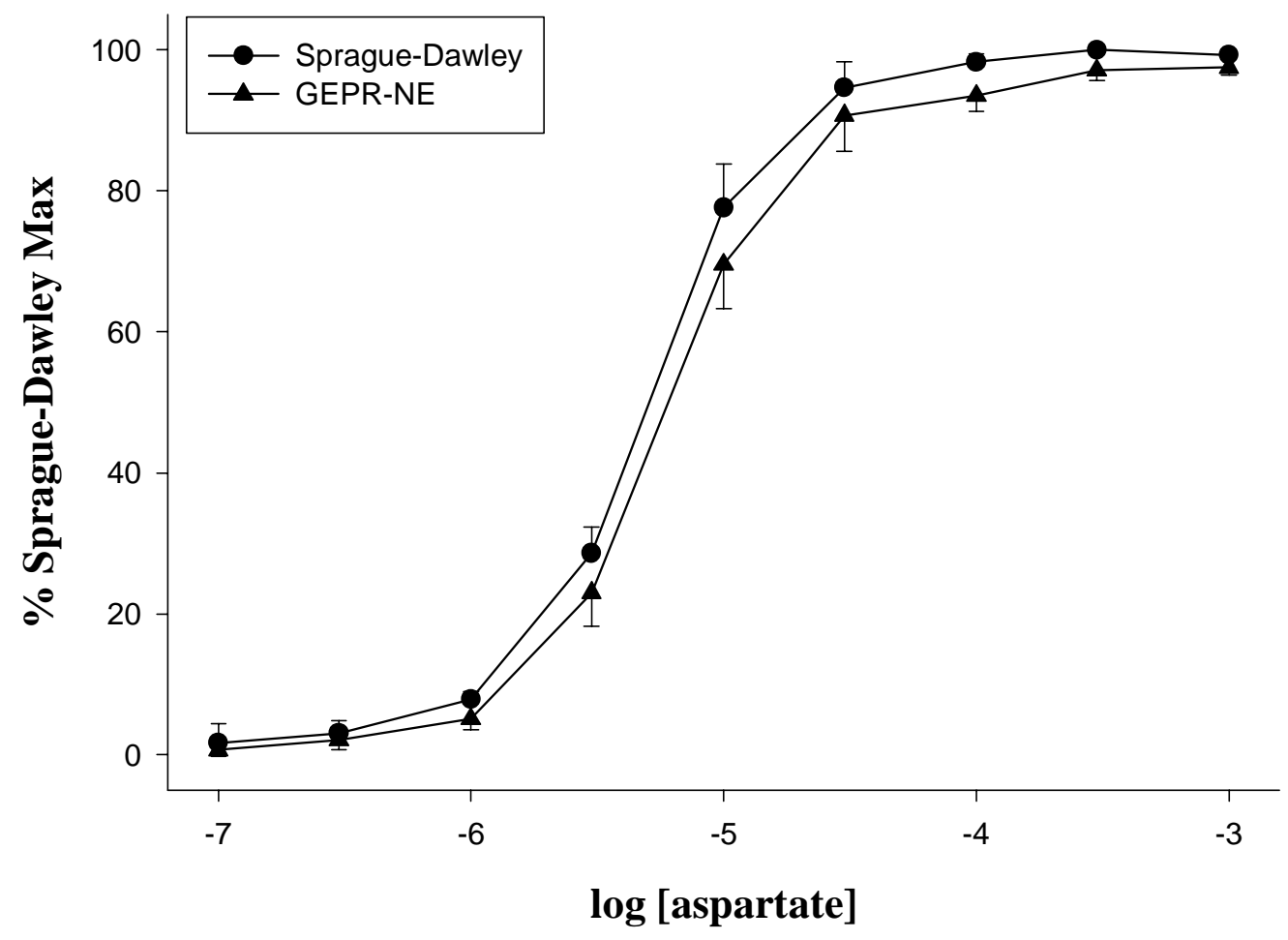

FIGURE 18. Concentration-response curves of Purkinje neurons to superfusion of aspartate. Depolarizing responses are normalized to the percent of the maximal Sprague-Dawley Purkinje neuron response. There were no statistically significant differences in the estimated geometric mean $\mathrm{EC}_{50}$ (see text) or maximal depolarization for Purkinje neurons from Sprague-Dawley and GEPR-NE rats $(\mathrm{p}>0.05)$. Data are presented as mean \pm S.E.M. 
Sprague-Dawley and GEPR-NE Purkinje neurons, respectively.

\section{Intracellular Comparison of Sprague-Dawley and GEPR-9 Purkinje Neurons}

Having found no differences in agonist responsiveness between the genetically-epilepsy prone rat control strain (GEPR-NE) and Sprague-Dawley rats, the next group of experiments to be performed was a comparison of GEPR-9 rats, the most severely seizure-prone strain, to SpragueDawley rats in order to determine if the subsensitivity to $\mathrm{GABA}_{\mathrm{A}}$-receptor activation observed in situ (Gould, 1991, 1995) was demonstrable in the in vitro model employed in the present studies and, if so, to determine the degree of this subsensitivity. In addition, further clues as to the mechanism of the decreased responsiveness were also sought. To accomplish these tasks, experiments similar to those just described above were employed utilizing intracellular recording techniques in vermal cerbellar slices of Sprague-Dawley and GEPR-9 rats. It should be noted that the data provided for neurons in the Sprague-Dawley strain presented in this section are the same data as those presented in the previous section for comparisons to the GEPR-NE.

The initial experiments performed examined the effect of single concentrations of various drugs and neurotransmitters on the membrane polarization of Purkinje neurons in cerebellar slices. The effects of various GABA receptor agonists (GABA, muscimol, and baclofen) and antagonists (bicuculline and picrotoxin) on Purkinje neurons from P10-14 and P15+ Sprague-Dawley and GEPR-9 rats are listed in Table 9. In response to both $1 \mu \mathrm{M}$ muscimol and $10 \mu \mathrm{M}$ GABA, Purkinje neurons from GEPR-9 rats displayed a significantly reduced hyperpolarization, irrespective of age $(p<0.05)$. The effects of both agonists were blocked by either bicuculline $(30 \mu \mathrm{M})$ and/or picrotoxin $(10 \mu \mathrm{M})$ indicating that GABA and muscimol were exerting their effects via $\mathrm{GABA}_{\mathrm{A}}$-receptor activation. In addition, bicuculline $(30 \mu \mathrm{M})$ was without significant effect when superfused alone. 


\begin{tabular}{|c|c|c|c|c|}
\hline & $\begin{array}{c}\text { Sprague-Dawley } \\
(\mathrm{P} 10-14)^{\infty}\end{array}$ & $\begin{array}{c}\text { GEPR-9 } \\
(\mathrm{P} 10-14)\end{array}$ & $\begin{array}{c}\text { Sprague-Dawley } \\
(\mathrm{P} 15+)^{\nabla}\end{array}$ & $\begin{array}{c}\text { GEPR-9 } \\
(\mathrm{P} 15+)\end{array}$ \\
\hline Muscimol $(1 \mu \mathrm{M})^{\S}$ & $\begin{array}{c}-11.3 \pm 0.4^{*} \\
(17)^{+}\end{array}$ & $\begin{array}{c}-5.0 \pm 0 . *^{*} \\
(11)\end{array}$ & $\begin{array}{c}-11.6 \pm 0.2^{* *} \\
(78)\end{array}$ & $\begin{array}{c}-5.2 \pm 0.2^{* *} \\
(69)\end{array}$ \\
\hline $\begin{array}{c}\text { Muscimol }(1 \mu \mathrm{M})+ \\
\text { Bicuculline }(10 \mu \mathrm{M})\end{array}$ & $\begin{array}{c}-0.3 \pm .2 \\
(3)\end{array}$ & $\begin{array}{c}0.2 \pm 0.3 \\
(3)\end{array}$ & $\begin{array}{c}-0.1 \pm 0.3 \\
(9)\end{array}$ & $\begin{array}{c}0.1 \pm 0.2 \\
(7)\end{array}$ \\
\hline GABA $(10 \mu \mathrm{M})^{\S}$ & $\begin{array}{c}-11.7 \pm 0.7 * \\
(5)\end{array}$ & $\begin{array}{c}-3.7 \pm 0.4^{*} \\
(7)\end{array}$ & $\begin{array}{c}-11.1 \pm 0.2^{* *} \\
(14)\end{array}$ & $\begin{array}{c}-4.8 \pm 0.2 * * \\
(12)\end{array}$ \\
\hline GABA $(10 \mu \mathrm{M})+$ & $-0.1 \pm 1.1$ & $0.1 \pm 0.7$ & $-1.2 \pm 0.3$ & $(4)$ \\
Bicuculline $(10 \mu \mathrm{M})$ & $(3)$ & $\begin{array}{c}-0.2 \pm 0.3 \\
(5)\end{array}$ \\
\hline $\begin{array}{c}\text { GABA }(10 \mu \mathrm{M})+ \\
\text { Picrotoxin }(10 \mu \mathrm{M})\end{array}$ & $\begin{array}{c}0.3 \pm 0.3 \\
(3)\end{array}$ & $\begin{array}{c}0.9 \pm 0.4 \\
(4)\end{array}$ & $\begin{array}{c}1.3 \pm 0.5 \\
(3)\end{array}$ & $\begin{array}{c}-0.1 \pm 0.2 \\
(5)\end{array}$ \\
\hline Bicuculline $(30 \mu \mathrm{M})$ & $\begin{array}{c}0.6 \pm 0.4 \\
(3)\end{array}$ & $\begin{array}{c}-0.7 \pm 0.3 \\
(4)\end{array}$ & $\begin{array}{c}1.0 \pm 0.5 \\
(6)\end{array}$ & $\begin{array}{c}0.2 \pm 0.2 \\
(8)\end{array}$ \\
\hline Baclofen $(10 \mu \mathrm{M})$ & $-1.6 \pm 0.2^{*}$ & $1.3 \pm 0.2^{*}$ & $-0.9 \pm 0.2$ & $0.3 \pm 0.2$ \\
$(3)$ & $(4)$ & $(6)$ & $(11)$ \\
\hline
\end{tabular}

TABLE 9. Changes in membrane potential of Purkinje neurons in vermal cerebellar slices from Sprague-Dawley and GEPR-9 rats induced by various GABA-receptor agonists and antagonists as determined using intracellular recording techniques. ${ }^{\S}$ Indicates that only hyperpolarizing responses to these $\mathrm{GABA}_{\mathrm{A}}$-receptor agonists were included in the mean values. Means are reported \pm S.E.M. *Denotes a significantly different response between the two animal strains for the indicated agonist during the 10-14 day postnatal age period ( $\mathrm{p}<0.05)$. ${ }^{*}$ Denotes a significantly different response between the two animal strains for the indicated agonist during the 15 day and older postnal age period $(\mathrm{p}<0.05)$. ${ }^{+}$Indicates sample size (number of cells). ${ }^{\infty}$ Indicates that the group includes only Purkinje neurons from animals between the ages of 10 and 14 days postnatal. ${ }^{\nabla}$ Indicates that the group includes only Purkinje neurons from animals 15 days postnatal or older. 
Baclofen $(10 \mu \mathrm{M}), \mathrm{GABA}_{\mathrm{B}}$-selective agonist, had minimal effects on Purkinje neurons from either animal strain. Though minimal, these effects were significantly different for animals 10-14 days of age (P10-14), inducing a slight hyperpolarization in Sprague-Dawley Purkinje neurons and a slight net depolarization in GEPR-9 Purkinje neurons.

As stated when comparing Sprague-Dawley and GEPR-NE Purkinje neurons, this table only includes hyperpolarizing responses to muscimol and GABA for animals in the P10-14 age group. Again, the depolarizing responses in the young animals were not further investigated as they were a minority of the neurons investigated (21\% for Sprague-Dawley, $31 \%$ for GEPR-9). However, it should be noted that the depolarizing responses to muscimol in P10-14 animals were significantly decreased for GEPR-9 Purkinje neurons compared to Sprague-Dawley neurons, with mean depolarizations of $2.1 \pm 0.4 \mathrm{mV}$ and $6.0 \pm 1.1 \mathrm{mV}$, respectively. There were not enough depolarizing responses to GABA to make statistical comparisons.

These studies next focused on excitatory neurotransmission by examining the depolarizing effects of single concentrations of glutamate $(10 \mu \mathrm{M})$, aspartate $(10 \mu \mathrm{M})$, and $\mathrm{N}$-methyl-D-aspartate (NMDA; $10 \mu \mathrm{M}$ ). As can be seen in Table 10, unlike the responses to GABA and muscimol, the responses to all three of these agonists, though varying with age, were never significantly different when comparing the two animal strains at equivalent ages ( $p>0.05)$. Once again, a significant increase in the effects of glutamate and aspartate were observed in the older (P15+) animals $(\mathrm{p}<0.05)$, but these shifts in responsiveness were equivalent for both groups of animals. Unexpectedly, the depolarizing responses to NMDA $(10 \mu \mathrm{M})$ had the exact opposite trend, that is, they were significantly decreased in the older animals (P15+). Examining these responses over a more precise time course further indicated that, whereas, glutamate and aspartate had large increases 


\begin{tabular}{|c|c|c|c|c|}
\hline & $\begin{array}{c}\text { Sprague-Dawley } \\
(\mathrm{P} 10-14)^{\infty}\end{array}$ & $\begin{array}{c}\text { GEPR-9 } \\
(\mathrm{P} 10-14)\end{array}$ & $\begin{array}{c}\text { Sprague-Dawley } \\
(\mathrm{P} 15+)^{\nabla}\end{array}$ & $\begin{array}{c}\text { GEPR-9 } \\
(\mathrm{P} 15+)\end{array}$ \\
\hline Glutamate $(10 \mu \mathrm{M})$ & $\begin{array}{c}12.8 \pm 0.3 \\
(7)^{+}\end{array}$ & $\begin{array}{c}12.6 \pm 0.4 \\
(6)\end{array}$ & $\begin{array}{c}16.7 \pm 0.2 \\
(9)\end{array}$ & $\begin{array}{c}16.2 \pm 0.2 \\
(12)\end{array}$ \\
\hline Aspartate $(10 \mu \mathrm{M})$ & $\begin{array}{c}10.8 \pm 0.4 \\
(4)\end{array}$ & $\begin{array}{c}11.7 \pm 0.5 \\
(7)\end{array}$ & $\begin{array}{c}13.6 \pm 0.2 \\
(9)\end{array}$ & $\begin{array}{c}13.1 \pm 0.2 \\
(12)\end{array}$ \\
\hline NMDA $(10 \mu \mathrm{M})$ & $\begin{array}{c}5.5 \pm 0.3 \\
(8)\end{array}$ & $\begin{array}{c}4.8 \pm 0.4 \\
(6)\end{array}$ & $\begin{array}{c}2.2 \pm 0.4 \\
(17)\end{array}$ & $\begin{array}{c}3.0 \pm 0.3 \\
(12)\end{array}$ \\
\hline
\end{tabular}

TABLE 10. Changes in membrane potential of Purkinje neurons in vermal cerebellar slices from Sprague-Dawley and GEPR-9 rats induced by excitatory agonists as determined using intracellular recording techniques. Means are reported \pm S.E.M. There were no significant differences between the responses for any of the agonists for identical age groups between the two animal strains ( $\mathrm{p}<0.05) .{ }^{+}$Indicates the sample size (number of cells). ${ }^{\circ}$ Indicates that the group includes only Purkinje neurons from animals between the ages of 10 and 14 days postnatal. ${ }^{\nabla}$ Indicates that the group includes only Purkinje neurons from animals 15 days postnatal or older. 
in response in P15-19 vs. P10-14 animals (Sprague-Dawley, GEPR-NE, and GEPR-9), the decrease in response to NMDA was quite gradual, slowly decreasing with age (data not shown).

Having demonstrated single concentrations at which GEPR-9 Purkinje neurons displayed reduced responses to both GABA and muscimol, the next step was to complete full concentration response curves in 15 day and older animals (P15+; as described above and in section VI) to better determine the nature and magnitude of this decreased responsiveness. All responses were normalized to the maximal response obtained in Sprague-Dawley neurons. Figure 19 contains concentration-response curves to GABA for both Sprague-Dawley and GEPR-9 Purkinje neurons. Though the magnitude of the maximal responses to GABA were not significantly different between Sprague-Dawley and GEPR-9 Purkinje neurons ( $\mathrm{p}>0.05 ;-14.5 \pm 0.9 \mathrm{mV}$ and $-15.2 \pm 1.1 \mathrm{mV}$, respectively), there was a distinct shift to the right of the concentration-response curve. Analysis of the best fit curves via non-linear regression analysis provided estimates of the GABA geometric mean $\mathrm{EC}_{50}$ values and were $6.6 \pm 0.7 \mu \mathrm{M}$ and $20.6 \pm 1.5 \mu \mathrm{M}$ for Sprague-Dawley and GEPR-9 Purkinje neurons, respectively. These $\mathrm{EC}_{50}$ values were significantly different $(\mathrm{p}<0.05)$ and revealed an approximate 3.1-fold rightward shift of the GABA concentration-response curve for GEPR-9 compared to Sprague-Dawley Purkinje neurons.

When concentration-response curves for muscimol were constructed for these two animal strains (Figure 20), similar results were seen. The maximal responses were, again, not statistically different ( $>>0.05 ;-15.1 \pm 0.7 \mathrm{mV}$ for Sprague-Dawley; $-14.2 \pm 0.6 \mathrm{mV}$ for GEPR-9), while there was a significant shift in the overall concentration-response curve. Muscimol geometric mean $\mathrm{EC}_{50}$ values obtained from the best fit parameters of these curves were estimated as $0.61 \pm 0.05 \mu \mathrm{M}$ for Sprague-Dawley neurons and 1.8 $\pm 0.2 \mu \mathrm{M}$ for GEPR-9 neurons, yielding an approximate 3.0-fold 


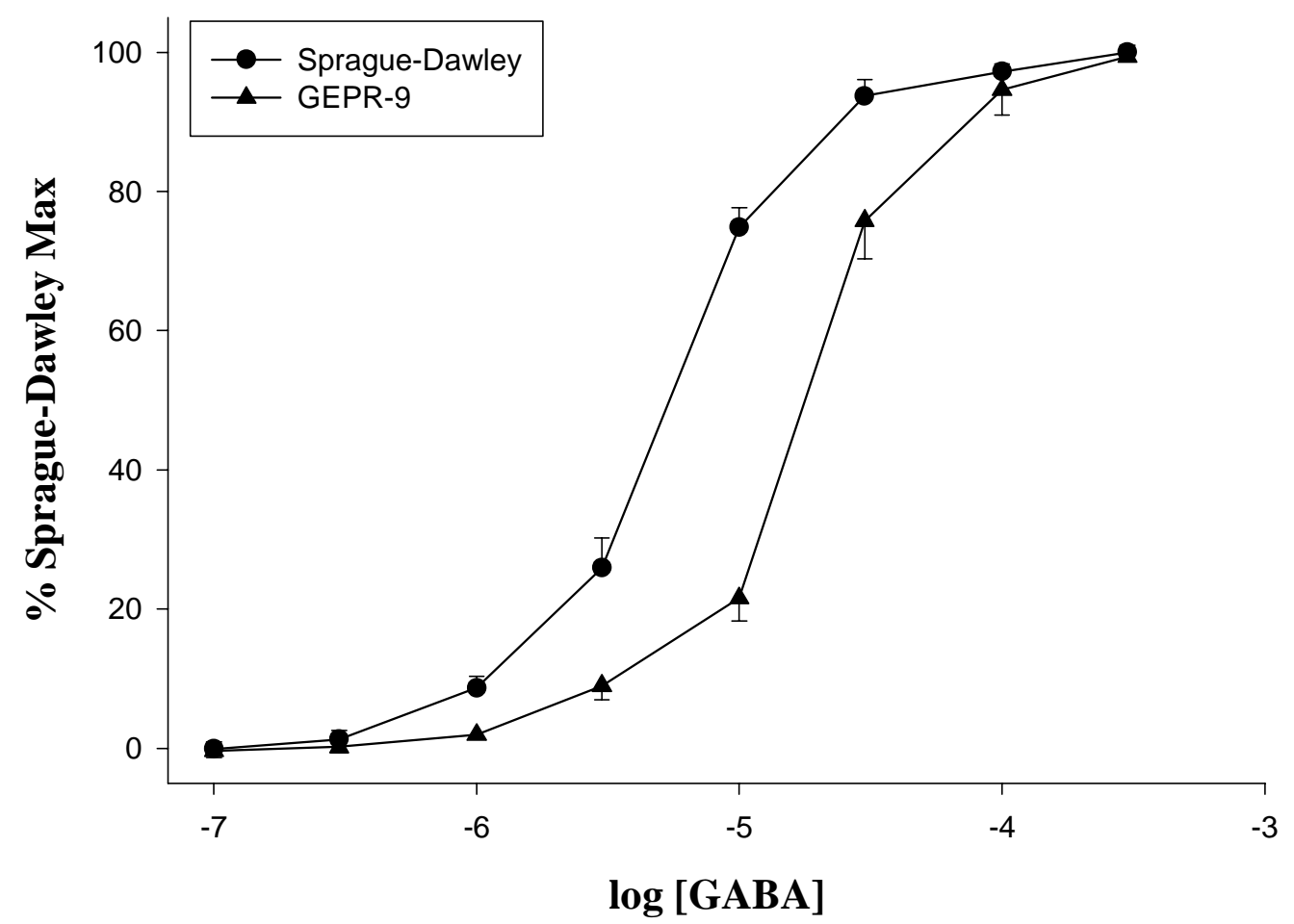

FIGURE 19. Concentration-response curves of Purkinje neurons to superfusion of GABA. Hyperpolarizing responses are normalized to the percent of the maximal Sprague-Dawley Purkinje neuron response. There was no statistically significant difference in the maximal hyperpolarization for Purkinje neurons from Sprague-Dawley and GEPR-9 rats ( $p>0.05)$. The estimated geometric mean $\mathrm{EC}_{50}$ for GEPR-9 Purkinje neurons was shifted approximately 3-fold to the right of that for Sprague-Dawley Purkinje neurons. Data are presented as mean \pm S.E.M. 


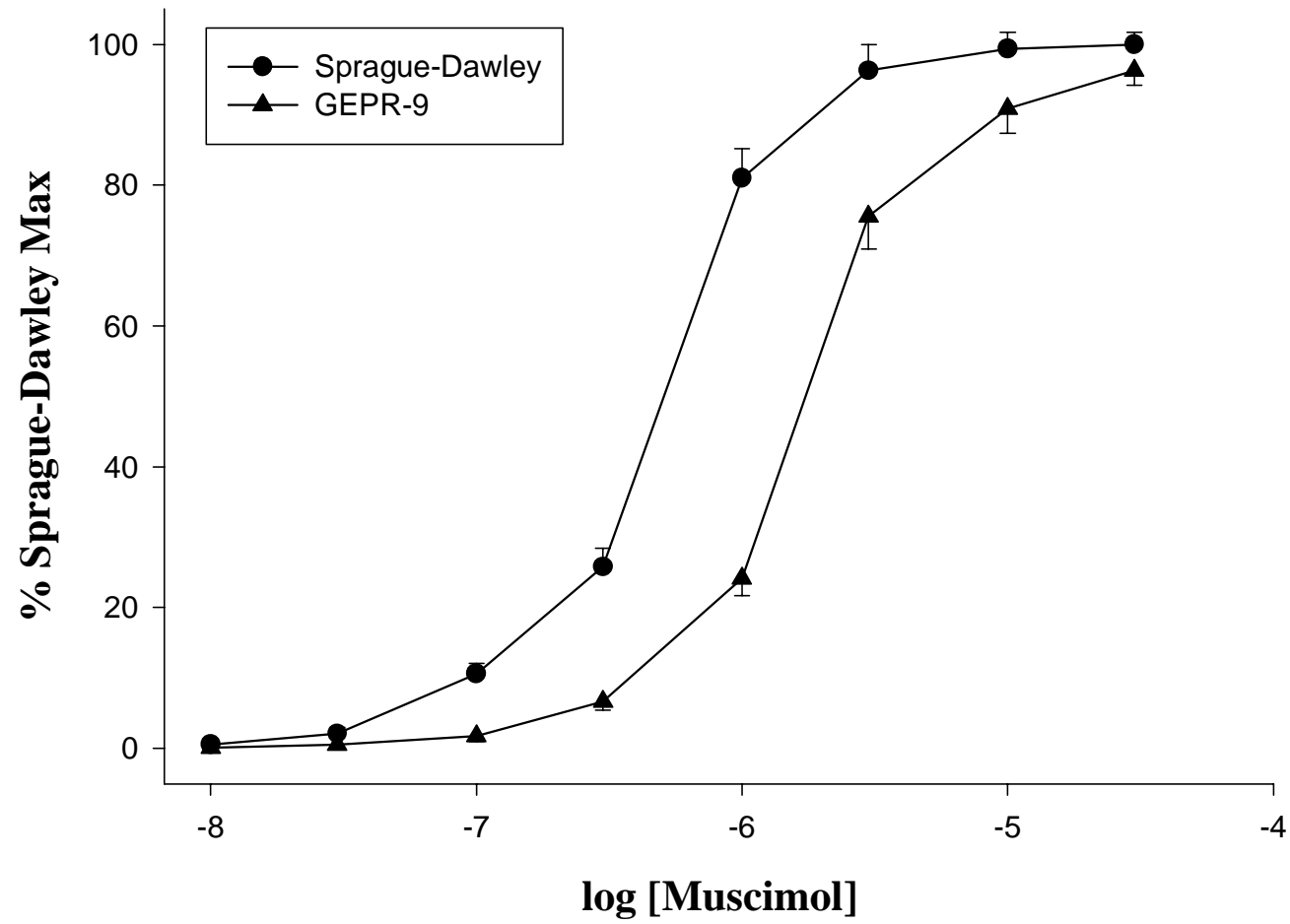

FIGURE 20. Concentration-response curves of Purkinje neurons to superfusion of muscimol. Hyperpolarizing responses are normalized to the percent of the maximal Sprague-Dawley Purkinje neuron response. There was no statistically significant difference in the maximal hyperpolarization for Purkinje neurons from Sprague-Dawley and GEPR-9 rats ( $p>0.05)$. The estimated geometric mean $\mathrm{EC}_{50}$ for GEPR-9 Purkinje neurons was shifted approximately 3-fold to the right of that for Sprague-Dawley Purkinje neurons. Data are presented as mean \pm S.E.M. 
shift of the concentration response curve.

To ensure that there were no differences in the responsiveness of GEPR-9 Purkinje neurons to glutamate or aspartate compared to Sprague-Dawley rats which were not revealed by the single concentration comparisons (such as a change in maximal response), concentration-response curves to these excitatory amino acids were also constructed and are depicted as Figures 21 and 22, respectively. As for the GEPR-NE Purkinje neurons, there were no significant differences in either the maximal responses obtained or in the geometric mean $\mathrm{EC}_{50}$ values for glutamate or aspartate in GEPR-9 Purkinje neurons compared to Sprague-Dawley neurons ( $>0.05)$. Maximal depolarizations of $17-18 \mathrm{mV}$ were obtained in both animal strains to glutamate and aspartate. Geometric mean $\mathrm{EC}_{50}$ values for GEPR-9 Purkinje neurons were $3.3 \pm 0.3 \mu \mathrm{M}$ for glutamate and $6.5 \pm 0.7 \mu \mathrm{M}$ for aspartate and were similar to those obtained for Sprague-Dawley Purkinje neurons (glutamate, $3.2 \pm 0.3 \mu \mathrm{M}$; aspartate $6.3 \pm 0.6 \mu \mathrm{M}$ ).

In an attempt to further elucidate the possible mechanism of this apparent selective subsensitivity of GEPR-9 Purkinje neurons to $\mathrm{GABA}_{\mathrm{A}}$-receptor activation, the next set of experiments surveyed the effects of two modulators of the $\mathrm{GABA}_{\mathrm{A}}$-receptor complex, norepinephrine and diazepam, on Purkinje neurons from P15+ aged animals. In order to conduct these experiments, GABA concentrations near the $\mathrm{EC}_{50}$ value for each animal (and thus equieffective) were chosen, and these were 7 and $20 \mu \mathrm{M}$ for Sprague-Dawley and GEPR-9 strains, respectively. Norepinephrine $(500 \mu \mathrm{M})$ or diazepam $(100 \mu \mathrm{M})$ was then superfused for 1 minute and the effects on membrane potential were measured. After a 5 minute recovery period, the appropriate estimated $\mathrm{EC}_{50}$ concentration of GABA was superfused for 1 minute and the effects on membrane potential were measured. Following another 5 minute recovery period, the combination 


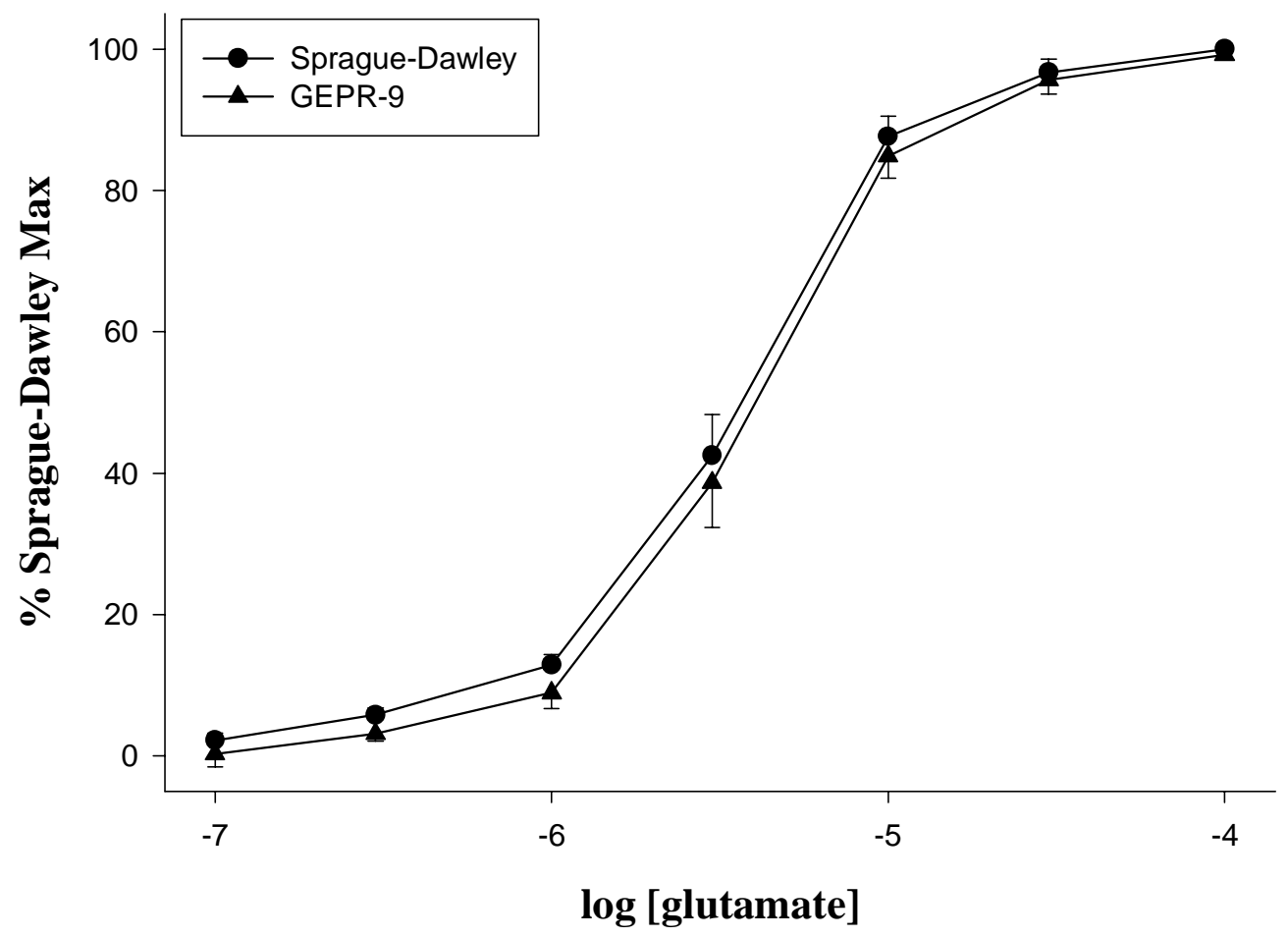

FIGURE 21. Concentration-response curves of Purkinje neurons to superfusion of glutamate. Depolarizing responses are normalized to the percent of the maximal Sprague-Dawley Purkinje neuron response. There were no statistically significant differences in the estimated geometric mean $\mathrm{EC}_{50}$ (see text) or maximal depolarization for Purkinje neurons from Sprague-Dawley and GEPR-9 rats $(\mathrm{p}>0.05)$. Data are presented as mean \pm S.E.M. 


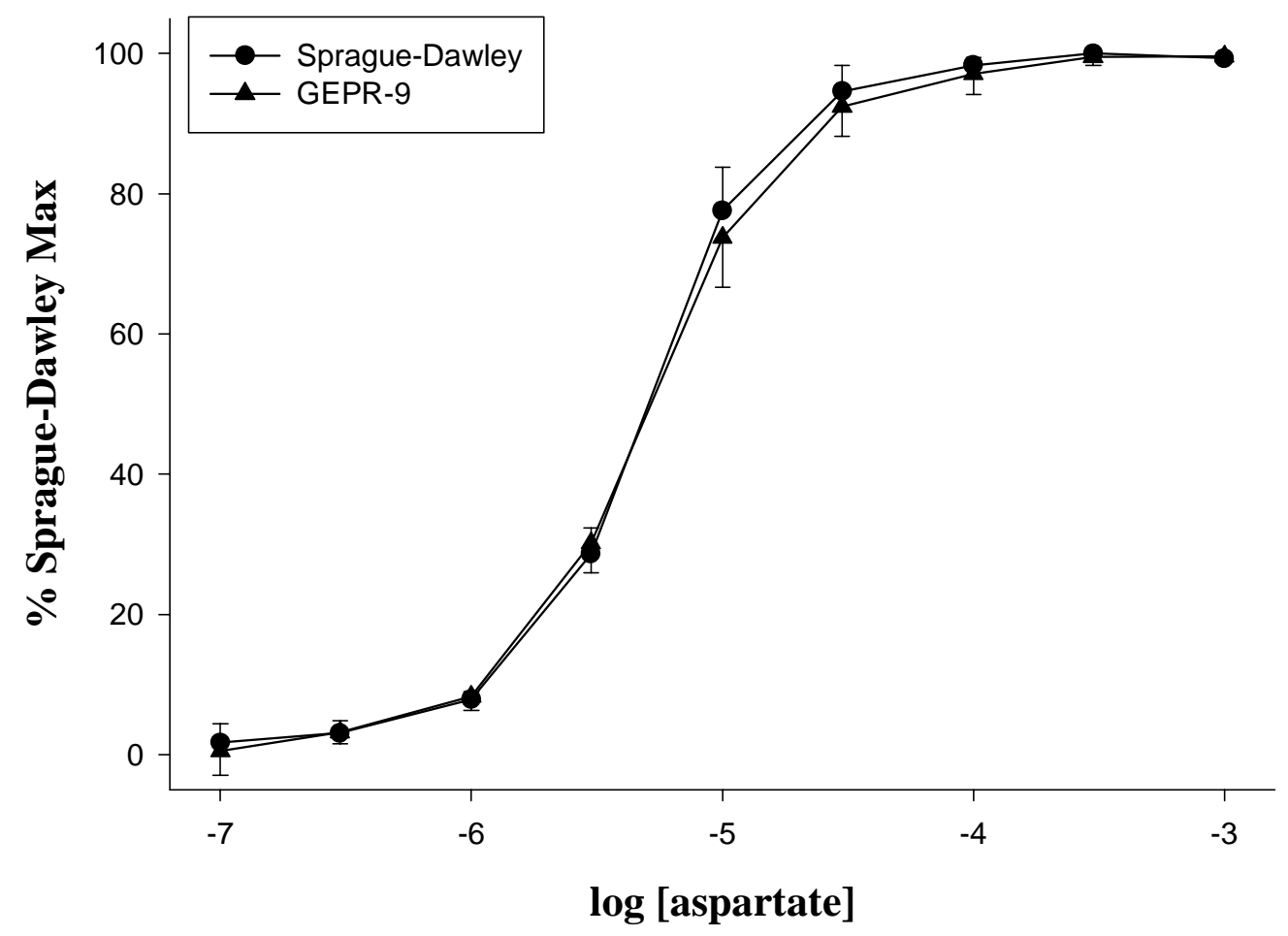

FIGURE 22. Concentration-response curves of Purkinje neurons to superfusion of aspartate. Depolarizing responses are normalized to the percent of the maximal Sprague-Dawley Purkinje neuron response. There were no statistically significant differences in the estimated geometric mean $\mathrm{EC}_{50}$ (see text) or maximal depolarization for Purkinje neurons from Sprague-Dawley and GEPR-9 rats $(\mathrm{p}>0.05)$. Data are presented as mean \pm S.E.M. 
of GABA and modulator (norepinephrine or diazepam) was superfused for 1 minute and the subsequent membrane polarization effects measured. The results of these experiments are detailed in Table 11.

As can be seen in Table 11, both norepinephrine and diazepam induced small hyperpolarizations when given alone to Purkinje neurons from both animal strains and these membrane potential changes were not significantly different between animal strains $(\mathrm{p}<0.05)$. Importantly, the concentrations of GABA chosen (7 $\mu$ M, Sprague-Dawley; $20 \mu \mathrm{M}$, GEPR-9) did produce statistically equivalent membrane hyperpolarizations of about half maximal responses as determined during concentration-response curve construction. When combinations of either GABA+norepinephrine or GABA+diazepam were applied, potentiated hyperpolarizations of roughly equivalent magnitude were observed for Purkinje neurons from either animal strain. Furthermore, the differences in the magnitude of the combination drug treatment and the GABA treatment were also not statistically different between animal strains $(\mathrm{p}<0.05)$. 


\begin{tabular}{|c|c|c|}
\hline & Sprague-Dawley & GEPR-9 \\
\hline Norepinephrine $(500 \mu \mathrm{M})$ & $-2.5 \pm 0.3$ & $-2.4 \pm 0.3$ \\
\hline $\mathrm{GABA}^{\mathrm{A}}$ & $-7.5 \pm 0.3$ & $-6.9 \pm 0.3$ \\
\hline $\begin{array}{c}{ }^{\ddagger} \mathrm{GABA}+ \\
\text { Norepinephrine }(500 \mu \mathrm{M})^{\mathrm{B}}\end{array}$ & $-13.5 \pm 0.3$ & $-12.7 \pm 0.6$ \\
\hline \multirow[t]{2}{*}{ Difference (B-A) } & $\begin{array}{c}-6.0 \pm 0.2 \\
(6)^{+}\end{array}$ & $\begin{array}{c}-5.8 \pm 0.3 \\
(5)\end{array}$ \\
\hline & Sprague-Dawley & GEPR-9 \\
\hline Diazepam $(100 \mu \mathrm{M})$ & $-1.4 \pm 0.3$ & $-1.1 \pm 0.3$ \\
\hline $\mathrm{GABA}^{\mathrm{C}}$ & $-8.4 \pm 0.4$ & $-7.6 \pm 0.3$ \\
\hline $\begin{array}{c}{ }^{\ddagger} \mathrm{GABA}+ \\
\text { Diazepam }(100 \mu \mathrm{M})^{\mathrm{D}}\end{array}$ & $-13.3 \pm 0.6$ & $-13.0 \pm 0.3$ \\
\hline Difference (D-C) & $\begin{array}{c}-4.9 \pm 0.5 \\
(6)\end{array}$ & $\begin{array}{c}-5.4 \pm 0.5 \\
(6)\end{array}$ \\
\hline
\end{tabular}

TABLE 11. Changes in membrane potential of Purkinje neurons in vermal cerebellar slices from Sprague-Dawley and GEPR-9 rats induced by GABA and/or modulators of the GABA $_{\mathrm{A}}$-receptor as determined using intracellular recording techniques. Drugs were superfused sequentially for 1 minute at 5 minute intervals. Concentrations of GABA used for each animal strain were chose to approximate the $\mathrm{EC}_{50}$ concentrations as reported in the text (Sprague-Dawley, $7 \mu \mathrm{M}$; GEPR-9, 20 $\mu \mathrm{M})$. Means are reported \pm S.E.M. There were no significantly different responses to drug superfusion between the two animal strains nor were the changes in response (for GABA vs. GABA + modulator) significantly different ( $\mathrm{p}<0.05)$. All animals used for these experiments were postnatal day 15 or older. ${ }^{+}$Indicates sample size (number of cells). 


\section{E. Intracellular comparison of Sprague-Dawley and GEPR-3 Purkinje Neurons}

Having observed an approximate 3-fold subsensitivity of GEPR-9 Purkinje neurons to $\mathrm{GABA}_{\mathrm{A}}$-receptor activation compared to Sprague-Dawley Purkinje neurons, the next set of experiments were similarly designed to investigate possible deficits in the GEPR-3, a moderately seizure-prone animal model. Thus, as with both the GEPR-NE and GEPR-9, these studies began by evaluating the responses of Purkinje neurons from GEPR-3 animals to single concentrations of drugs and comparing these effects to those observed for Sprague-Dawley Purkinje neurons. Once again, it should be noted that the data presented in this section for Sprague-Dawley Purkinje neurons have been previously presented in the preceding paragraphs.

The first set of experiments, looking at GABA receptor activation and blockade, employed the same concentrations of agonist as used previously. The results of these experiments are presented in Table 12. As can be seen in this table, the ability of both muscimol $(1 \mu \mathrm{M})$ and GABA $(10 \mu \mathrm{M})$ to evoke hyperpolarizations of GEPR-3 Purkinje neurons was slightly, but significantly reduced $(\mathrm{p}<0.05)$ for both young $(\mathrm{P} 10-14)$ and older $(\mathrm{P} 15+)$ animals. As expected these hyperpolarizations were antagonized by bicuculline $(30 \mu \mathrm{M})$ in both animal strains and bicuculline alone, at this concentration, had no significant effect on the membrane potential in either animal strain. Represented in this table are only the hyperpolarizing responses to GABA and muscimol. However, for GEPR-3 Purkinje neurons, only 1 cell (7\% of total) depolarized in the presence of GABA or muscimol (compared to $21 \%$ for Sprague-Dawley).

Similar to the results observed for GEPR-9 Purkinje neurons, baclofen (10 $\mu \mathrm{M})$ induced a slight depolarization of P10-14 GEPR-3 Purkinje neurons which was great enough to be statistically different from the minor hyperpolarization in response to baclofen for Sprague-Dawley Purkinje 


\begin{tabular}{|c|c|c|c|c|}
\hline & $\begin{array}{l}\text { Sprague-Dawley } \\
(\mathrm{P} 10-14)^{\infty}\end{array}$ & $\begin{array}{l}\text { GEPR-3 } \\
\text { (P10-14) }\end{array}$ & $\begin{array}{l}\text { Sprague-Dawley } \\
(\mathrm{P} 15+)^{\nabla}\end{array}$ & $\begin{array}{c}\text { GEPR-3 } \\
(\mathrm{P} 15+)\end{array}$ \\
\hline Muscimol $(1 \mu \mathrm{M})^{\S}$ & $\begin{array}{c}-11.3 \pm 0.4^{*} \\
(17)^{+}\end{array}$ & $\begin{array}{l}-8.5 \pm 0.4 * \\
(7)\end{array}$ & $\begin{array}{c}-11.6 \pm 0.2^{* * *} \\
(78)\end{array}$ & $\begin{array}{c}-9.6 \pm 0.3^{* *} \\
(14) \\
\end{array}$ \\
\hline $\begin{array}{l}\text { Muscimol }(1 \mu \mathrm{M})+ \\
\text { Bicuculline }(10 \mu \mathrm{M})\end{array}$ & $\begin{array}{c}-0.3 \pm .2 \\
(3)\end{array}$ & $\begin{array}{l}0.5 \pm 0.8 \\
\quad(4)\end{array}$ & $\begin{array}{c}-0.1 \pm 0.3 \\
(9)\end{array}$ & $\begin{array}{c}0.4 \pm 0.9 \\
(5)\end{array}$ \\
\hline GABA $(10 \mu \mathrm{M})^{\S}$ & $\begin{array}{c}-11.7 \pm 0.7^{*} \\
(5)\end{array}$ & $\begin{array}{c}-9.1 \pm 0.4 * \\
(5)\end{array}$ & $\begin{array}{c}-11.1 \pm 0.2^{* *} \\
(14)\end{array}$ & $\begin{array}{c}-10.1 \pm 0.3^{* *} \\
(15)\end{array}$ \\
\hline $\begin{array}{c}\text { GABA }(10 \mu \mathrm{M})+ \\
\text { Bicuculline }(10 \mu \mathrm{M})\end{array}$ & $\begin{array}{c}-0.1 \pm 1.1 \\
(3)\end{array}$ & $\begin{array}{l}1.0 \pm 0.6 \\
(5)\end{array}$ & $\begin{array}{c}-1.2 \pm 0.3 \\
\quad(4)\end{array}$ & $\begin{array}{l}0.6 \pm 0.5 \\
\quad(5)\end{array}$ \\
\hline Bicuculline $(30 \mu \mathrm{M})$ & $\begin{array}{l}0.6 \pm 0.4 \\
\quad(3)\end{array}$ & $\begin{array}{c}0.1 \pm 0.5 \\
\quad(4)\end{array}$ & $\begin{array}{l}1.0 \pm 0.5 \\
(6)\end{array}$ & $\begin{array}{c}-0.1 \pm 0.5 \\
(6)\end{array}$ \\
\hline Baclofen $(10 \mu \mathrm{M})$ & $\begin{array}{c}-1.6 \pm 0.2 * \\
(3)\end{array}$ & $\begin{array}{c}1.1 \pm 0.6^{*} \\
(4)\end{array}$ & $\begin{array}{c}-0.9 \pm 0.8 \\
(6)\end{array}$ & $\begin{array}{l}1.2 \pm 0.6 \\
(4)\end{array}$ \\
\hline
\end{tabular}

TABLE 12. Changes in membrane potential of Purkinje neurons in vermal cerebellar slices from Sprague-Dawley and GEPR-3 rats induced by various GABA-receptor agonists and antagonists as determined using intracellular recording techniques. ${ }^{8}$ Indicates that only hyperpolarizing responses to these $\mathrm{GABA}_{\mathrm{A}}$-receptor agonists were included in the mean values. Means are reported \pm S.E.M. *Denotes a significantly different response between the two animal strains for the indicated agonist during the 10-14 day postnatal age period $(\mathrm{p}<0.05)$. **Denotes a significantly different response between the two animal strains for the indicated agonist during the 15 day and older postnal age period $(\mathrm{p}<0.05)$. ${ }^{+}$Indicates sample size (number of cells). ${ }^{\circ}$ Indicates that the group includes only Purkinje neurons from animals between the ages of 10 and 14 days postnatal. ${ }^{\nabla}$ Indicates that the group includes only Purkinje neurons from animals 15 days postnatal or older. 
neurons $(\mathrm{p}<0.05)$. Presented in Table 13 are the single concentration responses of Purkinje neurons from GEPR-3 and Sprague-Dawley animals for the excitatory agonists, glutamate (10 $\mu \mathrm{M})$ and aspartate $(10 \mu \mathrm{M})$. As expected and as seen for GEPR-9 Purkinje neurons, there was no statistically significant difference between the responses of Purkinje neurons from GEPR-3 and Sprague-Dawley rats to either of these agonists for either age group $(\mathrm{p}>0.05)$ and the increase in responsiveness to both agonists increased with age in a similar manner.

To further evaluate the responsiveness of GEPR-3 Purkinje neurons to GABA, muscimol, glutamate, and aspartate, concentration-response curves were constructed for animals 15 days and older (P15+) and compared to those obtained from Sprague-Dawley Purkinje neurons. Figure 23 is a comparison of the GABA concentration-response curves. As can be seen in Figure 23, quite a different alteration in responsiveness to GABA was evident for GEPR-3 Purkinje neurons compared to Sprague-Dawley neurons than was observed for GEPR-9 neurons. Rather than the parallel rightward shift of the concentration-response curve which was observed for GEPR-9 neurons, GEPR-3 Purkinje neurons displayed a significantly decreased maximal response (-12.4 \pm $0.5 \mathrm{mV})$ when compared to Sprague-Dawley Purkinje neurons $(-14.9 \pm 0.9 \mathrm{mV})$ without displaying a significantly different geometric mean $\mathrm{EC}_{50}$ concentration $(\mathrm{p}>0.05)$. When approximated using non-linear regression analysis of the concentration-response curves, the GABA geometric mean $\mathrm{EC}_{50}$ values for Sprague-Dawley and GEPR-3 Purkinje neurons were $-6.6 \pm 0.7 \mu \mathrm{M}$ and $-6.4 \pm 0.7$ $\mu \mathrm{M}$, respectively.

When concentration-response curves to muscimol were constructed (Figure 24) a similar pattern was observed. While the maximal hyperpolarization induced by muscimol for GEPR-3 Purkinje neurons $(-13.2 \pm 0.6 \mathrm{mV})$ was significantly less than the maximal hyperpolarization 


\begin{tabular}{|c|c|c|c|c|}
\hline & $\begin{array}{c}\text { Sprague-Dawley } \\
(\mathrm{P} 10-14)^{\infty}\end{array}$ & $\begin{array}{c}\text { GEPR-3 } \\
(\mathrm{P} 10-14)\end{array}$ & $\begin{array}{c}\text { Sprague-Dawley } \\
(\mathrm{P} 15+)^{\nabla}\end{array}$ & $\begin{array}{c}\text { GEPR-3 } \\
(\mathrm{P} 15+)\end{array}$ \\
\hline Glutamate $(10 \mu \mathrm{M})$ & $\begin{array}{c}12.8 \pm 0.3 \\
(7)^{+}\end{array}$ & $\begin{array}{c}12.2 \pm 0.7 \\
(5)\end{array}$ & $\begin{array}{c}16.7 \pm 0.2 \\
(9)\end{array}$ & $\begin{array}{c}16.3 \pm 0.4 \\
(8)\end{array}$ \\
\hline Aspartate $(10 \mu \mathrm{M})$ & $\begin{array}{c}10.8 \pm 0.4 \\
(4)\end{array}$ & $\begin{array}{c}10.9 \pm 0.6 \\
(4)\end{array}$ & $\begin{array}{c}13.6 \pm 0.2 \\
(9)\end{array}$ & $\begin{array}{c}13.3 \pm 0.4 \\
(6)\end{array}$ \\
\hline
\end{tabular}

TABLE 13. Changes in membrane potential of Purkinje neurons in vermal cerebellar slices from Sprague-Dawley and GEPR-3 rats induced by excitatory agonists as determined using intracellular recording techniques. Means are reported \pm S.E.M. There were no significant differences between the responses for either agonist for identical age groups between the two animal strains $(p<0.05)$. ${ }^{+}$Indicates the sample size (number of cells). ${ }^{\infty}$ Indicates that the group includes only Purkinje neurons from animals between the ages of 10 and 14 days postnatal. ${ }^{7}$ Indicates that the group includes only Purkinje neurons from animals 15 days postnatal or older. 


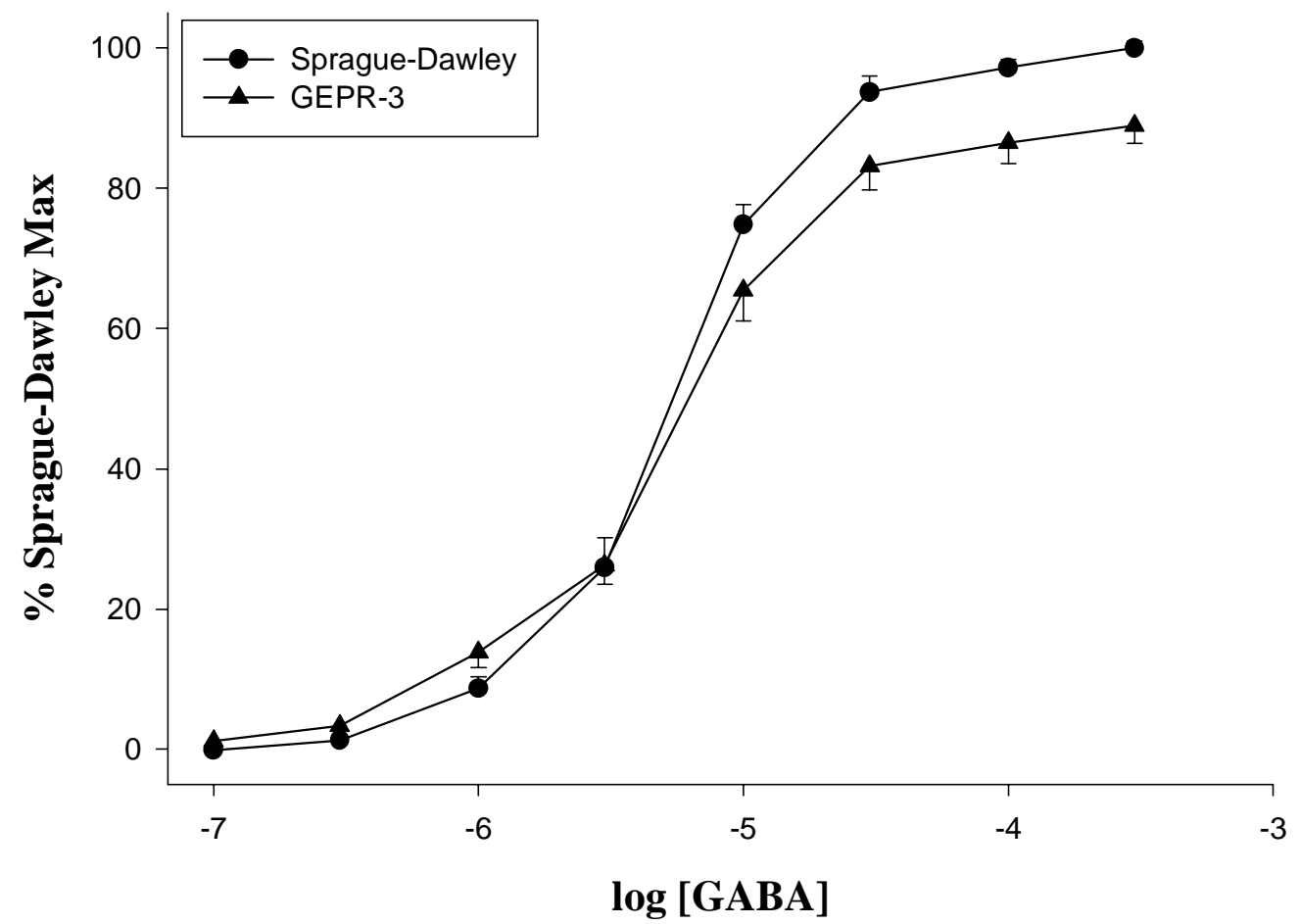

FIGURE 23. Concentration-response curves of Purkinje neurons to superfusion of GABA. Hyperpolarizing responses are normalized to the percent of the maximal Sprague-Dawley Purkinje neuron response. There was no statistically significant difference in the estimated geometric mean $\mathrm{EC}_{50}$ for Purkinje neurons from Sprague-Dawley and GEPR-3 rats $(\mathrm{p}>0.05)$. The responses of GEPR-3 Purkinje neurons were significantly reduced compared to those from Sprague-Dawley Purkinje neurons at concentrations of $10 \mu \mathrm{M}$ and above $(\mathrm{p}<0.05)$. Data are presented as the mean \pm S.E.M. 


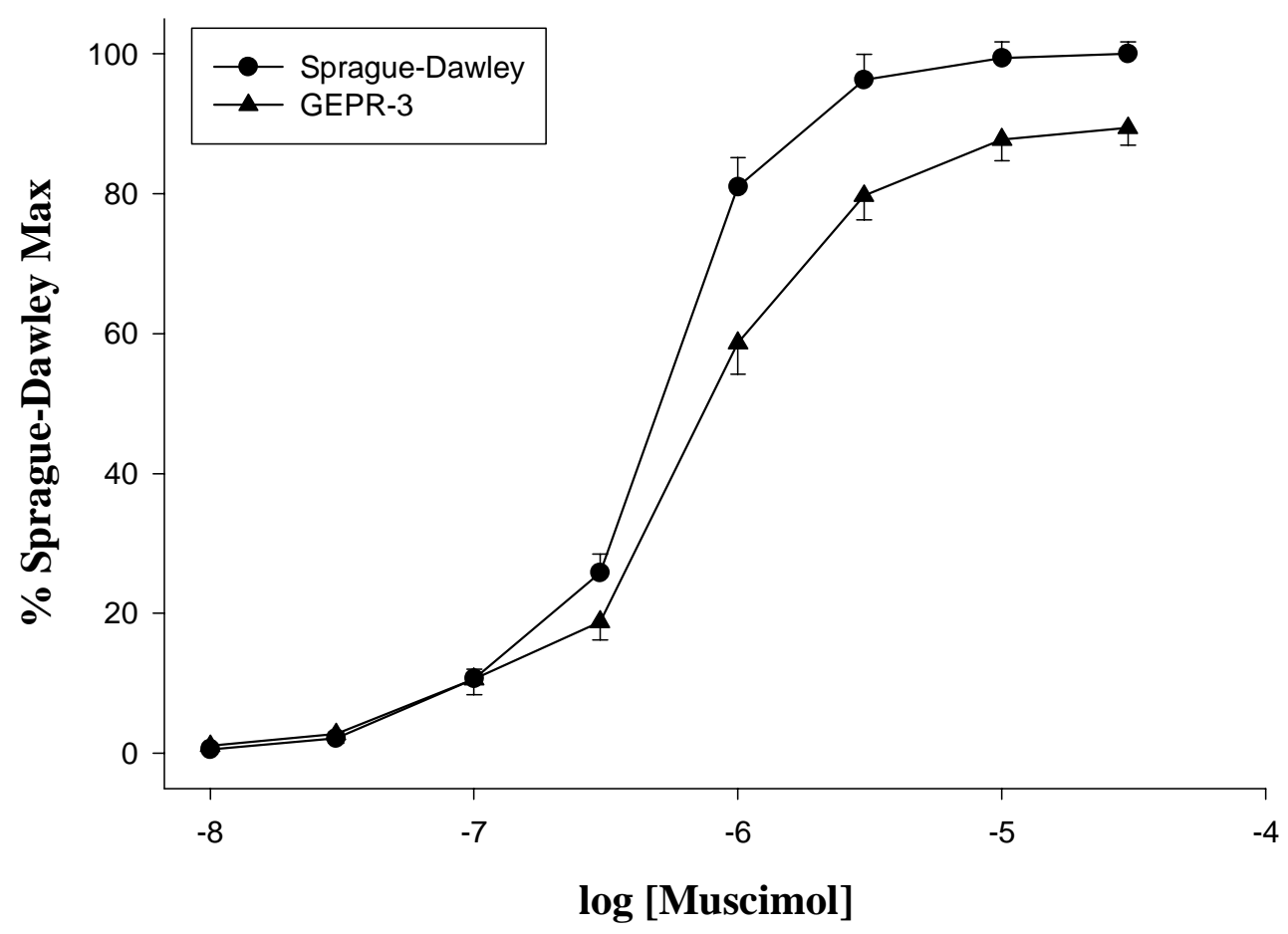

FIGURE 24. Concentration-response curves of Purkinje neurons to superfusion of muscimol. Hyperpolarizing responses are normalized to the percent of the maximal Sprague-Dawley Purkinje neuron response. There was no statistically significant difference in the estimated geometric mean $\mathrm{EC}_{50}$ for Purkinje neurons from Sprague-Dawley and GEPR-3 rats ( $\left.>0.05\right)$. The responses of GEPR-3 Purkinje neurons were significantly reduced compared to those from Sprague-Dawley Purkinje neurons at concentrations of $1 \mu \mathrm{M}$ and above $(\mathrm{p}<0.05)$. Data are presented as the mean \pm S.E.M. 
observed for Sprague-Dawley Purkinje neurons $(-15.1 \pm 0.7 \mathrm{mV} ; \mathrm{p}<0.05)$, the estimated geometric mean $\mathrm{EC}_{50}$ values were not significantly different $(\mathrm{p}>0.05)$. The geometric mean $\mathrm{EC}_{50}$ concentrations of muscimol were $0.61 \pm 0.05 \mu \mathrm{M}$ and $0.75 \pm 0.07 \mu \mathrm{M}$ for Sprague-Dawley and GEPR-3 Purkinje neurons, respectively.

The concentration-response curves for glutamate (Figure 25) and aspartate (Figure 26) revealed similar maximal depolarizations of the membrane potential as well as similar $\mathrm{EC}_{50}$ values when GEPR-3 and Sprague-Dawley Purkinje neurons were compared. Both agents induced approximately a 17-18 $\mathrm{mV}$ maximal depolarization of the neuronal membrane for cells from both animal strains. Using non-linear regression analysis to estimate geometric mean $\mathrm{EC}_{50} \mathrm{~s}$ gave values that were not statistically different between animal strains $(p>0.05)$. These values for glutamate were $3.2 \pm 0.3 \mu \mathrm{M}$ (Sprague-Dawley) and $2.9 \pm 0.3 \mu \mathrm{M}$ (GEPR-3). For aspartate, the geometric mean $\mathrm{EC}_{50}$ estimations were $6.3 \pm 0.6 \mu \mathrm{M}$ (Sprague-Dawley) and $5.3 \pm 0.5 \mu \mathrm{M}$ (GEPR-3).

As a summary of the results obtained from the construction of concentration-response curve for GABA, muscimol, glutamate, and aspartate in Sprague-Dawley, GEPR-NE, GEPR-3, and GEPR-9 animals, Table 14 lists geometric mean $\mathrm{EC}_{50}$ values as well as the relative shifts of the $\mathrm{EC}_{50} /$ concentration-response curve. The magnitude of the shift simply represents the $\mathrm{EC}_{50}$ value of the appropriate test group divided by the corresponding $\mathrm{EC}_{50}$ value estimated for Sprague-Dawley Purkinje neurons. This value is given as a discrete number without a standard error or confidence interval and is meant to represent an approximate shift of the concentration-response curve. 


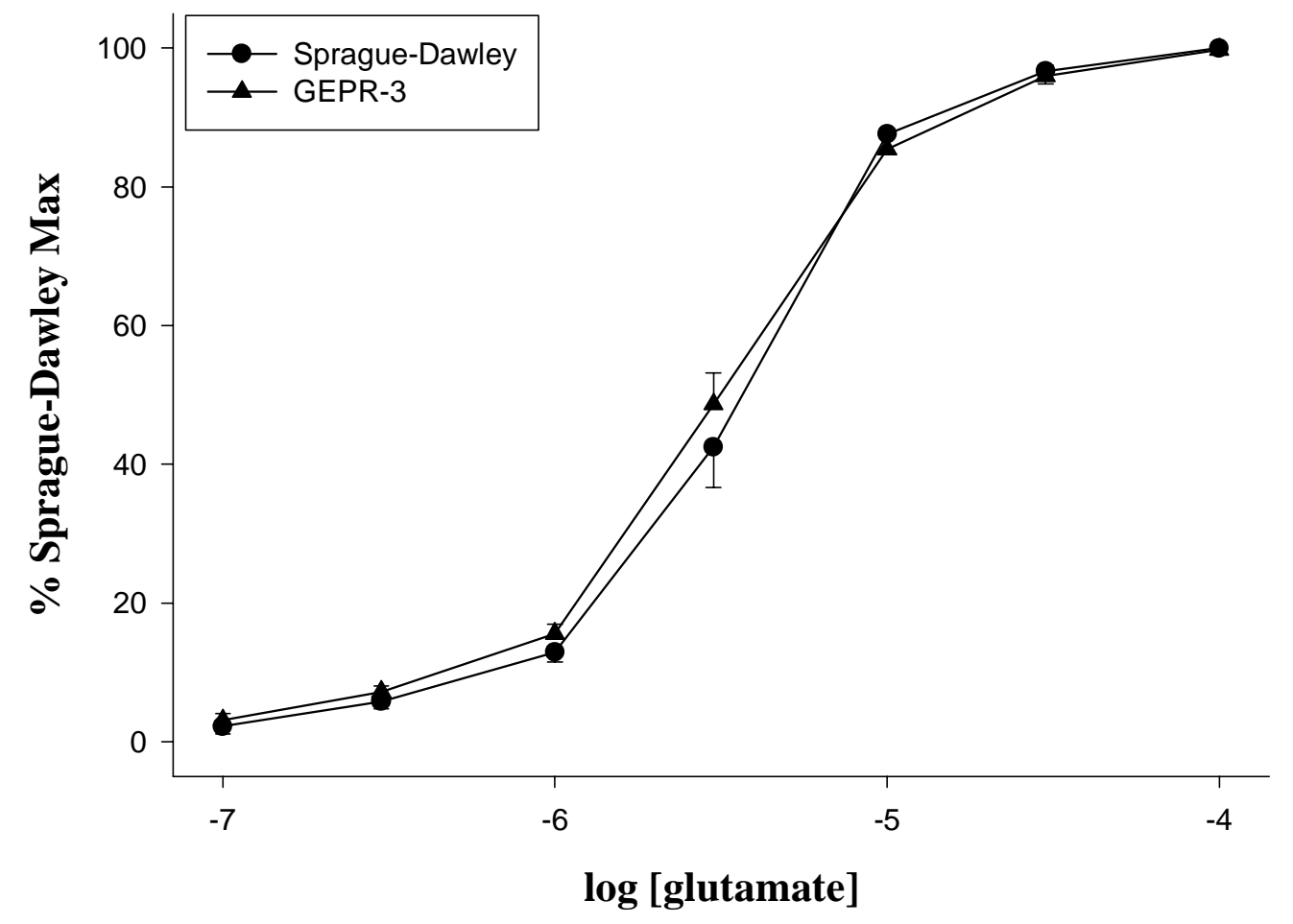

FIGURE 25. Concentration-response curves of Purkinje neurons to superfusion of glutamate. Depolarizing responses are normalized to the percent of the maximal Sprague-Dawley Purkinje neuron response. There were no statistically significant differences in the estimated geometric mean $\mathrm{EC}_{50}$ (see text) or maximal depolarization for Purkinje neurons from Sprague-Dawley and GEPR-3 rats $(\mathrm{p}>0.05)$. Data are presented as mean \pm S.E.M. 


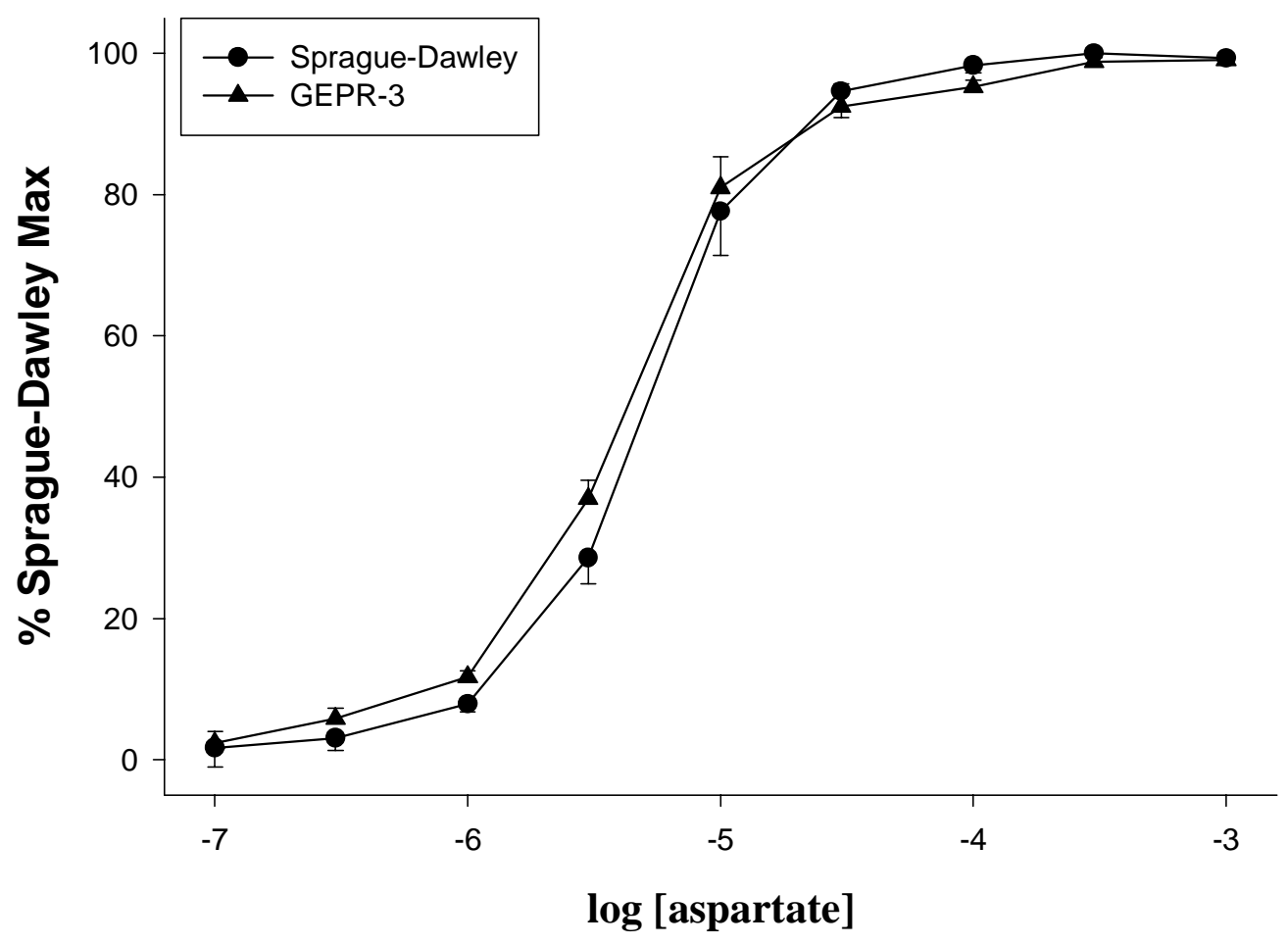

FIGURE 26. Concentration-response curves of Purkinje neurons to superfusion of aspartate. Depolarizing responses are normalized to the percent of the maximal Sprague-Dawley Purkinje neuron response. There were no statistically significant differences in the estimated geometric mean $\mathrm{EC}_{50}$ (see text) or maximal depolarization for Purkinje neurons from Sprague-Dawley and GEPR-3 rats $(\mathrm{p}>0.05)$. Data are presented as mean \pm S.E.M. 


\begin{tabular}{|c|c|c|c|c|}
\hline & Sprague-Dawley & GEPR-NE & GEPR-3 & GEPR-9 \\
\hline Aspartate $(\mu \mathrm{M})$ & $\begin{array}{c}6.3 \pm 0.6 \\
(6)\end{array}$ & $\begin{array}{c}7.2 \pm 0.6 \\
(5) \\
* 1.14\end{array}$ & $\begin{array}{c}5.4 \pm 0.5 \\
(5) \\
* 0.85\end{array}$ & $\begin{array}{c}6.5 \pm 0.7 \\
(6) \\
* 1.03\end{array}$ \\
\hline Glutamate $(\mu \mathrm{M})$ & $\begin{array}{c}3.2 \pm 0.3 \\
\text { (7) }\end{array}$ & $\begin{array}{c}3.0 \pm 0.2 \\
(5) \\
* 0.94\end{array}$ & $\begin{array}{c}2.9 \pm 0.3 \\
(5) \\
* 0.91\end{array}$ & $\begin{array}{c}3.3 \pm 0.3 \\
(6) \\
* 1.03\end{array}$ \\
\hline GABA $(\mu \mathrm{M})$ & $\begin{array}{c}6.6 \pm 0.7 \\
(7)\end{array}$ & $\begin{array}{c}6.1 \pm 0.6 \\
(6) \\
* 0.92\end{array}$ & $\begin{array}{c}6.4 \pm 0.7 \\
(6) \\
* 0.97\end{array}$ & $\begin{array}{c}\# 20.6 \pm 1.5 \\
(8) \\
* 3.12\end{array}$ \\
\hline Muscimol $(\mu \mathrm{M})$ & $\begin{array}{c}0.61 \pm 0.05 \\
\quad(8)\end{array}$ & $\begin{array}{c}0.70 \pm 0.05 \\
\quad(6) \\
* 1.14\end{array}$ & $\begin{array}{c}0.76 \pm 0.07 \\
\quad(7) \\
* 1.25\end{array}$ & $\begin{array}{c}\# 1.93 \pm 0.17 \\
(9) \\
* 3.16\end{array}$ \\
\hline
\end{tabular}

TABLE 14. Geometric mean $\mathrm{EC}_{50}$ values \pm S.E.M. (in $\mu \mathrm{M}$ ) determined from concentrationresponse curves (see text) for membrane polarization effects of various agonist using intracellular recording techniques in Purkinje neurons. Number in parentheses indicates the number cells. *Indicates relative magnitude of geometric mean values compared to Sprague-Dawley control animals as an indicator of the shift in the concentration-response curve (e.g., 1=no shift). "Indicates a statistically significant difference/shift of this $\mathrm{EC}_{50}$ value for GEPR-9 rats to both GABA and muscimol compared to all other groups $(\mathrm{p}<0.05)$. 


\section{F. Comparison of GABA Responses Using the Whole-Cell Patch-Clamp Technique}

The next phase of these studies was to investigate $\mathrm{GABA}_{\mathrm{A}}$-receptor activation using the whole-cell patch-clamp technique. This technique allowed for a more direct and precise comparison of receptor activation between animal strains. In these studies, P15+Sprague-Dawley, GEPR-3, and GEPR-9 animals were investigated. One technique used to make comparisons was to construct concentration-response curves for the peak $\left(\mathrm{I}_{\mathrm{P}}\right)$ and steady-state $\left(\mathrm{I}_{\mathrm{SS}}\right)$ whole-cell currents activated by GABA superfusion at a holding potential $\left(\mathrm{V}_{\mathrm{H}}\right)$ of $-60 \mathrm{mV}$, near the mean RMP determined for P15+ Purkinje neurons in the earlier intracellular studies (see Table 4). The second technique employed was to voltage-clamp the membrane potential at various potentials and measure the peak current induced by a saturating concentration of GABA $(1 \mathrm{mM})$. These results were then used to construct mean I/V curves for each animal strain (see section VI).

As mentioned in the methods (section VI), prior to voltage -clamping, RMP and IR values were briefly estimated upon initially achieving the whole-cell configuration. The mean RMP and IR values from these estimations are provided in Table 15. Though the RMP values obtained via the whole-cell patch-clamp technique were quite similar to the mean values obtained using intracellular techniques (Table 4), the mean IR values were dramatically increased compared to those obtained via intracellular recording (Table 5). Similar to the results obtained via intracellular recording, neither the RMP nor the IR were significantly different between animal strains ( $p>0.05)$.

The first series of experiments examined the whole-cell conductance properties of Purkinje neurons voltage-clamped at a holding potential of $-60 \mathrm{mV}$. After superfusing multiple concentrations of GABA for several neurons, mean concentration-response curves for whole cell conductance were constructed. Figure 27 presents concentration-response curves constructed for 


\begin{tabular}{|c|c|c|c|}
\hline & Sprague-Dawley & GEPR-3 & GEPR-9 \\
\hline $\begin{array}{c}\text { Resting Membrane } \\
\text { Potential }(\mathrm{mV})\end{array}$ & $-61.2 \pm 1.4$ & $-62.6 \pm 1.6$ & $-58.6 \pm 2.6$ \\
\hline $\begin{array}{c}\text { Input Resistance } \\
(\mathrm{M} \Omega)\end{array}$ & $454 \pm 22$ & $491 \pm 13$ & $445 \pm 22$ \\
\hline Number of Cells & 17 & 18 & 14 \\
\hline
\end{tabular}

TABLE 15. Resting membrane potential $(\mathrm{mV})$ and input resistance $(\mathrm{M} \Omega)$ of Purkinje neurons in cerebellar slices immediately following attainment of whole cell configuration of the patch-clamp technique. There were no statistically significant differences between animal strains $(\mathrm{p}<0.05)$. 
Sprague-Dawley, GEPR-3, and GEPR-9 Purkinje neuron peak current $\left(\mathrm{I}_{\mathrm{P}}\right)$ amplitudes. Also included as an inset to Figure 27 is the plot to determine the Hill coefficient $\left(\log -\log\right.$ plot of $\mathrm{I}_{\mathrm{P}} \div$ $\left(I_{\max }-I_{P}\right)$ vs. $\left.[G A B A]\right)$. Similar to concentration-response curves obtained via intracellular recording, the GEPR-9 response curve was shifted rightward without a significant decrease in maximal response $\left(\mathrm{I}_{\mathrm{P}}\right)$. Unlike the concentration-response curves obtained for GEPR-3 Purkinje neurons there was no decrease in maximal response when whole-cell peak currents were measured. The estimated geometric mean $\mathrm{EC}_{50}$ values for the whole-cell concentration response curves were 9.1 $\pm 0.6 \mu \mathrm{M}$ (Sprague-Dawley), 9.2 $\pm 0.9 \mu \mathrm{M}$ (GEPR-3), and 18.2 $\pm 1.1 \mu \mathrm{M}$ (GEPR-9), indicating no shift and a 2-fold rightward shift of the concentration response curves of GEPR-3 and GEPR-9 Purkinje neurons compared to Sprague-Dawley, respectively. The Hill coefficients are represented in Figure27 as the slopes of the corresponding inset plot. These values were 1.78 (Sprague-Dawley), 1.48 (GEPR-3), and 1.67 (GEPR-9).

Since concentrations of GABA near the $\mathrm{EC}_{50}$ concentration and higher typically caused a marked level of desensitization with prolonged exposure, concentration-response curves were also constructed to compare the steady-state $\left(\mathrm{I}_{\mathrm{SS}}\right.$ ) currents as a function of the higher GABA concentrations $(10 \mu \mathrm{M}-100 \mu \mathrm{M})$ employed. These plots can be found in Figure 28. The results of this analysis revealed that, though GEPR-9 and Sprague-Dawley Purkinje neurons had statistically equivalent $I_{S s}$ levels at each of these concentrations, GEPR-3 Purkinje neurons displayed significantly reduced $\mathrm{I}_{\mathrm{SS}}$ levels compared to Sprague-Dawley Purkinje neurons at both 30 and 100 $\mu \mathrm{M}$ GABA $(\mathrm{p}<0.05)$.

The next set of experiments examined the conductance characteristics of Purkinje neurons at various holding potentials $\left(\mathrm{V}_{\mathrm{H}}\right)$ at a concentration of GABA $(1 \mathrm{mM})$ which gave maximal peak 


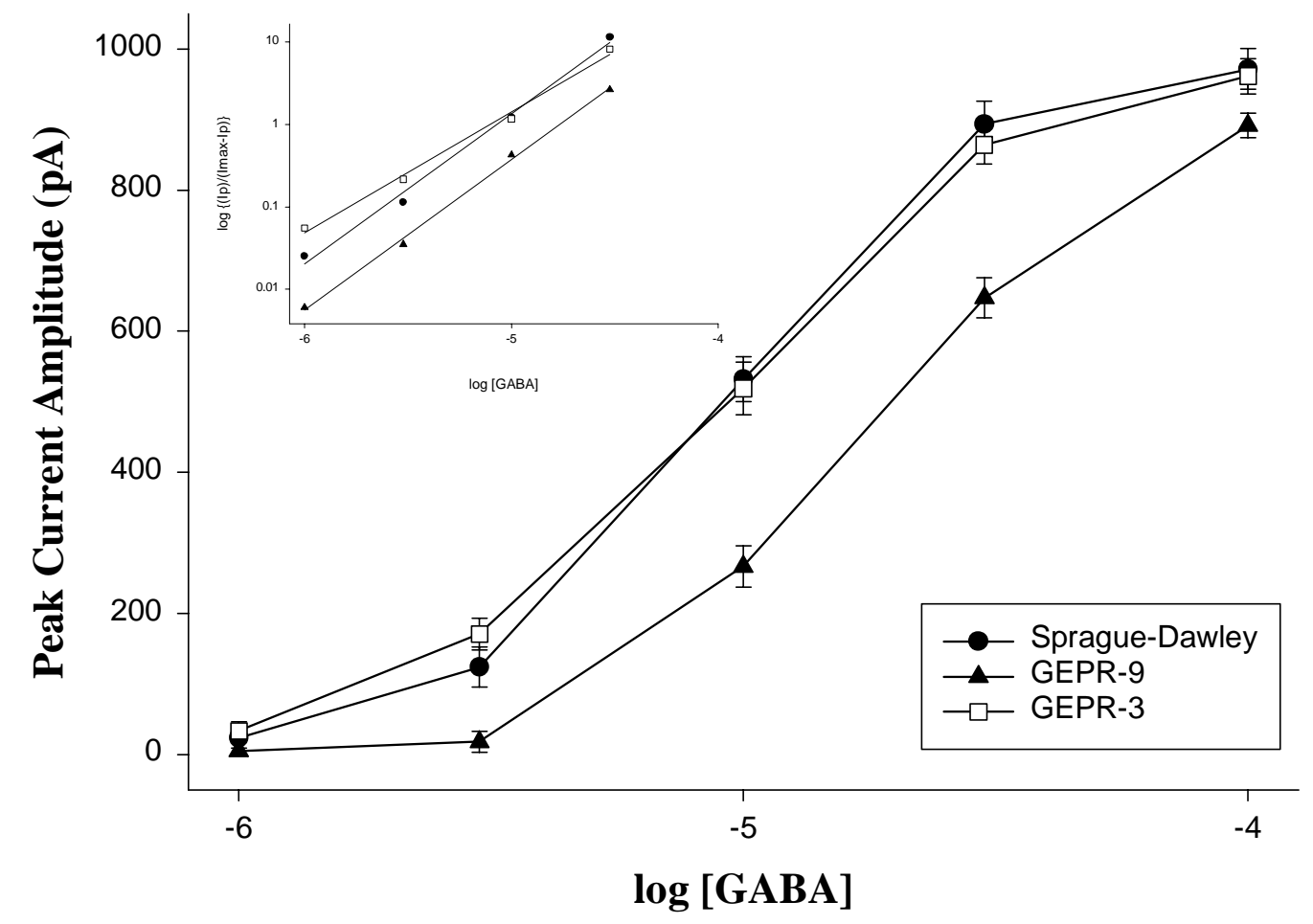

Figure 27. Concentration response curves of the mean neuron peak current amplitudes of Purkinje neurons to superfusion of GABA. Inset represents the Hill plot of concentration response data. 


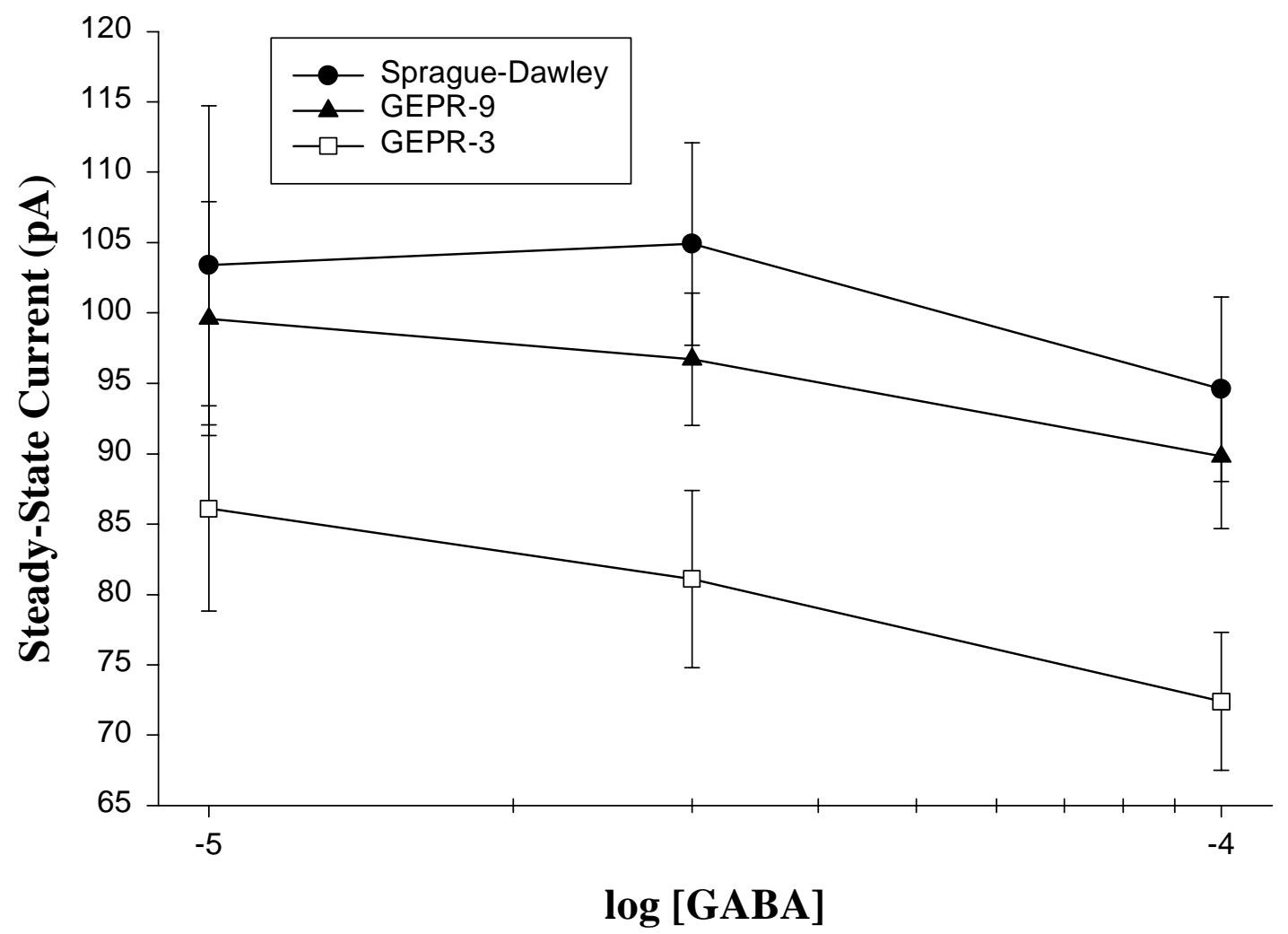

Figure 28. Mean concentration response curve of Purkinje neurons to superfusion of higher concentrations of GABA depicting the steady state current. Note that GEPR-3 neurons showed reduced steady state current. 
currents in all three animal strains. The mean I/V curves constructed from these experiments are plotted in Figure 29. Though standard error bars are not included for the plots in this curve for presentation purposes, it can be seen that Purkinje neurons from all three animal strains displayed similar peak current characteristics for $1 \mathrm{mM} \mathrm{GABA}$, not differing in $I_{P}$ level at any $V_{H}$. Furthermore, the reversal potentials of Purkinje neurons were similar for all three animal strains at a potential near zero. At a $\mathrm{V}_{\mathrm{H}}$ of $0 \mathrm{mV}$, the closest holding potential to the reversal potential, the current amplitudes of each animal strain were $74 \pm 34 \mathrm{pA}$ (Sprague-Dawley), $66 \pm 28 \mathrm{pA}$ (GEPR-3), and $14 \pm 24$ pA (GEPR-9). 


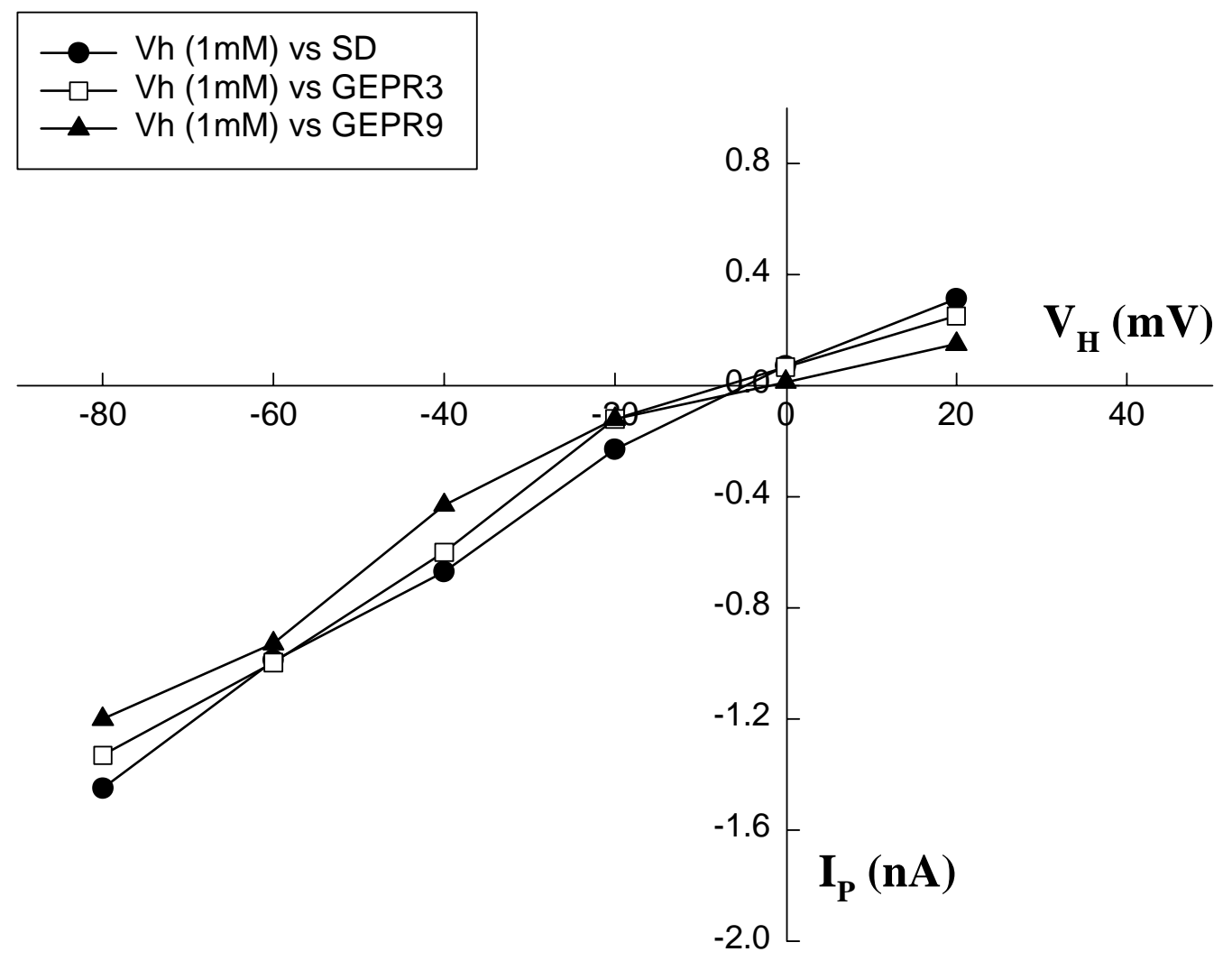

Figure 29. Mean I/V curves of Purkinje neurons exposed to $1 \mathrm{mM}$ GABA held at various membrane potentials. 


\section{G. Comparison of GABA Responses in Single-Channel Outside-Out Patches}

As a final examination of the response characteristics of Purkinje neurons to $\mathrm{GABA}_{\mathrm{A}^{-}}$ receptor activation, single channel characteristics were studied using the outside-out patch-clamp technique. The aim of these experiments was to compare the basic conductance properties of single $\mathrm{GABA}_{\mathrm{A}}$-receptor channels from Sprague-Dawley, GEPR-3, and GEPR-9 Purkinje neurons to determine whether single channel conductance amplitudes were different between animal strains. Specifically, neuronal steady-state conductances $\left(\mathrm{I}_{\mathrm{SS}}\right)$ were compared with regard to the magnitude of the single channel conductance states, mean open times, and mean closed times in response to applications of $100 \mu \mathrm{M}$ GABA.

These experiments identified two conductance states of the $\mathrm{GABA}_{\mathrm{A}}$-receptor, one of approximately $28 \mathrm{pS}\left(1.70 \mathrm{pA}\right.$ current at $\mathrm{V}_{\mathrm{H}}$ of $\left.-60 \mathrm{mV}\right)$ and another of approximately $21 \mathrm{pS}(1.26$ pA current at $\mathrm{V}_{\mathrm{H}}$ of $-60 \mathrm{mV}$ ). Examples of these two different conductance states are shown in Figure 9 (section VI). A histogram plot depicting these separate conductance states for GEPR-9 Purkinje neurons is presented in Figure 30. The histogram plots the amplitude of detected open events versus the frequency with which each of these amplitudes was detected into $0.02 \mathrm{pA}$ bins. These conductance states were highly consistent between patches from not only single Purkinje neurons, but also patches from Purkinje neurons from all three animal strains. The larger conductance level accounted for approximately $95 \%$ of the total current observed in these patches, with only rare openings to the $21 \mathrm{pS}$ "subconductance" level.

Using the Fetchan analysis program of the pClamp software package (Axon Instruments), the observed total number of openings, mean open durations, and mean closed durations for the main conductance level ( $28 \mathrm{pS})$ at $\mathrm{I}_{\mathrm{sS}}$ in response to $100 \mu \mathrm{M}$ GABA were determined and are 
presented in Table 16. Mean observed times are listed as no manipulation of the data was performed in order to account for missed open and closed events. Figure 31 presents histograms of open durations for each animal strain, illustrating the similar distribution of open durations between Purkinje neurons from each strain. A statistical comparison of the mean open and closed durations revealed no differences between Purkinje neurons from these three animal strains. 


\begin{tabular}{|c|c|c|c|}
\hline & Sprague-Dawley & GEPR-3 & GEPR-9 \\
\hline \hline $\begin{array}{c}\text { Mean open duration } \\
\text { (msec) }\end{array}$ & $4.20 \pm 0.11$ & $3.90 \pm 0.34$ & $4.16 \pm 0.15$ \\
\hline $\begin{array}{c}\text { Mean closed duration } \\
\text { (msec) }\end{array}$ & $81.7 \pm 2.8$ & $89.1 \pm 5.4$ & $85.6 \pm 3.6$ \\
\hline Number of Openings & 2472 & 1351 & 1822 \\
\hline
\end{tabular}

TABLE 16. Mean open durations (msec) and closed durations (msec) obtained from single-channel recordings of Purkinje neurons from Sprague-Dawley, GEPR-3, and GEPR-9 animals. The number of events represents to total pooled events for each given animal. Data are presented as mean \pm S.E.M. There were no significant differences in mean open or closed duration when comapring any of the three animal strains $(\mathrm{p}>0.05)$. 


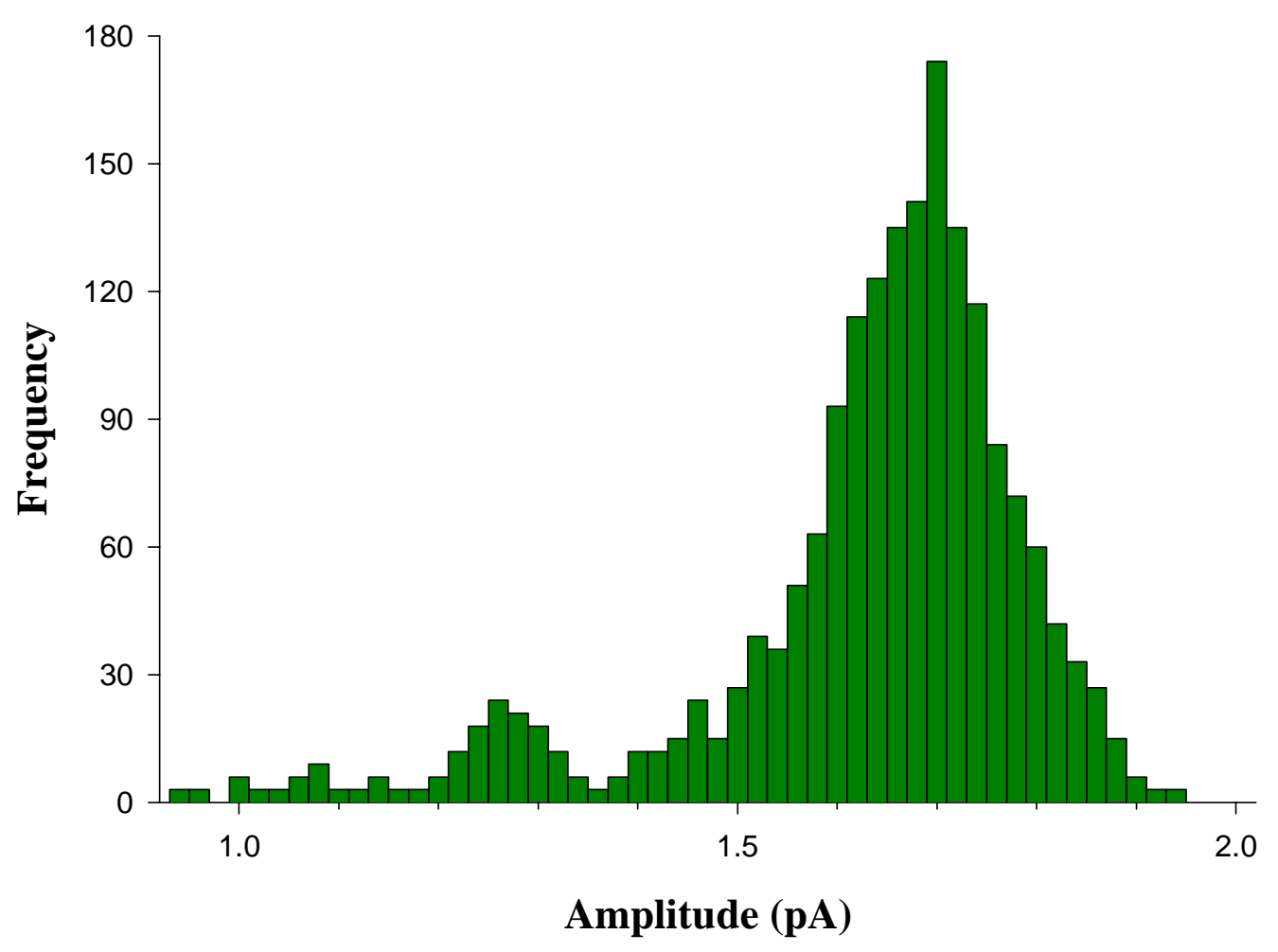

FIGURE 30. Histogram plot of the amplitude of detected open events for GEPR-9 Purkinje neurons. Amplitudes are binned in $0.02 \mathrm{pA}$ increments. Amplitudes include all open events for GEPR-9 Purkinje neurons $(\mathrm{n}=1822)$. 


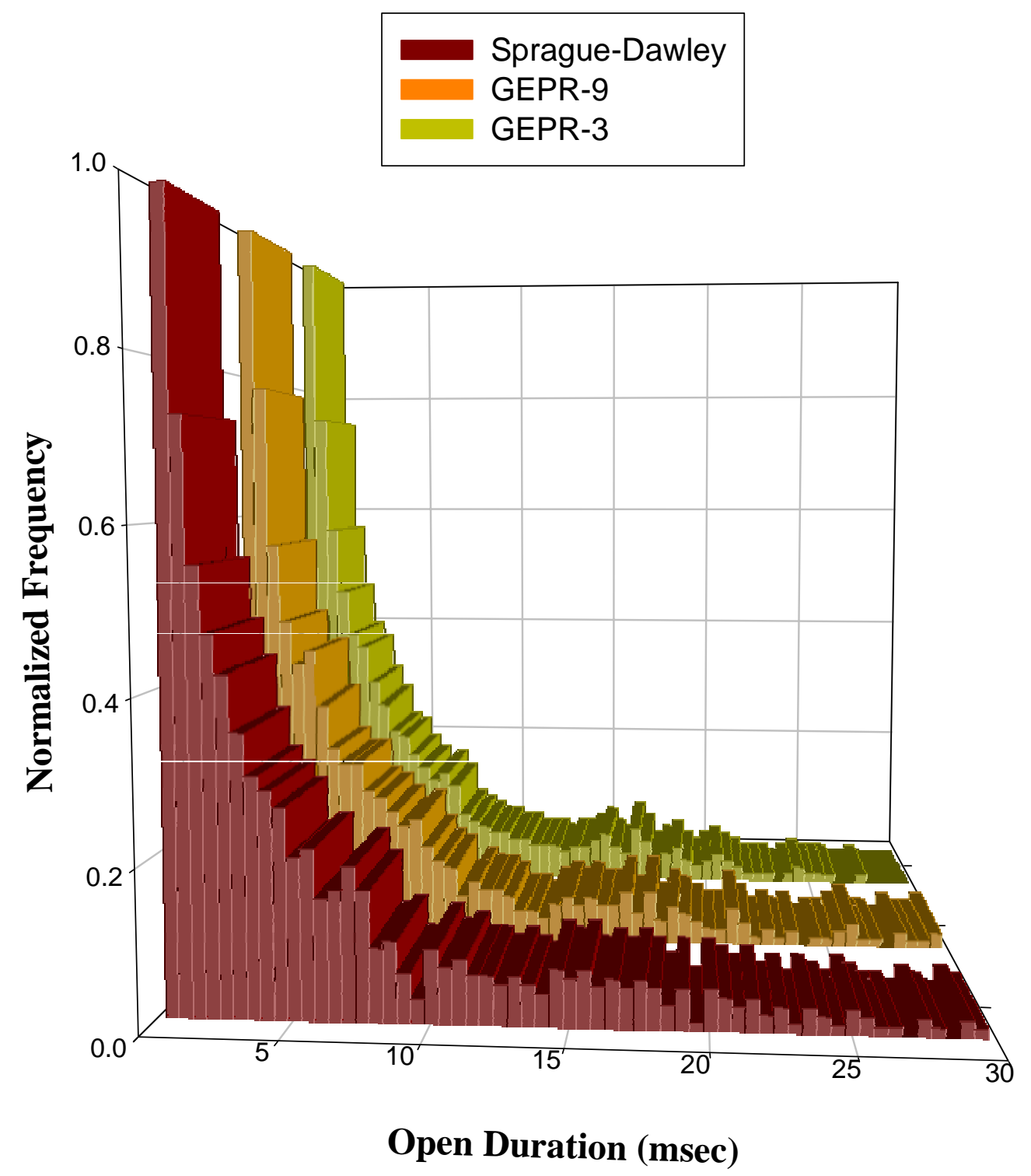

FIGURE 31. Histogram plots of open durations for Sprague-Dawley, GEPR-3, and GEPR-9 Purkinje neurons upon application of $100 \mu \mathrm{M}$ GABA. Open durations are plotted in $0.5 \mathrm{msec}$ bins and plotted as normalized frequency. 


\section{Discussion}

The regulation of cellular responsiveness plays a prominent role in how neurons of the mammalian central nervous system communicate with one another, and thus, improper regulation of responsiveness represents a potential form of pathology of the nervous system. Many forms of epilepsy represent just such pathological conditions in that neurons are hyperexcitable (i.e., too responsive to excitatory drive or unresponsive to inhibitory input). To study the mechanisms by which this hyperexcitability develops in epilepsy, many investigators have chosen to examine genetic animal models of epilepsy since many of these models share important traits with human forms of epilepsy (Jobe et al., 1991). In the present studies, Purkinje neurons of the cerebellum of genetically epilepsy-prone rats (GEPRs) were studied electrophysiologically in an attempt to ascertain a general mechanism which may account for the seizure susceptibility of these animals.

The GEPR-9, the most severely seizure-prone of the GEPRs, is an animal model which appears to have numerous central nervous system abnormalities. The most prominently investigated and documented of these abnormalities are the alterations in serotonergic and noradrenergic signaling systems. In the mammalian brain, these neurotransmitter systems are rather diffuse and appear to serve primarily to modulate the activity of other signaling systems (Cooper et al., 1991). Though some investigators have claimed that "epileptic predispositions in GEPRs is partially caused by noradrenergic and serotonergic deficits" (Jobe et al., 1991) based upon the observations that there are numerous deficits in these systems and that experimentally inducing further deficits increases seizure susceptibility, a causal role for these systems has never been shown, only a correlative role. Furthermore, lesions of the locus coeruleus (Anselmo-Franci et al., 1997), the 
major noradrenergic nucleus in the mammalian brain, or of the raphe nuclei (Jacobs and Fornal, 1995), the major serotonergic nuclei of the mammalian brain, do not appear to increase seizure susceptibility in otherwise normal animals. Similarly, measurement of fos-like-immunoreactivity in the locus coeruleus following audiogenic seizures in the GEPR-9 indicates that the locus coeruleus activity in the GEPR-9 is equivalent to that of control rats (Eells et al., 1997). These latter observations, combined with the ability of noradrenergic and serotonergic systems to enhance both inhibitory and excitatory neurotransmission (Cooper et al., 1991), suggest that other factors are likely to be involved in the seizure-predisposition of these animals.

To this end, some excesses in excitatory transmission utilizing glutamate and aspartate have been noted in the GEPR-9 (Jobe et al., 1991). However, deficiencies of the inhibitory GABAergic system appear to be more plentiful and uniform throughout the GEPR-9 brain. As the major inhibitory neurotransmitter in the mammalian central nervous system, GABA stands to play a pivotal role in determining the general state of excitability of the brain. Although excess numbers of GABAergic terminals have been noted in a few areas, a deficient level of GABAergic transmission has been observed in all areas of the GEPR brain studied (see review by Jobe et al., 1991).

In addition to the GEPR-9, there are two other GEPR strains, the GEPR-NE and the GEPR3. The GEPR-NEs serve as a genetic control for GEPR-3 and GEPR-9 animals in that they do not exhibit any heightened level of seizure-predisposition compared to the Sprague-Dawley animals from which they and the GEPR-3/9s were derived (Jobe et al., 1993a). Having a genetic control such as the GEPR-NE provides a valuable tool for the investigation of factors which may contribute to the seizure-prone state of the GEPR-3 and GEPR-9 animals. Simply put, differences from normal 
Sprague-Dawley animals which are common to both seizure-prone GEPRs (3s and 9s) and nonseizure-prone GEPR-NEs are not likely to represent differences which contribute to the epileptic state of the seizure-prone GEPRs. Thus, the GEPR-NE serves as a powerful means by which to discriminate between deficits that may be contributory to the seizure-prone state of GEPR-3s and 9s and those which likely are not involved in this predisposition.

The GEPR-3 animals present moderate seizure severity upon audiogenic stimulation (Jobe et al., 1991). Due to this fact, more subtle or less profound differences are commonly assumed to be present in these animals (as compared to GEPR-9s) and, thus, these animals have not been nearly as thoroughly investigated as the GEPR-9s (Jobe et al., 1991). The only consistent finding in the GEPR-3s is that they are not simply "milder" versions of the GEPR-9. That is, they do not directly exhibit intermediate levels of deficits which have been found in the GEPR-9. For example, the response of GEPR-3 animals to anti-epileptic drugs compared to GEPR-9s is erratic. Though certain agents are equally effective in both animals (e.g., clonazepam, phenobarbital), others are more effective in the GEPR-3 (e.g., valproate, loreclezole), and still others are less effective (e.g., phenytoin, carbamazepine; Dailey et al., 1996). These findings emphasize the point that epilepsy is a group of related, yet distinct, neurological diseases with neuronal hyperexcitability as their common, underlying cause. The ability to gain advances in the treatment of these diseases will derive from the concerted efforts of investigating and understanding its various forms.

Based primarily upon the information available for the GEPR-9s, the present studies investigated the GABAergic system of the GEPR strains in a region of the brain well suited for such studies, the cerebellum. The cerebellum is an excellent model system for studying GABAergic neurotransmission, especially in the rat, for a number of reasons (see review by Wisden et al., 
1996), including:

1) It is a structure which has been conserved throughout evolution (Ito, 1984),

2) It has a well documented development (see section III),

3) It is readily accessible,

4) Individual neuronal populations can be identified, and

5) GABA-receptor expression for most cell types has been intricately detailed (see section IV)

Studies by Gould et al. (1991, 1995) utilizing extracellular recording techniques in situ, indicated that GEPR-9 Purkinje neurons are specifically subsensitive to $\mathrm{GABA}_{\mathrm{A}}$-receptor activation. Since such a specific subsensitivity would indicate either an alteration in receptor number/density or in single chloride channel characteristics (see section IA), these investigators also chose to measure radioligand binding sites for $\left[{ }^{3} \mathrm{H}\right]$-muscimol and $\left[{ }^{3} \mathrm{H}\right]$-flunitrazepam, both of which bind the $\mathrm{GABA}_{\mathrm{A}}$-receptor complex, in cerebellar homogenates from GEPR-9 and control animals (Gould et al., 1995). These studies indicated that such binding sites were not quantitatively different between GEPR-9 and control rats. Based upon the findings of these authors, the present studies have focused on the general hypothesis that the GABA subsensitivity in Purkinje neurons of the GEPR-9 is due to a decreased ability to conduct chloride ions upon activation of $\mathrm{GABA}_{\mathrm{A}}$-receptors. However, in order to more fully investigate this possibility, recording techniques offering greater precision and providing the ability to record from cell somata needed to be employed, namely, intracellular and patch-clamp recording from in vitro cerebellar slices to allow greater examination of activity at the cellular level. 


\section{A. Purkinje Neurons in Cerebellar Slices Obtained from Sprague-Dawley, GEPR-NE, GEPR-3, and GEPR-9 Animals Have Equivalent Basic Electrical Membrane Properties}

In order to start investigating possible GABAergic deficits in the GEPR cerebellum, it was first important to be sure that such a deficit existed in the recording model chosen. Once preliminary studies had shown this to be the case for GEPR-9s (see section VIIID for greater detail), the first goal was to test two similar hypotheses. One was that the resting membrane potential (RMP) and input resistance (IR) of Purkinje neurons from GEPR and control animals would be similar in the adult animals that previous investigators had studied (Gould et al., 1991, 1995). The second hypothesis was that these properties would also be similar at younger ages (near 15 days of age) both prior to the development of seizure-susceptibility and shortly thereafter. If this latter hypothesis was true, it would permit the use of these younger animals in later experiments focused on cellular mechanisms, since these are better suited for studying slices from immature animals. The results of these experiments can be see in Tables 4 and 5, as well as Figures 10 and 11 .

In every age group examined, there was never a difference in RMP or IR among the four animal strains even though there were parallel developmental changes in these properties for each. Such developmental changes common to all strains are discussed in section VIIIB. Though RMPs and IRs for Purkinje neurons have been rarely reported in the literature for normal rats and not at all for the GEPRs, the values obtained in the present experiments are quantitatively similar to previous studies which have measured and reported these values. Using whole-cell patch clamp recording techniques, Puia et al. (1994) reported a mean RMP for cerebellar Purkinje neurons of adult rats of $-61 \mathrm{mV}$. The small discrepancy between these values and the ones obtained in the present study ( -57 to $-58 \mathrm{mV}$ ) may be attributable to the different techniques used to obtain them. 
One of the disadvantages that the intracellular recording technique presents is that impalement of a cell with a sharp electrode essentially creates a hole in the membrane. By doing so, a voltageindependent conductance is created that is not ion selective, with a reversal potential of approximately $0 \mathrm{mV}$ (Hagiwara and Jaffe, 1979). This may result in an unavoidable disruption of the "true" RMP and thus yield a slight depolarization of the membrane potential. However, using careful technique and permitting time for repolarization can help to minimize this effect and allow meaningful comparisons to be made. Since the values obtained in these experiments are fairly close to those values obtained using the less invasive technique of whole-cell patch clamping both later in these studies (see Results, Table 15), as well as by others (Puia et al., 1994), they are likely to adequately represent an accurate estimation of the true RMP of Purkinje neurons in cerebellar slices.

The IRs determined in the present studies are also similar to published values for Purkinje neurons obtained using intracellular recording. As with RMP, the leakage current due to cell impalement appears to alter the IR obtained using intracellular recording as compared to patch clamp techniques. In cerebellar slices, intracellular recordings have yielded a mean IR of $6 \mathrm{M} \Omega$ (Crepel and Delhaye-Bouchaud, 1979), whereas a mean of $167 \mathrm{M} \Omega$ was reported in studies using patch clamp recording (Llano et al., 1991), and a mean of around $450 \mathrm{M} \Omega$ was found in the present study (see Table 15) using similar techniques. Such a discrepancy casts doubt as to how well IRs obtained with intracellular recording represent and relate to those which might be found in vivo. However, if one assumes that the effect of the leakage current created is approximately the same over a large population of cells and since changes in IR can be detected during drug exposure, these values may still serve as valuable qualitative tools in determining changes in IR, and thus the possible involvement of changes in ion conductance during such drug exposures. In conclusion, 
though the values of the electrical membrane properties measured in the present experiments may not perfectly reflect in vivo values, they are similar to values reported by other investigators for similar preparations and lend further support to the proposition that RMP and IR are not significantly different between Purkinje neurons from Sprague-Dawley, GEPR-NE, GEPR-3, and GEPR-9 rats. Thus, any differences in agonist sensitivity are unlikely to be the result of a general change in the excitability of Purkinje neurons as is strongly supported by the pharmacological data (see below).

\section{B. Developmental Changes in Cellular Responsiveness of Purkinje Neurons}

The primary task undertaken in the present studies was to use intracellular recording techniques to investigate the cellular responsiveness of Purkinje neurons in vermal cerebellar slices. These experiments employed the superfusion of drugs while measuring changes in membrane polarization as the pharmacological response. In order to discuss the results of these experiments in an organized and logical manner, the results obtained from Sprague-Dawley control animals will first be focused upon, followed by a comparison to the results obtained from the other animals strains in section VIIID.

Before embarking on the discussion of the pharmacological responsiveness of Purkinje neurons, however, a brief discussion of the developmental findings (common to all animal strains) is pertinent. As noted in VIIIA, during the course of comparing the resting membrane potential (RMP) and input resistance (IR) of Purkinje neurons from Sprague-Dawley and GEPR rats of various ages, an unexpected developmental change in these properties became apparent in each animal strain. As seen in Figures 10, 11, and 12 as well as Tables 4 and 5, there is a significant 
hyperpolarization of the membrane potential and significant decrease in IR from animals aged 15 days postnatal and older compared to animals 10-14 days of age. Attempts to determine if these changes had been previously reported in the literature were unsuccessful. However, pieces of various studies do lend support to the idea that this change is a true alteration and not the effect of the experimental model system used (i.e., the in vitro slice method).

Mariani and Changeux (1981a) determined RMP using intracellular recording methods for 30 Purkinje neurons from normal rats which yielded a mean of $-51 \mathrm{mV}$. The neurons were from animals of various ages $(\mathrm{P} 5-9, \mathrm{n}=4 ; \mathrm{P} 10-15, \mathrm{n}=21$; and $\mathrm{P} 16+, \mathrm{n}=5)$ which makes interpretation a little more difficult. However, the RMP is decreased compared to the P15+ animals reported here and the RMP for Purkinje neurons from adult animals reported by Crepel et al. (1982), and are similar to the values obtained in the present experiments for P10-14 aged animals. Furthermore, it would appear that most of the Purkinje neurons in the Mariani and Changeux (1981a) study came from animals less than 15 days of age, though the exact number is not reported. The study also reported input resistances for Purkinje neurons from rats age P5-11 (10.7 M $\Omega$ ) and P13-15 (7.3 $\mathrm{M} \Omega$ ). Thus, there is also precedence for a developmental decrease in IR as well. Other than these studies, the literature appears to be devoid of data on the basic electrical membrane properties of Purkinje neurons of the developing rat cerebellum.

Since this hyperpolarization of the Purkinje neuron membrane potential happened to coincide with the postnatal age at which GEPRs become seizure-prone, some basic steps were taken in order to gain a better understanding of the mechanism by which it may be occuring. To this end, the experiments described in VIB, employing the superfusion of ouabain onto Purkinje neurons from Sprague-Dawley rats of various postnatal ages, were performed. The $\mathrm{Na}^{+}, \mathrm{K}^{+}$-pump was used 
as an initial target for these investigations due to its prominent role in determining the membrane potential (see section I) and the fact that some relatively simple experiments could be performed to gain a resonably rapid understanding of this process.

If regulation of the activity of the sodium-pump was involved in the developmental hyperpolarization of Purkinje neurons, it was expected that saturating concentrations $(1 \mathrm{mM})$ of the pump-inhibitor, ouabain, would have a more prominent effect on the membrane potential in animals older than 15 days compared to P10-14 animals. The results of these experiments (see Figure 14 and Table 6) revealed that ouabain did have an increased effect on the membrane potential of Purkinje neurons from older animals, coincident with the developmental hyperpolarization of these neurons. In addition, as detailed in Table 6 , the final membrane potential after ouabain exposure was statistically equivalent for all age groups ( $p>0.05$ ). These findings are thus solid evidence for an increased $\mathrm{Na}^{+}, \mathrm{K}^{+}$-pump activity underlying the developmental hyperpolarization of Purkinje neurons around postnatal age 15 (P15).

In light of the observations that Purkinje neuron membranes became hyperpolarized during development and that the magnitude of ouabain-induced depolarizations of the membrane increased during development, other members of the laboratory performed radioligand binding studies using $\left[{ }^{3} \mathrm{H}\right]$-ouabain in cerebellar homogenates to determine if binding sites for this ligand were increased in P15+ Sprague-Dawley animals compared to P10-14 animals. The results of these studies indicated an approximate 2-fold increase in the $\mathrm{B}_{\max }$ (maximal binding) and no significant change in the $\mathrm{K}_{\mathrm{D}}$ for ouabain binding (Taylor et al., 1998). Similarly, studies by Atterwill et al. (1985) noted a 4-fold increase in $\mathrm{Na}^{+}, \mathrm{K}^{+}$-ATPase activity in rats age $\mathrm{P} 22$ versus rats age $\mathrm{P} 11$. The findings from these studies along with those of the present study suggest that there is a developmental 
increase in the number of $\mathrm{Na}^{+}, \mathrm{K}^{+}$-pump sites, the level of $\mathrm{Na}^{+}, \mathrm{K}^{+}$-ATPase activity, and the contribution of this activity to the RMP.

Another developmental difference seen in each animal strain was in the pharmacological responsiveness of Purkinje neurons to various agonists. As noted in Tables 7, 9, and 12, there were occasional (approximately $20-25 \%$ overall) depolarizing responses to GABA and/or muscimol for Purkinje neurons from P10-14 animals of each strain tested. Although no evidence of such findings was discovered in the literature, there are a number of instances where evidence has revealed that $\mathrm{GABA}_{\mathrm{A}}$-receptor activation leads to depolarizing responses transiently during the developmental period of a variety of other neurons (Ben-Ari et al., 1989; Cherubini et al., 1990; Conner et al., 1987; Janigro and Schwartzkroin, 1988; Wu et al., 1992; Yuste and Katz, 1991). In general, these depolarizing responses have been found to be the result of changes in intracellular chloride ion concentration, though some authors have proposed a role for bicarbonate ion in this process (Staley et al., 1995).

Young animals (P10-14) from each strain also displayed a decreased responsiveness to aspartate and glutamate (see Tables 8, 10, and 13). In contrast, NMDA was more effective in depolarizing Purkinje neurons from young Sprague-Dawley and GEPR-9 animals (the only animal strains for which NMDA was examined; see Table 10). Though these results were not initially expected, precedence for these findings were found in the literature. Dupont et al. (1987), studying the postnatal development of sensitivity in the rat cerebellum, found both increases in response to aspartate and glutamate with animal age as well as a similar decrease in responsiveness to NMDA.

Though each of these previously mentioned developmental alterations in Purkinje neuron responsiveness represent interesting findings, they do, in fact, deviate from the primary focus of the 
present study. For this reason, the remaining discussion will focus upon the experimental results obtained from animals 15 days and older. Thus, all data discussed below will be assumed to be from the P15+ population of animals unless otherwise specified.

\section{Cellular Responsiveness of Sprague-Dawley Purkinje Neurons to Various Agonists}

This discussion will focus upon the control results obtained from Sprague-Dawley Purkinje neurons using intracellular recording techniques in cerebellar slices. As alluded to in section VIIIA, there have not been many studies reporting the results of intracellular recording of Purkinje neurons in slices. However, there have been enough studies using similar techniques to make meaningful comparisons to the results obtained in the present study. Itier et al. (1996), studying acutely dissociated Purkinje neurons, found that GABA induced inward currents in a concentrationdependent manner with an $\mathrm{EC}_{50}$ of approximately $4 \mu \mathrm{M}$, which is very similar to the value of 6.6 $\mu \mathrm{M}$ obtained in the present study for GABA-induced hyperpolarizations (see Figures 15, 19, and 23 and Table 14).

Although approximate $\mathrm{EC}_{50}$ values for muscimol in similar experiments have not been found in the literature, inferences can be made from studies which have employed iontophoretic application of both GABA and muscimol. A study of dissociated Purkinje neurons from normal rats by Cheun and Yeh (1992) found that approximately three times more current was evoked by iontophoretically applied muscimol compared to similar levels of application of GABA. Although this value is a bit lower than the nine- to ten-fold difference seen in the present experiments, two important differences between the comparisons should be noted. The first is that muscimol-evoked responses in the study by Cheun and Yeh (1992) were near maximal currents and thus may 
underestimate the difference in the effectiveness of these two compounds to elicit a response, since comparisons made at either end of a concentration-response curve may not accurately reflect comparisons made from the linear portion of the curve. Secondly, there is less likelihood of GABA uptake playing a role in dissociated cells as compared to in slices. Since muscimol is not susceptible to uptake by GABA transporters whereas GABA is, for equal concentrations of applied drug, more muscimol may reach the biophase than will GABA and thus a slight overestimation of the difference in effectiveness of these two compounds may result from studies done in slices.

Another important finding in Sprague-Dawley Purkinje neurons, which was also found for the other animal strains, was that there was very little, if any, $\mathrm{GABA}_{\mathrm{B}}$-receptor activity in these slices. This was confirmed by two findings during the single concentration studies. The first was that both picrotoxin and bicuculline, $\mathrm{GABA}_{\mathrm{A}}$-receptor selective antagonists, fully blocked the effects of either GABA or muscimol when applied concomitantly (see Tables 7, 9, or 12). This indicated that $\mathrm{GABA}$, in addition to muscimol, was exerting its effects solely via $\mathrm{GABA}_{\mathrm{A}}$-receptor activation. Also, neither bicuculline nor picrotoxin had significant membrane polarization effects when applied alone (again, see Tables 7, 9, or 12), which also indicated a lack of basal GABAergic tone in these cerebellar slices for Purkinje neurons. In addition, baclofen, a GABA $A_{B}$-receptor selective agonist, was without significant effect in these preparations (see Table 7, 9, or 12). The $\mathrm{GABA}_{\mathrm{B}}$-receptor, a G-protein coupled receptor that regulates $\mathrm{Ca}^{++}$and/or $\mathrm{K}^{+}$conductance (Cherubini and North, 1984; Deisz and Lux, 1985; Desarmenien et al., 1984; Gähwiler and Brown, 1985; Inoue et al., 1985a,b), has been found in the cerebellum with the highest concentrations being in the molecular layer (Bowery et al., 1987) which contains the Purkinje neuron dendrites (see section IIIA). However, previous studies have shown little effect of $\mathrm{GABA}_{B}$-receptor activation on Purkinje 
neuron activity (Parfitt et al. 1990; Cheun and Yeh, 1992). Thus, in agreement with other studies, it can be concluded from the results of these experiments that the primary effects of GABA neurotransmission are mediated via the $\mathrm{GABA}_{\mathrm{A}}$-receptor for Purkinje neurons of the rat cerebellum. The effects of the excitatory amino acids, glutamate and aspartate (as well as NMDA), were also as expected for Sprague-Dawley Purkinje neurons. In response to glutamate or aspartate, depolarizations of the membrane potential were accompanied by a decrease in the IR, indicating a direct effect on the Purkinje neurons via increased ion conductance. Although $\mathrm{EC}_{50}$ values for these agonists on Purkinje neurons in cerebellar slices were not found in the literature, Dupont et al. (1987) found that glutamate was approximately twice as potent as aspartate and Crepel et al. (1982), using iontophoretic application of drugs, reported the ratio of $\mathrm{IC}_{50}$ values (glutamate/aspartate) to be approximately 1.45 for Purkinje neurons from normal rats. These values are very similar to the ratio of $\mathrm{EC}_{50}$ values found in the present study (1.97; see Table 14). In addition, the maximal depolarizations reported for both agonists by Crepel et al. (1982) were approximately $18 \mathrm{mV}$ in amplitude, as was found in the present study.

NMDA did not have as clear an effect on Purkinje neurons as glutamate and aspartate in the present study. The effect of NMDA on input resistance was quite variable, with only 10 of 17 (59\%) Sprague-Dawley Purkinje neurons responding with a decrease in IR. Furthermore, NMDA yielded only minor depolarizations (mean $=2.2 \pm 0.4$ ) when applied to Sprague-Dawley Purkinje neurons. These variable effects on IR and relatively minor depolarizations are, however, consistent with previous studies which studied adult rat Purkinje neuron responses to NMDA (Dupont et al., 1987; Garthwaite and Beaumont, 1989; Crepel et al., 1982). 


\section{Comparison of the Responsiveness of Purkinje Neurons from GEPR-NE, GEPR-3, and}

\section{GEPR-9 Animals to that of Sprague-Dawley Purkinje Neurons}

The primary hypothesis to be tested was that Purkinje neurons in cerebellar slices from the GEPR-9 would display subsensitivity to the neurotransmitter GABA and that this subsensitivity is specifically mediated via the $\mathrm{GABA}_{\mathrm{A}}$-receptor subtype. In addition, it was hypothesized that GEPRNE Purkinje neurons would display no differences in responsiveness compared to Sprague-Dawley Purkinje neurons. No firm hypotheses were made concerning the cellular responsiveness of GEPR3 Purkinje neurons due to the lack of available data concerning these animals. However, it was hypothesized that their cellular responsiveness would be different from both control animals (Sprague-Dawley and GEPR-NE) and GEPR-9 animals. This was based upon the fact that (1) they display a different seizure-prone state than both of these populations of animals (see section II) and (2) the seizure-prone state is believed to be highly dependent upon the level of cellular responsiveness (see sections I and II). Thus, differing seizure-prone states would likely be due to different levels of altered responsiveness.

The first portion of these studies relied upon the application of single doses of drug via superfusion to Purkinje neurons in cerebellar slices. The drugs used in each of these studies included: GABA $(10 \mu \mathrm{M})$, muscimol $(1 \mu \mathrm{M})$, bicuculline (10 and $30 \mu \mathrm{M})$, baclofen $(10 \mu \mathrm{M})$, glutamate $(10 \mu \mathrm{M})$, and aspartate $(10 \mu \mathrm{M})$. In addition, picrotoxin $(10 \mu \mathrm{M})$, norepinephrine (500 $\mu \mathrm{M})$, and diazepam $(100 \mu \mathrm{M})$ were also employed in the study of GEPR-9 Purkinje neurons. The results from norepinephrine and diazepam applications on GEPR-9 Purkinje neurons (Table 11) will be discussed at the end of this section. The results of these single-concentration studies can be found in Tables 7/8(GEPR-NE), 9/10 (GEPR-9), and 12/13 (GEPR-3). 
These results were in agreement with our initial hypotheses. First, there were no differences unveiled when comparing GEPR-NE Purkinje neurons to those of Sprague-Dawley animals to any of the agonists used. Secondly, GEPR-9 Purkinje neurons of adult (P15+) animals were selectively subsensitive to the effects of GABA and muscimol, the effects of which could be blocked by bicuculline and/or picrotoxin, indicating a specific subsensitivity of GEPR-9 Purkinje neurons to $\mathrm{GABA}_{\mathrm{A}}$-receptor activation. Thirdly, GEPR-3 Purkinje neurons displayed a selectively subsensitive response to GABA and muscimol when compared to Sprague-Dawley Purkinje neurons. In addition, though not directly compared in the results section, if GEPR-3 and GEPR-9 hyperpolarizing responses in P15+ animals are compared, they, too, are found to be significantly different at the concentrations of GABA $(10 \mu \mathrm{M})$ and muscimol $(1 \mu \mathrm{M})$ employed $(\mathrm{p}<0.05)$. Thus, the key findings of these experiments were (for the single concentrations of agonists and antagonists employed, compared to Sprague-Dawley rats):

1) GEPR-NE Purkinje neurons display an equivalent level of pharmacological responsiveness to both excitatory and inhibitory endogenous neurotransmitter receptor activation,

2) GEPR-9 Purkinje neurons display a robustly diminished response to $\mathrm{GABA}_{\mathrm{A}}$-receptor activation without displaying similar alterations in their responsiveness to excitatory neurotransmitters,

3) GEPR-3 Purkinje neurons display a slightly diminished response to GABA $_{\mathrm{A}}$-receptor activation without displaying similar alterations in their responsiveness to excitatory neurotransmitters, and

4) GEPR-3 and GEPR-9 Purkinje neurons differ selectively in their response to GABA $\mathrm{A}^{-}$ 
receptor activation.

The next step in this study was to more thoroughly investigate the responsiveness of Purkinje neurons from these animal strains by comparing complete concentration response curves. Doing so allowed for a more precise description and better understanding of the neuronal deficits in the seizure prone animals. Also, it was important to construct these curves to ensure that the concentrations of drugs used had not simply obscured the ability to discriminate actual differences which existed. When comparing the curves constructed to GABA, muscimol, glutamate, and aspartate for GEPR-NE and Sprague-Dawley animals (Figures 15 through 18, respectively), it is clear that the responsiveness of Purkinje neurons from these two animal strains is quite similar. No statistically significant differences were found in either the maximal membrane polarization responses or $\mathrm{EC}_{50}$ values for any of these agonists.

When these same comparisons are made for GEPR-9 and GEPR-3 Purkinje neurons, some discernable differences do become evident. For both GEPR-9 and GEPR-3 Purkinje neurons, the maximal responses and $\mathrm{EC}_{50}$ values in response to aspartate and glutamate were equivalent to those of Sprague-Dawley Purkinje neurons, as was expected (Figures 21, 22, 25, and 26 and Table14). This was not the case for GABA and muscimol concentration-response curves. For the GEPR-9s, both of these curves demonstrated similar phenomena (Figures 19 and 20 and Table 14). GEPR-9 Purkinje neurons had the same maximal hyperpolarization as those from Sprague-Dawley rats; however, it took increased quantities of agonist to obtain these responses. In addition, the estimated geometric mean $\mathrm{EC}_{50}$ concentrations for GABA and muscimol for GEPR-9 Purkinje neurons were both approximately 3-fold greater than the corresponding concentrations for Sprague-Dawley Purkinje neurons. Thus, the responses obtained from the GEPR-9 display a classical rightward shift 
of the concentration-response curve without a change in maximal response, indicating a specific subsensitivity of these Purkinje neurons to $\mathrm{GABA}_{\mathrm{A}}$-receptor activation.

The GABA and muscimol concentration-response curves obtained for GEPR-3 Purkinje neurons (Figures 23 and 24) implied a different form of subsensitive response of these neurons to $\mathrm{GABA}_{\mathrm{A}}$-receptor activation. In this case, the $\mathrm{EC}_{50}$ concentrations were not significantly shifted to the right, but the maximal obtainable hyperpolarization was decreased by approximately $10-15 \%$ for both agonists. In fact, for all concentrations of muscimol $\geq 1 \mu \mathrm{M}$ and concentrations of GABA $\geq 10 \mu \mathrm{M}$, the mean hyperpolarizing responses for GEPR-3 Purkinje neurons were decreased. The results of these studies further support the conclusions drawn from the single-concentration studies and emphasize that the subsensitivity of GEPR-9 Purkinje neurons exists over the entire response range, whereas the subsensitive responses of GEPR-3 Purkinje neurons occur only at the higher concentrations of agonist.

In an attempt to gain further insight into the nature of the GEPR-9 Purkinje neurons subsensitivity to $\mathrm{GABA}_{\mathrm{A}}$-receptor activation, we next examined the effects of modulators of the $\mathrm{GABA}_{\mathrm{A}}$-receptor on Purkinje neurons in cerebellar slices. As discussed in section IV, two such modulators are diazepam, a benzodiazepine, and norepinephrine. It was thought that if either of these modulators displayed an altered level of activity in the GEPR-9 then valuable clues could be obtained regarding the exact cellular mechanism of the subsensitivity to $\mathrm{GABA}_{\mathrm{A}}$-receptor activation in these animals due to the fact that the actions of these modulatory agonists are highly dependent upon subunit composition of the receptor and the existing level of GABAergic activity. In order to make these comparisons, approximate $\mathrm{EC}_{50}$ concentrations of GABA were used for each animal in an attempt to create an equal "starting point" for receptor modulation. The responses to these 
concentrations of GABA were then compared to responses of GABA in the presence of either norepinephrine or diazepam (see Table 14). Though it was hypothesized that differences might likely exist for the modulatory actions of these compounds, no such differences were found. The responses to norepinephrine $(500 \mu \mathrm{M})$, diazepam $(100 \mu \mathrm{M})$, and combinations of each of these drugs with GABA were not significantly different between GEPR-9 and Sprague-Dawley Purkinje neurons.

\section{E. Comparison of GEPR-9, GEPR-3, and Sprague-Dawley Purkinje Neuron Whole-Cell and Single-Channel Conductance Responses to GABA}

Having found a decreased membrane polarization response to GABA in both the GEPR-9 and the GEPR-3, the next step was to look at macroscopic chloride conductance. Presumably, since the membrane hyperpolarization in response to GABA was decreased for a given GABA concentration (or at high concentrations for the GEPR-3), the chloride conductance response would also be subsensitive to GABA. Thus, the aim of the whole-cell patch-clamp studies was two-fold. First, concentration response-curves for GABA-activation of macroscopic chloride conductance were constructed with the hypothesis that these response curves would be similar in nature to the membrane hyperpolarization concentration-response curves.

For the GEPR-9, the peak current amplitude $\left(I_{P}\right)$ response curve (Figure 27) revealed just that. Again, a parallel rightward shift of this curve with no significant change in the maximal peak current $\left(\mathrm{I}_{\max }\right)$ was obtained. Although the shift in $\mathrm{EC}_{50}$ was not quite as large as that for the intracellular response curves (2-fold and 3-fold, respectively), it was significant $(\mathrm{p}<0.05)$. $\mathrm{I}_{\mathrm{P}^{-}}$ response curves for GEPR-3s, however, did not reveal the same pattern as did the curves obtained 
via intracellular recording. In this case (Figure 27), there was no change in $\mathrm{EC}_{50}$ or maximal peak current response. However, plots to determine the Hill coefficient (Figure 27, inset), revealed values of 1.78 (Sprague-Dawley), 1.67 (GEPR-9), and 1.48 (GEPR-3), indicating a possible decrease in the positive co-operativity between GABA molecules in activating chloride conductance.

When concentration-response curves for steady-state current $\left(\mathrm{I}_{\mathrm{SS}}\right)$ were constructed for GABA concentrations which yielded a significant desensitization of the conductance response (Figure 28), it was found that GEPR-3 Purkinje neurons had a significantly decreased $\mathrm{I}_{\mathrm{SS}}(\mathrm{p}<0.05)$ at GABA concentrations $\geq 30 \mu \mathrm{M}$. Though $\mathrm{I}_{\mathrm{SS}}$ was less for GEPR-9 Purkinje neurons as well, it was not a statistically significant decrease ( $>0.05$ ). Thus, at concentrations roughly corresponding to GABA concentrations which produced significantly less hyperpolarization in the GEPR-3 $(\geq 10$ $\mu \mathrm{M})$, there was a decreased steady-state current (e.g., increased level of receptor desensitization).

The other aim of these whole-cell current studies was to determine if there was a shift in the reversal potential for the chloride conductance by constructing $\mathrm{I} / \mathrm{V}$ curves to a saturating concentration of GABA (1 mM; Figure 29). Such a shift in reversal potential could indicate that reduced macroscopic current responses were due to a decreased driving force for chloride ions. However, when these curves were constructed for holding potentials $\left(\mathrm{V}_{\mathrm{H}}\right)$ between $-80 \mathrm{mV}$ and +20 $\mathrm{mV}$ (at $20 \mathrm{mV}$ steps), very similar chloride reversal potentials near $0 \mathrm{mV}$ were observed. Thus, in accordance with the general hypothesis of the present study, whole cell chloride current amplitudes were subsensitive to $\mathrm{GABA}_{\mathrm{A}}$-receptor activation in the GEPR-9. Furthermore, this subsensitivity is likely due to the activation of the receptor rather than merely a change in the driving potential for chloride ions. Although whole-cell currents recorded from GEPR-3 Purkinje neurons did not reveal quite as clear an answer, it does appear that their decreased responsiveness at high concentrations 
of GABA is based upon a greater level of desensitization of the receptor without a change in peak current response $\left(\mathrm{I}_{\mathrm{P}}\right)$.

As a final step to gain additional understanding of the mechanism of GABA subsensitivity in the GEPR, single-channel currents were examined to determine if conductance amplitudes of these currents were diminished. As revealed in Table 16, the single-channel conductance amplitudes in response to $10 \mu \mathrm{M}$ GABA were not significantly different between animal strains ( $>0.05)$ and were consistent with previous reports of single-channel chloride conductance levels (Hamill et al., 1983; Sakmann et al., 1983; Macdonald and Olsen, 1994). Furthermore, mean open and closed times were similar between animal strains. Thus, the mechanisms for GABA subsensitivity in Purkinje neurons of the GEPR-9 and increased current desensitization for the GEPR-3 do not appear to rely upon a decrease in the ability of single $\mathrm{GABA}_{\mathrm{A}}$-receptor channels to conduct chloride ions upon activation by ligand.

\section{F. Conclusions}

In general, it can be clearly stated that the data obtained in the present study strongly support the hypothesis that a specific subsensitivity to $\mathrm{GABA}_{\mathrm{A}}$-receptor activation exists for Purkinje neurons of the GEPR-9 compared to those of control animals. Furthermore, it can be concluded that this subsensitivity to GABA is due to a decreased macroscopic chloride conductance in these neurons which is due to activation of the receptor-channel by GABA, rather than a shift in the driving force for chloride ions. In addition, it can be concluded that single-channel conductance amplitude is not the underlying mechanism for this decreased whole-cell conductance.

Though it was beyond the scope of the present study to more thoroughly investigate the 
single-channel properties of these animals, it appears that such studies will ultimately be required before the molecular mechanism for GABA subsensitivity in the GEPR-9s is detailed. Such studies will need to examine the ability of the $\mathrm{GABA} / \mathrm{GABA}_{\mathrm{A}}$-receptor interaction to activate chloride conductance as it appears that the decreased whole-cell conductance must rely on the ability of GABA to open the channel rather than the conductance of the channel once opened. This is supported by the findings that peak whole-cell current $\left(I_{P}\right)$ is decreased in the GEPR-9 without a concomitant decrease in single channel current amplitude.

For GEPR-3 Purkinje neurons, the primary conclusion is that they display a subsensitivy to high concentrations of GABA which is likely due an increased level of receptor desensitization but not due to a difference in single-channel conductance amplitude. In addition, it is possible that decreased co-operativity between the two GABA molecules required for maximal receptor activation may be present for Purkinje neurons of the GEPR-3. Thus, for the GEPR-3 as well, it appears that the underlying cellular mechanisms rely upon the $\mathrm{GABA} / \mathrm{GABA}_{\mathrm{A}}$-receptor interaction rather than chloride conductance, per se. Future studies to delineate the exact molecular mechanisms underlying these two different forms of GABA subsensitivity in the GEPR-9 and GEPR-3 will need to focus on the subunit composition of the $\mathrm{GABA}_{\mathrm{A}}$-receptors in these animals as it is these subunits which determine the manner in which receptors interact with GABA. Preliminarily, it can be stated that these studies will need to focus on the $\alpha$ and $\beta$ subunits of the receptor since these subunits appear to comprise the GABA binding sites and, thus, influence the GABA interaction with the receptor. 


\section{REFERENCES}

Abraham, W. C. and Tate, W. P.: Metaplasticity: A new vista across the field of synaptic plasticity. Prog. Neurobiol. 52: 303-323, 1997.

Addison, W. H. F.: The development of the Purkinje cells and of the cortical layers in the cerebellum of the albino rat. J. Comp. Neurol. 21: 459-487, 1911.

Akaike, N., Shirasaki, T., and Yakushiji, T.: Quinolones and fenbufen interact with $\mathrm{GABA}_{\mathrm{A}}$ receptor in dissociated hippocampal cells of rat. J. Neurophysiol. 66: 497-504, 1991.

Altman, J.: Autoradiographic and histological studies of postnatal neurogenesis III. Dating the time of production and onset of differentiation of cerebellar microneurons in rats. J. Comp. Neurol. 136: 269-294, 1969.

Altman, J.: Postnatal development of the cerebellar cortex in the rat I. The external germinal layer and the transitional molecular layer. J. Comp. Neurol. 145: 353-398, 1972a.

Altman, J.: Postnatal development of the cerebellar cortex in the rat II. Phases in the maturation of Purkinje cells and of the molecular layer. J. Comp. Neurol. 145: 399-464, 1972b.

Altman, J.: Postnatal development of the cerebellar cortex in the rat III. Maturation of the components of the granular layer. J. Comp. Neurol. 145: 465-514, 1972c.

Altman, J. and Bayer, S. A.: Prenatal development of the cerebellar system in the rat. I. Cytogenesis and histogenesis of the deep nuclei and the cortex of the cerebellum. J. Comp. Neurol. 179: 23-48, 1978.

Altman, J. and Winfree, A. T.: Postnatal development of the cerebellar cortex in the rat V. Spatial organization of Purkinje cell perikarya. J. Comp. Neurol. 171: 1-16, 1977.

Angaut, P. and Brodal, A.: The projection of the "vestibulocerebellum" onto the vestibular nuclei in the cat. Arch. Ital. Biol. 105: 441-479, 1967.

Angelotti, T. and Macdonald, R. L.: Assembly of GABA $A_{A}$ receptor subunits: $\alpha_{1} \beta_{1}$ and $\alpha_{1} \beta_{1} \gamma_{2 s}$ subunits produce unique ion channels with dissimilar single-channel properties. J. Neurosci. 13: 1429-1440, 1993.

Anselmo-Franci, J. A., Franci, C. R., Krulich, L., Antunes-Rodrigues, J., and McCann, S. M.: Locus coeruleus lesions decrease norepinephrine input into the medial preoptic area and medial basal hypothalamus and block the LH, FSH, and prolactin preovulatory surge. Brain Res. 767: 289-296, 1997. 
Artola, A. and Singer, W.: Long-term depression of excitatory synaptic transmission and its relationship to long-term potentiation. Trends Neurol. Sci. 16: 480-487, 1993.

Artola, A., Bröcher, S., and Singer, W.: Different voltage-dependent thresholds for inducing longterm depression and long-term potentiation in slices of rat visual cortex. Nature 347: 69-72, 1990.

Attali, B. and Vogel, Z.: Long-term opiate exposure leads to reduction of the $\alpha_{\mathrm{i}}-1$ subunit of GTPbinding proteins. J. Neurochem. 53: 1636-1639, 1989.

Atterwill, C. K., Reid, J., and Athayde, C. M.: Effect of thyroid status on the development of the different molecular forms of $\mathrm{Na}^{+}, \mathrm{K}^{+}$-ATPase in rat brain. Mol. Cell. Endo. 40:149-158, 1985.

Axelson, J. and Thesleff, S.: A study of supersensitivity in denervated mammalian skeletal muscle. J. Physiol. 147: 178-193, 1959.

Backus, K. H., Arigoni, M., Drescher, U., Scheurer, L., Malherbe, P., Möhler, H., and Benson, J. A.: Stoichiometry of a recombinant $\mathrm{GABA}_{\mathrm{A}}$-receptor deduced from mutation-induced rectification. Neuroreport 5: 285-288, 1993.

Barker, J. L. and McBurney, R. M.: Phenobarbitone modulation of postsynaptic GABA receptor function on cultured neurons. Proc. R. Soc. Lond. Ser. 206: 319-327, 1979.

Barnard, E. A.: The molecular biology of $\mathrm{GABA}_{\mathrm{A}}$ receptors and their structural determinants. In: $G A B A_{A}$ Receptors and Anxiety. From Neurobiology to Treatment, Advances in Biochemical Psychopharmacology, vol. 48. Eds. G. Biggio, E. Sanna, M. Serra, and E. Costa, Raven Press, New York, pp. 1-16, 1995.

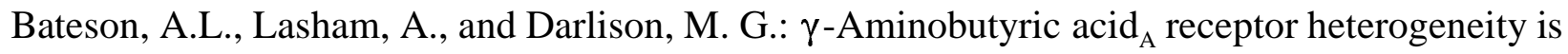
increased by alternative splicing of a novel $\beta$-subunit gene transcript. J. Neurochem. 56: 14371442, 1991.

Belelli, D., Callachan, H., Hill-Venning, C., Peters, J. A., and Lambert, J. J.: Interaction of positive allosteric modulators with human and Drosophila recombinant GABA receptors expressed in Xenopus laevis oocytes. Br. J. Pharmacol. 118: 563-576, 1996.

Ben-Ari, Y., Cherubini, E., Corradetti, R., and Gaiarsa, J. L.: Giant synaptic potentials in immature CA3 hippocampal neurones. J. Physiol. 416: 303-325, 1989.

Benke, D., Cicin-Sain, A., Mertens, S., and Möhler, H.: Immunochemical identification of the $\alpha 1$ and $\alpha 3$-subunits of the $\mathrm{GABA}_{\mathrm{A}}$-receptor in rat brain. J. Recept. Res. 11: 407-424, 1991a.

Benke, D., Fritschy, J. -M., Trzeciak, A., Bannwarth, W., and Möhler, H.: Distribution, prevalence, and drug binding profile of $\gamma$-aminobutyric acid type A receptor subtypes differing in the $\beta$-subunit 
variant. J. Biol. Chem. 269: 27100-27107, 1994.

Benke, D., Mertens, S., Trzeciak, A., Gillessen, D., and Möhler, H.: GABA $\mathrm{A}_{\mathrm{A}}$ receptors display association of $\gamma 2$-subunit with $\alpha 1$ - and $\beta 2 / 3$ subunits. J. Biol. Chem. 266: 4478-4483, 1991 b.

Benke, D., Mertens, S., Trzeciak, A., Gillessen, D., and Möhler, H.: Identification and immunohistochemical mapping of $\mathrm{GABA}_{\mathrm{A}}$ receptor subtypes containing the $\delta$-subunit in rat brain. FEBS Lett. 283: 145-149, 1991c.

Berry, M. and Bradley, P.: The growth of the dendritic trees of Purkinje cells in the cerebellum of the rat. Brain Res. 112: 1-35, 1976.

Betz, H.: Ligand-gated ion channels in the brain: the amino acid receptor superfamily. Neuron 5: 383-392, 1990.

Bliss, T. V. P. and Lømo, T.: Long-lasting potentiation of synaptic transmission in the dentate area of the anaesthetized rabbit following stimulation of the perforant pathway. J. Physiol. 232: 331$356,1973$.

Bliss, T. V. P. and Collinridge, G. L.: A synaptic model of memory: Long-term potentiation in the hippocampus. Nature 361: 31-39, 1993.

Bohlhalter, S., Weinmann, O., Möhler, H., and Fritschy, J.M.: Laminar compartmentalization of $\mathrm{GABA}_{\mathrm{A}}$-receptor subtypes in the spinal cord. J. Neurosci . 16: 283-297, 1996.

Bormann, J. Electrophysiology of $\mathrm{GABA}_{\mathrm{A}}$ and $\mathrm{GABA}_{\mathrm{B}}$ receptor subtypes. Trends Neurol. Sci. 11: 112-116, 1988.

Boulter, J., Connolly, J., Deneris, E., Goldman, D., Heinemann, S., and Patrick, J.: Functional expression of two neuronal nicotinic acetylcholine receptors from cDNA clones identifies a gene family. Proc. Natl. Acad. Sci. USA 84: 7763-7767, 1987.

Bowery, N. G., Hudson, A. L., and Price, G. W.: $\mathrm{GABA}_{\mathrm{A}}$ and $\mathrm{GABA}_{\mathrm{B}}$ receptor site distribution in the rat central nervous system. Neuroscience 20: 365-383, 1987.

Bröcher, S., Artola, A., and Singer, W.: Intracellular injection of $\mathrm{Ca}^{++}$chelators blocks induction of long-term depression in rat visual cortex. Proc. Natl. Acad. Sci. USA 89: 123-127, 1992.

Browning, R. A., Lanker, M. L., and Faingold, C.: Injections of noradrenergic and GABAergic agonists into the inferior colliculus: effects on audiogenic seizures in genetically epilepsy-prone rats. Epilepsy Res. 4: 119-125, 1989c.

Browning, R. A., Wade, D. R., Marcinczyk, M., Long, G. L., and Jobe, P. C.: Regional brain $-163-$ 
abnormalities in norepinephrine uptake and dopamine beta-hydroxylase activity in the geneticallyepilepsy-prone rat. J. Pharmacol. Exp. Ther. 249: 229-235, 1989a.

Browning, R. A., Wade, D.R., Marcinczyk, M., Long, G. L., and Jobe, P.C.: Regional brain abnormalities in norepinephrine uptake and dopamine beta-hydroxylase activity in the genetically epilepsy-prone rat. J. Pharmacol. Exp. Ther. 249: 229-235, 1986.

Browning, R. A., Wang, C., and Jobe, P. C.: Effect of regional norepinephrine depletion on seizure severity in the genetically epilepsy-prone rat. Epilepsia 30: 651, $1989 \mathrm{~b}$.

Browning, R.A., Wang, C., Lanker, M. L., and Jobe, P. C.: Electroshock- and pentylenetetrazolinduced seizures in genetically epilepsy-prone rats: differences in threshold and pattern. Epilepsy Res. 6: 1, 1990.

Bureau, M. H. and Olsen, R. W.: GABA $\mathrm{A}_{\mathrm{A}}$ receptor subtypes: ligand binding heterogeneity demonstrated by photoaffinity labeling and autoradiography. J. Neurochem. 61: 1479-1491, 1993.

Bureau, M. and Olsen, R. W.: Multiple distinct subunits of the $\gamma$-aminobutyric acid-A receptor protein show different ligand-binding affinities. Mol. Pharmacol. 37: 497-502, 1990.

Callachan, H., Cottrell, G. A., Hather, N. Y., Lambert, J. J., Nooney, J. M., and Peters, J. A.: Modulation of the GABA $\mathrm{a}_{\mathrm{a}}$ receptor by progesterone metabolites. Proc. R. Soc. Lond. 231: 359-389, 1987a.

Callachan, H., Lambert, J. J., and Peters, J. A.: Modulation of the GABA $A_{A}$ receptor by barbiturates and steroids. Neurosci. Lett. Suppl. 29: S21, 1987b.

Campbell, N. C. and Armstrong, D. M.: Topographical localization in the olivocerebellar projection in the rat: An autoradiographic study. Brain Res. 275: 235-249, $1983 \mathrm{~b}$.

Campbell, N. C.: The inferior olive as a source of climbing fibres throughout the cerebellar cortex of rats. J. Physiol. 303: 24P, 1980.

Campbell, N. C. and Armstrong, D. M.: The olivocerebellar projection in the rat: An autoradiographic study. Brain Res. 275: 215-233, 1983a.

Carpenter, M. B.: Core Text of Neuroanatomy. Fourth Edition, Williams \& Wilkins, Baltimore, MD, 1991.

Casida, J. E.: Insecticide action at the GABA-gated chloride channel: recognition, progress, and prospects. Arch. Insect. Biochem. Physiol. 22: 13-23, 1993.

Celentano, J. J., Gyenes, M., Gibbs, T. T., and Farb, D. H.: Negative modulation of the $\gamma$ - 
aminobutyric acid response by extracellular zinc. Mol. Pharmacol. 40: 766-773, 1991.

Chan-Palay, V. and Palay, S. L.: Interrelations of basket cell axons and climbing fibres in the cerebellar cortex of the rat. Z. Anat. Entwickl. Gesch. 132: 191-227, 1970.

Cherubini, E., Ben-Ari, Y., and Krnjevic, K.: Periodic inward currents triggered by NMDA in immature CA3 hippocampal neurones. Adv. Exp. Med. Biol. 268: 147-150, 1990.

Cheun, J. E. and Yeh, H. H.: Modulation of GABA A $_{\mathrm{A}}$ receptor-activated current by norepinephrine in cerebellar Purkinje cells. Neuroscience 51: 951-960, 1993.

Cheun, J. E. and Yeh, H. H.: Noradrenergic potentiation of cerebellar Purkinje cell responses to GABA: Cyclic AMP as intracellular intermediary. Neuroscience 74: 835-844, 1996.

Choi, D. W., Farb, D. H., and Fischbach, G. D.: Chlordiazepoxide selectively augments GABA action in spinal cord cell cultures. Nature 269: 342-344, 1977.

Coloma, F. M., and Niles, L. P.: Melatonin enhancement of $\left[{ }^{3} \mathrm{H}\right] \gamma$-aminobutyric acid and $\left[{ }^{3} \mathrm{H}\right]$ muscimol binding in rat brain. Biochem. Pharmacol. 37: 1271-1274, 1988.

Colquhoun, D. and Sigworth, F. J.: Fitting and statistical analysis of single-channel records. In: Single-Channel Recordings. edited by B. Sakmann and E. Neher, pp. 191-263. Plenum Press, New York, 1983.

Concas, A., Santoro, G., Serra, M., Sanna, E., and Biggio, G.: Neurochemical action of the general anesthetic propofol on the chloride ion channel coupled with $\mathrm{GABA}_{\mathrm{A}}$ receptors. Brain Res. 542: 225-232, 1991.

Connor, J. A., Tseng, H. Y., and Hockberger, P. E.: Depolarization- and transmitter induced changes in intracellular $\mathrm{Ca}^{2+}$ of rat cerebellar granule cells in explant cultures. J. Neurosci. 7: 13841400, 1987.

Cooper, J. R., Bloom, F. E., and Roth, R. H.: The Biochemical Basis of Neuropharmacology. Oxford University Press, New York, 1991.

Courville, J. and Faraco-Cantin, F.: On the origin of the climbing fibers of the cerebellum. An experimental study in the cat with an autoradiographic tracing method. Neuroscience 3: 797-809, 1978.

Crepel, F., Delhaye-Bouchaud, N., and Dupont, J. L.: Fate of the multiple innervation of cerebellar Purkinje cells by climbing fibres in immature control, X-irradiated and hypothyroid rats. Dev. Brain Res. 1: 59-71, 1982. 
Crepel, F., Dhanjal, S. S., and Garthwaite, J.: Morphological and electrophysiological characteristics of rat cerebellar slices maintained in vitro. J. Physiol. 316: 127-138, 1981.

Crepel, F.: Maturation of the cerebellar Purkinje cells. I. Postnatal evolution of the Purkinje cell spontaneous firing in the rat. Exp. Brain Res. 14: 463-471, 1972.

Crepel, F. and Delhaye-Bouchaud, N.: Distribution of climbing fibres on cerebellar Purkinje cells in X-irradiated rats. An electrophysiological study. J. Physiol. 290: 97-112, 1979.

Crepel, F., Delhaye-Bouchaud, N., and LeGrand, J.: Electrophysiological analysis of the circuitry and of the corticonuclear relationships in the agranular cerebellum of irradiated rats. Arch. Ital. Biol. 114: 49-74, 1976.

Cutting, G. R., Luo, I., O’Hara, B. F., Kasch, L. M., Montrose-Rafizadeh, C., Donovan, D. M., Shimada, S., Antonarakis, S. E., Guggino, W. B., Uhl, G. R., and Kazazian, H. H.: Cloning of the GABA (rho1) p1 cDNA: a novel GABA A receptor subunit highly expressed in retina. Proc. Natl. Acad. Sci. U.S.A. 88: 2673-2677, 1991.

Dailey, J. W. and Jobe, P. C.: Indices of noradrenergic function in the central nervous system of seizure-naive genetically epilepsy-prone rats. Epilepsia 27: 665-670, 1986.

Dailey, J. W., Mishra, P. K., Ko, K. H., Penny, J., and Jobe, P. C.: Noradrenergic abnormalities in the central nervous system of seizure-naive genetically epilepsy-prone rats. Epilepsia 32: 168-173, 1991.

Dailey, J. W., Mishra, P. K., Ko, K. H., Penny, J., and Jobe, P. C.: Life Sci. 50: 319-326, 1992.

Dailey, J. W., Reigel, C. E., Mishra, P. K., and Jobe, P.C.: Neurobiology of seizure predisposition in the genetically epilepsy-prone rat. Epilepsy Res. 3: 3-17, 1989.

Dailey, J. W. and Jobe, P. C.: Anticonvulsant drugs and the genetically epilepsy-prone rat. Fed. Proc. 44: 2640-2644, 1985.

Dailey, J. W., Yan, Q., Mishra, P. K., Burger, R. L., and Jobe, P. C.: J. Pharmacol. Exp. Ther. 260: 533-540, 1992.

Das, G. D and Nornes, H. O.: Neurogenesis in the cerebellum of the rat: An autoradiographic study. Z. Anat. Entwickl. Gesch. 138: 155-165, 1972.

DeDeyn, P. P., D'Hooge, R., Marescau, B., and Pei, Y.-Q.: Chemical models of epilepsy with some reference to their applicability in the development of anticonvulsants. Epilepsy Res. 12: 87-110, 1992. 
DeDeyn, P.P., Marescau, B., and Macdonald, R.L.: Epilepsy and the GABA-hypothesis a review and some examples. Acta Neurol. Beig. 90: 65-81, 1990.

Deisz, R. A. and Lux, H. D.: $\gamma$-Aminobutyric acid-induced depression of calcium currents of chick sensory neurons. Neurosci. Lett. 56: 205-210, 1985.

Delgado-Escueta, A. V., Ward, A. A., Woodbury, D. M., and Porter, R. J.: New Wave of Research in the Epilepsies. In: Advances in Neurology. Eds. A. V. Delgado-Escueta, A. A. Ward, D. M. Woodbury, and R. J. Porter, pp. 3-55, Raven Press, New York, 1986.

Desclin, J. C.: Histological evidence supporting the inferior olive as the major source of cerebellar climbing fibers in the rat. Brain Res. 77: 365-384, 1974.

Desclin, J. C.: Early terminal degeneration of cerebellar climbing fibers after destruction of the inferior olive in the rat. Synaptic relationships in the molecular layer. Anat. Embryol. 149: 87-112, 1976.

Dillon, G. H., Im, H. K., Hamilton, B. J., Carter, D. B., Gammill, R. B., Judge, T. M., and Im, W. B.: U-93631 causes rapid decay of $\gamma$-aminobutyric acid-induced chloride currents in recombinant rat $\gamma$-aminobutyric acid type A receptors. Mol. Pharmacol. 44: 860-864, 1993.

Draguhn, A., Verdoorn, T. A., Ewert, M., Seeburg, P. H., and Sakmann, B.: Functional and molecular distinction between recombinant rat $\mathrm{GABA}_{\mathrm{A}}$ receptor subtypes by $\mathrm{Zn}^{2+}$. Neuron 5: 781$788,1990$.

Drescher, D. G., Green, G. E., Khan, K. M., Hajela, K., Beisel, K. W., Morley, B. J., and Gupta, A. K.: Analysis of $\gamma$-aminobutyric acid ${ }_{\mathrm{A}}$ receptor subunits in the mouse cochlea by means of the polymerase chain reaction. J. Neurochem. 61: 1167-1170, 1993.

Drexler, G. and Sieghart, W.: $\left[{ }^{35}\right.$ S]tert-butylbicyclophosphorothionate and avermectin bind to different sites associated with the $\gamma$-aminobutyric acid-benzodiazepine receptor complex. Neurosci. Lett. 50: 273-277, 1984a.

Drexler, G. and Sieghart, W.: Properties of a high affinity binding site for $\left[{ }^{3} \mathrm{H}\right]$ avermectin $\mathrm{B}_{1}$ a. Eur. J. Pharmacol. 99: 269-277, 1984b.

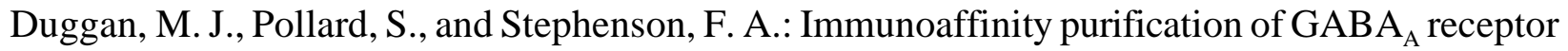
$\alpha$-subunit iso-oligomers. Demonstration of receptor populations containing $\alpha 1 \alpha 2, \alpha 1 \alpha 3$, and $\alpha 2 \alpha 3$ subunit pairs. J. Biol. Chem. 266: 778-784, 1991.

Dupont, J.-L., Gardette, R., and Crepél, F.: Postnatal development of the chemosensitivity of rat cerebellar Purkinje cells to excitatory amino acids. An in vitro study. Devel. Brain Res. 34: 59-68, 1987. 
Eccles, J. C., Llínas, R., and Sasaki, K.: Intracellularly recorded responses of the cerebellar Purkinje cells. Exp. Brain Res. 1: 161-183, 1966.

Eccles, J. C., Sasaki, K., and Strata, P.: A comparison of the inhibitory actions of Golgi cells and of basket cells. Exp. Brain Res. 3: 81-94, $1967 \mathrm{~b}$.

Eccles, J. C., Sasaki, K., and Strata, P.: Interpretation of the potential fields generated in the cerebellar cortex by a mossy fibre volley. Exp. Brain Res. 3: 58-80, 1967 a.

Edgar, P. P. and Schwarz, R. D.: Functionally relevant $\gamma$-aminobutyric acid $_{\mathrm{A}}$ receptors: equivalence between receptor affinity $\left(\mathrm{K}_{\mathrm{D}}\right)$ and potency $\left(\mathrm{EC}_{50}\right)$ ? Mol. Pharmacol. 41: 1124-1129, 1992.

Eells, J. B., Clough, R. W., Browning, R. A., and Jobe, P. C.: Fos in locus coeruleus following audiogenic seizure in the genetically epilepsy-prone rat: comparison to electroshock and pentylenetetrazol seizure models. Neurosci. Lett. 12: 21-24, 1997.

Elliot, K. A. C. and Wolfe, L.: Brain tissue respiration and glycolysis. In: Neurochemistry. Eds. K. A. C. Elliot, L. Wolfe, and J. H. Quastel. Thomas, Springfield, Illinois, 1962.

Faingold, C. L., Gehlbach, G., Caspary, D. M.: Decreased effectiveness of GABA-mediated inhibition in the inferior colliculus of the genetically epilepsy-prone rat. Exp. Neurol. 93: 145-159, 1986a.

Faingold, C. L., Gehlbach, G., Travis, M. A., and Caspary, D. M.: Inferior colliculus neuronal response abnormalities in genetically epilepsy-prone rats: evidence for a deficit of inhibition. Life Sci. 39: 869-878, $1986 b$.

Fleming, W. W., McPhillips, J. J., and Westfall, D. P.: Postjunctional supersensitivity and subsensitivity of excitable tissues to drugs. In: Reviews of Physiology. Eds. R. H. Adrian, E. Helmreich, H. Holzer, R. Jung, K. Kramer, O. Krayer, F. Lynen, P. A. Miescher, H. Rasmussen, A. E. Renold, U. Trendelenburg, K. Ullrich, W. Vogt, and A. Weber, pp. 55-119, Heidelberg, New York, 1973.

Fleming, W. W. and Westfall, D. P.: Altered resting membrane potential in the supersensitive vas deferens of the guinea pig. J. Pharmacol. Exp. Ther. 192: 381-389, 1975.

Fleming, W. W. and Taylor, D. A.: Cellular Mechanisms of Opioid Tolerance and Dependence. In: Pharmacology of Opioid Peptides. Ed. L. F. Tseng, pp. 463-502, Harwood Academic Publishers, Amsterdam, 1995.

Fleming, W. W.: The electrogenic $\mathrm{Na}^{+}, \mathrm{K}^{+}$-pump in smooth muscle: Physiologic and pharmacologic significance. Ann. Rev. Pharmacol. Toxicol. 20: 129-149, 1980. 
Fleming, W. W. and Westfall, D. P.: Adaptive Supersensitivity. In: Handbook of Experimental Pharmacology. Eds. U. Trendelenburg and N. Weiner, pp. 509-559, Springer-Verlag, Berlin, 1988.

Freedman, R., Hoffer, B. J., Woodward, D. J., and Puro, D.: Interaction of norepinephrine with cerebellar activity evoked by mossy and climbing fibers. Exp. Neurol. 55: 269-288, 1977.

French, J.: The long-term therapeutic management of epilepsy. Ann. Intern. Med. 120: 411-422, 1994.

Fritschy, J. M., Paysan, J., Enna, A., and Möhler, H.: Switch in the expression of rat GABA $\mathrm{A}^{-}$ receptor subtypes during postnatal development: an immunohistochemical study. J. Neurosci. 14: 5302-5324, 1994.

Fritschy, J.M. and Möhler, H.: GABA ${ }_{\mathrm{A}}$-receptor heterogeneity in the adult rat brain: differential regional and cellular distribution of seven major subunits. J. Comp. Neurol. 359: 154-194, 1995.

Fuchs, K., Möhler, H., and Sieghart, W.: Various proteins from rat brain, specifically and irreversibly labeled by $\left[{ }^{3} \mathrm{H}\right]$ flunitrazepam, are distinct $\alpha$-subunits of the GABA benzodiazepine receptor complex. Neurosci. Lett. 90: 314-319, 1988.

Fujii, T., Baumgartl, H., and Lubbers, D. W.: Limiting section thickness of guinea pig olfactory cortical slices studied from tissue $\mathrm{pO} 2$ values and electrical activities. Pflügers Arch. 393: 83-87, 1982.

Gähwiler, B. H. and Brown, D. A.: $\mathrm{GABA}_{\mathrm{B}}$-receptor-activated $\mathrm{K}^{+}$current in voltage-clamped CA3 pyramidal cells in hippocampal cultures. Proc. Natl. Acad. Sci. USA 82: 1558-1562, 1985.

Gale, K.: GABA and epilepsy: Basic concepts from preclinical research. Epilepsia 33: S3-S12, 1992.

Gale, K.: GABA and epilepsy: The pharmacological basis. Epilepsia 30: S1-S11, 1989.

Galzi, J. L. and Changeux, J. P.: Neurotransmitter-gated ion channels as unconventional allosteric proteins. Curr. Opin. Struct. Biol. 4: 554-565, 1994.

Gammill, R. B. and Carter, D. B.: Neuronal BZD receptors: new ligands, clones and pharmacology. Annu. Rep. Med. Chem. 28: 19-27, 1993.

Garthwaite, J., Woodhams, P. L., Collins, M. J., and Balazs, R.: On the preparation of brain slices: Morphology and cyclic nucleotides. Brain Res. 173: 373-377, 1979.

Garthwaite, J. and Beaumont, P. S.: Excitatory amino acid receptors in the parallel fibre pathway in rat cerebellar slices. Neurosci. Lett. 107: 151-156, 1989. 
Gee, K. W., Bolger, M. B., and Brinton, R.E.: Steroid modulation of the chloride iontophore in rat brain: structure-activity requirements, regional dependance and mechanism of action. J. Pharmacol. Exp. Ther. 246: 803-812, 1988.

Gerthoffer, W. T., Fedan, J. S., Westfall, D. P., Goto, K., and Fleming, W. W.: Involvement of the sodium-potassium pump in the mechanism of postjunctional supersensitivity of the vas deferens of the guinea pig. J. Pharmacol. Exp. Ther. 210: 27-36, 1979.

Gilad, G. M., Gilad, V. H., and Wyatt, R. J.: Polyamines modulate the binding of $\mathrm{GABA}_{\mathrm{A}^{-}}$ benzodiazepine receptor ligands in membranes from the rat forebrain. Neuropharmacology 31: 895898, 1992.

Glass, M. and Dragunow, M.: Neurochemical and morphological changes associated with human epilepsy. Brain Res. Rev. 21: 29-41, 1995.

Goto, K., Westfall, D. P., and Fleming, W. W.: Denervation-induced changes in electrophysiologic parameters of the smooth muscle of the guinea-pig and rat vas deferens. J. Pharmacol. Exp. Ther. 204: 325-333, 1978.

Gould, E. M., Curto, K. A., Craig, C. R., Fleming, W. W., and Taylor, D. A.: The role of GABA receptors in the subsensitivity of Purkinje neurons to GABA in genetic epilepsy prone rats. Brain Res. 698: 62-68, 1995.

Gould, E. M., Craig, C. R., Fleming, W. W., and Taylor, D. A.: Sensitivity of cerebellar Purkinje neurons to neurotransmitters in genetically epileptic rats. J. Pharmacol. Exp. Ther. 259: 1008-1012, 1991.

Grenningloh, G., Rienitz, A., Schmitt, B., Methfessel, C., Zensen, M., Beyreuther, K., Gundelfinger, D. E., and Betz, H.: The strychnine-binding subunit of the glycine receptor shows homology with nicotinic acetylcholine receptors. Nature 328: 215-220, 1987.

Gutierrez, A., Khan, Z. U., Morris, S. J., and De Blas, A. L.: Age-related decrease of GABA receptor subunits and glutamic acid decarboxylase in the rat inferior colliculus. J. Neurosci. 14: 7469-7477, 1994.

Hager, G., Dodt, H. -U., Zieglgansberger, W., and Liesi, P.: Novel forms of neuronal migration in the rat cerebellum. J. Neurosci. Res. 40: 207-219, 1995.

Hagiwara, S. and Jaffe, L. A.: Electrical properties of egg cell membranes. Ann. Rev. Biophys. Bioeng. 8: 385-416, 1979.

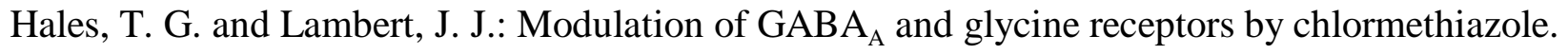
Eur. J. Pharmacol. 210: 239-246, 1992. 
Hales, T. G. and Lambert, J. J.: The actions of propofol on inhibitory amino acid receptors of bovine adrenomedullary chromaffin cells and rodent central neurons. Br. J. Pharmacol. 104: 619-628, 1991.

Hamill, O. P., Marty, A., Neher, E., Sakmann, B., and Sigworth, F. J.: Improved patch-clamp techniques for high-resolution current recording from cells and cell-free membrane patches. Pflügers Arch. 391: 85-100, 1981.

Hamill, O. P., Bormann, J., and Sakmann, B.: Activation of multiple-conductance state chloride channels in spinal neurones by glycine and GABA. Nature 305: 805-808, 1983.

Harvey, R. J., Kim, H. C., and Darlison, M. G.: Molecular cloning reveals the existence of a fourth $\gamma$-subunit of the vertebrate brain $\mathrm{GABA}_{\mathrm{A}}$ receptor. FEBS Lett. 331: 211-216, 1993.

Hendry, S. H. C., Huntsman, M. M., Vinuela, A., Möhler, H., de Blas, A. L., and Jones, E. G.: $\mathrm{GABA}_{\mathrm{A}}$ receptor subunit immunoreactivity in primate visual cortex: distribution in macaques and humans and regulation by visual input in adulthood. J. Neurosci. 14: 2383-2401, 1994.

Hershman, K. M., Taylor, D. A., and Fleming, W. W.: Adaptive supersensitivity in the guinea pig vas deferens is associated with a reduction in the abundance of the $\alpha 2$ subunit isoform of $\mathrm{Na}^{+} / \mathrm{K}^{+}$ATPase. Mol. Pharmacol. 43: 833-837, 1993.

Hershman, K. M., Taylor, D. A., and Fleming, W. W.: Adaptive supersensitivity and the $\mathrm{Na}^{+} / \mathrm{K}^{+}$ pump in the guinea pig vas deferens: Time course of the decline in the $\alpha 2$ subunit. Mol. Pharmacol. 47: 726-729, 1995.

Hirsch, J. C. and Crépel, F.: Postsynaptic $\mathrm{Ca}^{++}$is necessary for the induction of LTP and LTD of monosynaptic EPSPs in prefrontal neurons: an in vitro study in the rat. Synapse 10: 173-175, 1992.

Hoffer, B. J., Siggins, G. R., Oliver, A. P., and Bloom, F.E.: Activation of the pathway from locus coeruleus to rat cerebellar Purkinje neurons: Pharmacological evidence of noradrenergic central inhibition. J. Pharmacol. Exp. Therap. 184: 553-569, 1973.

Holland, K. D., Bouley, M. G., Covey, D. F., and Ferrendelly, J. A.: Alkyl-substituted $\gamma-$ butyrolactones act at a distinct site allosterically linked to the TBPS/picrotoxinin site on the $\mathrm{GABA}_{\mathrm{A}}$ receptor complex. Brain Res. 615: 170-174, 1993.

Hopkins, A. and Appleton, R.: Epilepsy the Facts. Oxford University Press, Oxford, 1996.

Houser, C. R.: GABA neurons in seizure disorders: A review of immunocytochemical studies. Neurochem. Res. 16: 295-308, 1991.

Huntsman, M. M., Isackson, P. J., and Jones, E. G.: Lamina-specific expression and activity- 
dependent regulation of seven $\mathrm{GABA}_{\mathrm{A}}$ receptor subunit mRNAs in monkey visual cortex. J. Neurosci. 14: 2236-2259, 1994.

Im, H. K., Im, W. B., Judge, T. M., Gammill, R. B., Hamilton, B. J., Carter, D. B., and Pregenzer, J. F.: Substituted pyrazinones, a new class of allosteric modulators for $\gamma$-aminobutyric $\operatorname{acid}_{\mathrm{A}}$ receptors. Mol. Pharmacol. 44: 468-472, 1993.

Inomata, N., Tokutomi, N., Oyama, Y., and Akaike, N.: Intracellular picrotoxin blocks pentobarbital-gated $\mathrm{Cl}^{-}$conductance. Neurosci. Res. 6: 72-75, 1988.

Inukai, T.: On the loss of Purkinje cells, with advancing age, from the cerebellar cortex of the albino rat. J. Comp. Neurol. 45: 1-31, 1928.

Itier, V., Depoortere, H., Scatton, B., and Avenet, P.: Zolpidem functionally discriminates subtypes of native $\mathrm{GABA}_{\mathrm{A}}$ receptors in acutely dissociated rat striatal and cerebellar neurons. Neuropharmacology 35: 137-145, 1996.

Ito, M.: The Cerebellum and Neural Control. Raven Press, New York, 1984.

Jacobs, B. L. and Fornal, C. A.: Serotonin and behavior. In: Psychopharmacology, the Fourth Generation in Progress. Eds. F. E. Bloom and D. J. Kupfer, pp. 461-470, Raven Press, New York, 1995.

Jacobsen, M.: Histogenesis and Morphogenesis of Cortical Structures. In: Developmental Neurobiology, pp. 430-451, Plenum Press, New York, 1991.

Jakob, A. P.: Das Kleinhirn. In: Handbuch der Microskofischen Anatomie des Menchen. edited by W. V. Möllendorff, pp. 674-911. Springer-Verlag, Berlin, 1928.

Janigro, D. and Schwartzkroin, P. A.: Effects of GABA and baclofen on pyramidal cells in the developing rabbit hippocampus: an in vitro study. Brain Res. 469: 171-178, 1988.

Jobe, P. C., Dailey, J. W., and Reigel, C. E.: Noradrenergic and serotonergic determinants of seizure susceptibility and severity in genetically epilepsy-prone rats. Life Sci. 39: 775-782, 1986.

Jobe, P. C., Ko, K. H., and Dailey, J. W.: Abnormalities in norepinephrine turnover rate in the central nervous system of the genetically epilepsy-prone rat. Brain Res. 290: 357-360, 1984.

Jobe, P. C., Mishra, P. K., Ludvig, N., and Dailey, J. W.: Scope and contribution of genetic models to an understanding of the epilepsies. Crit. Rev. Neurobio. 6: 183-210, 1991.

Jobe, P. C., Picchioni, A. L., and Chin, L.: Role of brain norepinephrine in audiogenic seizure in the rat. J. Pharmacol. Exp. Ther. 184: 1-10, 1973. 
Jobe, P. C., Brown, R. D., Dailey, J. W., Ray, T. B., Woods, T. W., Mims, M. E., and Bairnsfather, S.: Effects of multiple exposures to intense acoustical stimulation on audiogenic seizures (AGS) susceptibility and intensity in rats. I. A developmental study in progeny from a genetically susceptible colony. Soc. Neurosci. Abst. 6: 824, 1980.

Jobe, P. C., Mishra, P. K., Ludvig, N., and Dailey, J. W.: Genetic models of the epilepsies. In: Epilepsy: Models, Mechanisms, and Concepts. Ed. P. A. Schwartzkroin, pp. 94-140, Cambridge University Press, Cambridge, 1993a.

Jobe, P. C., Mishra, P. K., Ludvig, N., and Dailey, J. W.: Recent advances in genetic models of the epilepsies. In: Epilepsy: Models, Mechanisms, and Concepts. Ed. P. A. Schwartzkroin, pp. 494499, Cambridge University Press, Cambridge, 1993b.

Kaas, J. H. and Florence, S. L.: Mechanisms of reorganization in sensory systems of primates after peripheral nerve injury. In: Brain Plasticity, Advances in Neurology. Eds. H.-J. Freund, B. A. Sabel, and O. W. Witte, pp. 147-158, Lippincott-Raven, Philadelphia, 1997.

Kandel, E. R., Schwartz, J. H., and Jessell, T. M.: Principles of Neural Science. Third Edition, Appleton \& Lange, Norwalk, CT, 1991.

Kang, I., Thompson, M. L., Heller, J., and Miller, L. G.: Persistent elevation in $\mathrm{GABA}_{\mathrm{A}}$ receptor subunit mRNAs following social stress. Brain Res. Bull. 26: 809-812, 1991.

Kano, M. and Konnerth, A.: Cerebellar slices for patch clamp recording. In: Practical Electrophysiological Methods. Eds. H. Kettenmann and R. Grantyn. pp. 54-57, Wiley-Liss, New York, 1992.

Kardos, J. and Cash, D. J.: ${ }^{36} \mathrm{Cl}^{-}$flux measurements and desensitization of the $\gamma$-aminobutyric acid receptor. J. Neurochem. 55: 1095-1099, 1990.

Kawamura, K. and Hashikawa, T.: Projections from the pontine nuclei proper and reticular tegmental nucleus onto the cerebellar cortex in the cat. An autoradiographic study. J. Comp. Neurol. 201: 395-413, 1981.

Knoflach, F., Rhyner, T., and Villa, M.: The $\gamma 3$-subunit of the GABA $_{\mathrm{A}}$-receptor confers sensitivity to benzodiazepine receptor ligands. FEBS Lett. 293: 191-194, 1991.

Kofuji, P., Wang, J. B., Moss, S. J., Huganir, R. L., and Burt, D.B.: Generation of two forms of the $\gamma$-aminobutyric acid ${ }_{\mathrm{A}}$ receptor $\gamma_{2}$-subunit in mice by alternative splicing. J. Neurochem. 56: 713$715,1991$.

Korpi, E. R., Kleingoor, C., Ketenmann, H., and Seeburg, P. H.: Benzodiazepine-induced motor impairment linked to point mutation in cerebellar $\mathrm{GABA}_{\mathrm{A}}$ receptor. Nature 361: 356-359, 1993. 
Korpi, E. R. and Lüddens, H.: Regional $\gamma$-aminobutyric acid sensitivity of $t$-butylbicyclophosphoro$\left[{ }^{35} \mathrm{~S}\right]$-thionate binding depends on $\gamma$-aminobutyric acid $_{\mathrm{A}}$ receptor $\alpha$ subunit. Mol. Pharmacol. 44: 87-92, 1993.

Laird, H. E., II and Jobe, P. C.: The genetically epilepsy-prone rat. In: Neurotransmitters and Epilepsy. Eds. P. C. Jobe and H. E. Laird II, pp. 57-94, Humana Press, Clifton, NJ, 1987.

Larramendi, L. M. H.: Analysis of synaptogenesis in the cerebellum of the mouse. In: Neurobiology of Cerebellar Evolution and Development. edited by R. Llinás, pp. 803-843, American Medical Association, Chicago, 1969.

Larramendi, L. M. H. and Victor, T.: Synapses on the Purkinje cell spines in the mouse an electron microscopic study. Brain Res. 5: 15-30, 1967.

Larsell, O.: The cerebellum. Arch. Neurol. Psych. 38: 580-607, 1937.

Larsell, O.: The Comparative Anatomy and Histology of the Cerebellum from Monotremes through Apes, Vol. 1. ed. J. Jansen, University of Minnesota Press, Minneapolis, 1967.

Lasley, S. M., Burger, R. L., Dailey, J. W., and Jobe, P. C.: Regional brain content of amino acid transmitters in genetically epilepsy-prone rats GEPR. Soc. Neurosci. Abst. 15: 1215, 1989.

Laurie, D. J., Seeburg, P. H., and Wisden, W.: The distribution of $13 \mathrm{GABA}_{\mathrm{A}}$ receptor subunit mRNAs in the rat brain. II. Olfactory bulb and cerebellum. J. Neurosci. 12:1063-1076, 1992 a.

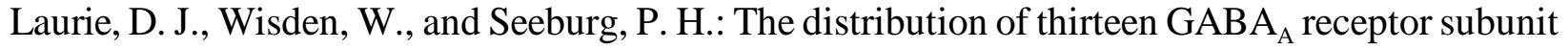
mRNAs in the rat brain. III. Embryonic and postnatal development. J. Neurosci. 12: 4151-4172, 1992b.

Lauterborn, J. C. and Ribak, C. E.: Differences in dopamine $\beta$-hydroxylase immunoreactivity between the brains of genetically epilepsy-prone and Sprague-Dawley rats. Epilepsy Res. 4: 161, 1989.

Lin, Y. F., Browning, M. D., Dudek, E. M., and Macdonald, R. L.: Protein kinase C enhances recombinant bovine $\alpha 1 \beta 1 \gamma 2 \mathrm{~L} \mathrm{GABA}_{\mathrm{A}}$ receptor whole-cell currents expressed in L929 fibroblasts. Neuron 13: 1421-1431, 1994.

Linden, D. J., Dickinson, M. H., Smeyne, M., and Connor, J. A.: A long-term depression of AMPA currents in cultured cerebellar Purkinje neurons. Neuron 7: 81-89, 1991.

Linden, D. J.: Long-term synaptic depression in the mammalian brain. Neuron 12: 457-472, 1994.

Llano, I., Marty, A., Armstrong, C. M., and Konnerth, A.: Synaptic- and agonist-induced excitatory 
currents of Purkinje cells in rat cerebellar slices. J. Physiol. 434: 183-213, 1991.

Llinás, R. and Sugimori, M.: Electrophysiological properties of in vitro Purkinje cell somata in mammalian cerebellar slices. J. Physiol. 305: 171-195, 1980a.

Llinás, R. and Sugimori. M.: Electrophysiological properties of in vitro Purkinje cell dendrites in mammalian cerebellar slices. J. Physiol. 305:197-213, 1980 b.

Lüddens, H., Pritchett, D. B., Kohler, M., Killisch, I., Keinanen, L., Monyer, H., Sprengel, R., and Seeburg, P. H.: Cerebellar GABA ${ }_{A}$-receptor selective for a behavioral alcohol antagonist. Nature 346: 648-651, 1990.

Lüddens, H., Korpi, E. R., and Seeburg, P. H.: GABA $/$ /Benzodiazepine receptor heterogeneity: neurophysiological implications. Neuropharmacology 34: 245-254, 1995.

Lüddens, H., Pritchett, D. B., Köhler, M., Killisch, I., Keinänen, K., Monyer, H., Sprengel, R., and Seeburg, P. H.: Cerebellar $\mathrm{GABA}_{\mathrm{A}}$ receptor selective for behavioural alcohol antagonist. Nature 346: 648-651, 1990.

Lüddens, H., Seeburg, P. H., and Korpi, E. R.: Impact of $\beta$ and $\gamma$ variants on ligand-binding properties of $\gamma$-aminobutyric acid type A receptors. Mol. Pharmacol. 45: 810-814, 1994.

Lüddens, H. and Wisden, W.: Function and pharmacology of multiple $\mathrm{GABA}_{\mathrm{A}}$ receptor subunits. Trends Pharmacol. Sci. 12: 49-51, 1991.

Luntz-Leybman, V., Frostholm, A., Fernando, L., De Blas, A., and Rotter, A.: GABA ${ }_{\AA} /$ benzodiazepine receptor $\gamma_{2}$ subunit gene expression in developing normal and mutant mouse cerebellum. Molec. Brain Res. 19: 9-21, 1993.

Lust, W. D., Whittingham, T. S., and Passonneau, J. V.: Effects of slice thickness and method of preparation on energy metabolism in the in vitro hippocampus. Soc. Neurosci. Abst. 8: 1000, 1982.

Ma, J. Y. and Narahashi, T.: Differential modulation of $\mathrm{GABA}_{\mathrm{A}}$ receptor-channel complex by polyvalent cations in rat dorsal root ganglion neurons. Brain Res. 607: 222-232, 1993 a.

Ma, J. Y. and Narahashi, T.: Enhancement of $\gamma$-aminobutyric acid activated chloride channel currents by lanthanides in rat dorsal root ganglion neurons. J. Neurosci. 13: 4872-4879, 1993b.

Macdonald, R. L. and Olsen, R. W.: GABA ${ }_{\mathrm{A}}$ receptor channels. Ann. Rev. Neurosci. 17: 569-602, 1994.

Macdonald, R. L. and Barker, J. L.: Specific antagonism of GABA-mediated postsynaptic inhibition in cultured mammalian neurons: a common mode of anticonvulsant action. Neurology 28: 325-330, 
1978a.

Macdonald, R. L. and Barker, J. L.: Benzodiazepines specifically modulate GABA-mediated postsynaptic inhibition in cultured mammalian neurones. Nature 271: 563-564, 1978b.

Madison, D. V., Malenka, R. C., and Nicoll, R. A.: Mechanisms underlying long-term potentiation of synaptic transmission. Ann. Rev. Neurosci. 14: 379-397, 1991.

Malenka, R. C. and Nicoll, R. A.: NMDA-receptor-dependent synaptic plasticity: multiple forms and mechanisms. Trends Neurosci. 16: 521-527, 1993.

Mariani, J. and Changeux, J. -P.: Ontogenesis of olivocerebellar relationships II. Spontaneous activity of inferior olivary neurons and climbing fiber-mediated activity of cerebellar Purkinje cells in developing rats. J. Neurosci. 1: 703-709, 1981 b.

Mariani, J. and Changeux, J. -P.: Ontogenesis of olivocerebellar relationships I. Studies by intracellular recordings of the multiple innervation of Purkinje cells by climbing fibers in the developing rat cerebellum. J. Neurosci. 1: 696-702, 1981a.

Martin, J. H.: The collective electrical behavior of cortical neurons: The electroencephalogram and the mechanisms of epilepsy. In: Principles of Neural Science, Third Edition. Eds. E.R. Kandel, J.H. Schwartz, and T.M. Jessell. Appleton \& Lange, Norwalk, Connecticut, pp. 777-791, 1991.

McCrea, R. A., Bishop, G. A., and Kitai. S. T.: Intracellular staining of Purkinje cells and their axons with horseradish peroxidase. Brain Res. 118: 132-136, 1976.

McIlwain, H. and Bachelard, H. S.: Biochemistry and the Central Nervous System. Churchill Livingston, Edinburgh, 1971.

McNamara, J. O.: Kindling model of epilepsy. In: Advances in Neurology, Vol. 44. Eds. A.V. Delgado-Escueta, A.A. Ward, Jr., D.M. Woodbury, and R.J. Porter. Raven Press, New York, pp. 303-?, 1986.

Meldrum, B.: Mechanism based approaches to anticonvulsant therapies: Modulation of inhibitory and excitatory transmission. Curr. Fut. Trends Anticonvulsant, Anxiety, and Stroke Therapy 31-43, 1990.

Mertens, S., Benke, D., and Möhler, H.: $\mathrm{GABA}_{\mathrm{A}}$ receptor populations with novel subunit combinations and drug binding profiles identified in brain by $\alpha 5$ - and $\delta$-subunitspecific immunopurification. J. Biol. Chem. 268: 5965-5973, 1993.

Mhatre, M. and Ticku, M. K.: Chronic ethanol treatment upregulates the GABA $\mathrm{A}_{\mathrm{A}}$ receptor $\beta$ subunit expression. Mol. Brain Res. 23: 246-252, 1994. 
Millan, M. H., Wardley-Smith, B., Durmuller, N., and Meldrum, B. S.:The high pressure neurological syndrome in genetically epilepsy prone rats: Protective effect of 2-amino-7-phosphono heptanoate. Exp. Neurol. 112: 317-320, 1991.

Miralles, C. P., Gutiérrez, A., Khan, Z. U., Vitorica, J., and De Blas, A. L.: Differential expression of the short and long forms of the $\gamma_{2}$ subunit of the $\mathrm{GABA}_{\mathrm{A}} /$ benzodiazepine receptors. Molec. Brain Res. 24: 129-139, 1994.

Misgeld, U. and Frotscher, M.: Dependence of the viability of neurons in hippocampal slices on oxygen supply. Brain Res. Bull. 8: 95-100, 1982.

Möhler, H., Fritschy, J. M., Lüscher, B., Rudolph, U., Benson, J., and Benke, D.: The GABA $A^{-}$ receptors: from subunits to diverse functions. In: Ion Channels, vol. 4. Ed. T. Narahashi, Plenum Press, New York, pp. 89-113, 1995.

Moises, H. C. and Woodward, D. J.: Potentiation of GABA inhibitory action in cerebellum by locus coeruleus stimulation. Brain Res. 182: 327-344, 1980.

Montarolo, P. G., Raschi, F., and Strata, P.: On the origin of the climbing fibers of the cerebellar cortex. Pflügers Arch. Ges. Physiol. 383: 137-142, 1980.

Montpied, P., Morrow, A. L., Karanian, J. W., Ginns, E. I., Martin, B. M., and Paul, S. M.: Prolonged ethanol inhalation decreases $\gamma$-aminobutyric acid ${ }_{\mathrm{A}}$ receptor $\alpha$ subunit mRNAs in the rat cerebral cortex. Mol. Pharmacol. 39: 157-163, 1991.

Moody, E. J. and Skolnick, P.: Chlormethiazole: neurochemical actions at the $\gamma$-aminobutyric acid receptor complex. Eur. J. Pharmacol. 164: 153-158, 1989.

Morrow, A. L., Pace, J. R., Purdy, R. H., and Paul, S. M.: Characterization of steroid interactions with the GABA receptor-gated ion channel: evidence for multiple steroid recognition sites. Mol. Pharmacol. 37: 263-270, 1990.

Moss, S. J., Gorrie, G. H., Amato, A., and Smart, T. G.: Modulation of GABA $A_{A}$ receptors by tyrosine phosphorylation. Nature 377: 344-348, 1995.

Moss, S. J., Smart, T. G., Blackstone, C. D., and Huganir, R. L.: Functional modulation of GABA receptors by cAMP-dependent protein phosphorylation. Science 257: 661-665, 1992.

Mugnaini, E.: The histology and cytology of the cerebellar cortex. In: The Comparative Anatomy and Histology of the Cerebellum. The Human Cerebellum, Cerebellar Connections, and Cerebellar Cortex. edited by O. Larsell and J. Jansen, pp. 201-264. University of Minnesota Press, Minneapolis, 1972. 
Mugnaini, E., Dino, M. R., and Jaarsma, D.: The unipolar brush cells of the mammalian cerebellum and cochlear nucleus: cytology and microcircuitry. In: Progress in Brain Research. Eds. C. I. de Zeeuw, P. Strata, and J. Voogd, pp. 131-150, Elsevier Science, 1997.

Mugnaini, E.: Ultrastructural studies on the cerebellar histogenesis. II. Maturation of nerve cell populations and establishment of synaptic connections in the cerebellar cortex of the chick. In: Neurobiology of Cerebellar Evolution and Development. edited by R. Llinás, pp. 749-782. American Medical Association, Chicago, 1969.

Mulkey, R. M. and Malenka, R. C.: Mechanisms underlying induction of homosynaptic long-term depression in area CA1 of the hippocampus. Neuron 9: 967-975, 1992.

Müller, T., Fritschy, J. M., Grosche, J., Pratt, G. D., Möhler, H., and Kettenmann, H.: Developmental regulation of voltage gated $\mathrm{K}^{+}$channel and $\mathrm{GABA}_{\mathrm{A}}$ receptor expression in Bergmann glial cells. J. Neurosci. 14: 2503-2514, 1994.

Nagata, K. and Narahashi, T.: Dual action of the cyclodiene insecticide dieldrin on the $\gamma$ aminobutyric acid receptor-chloride channel complex of rat dorsal root ganglion neurons. J. Pharmacol. Exp. Ther. 269: 164-171, 1994.

Nayeem, N., Green, T. P., Martin, I. L., and Barnard, E. A.: Quaternary structure of the native $\mathrm{GABA}_{\mathrm{A}}$ receptor determined by electron microscopic image analysis. J. Neurochem. 62: 815-818, 1994.

Nicholson, C. and Hounsgaard, J.: Diffusion in the slice microenvironment and implications for physiological studies. Fed. Proc. 42: 2865-2868, 1983.

O'Leary, J. L., Inukai, J., and Smith, J. M.: Histogenesis of the cerebellar climbing fiber in the rat. J. Comp. Neurol. 142: 377-392, 1971.

Olsen, R. W.: Drug interactions at the GABA receptor-ionophore complex. Annu. Rev. Pharmacol. Toxicol. 22: 245-277, 1982.

Olsen, R. W., Bergmann, M. O., Van Ness, P. C., Lummis, S. C., Watkins, A. E., Napias, C., and Greenlee, D. V.: $\gamma$-Aminobutyric acid receptor binding in mammalian brain. Heterogeneity of binding sites. Mol. Pharmacol. 19: 217-227, 1981.

Olsen, R. W.: GABA-benzodiazepine-barbiturate receptor interactions. J. Neurochem. 37: 1-13. 1981.

Olsen, R. W.: The $\gamma$-aminobutyric acid/benzodiazepine/barbiturate receptor chloride ion channel complex of mammalian brain. In: Synaptic Function. edited by G. M. Edelman, W. E. Gall, and W. M. Cowan, pp. 257-271. Neuroscience Research Foundation/Wiley, 1987. 
Palay, S. L. and Chan-Palay, V.: Cerebellar Cortex. Springer-Verlag, New York, Heidelberg, Berlin, 1974.

Palkovits, M., Magyar, P., and Szentagothai, J.: Quantitative histological analysis of the cerebellar cortex in the cat. II. Cell numbers and densities in the granular layer. Brain Res. 32: 15-30, 1971.

Parfitt, K. D., Hoffer, B. J., and Bickford-Wimer, P. C.: Potentiation of gamma-aminobutyric acidmediated inhibition by isoproterenol in the cerebellar cortex: receptor specificity. Neuropharmacology 29: 909-916, 1990.

Payne, G. T. and Soderlund, D. M.: Actions of avermectin analogues on $\gamma$-aminobutyric acid (GABA)-sensitive and GABA-insensitive chloride channels in mouse brain. Pesticide Biochem. Physiol. 47: 178-184, 1993.

Persohn, E., Malherbe, P., and Richards, J. G.: Comparative molecular neuroanatomy of cloned $\mathrm{GABA}_{\mathrm{A}}$ receptor subunits in the rat CNS. J. Comp. Neurol. 326: 193-216.

Peters, J. A., Kirkness, E. F., Callachan, H., Lambert, J. L., and Turner, A. J.: Modulation of the $\mathrm{GABA}_{\mathrm{A}}$ receptor by depressant barbiturates and pregnane steroids. Br. J. Pharmacol. 94: 1257$1269,1988$.

Pollard, S., Duggan, M. J., and Stephenson, F. A.: Promiscuity of GABA $A_{A}$-receptor $\beta 3$ subunits as demonstrated by their presence in $\alpha 1, \alpha 2$, and $\alpha 3$ subunit-containing receptor subpopulations. FEBS Lett. 295: 81-83, 1991.

Porter, N. M., Twyman, R. E., Uhler, M. D., and Macdonald, R. L.: Cyclic AMP-dependent protein kinase decreases $\mathrm{GABA}_{\mathrm{A}}$ receptor current in mouse spinal neurons. Neuron 5: 789-796, 1990.

Primus, R. J. and Gallager, D. W.: GABA $\mathrm{A}_{\mathrm{A}}$ receptor subunit mRNA are differentially influenced by chronic FG 7142 and diazepam exposure. Eur. J. Pharmacol. 226: 21-28, 1992.

Pritchett, D. B. and Seeburg, P. H.: $\gamma$-Aminobutyric acid type A receptor point mutation increases the affinity of compounds for the benzodiazepine site. Proc. Natl. Acad. Sci. U.S.A. 88: 1421-1425, 1991.

Pritchett, D. B. and Seeburg, P. H.: $\gamma$-Aminobutyric acid ${ }_{\mathrm{A}}$ receptor $\alpha_{5}$-subunit creates novel type II benzodiazepine receptor pharmacology. J. Neurochem. 54: 1802-1804, 1990.

Pritchett, D. B., Lüddens, H., and Seeburg, P.H.: Type I and type II GABA ${ }_{\mathrm{A}}$-benzodiazepine receptors produced in transfected cells. Science 245: 1389-1392, 1989a.

Pritchett, D. B., Sontheimer, H., Shivers, B. D., Ymer, S., Kettenmann, H., Schofield, P. R., and Seeburg, P. H.: Importance of a novel GABA $A_{A}$ receptor subunit for benzodiazepine pharmacology. 
Nature 338: 582-585, $1989 b$.

Puia, G., Vicini, S., Seeburg, P. H., and Costa, E.: Influence of recombinant (gamma)-aminobutyric acid- ${ }_{\mathrm{A}}$ receptor subunit composition on the action of allosteric modulators of (gamma)-aminobutyric acid-gated $\mathrm{Cl}^{-}$currents. Mol. Pharmacol. 39: 691-696, 1991.

Puia, G., Costa, E., and Vicini, S.: Functional diversity of GABA-activated $\mathrm{Cl}^{-}$currents in Purkinje versus granule neurons in rat cerebellar slices. Neuron 12: 117-126, 1994.

Puro, D. G. and Woodward, D. J.: Maturation of evoked climbing fiber input to rat cerebellar Purkinje cells. Exp. Brain Res. 28: 85-100, 1977.

Raichle, M. E., Kutt, H., Louis, S., and McDowell, F.: Neurotoxicity of intravenously administered penicillin G. Arch. Neurol. 25: 232-239, 1971.

Ribak, C. E., Byun, M. Y., Ruiz, G. T., and Reiffenstein, R. J.: Increased levels of amino acid transmitters in the inferior colliculus of the genetically epilepsy-prone rat. Epilepsy Res. 2: 9-13, 1988a.

Ribak, C. E., Roberts, R. C., Byun, M. Y., and Kim, H. L.: Anatomical and behavioral analyses of inheritance of audiogenic seizures in the progeny of genetically epilepsy-prone and Sprague-Dawley rats. Epilepsy Res. 2: 345, 1988 b.

Richens, A.: New drugs for epilepsy: A rapidly changing scene. Acta Neurol. Scand, 140: 65-70, 1992.

Rogers, C. J., Twyman, R. E., and Macdonald, R. L.: The benzodiazepine diazepam and the betacarboline DMCM modulate $\mathrm{GABA}_{\mathrm{A}}$ receptor currents by opposite mechanisms. Soc. Neurosci. Abstr. 15: 1150, 1989.

Rogers, C. J., Twyman, R. E., and Macdonald, R. L.: Diazepam does not alter the gating kinetics of GABA receptor channels. Soc. Neurosci. Abstr. 14: 642, 1988.

Sakmann, B., Hamill, O. P., and Bormann, J.: Patch-clamp measurements of elementary chloride currents activated by the putative inhibitory transmitters GABA and glycine in mammalian spinal neurons. J. Neural Trans. Suppl. 18: 83-95. 1983.

Sakurai, M.: Calcium is an intracellular mediator of the climbing fiber in induction of cerebellar long-term depression. Proc. Natl. Acad. Sci. USA 87: 3383-3385, 1990.

Sarges, R., Howard, H. R., Koe, B. K., and Weissman, A.: A novel class of "GABAergic" agents: 1-aryl-3-(aminoalkylidene)-oxindoles. J. Med. Chem. 32: 437-444, 1989. 
Savage, D. D., Reigel, C. E., and Jobe, P. C.: The development of kindled seizures is accelerated in the genetically epilepsy-prone rat. Life Sci. 39: 879-886, 1986 a.

Savage, D. D., Reigel, C. E., and Jobe, P. C.: Angular bundle kindling is accelerated in rats with a genetic predisposition to acoustic stimulus-induced seizures. Brain Res. 376: 412-415, 1986b.

Saxena, N. C. and Macdonald, R. L.: Assembly of $\mathrm{GABA}_{\mathrm{A}}$ receptor subunits: role of the $\delta$ subunit. J. Neurosci. 14: 7077-7086, 1994.

Schallert, T., Kozlowski, D. A., Humm, J. L., and Cocke, R. R.: Use-Dependent Structural Events in Recovery of Function. In: Brain Plasticity, Advances in Neurology. Eds. H.-J. Freund, B. A. Sabel, and O. W. Witte, pp. 229-238, Lippincott-Raven, Philadelphia, 1997.

Scheibel, M. E. and Scheibel, A. B.: Observations on the intracortical relations of the climbing fibers of the cerebellum. J. Comp. Neurol. 101: 733-763, 1954.

Schofield, P. R., Darlison, M. G., Fujita, N., Burt, D. R., Stephenson, F. A., Rodriguez, H., Rhee, L. M., Ramachandran, J., Reale, V., Glencorse, T. A., Seeburg, P. H., and Barnard, E. A.: Sequence and functional expression of the $\mathrm{GABA}_{\mathrm{A}}$ receptor shows a ligand-gated receptor super-family. Nature 328: 221-227, 1987.

Schumacher, M. and McEwen, B. S.: Steroid and barbiturate modulation of the GABA $\mathrm{A}_{\mathrm{A}}$ receptor. Mol. Neurobiol. 3: 275-304, 1989.

Schwartz, R. D. and Yu, W.: Inhibition of GABA-gated chloride channel function by arachidonic acid. Brain Res. 585: 405-410, 1992.

Schwartz, R. D., Skolnick, P., and Paul, S.: Regulation of gamma-aminobutyric acid/barbiturate receptor-gated chloride ion flux in brain vesicles by phospholipase A: possible role of oxygen radicals. J. Neurochem. 50: 565-571, 1988.

Seeburg, P. H., Wisden, W., Verdoorn, T. A., Pritchett, D. B., Werner, P., Herb, A., Lüddens, H., Sprengel, R., and Sakmann, B.: The $\mathrm{GABA}_{\mathrm{A}}$ receptor family: molecular and functional diversity. Cold Spring Harb. Symp. Quant. Biol. 55: 29-40, 1990.

Seeman, P.: Brain dopamine receptors. Pharmacol. Rev. 32: 229-313, 1980.

Segal, M. and Barker, J. L.: Rat hippocampal neurones in culture: properties of GABA activated $\mathrm{Cl}^{-}$ion conductance. J. Neurophysiol. 55: 500-515, 1984.

Sejnowski, T. J.: Synaptic mechanisms for long-term depression. Curr. Biol. 1: 38-40, 1991.

Sessler, F. M., Mouradian, R. D., Cheng, J. -T., Yeh, H. H., Liu, W., and Waterhouse, B. D.: 
Noradrenergic potentiation of cerebellar Purkinje cell responses to GABA: evidence for mediation through the $\beta$-adrenoceptor-coupled cyclic AMP system. Brain Res. 499: 27-38, 1989.

Shimono, T., Nosaka, S., and Sasaki, K.: Electrophysiological study on the postnatal development of neuronal mechanisms in the rat cerebellar cortex. Brain Res. 108: 279-294, 1997.

Shin, C. and McNamara, J. O.: Mechanism of epilepsy. Ann. Rev. Med. 45: 379-389, 1994.

Sieghart, W.: GABA $A_{\mathrm{A}}$ receptors: ligand-gated $\mathrm{Cl}^{-}$ion channels modulated by multiple drug binding sites. Trends Pharmacol. Sci. 13: 446-450, 1992.

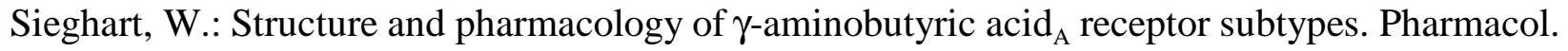
Rev. 47: 181-234, 1995.

Sigel, E., Baur, R., Trube, G., Möhler, H., and Malherbe, P.: The effect of subunit composition of rat brain $\mathrm{GABA}_{\mathrm{A}}$ receptors on channel function. Neuron 5: 703-711, 1990.

Siggins, G. R., Hoffer, B. J., and Bloom, F. E.: Studies on norepinephrine-containing afferents to Purkinje cells of rat cerebellum. III. Evidence for mediation of norepinephrine effects by cyclic 3',5'-adenosine monophosphate. Brain Res. 25: 535-553, 1971.

Skrede, K. K. and Westgaard, R. H.: The transverse hippocampal slice: A well defined cortical structure maintained in vitro. Brain Res. 35: 589-593, 1971.

Slater, N. T., Rossi, D. J., and Kinney, G. A.: Physiology of transmission at a giant glutamatergic synapse in cerebellum. In: Progress in Brain Research. Eds. C. I. de Zeeuw, P. Strata, and J. Voogd, pp. 151-163, Elsevier Science, 1997.

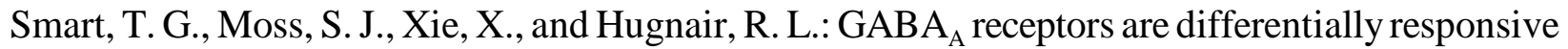
to zinc: dependence on subunit composition. Br. J. Pharmacol. 99: 643-654, 1991.

Smart, T. G.: A novel modulatory binding site for zinc on the $\mathrm{GABA}_{\mathrm{A}}$ receptor complex in cultured rat neurons. J. Physiol. 447: 587-625, 1992.

Smart, T. G. and Constanti, A.: Differential effect of zinc on the vertebrate $\mathrm{GABA}_{\mathrm{A}}$ receptor complex. Br. J. Pharmacol. 99: 643-654, 1990.

Smith, G. B. and Olsen, R. W.: Functional domains of GABA $A_{A}$ receptors. Trends Pharmacol. Sci. 16: 162-167, 1995.

Snodgrass, S. R.: GABA and epilepsy: Their complex relationship and the evolution of our understanding. J. Child Neurol. 7: 77-86, 1992. 
Somogyi, P., Takagi, H., Richards, J. G., and Möhler, H.: Subcellular localization of benzodiazepine/ $\mathrm{GABA}_{\mathrm{A}}$ receptors in the cerebellum of rat, cat, and monkey using monoclonal antibodies. J. Neurosci. 9: 2197-2209, 1989.

Squires, R. F., Casida, J. E., Richardson, M., and Saederup, E.: $\left.{ }^{35} \mathrm{~S}\right] \mathrm{t}-$ butylbicyclophosphorothionate binds with high affinity to brain-specific sites coupled to $\gamma$ aminobutyric $\operatorname{acid}_{\mathrm{A}}$ and ion recognition sites. Mol. Pharmacol. 23: 326-336, 1983.

Squires, R. F. and Saederup, E.: Antidepressants and metabolites that block $\mathrm{GABA}_{\mathrm{A}}$ receptors coupled to $\left[{ }^{35} \mathrm{~S}\right] \mathrm{t}$-butylbicyclophosphorothionate binding sites in rat brain. Brain Res. 441: 15-22, 1988.

Staley, K. J., Soldo, B. L., and Procotr, W. R.: Ionic mechanisms of neuronal excitation by inhibitory GABA $A_{A}$ receptors. Science 269: 977-981, 1995.

Statnick, M. A., Dailey, J. W., Jobe, P. C., and Browning, R. A.: Abnormalities in brain serotonin concentration, high-affinity uptake, and tryptophan hydroxylase activity in severe-seizure genetically epilepsy-prone rats. Epilepsia 37: 311-321, 1996.

Stephenson, F. A.: The GABA ${ }_{\mathrm{A}}$ receptors. Biochem. J. 310: 1-9, 1995.

Stephenson, F. A., Duggan, M. J., and Pollard, S.: The $\gamma_{2}$-subunit is an integral component of the $\gamma$-aminobutyric $\operatorname{acid}_{\mathrm{A}}$ receptor, but the $\alpha_{1}$ polypeptide is the principal site of the agonist benzodiazepine photoaffinity labeling reaction. J. Biol. Chem. 265: 16-165, 1990.

Study, R. E. and Barker, J. L.: Diazepam and (+/-) pentobarbital: Fluctuation analysis reveals different mechanisms for potentiation of $\gamma$-aminobutyric acid responses in cultured central neurons. Proc. Natl. Acad. Sci. U.S.A. 78: 7180-7184, 1981.

Sweadner, K. J.: Isozymes of the $\mathrm{Na}^{+} / \mathrm{K}^{+}$-ATPase. Biochim. Biophys. Acta 988: 185-220, 1989.

Tasker, J. G. and Dudek, F. E.: Electrophysiology of GABA-mediated synaptic transmission and possible roles in epilepsy. Neurochem. Res. 16: 251-262, 1991.

Taylor, D. A., Molnar, L. R., Thayne, K.A., and Fleming, W. W.: Developmental hyperpolarization of rat cerebellar Purkinje neurons is associated with an increase in sodium pump sites. Soc. Neurosci. Abst. 24: 666, 1998.

Thach, W. T.: Discharge of cerebellar neurons related to two maintained postures and two prompt movements. II. Purkinje cell output and input. J. Neurophysiol. 33: 537-547, 1970.

Thach, W. T.: Discharge of Purkinje and cerebellar nuclear neurons during rapidly alternating arm movements in the monkey. J. Neurophysiol. 31: 785-797, 1968. 
Thesleff, S.: Effects of motor innervation on the chemical sensitivity of skeletal muscle. Physiol. Rev. 40: 734-752, 1960.

Thomas, R. C.: Electrogenic sodium pump in nerve and muscle cells. Physiol. Rev. 52: 563-594, 1972.

Tietz, E. I., Huang, X., Weng, X., Rosenberg, H. C., and Chiu, T. H.: Expression of $\alpha 1$, $\alpha$, and $\gamma 2$ $\mathrm{GABA}_{\mathrm{A}}$ receptor subunit mRNAs measured in situ in rat hippocampus and cortex following chronic flunitrazepam administration. J. Mol. Neurosci. 4: 277-292, 1993.

Togel, M., Mossier, B., Fuchs, K., and Sieghart, W.: $\gamma$-Aminobutyric acid A $_{\text {receptors displaying }}$ association of $\gamma 3$-subunits with $\beta 2 / 3$ and different $\alpha$-subunits exhibit unique pharmacological properties. J. Biol. Chem. 269: 993-998, 1994.

Tsien, R. W. and Malinow, R.: Changes in presynaptic function during long-term potentiation. Ann. NY Acad. Sci. 635: 208-220, 1991.

Turner, D. M., Ransom, R. W., Yang, J. S.-J., and Olsen, R. W.: Steroid anesthetics and naturally occurring analogs modulate the (gamma)-aminobutyric acid receptor complex at a site distinct from barbiturates. J. Pharmacol. Exp. Ther. 248: 960-966, 1989.

Tvrdeic, A. and Pericic, D.: Dihydroergotoxine modulation of the $\mathrm{GABA}_{\mathrm{A}}$ receptor-associated $\mathrm{Cl}^{-}$ ionophore in mouse brain. Eur. J. Pharmacol. 221: 139-143, 1992.

Tvrdeic, A. and Pericic, D.: Dihydrogenated ergot compounds bind with high affinity to GABA receptor-associated $\mathrm{Cl}^{-}$ionophore. Eur. J. Pharmacol. 202: 109-111, 1991.

Twyman, R. E., Rogers, C. J., and Macdonald, R. L.: Differential regulation of (gamma)-aminobutyric acid receptor channels by diazepam and phenobarbital. Ann. Neurol. 25: 213-220, 1989.

Twyman, R. E. and Macdonald, R. L.: Neurosteroid regulation of GABA A $_{\mathrm{A}}$ receptor single-channel kinetic properties of mouse spinal cord neurons in culture. J. Physiol. 456: 215-245, 1992.

Unwin, N.: Projection structure of the nicotinic acetylcholine receptor: distinct conformations of the alpha subunits. J. Mol. Biol. 229: 1101-1124, 1993.

Upton, N. and Blackburn, T.: Pharmacology of mammalian $\mathrm{GABA}_{\mathrm{A}}$ receptors. In: The GABA Receptors. Eds. S.J. Enna and N.G. Bowery, Humana Press, Totowa, N.J., pp. 83-120, 1997.

Urquilla, P. R., Westfall, D. P., Goto, K., and Fleming, W. W.: The effects of ouabain and alterations in potassium concentration on the sensitivity to drugs and the membrane potential of the smooth muscle of the guinea-pig and rat vas deferens. J. Pharmacol. Exp. Ther. 207: 347-355, 1978. 


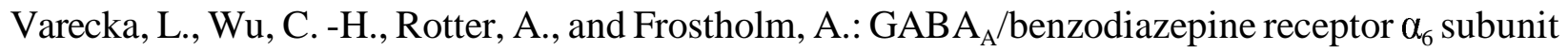
mRNA in granule cells of the cerebellar cortex and cochlear nuclei: expression in developing and mutant mice. J. Comp. Neurol. 339: 341-352, 1994.

Vicini, S., Mienville, J. M., and Costa, E.: Actions of benzodiazepine and beta-carboline derivatives on gamma-aminobutyric acid-activate $\mathrm{Cl}^{-}$channels recorded from membrane patches of neonatal cortical neurons in culture. J. Pharmacol. Exp. Ther. 243: 1195-1201, 1987.

von Blankenfeld, G., Ymer, S., Pritchett, D. B., Sontheimer, H., Ewert, M., Seeburg, P.H., and Kettenamann, H.: Differential benzodiazepine pharmacology of mammalian recombinant GABA receptors. Neurosci. Lett. 115: 269-273, 1990.

Wafford, K. A., Bain, C. J., Quirk, K., McKernan, R. M., Wingrove, P. B., Whiting, P. J., and Kemp, J. A.: Neuron 12: 775-782, 1994.

Wafford, K. A., Burnett, D. M., Leidenheimer, N. J., Burt, D. R., Wang, J. B., Kofuji, P., Dunwiddie, T. V., Harris, R. A., and Sikola, J. M.: Ethanol sensitivity of the $\mathrm{GABA}_{\mathrm{A}}$ receptor expressed in Xenopus oocytes requires 8 amino acids contained in the $\gamma 2 \mathrm{~L}$ subunit. Neuron 7: 2733, 1991.

Waterhouse, B. D.: Electrophysiological assessment of monoamine synaptic function in neuronal circuits of seizure susceptible brains. Life Sci. 39: 807-818, 1986.

Waterhouse, B. D., Moises, H. C., Yeh, H. H., and Woodward, D. J.: Norepinephrine enhancement of inhibitory synaptic mechanisms in cerebellum and cerebral cortex: Mediation by beta adrenergic receptors. J. Pharmacol. Exp. Ther. 221: 495-506, 1982.

Westfall, D. P., McClure, D. C., and Fleming, W. W.: The effects of denervation, decentralization and cocaine on the response of the smooth muscle of the guinea-pig vas deferens to various drugs. J. Pharmacol. Exp. Ther. 181: 328-338, 1972.

Westfall, D. P.: Nonspecific supersensitivity of the guinea-pig vas deferens produced by decentralization and reserpine treatment. Br. J. Pharmacol. 39: 110-120, 1970.

Whiting, P., McKernan, R. M., and Iversen, L. L.: Another mechanism for creating diversity in $\gamma$ aminobutyrate type A receptors: RNA splicing directs expression of two forms of $\gamma 2$ subunit, one of which contains a protein kinase C phosphorylation site. Proc. Natl. Acad. Sci. U.S.A. 87: 99669970, 1990.

Wieland, H. A., Lüddens, H., and Seeburg, P. H.: A single histidine in GABA A $_{\mathrm{A}}$ receptors is essential for benzodiazepine agonist binding. J. Biol. Chem. 267: 1426-1429, 1992.

Wingrove, P. B., Wafford, K. A., Bain, C., and Whiting, P. J.: The modulatory action of loreclezole 
at the $\gamma$-aminobutyric acid type A receptor is determined by a single amino acid in the $\beta_{2}$ - and $\beta_{3^{-}}$ subunit. Proc. Natl. Acad. Sci. USA 91: 4569-4573, 1994.

Wisden, W., Korpi, E. R., and Bahn, S.: The cerebellum: a model system for studying GABA receptor diversity. Neuropharmacology 35: 1139-1160, 1996.

Wisden, W., Laurie, D. J., Monyer, H., and Seeburg, P. H.: The distribution of 13 GABA $_{\mathrm{A}}$ receptor subunit mRNAs in the rat brain. I. Telencephalon, diencephalon, mesencephalon. J. Neurosci. 12:1040-1062, 1992.

Wisden, W., Herb, A., Wieland, H., Keinanen, K., Lüddens, H., and Seeburg, P. H.: Cloning, pharmacological characteristics and expression pattern of the rat $\mathrm{GABA}_{\mathrm{A}}$ receptor $\alpha 4$ subunit. FEBS Lett. 289: 227-230, 1991.

Wong, S. K., Westfall, D. P., Fedan, J. S., and Fleming, W. W.: The involvement of the sodiumpotassium pump in postjuctional supersensitivity of the guinea-pig vas deferens as assessed by $\left[{ }^{3} \mathrm{H}\right]$ ouabain binding. J. Pharmacol. Exp. Ther. 219: 163-169, 1981.

Woodward, D. J., Hoffer, B. J., Siggins, G. R., and Bloom, F. E.: The ontogenetic development of synaptic junctions, synaptic activation and responsiveness to neurotransmitter substances in rat cerebellar Purkinje cells. Brain Res. 34: 73-97, 1971.

Woodward, D. J., Hoffer, B. J., and Lapham, L. W.: Postnatal development of electrical and enzyme histochemical activity in Purkinje cells. Exp. Neurol. 23: 120-139, 1969.

Woodward, R. M., Polenzani, L., and Miledi, R.: Effects of steroids on $\gamma$-aminobutyric acid receptors expressed in Xenopus oocytes by poly(A)+ RNA from mammalian brain and retina. Mol. Pharmacol. 41: 89-103, 1992.

Woodward, D. J., Moises, H. C., Waterhouse, B. D., Hoffer, B, J., and Freedman, R.: Modulatory actions of norepinephrine in the central nervous system. Fed. Proc. 38: 2109-2116, 1979

Woodward, R. M., Polenzani, L., and Miledi, R.: Effects of fenamates and other non-steroidal antiinflammatory drugs on rat brain $\mathrm{GABA}_{\mathrm{A}}$ receptors expressed in Xenopus oocytes. J. Pharmacol. Exp. Ther. 268: 806-817, 1994.

Wu, W. L., Ziskind-Conhaim, L., and Sweet, M. A.: Early development of glycine- and GABAmediated synapses in rat spinal cord. J. Neurosci. 12: 3935-3945, 1992.

Yamamoto, C. and Kurokawa, M.: Synaptic potentials recorded in brain slices and their modification by changes in the level of tissue ATP. Exp. Brain Res. 10: 159-170, 1970.

Yeh, H. H. and Woodward, D. J.: Beta-1 adrenergic receptors mediate noradrenergic facilitation of 
Purkinje cell responses to gamma-aminobutyric acid in the cerebellum of the rat. Neuropharmacology 22: 629-639, 1983.

Yoon, K. W., Covey, D. F., and Rothman, S. M.: Multiple mechanisms of picrotoxin block of GABA-induced currents in rat hippocampal neurons. J. Physiol. 464: 423-439, 1993.

Yuste, R. and Katz, L. C.: Control of postsynaptic $\mathrm{Ca}^{2+}$ influx in developing neocortex by excitatory and inhibitory neurotransmitters. Neuron 6: 333-344, 1991.

Zagon, I. S.: Prolonged gestation and cerebellar development in the rat. Exp. Neurol. 46: 69-77, 1975.

Zdilar, D., Luntz-Leybman, V., Frostholm, A., and Rotter, A.: Differential expression of $\mathrm{GABA}_{\AA} /$ benzodiazepine beta 1 , beta 2 , and beta 3 subunit mRNAs in the developing mouse cerebellum. J. Comp. Neurol. 326: 580-594, 1992.

Zdilar, D., Rotter, A., and Frostholm, A.: Expression of GABA $A_{A} /$ benzodiazepine receptor $\alpha_{1}$-subunit mRNA and $\left[{ }^{3} \mathrm{H}\right]$ flunitrazepam binding sites during postnatal development of the mouse cerebellum. Devel. Brain Res. 61: 63-71, 1991. 


\title{
Cellular Mechanisms of Altered Neuronal Sensitivity in the Genetically Epilepsy-Prone Rat
}

\author{
by \\ Lance R. Molnar \\ DISSERTATION \\ Submitted to the School of Medicine \\ West Virginia University \\ Morgantown, WV \\ APPROVAL OF EXAMINING COMMITTEE
}

James L. Culberson, Ph.D.

Ronald Millecchia, Ph.D.

William F. Wonderlin, Ph.D.

Charles R. Craig, Ph.D.

William W. Fleming, Ph.D.

David A. Taylor, Ph.D.

Chairperson

Date 